O

$0^{\circ}$ Telephone triage of patients with chest O

\title{
discomfort
}

co

c)

(2)

(c)

C 0

0

0

(1)

())

0

(c)<smiles>[O]C1CC1</smiles>

(1) $\mathrm{O}_{0}$

(1) 0

( ) 17

(1)

(1)

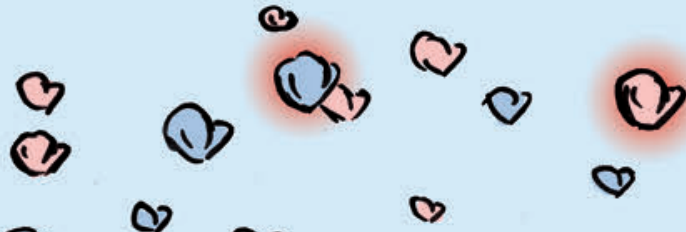

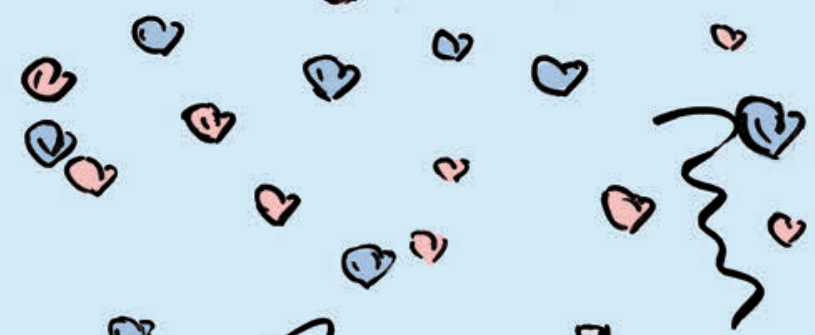

(1) 0

0
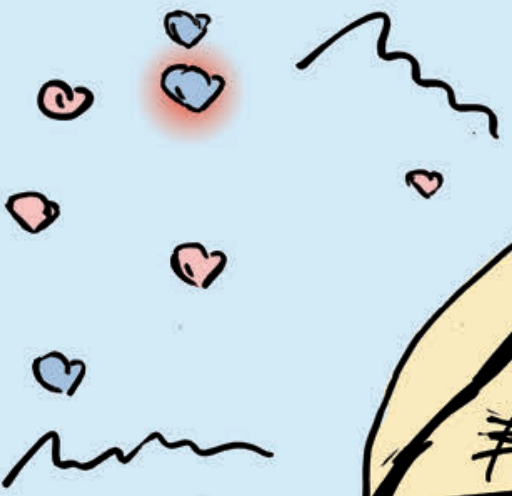

Q)

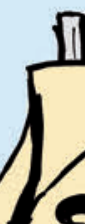

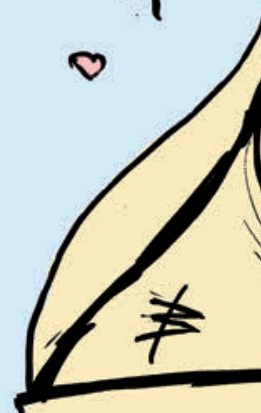

$0 \frac{54320}{5}$

(c)

(4)

c

0

(1) $\infty$

(1) 



\section{Telephone triage of patients with chest discomfort}




\section{Colofon}

Telephone triage of patients with chest discomfort

Julius Center for Health Sciences and Primary Care, University Medical Center Utrecht, Utrecht University, the Netherlands.

PhD thesis

ISBN: $\quad 978-94-6421-056-9$

Author: $\quad$ Louise (Loes) T.C.M. Wouters

Cover design: S.H.M.A. Wouters

Lay-out: Lara Leijtens, persoonlijkproefschrift.nl

Printed by: Ipskamp Printing, proefschriften.net

Copyright (c) 2020 L.T.C.M. Wouters

All rights reserved. No part of this thesis may be reproduced, stored or transmitted in any way or by any means without the prior permission of the author.

Financial support by the Julius Center for Health Sciences and Primary Care, University Medical Center and the $\mathrm{SBOH}$, employer of GP trainee.

\section{SBOHK}




\section{Telephone triage of patients with chest discomfort}

Telefonische triage van patiënten met borstkasklachten (met een samenvatting in het Nederlands)

\section{Proefschrift}

ter verkrijging van de graad van doctor aan de Universiteit Utrecht

op gezag van de

rector magnificus, prof. dr. H.R.B.M. Kummeling, ingevolge het besluit van het college voor promoties in het openbaar te verdedigen op

vrijdag 27 november 2020 des middags te 12.45 uur

door

Louise Theodora Catharina Maria Wouters

geboren op 20 mei 1988

te Eindhoven 


\section{Promotoren:}

Prof. dr. F.H. Rutten

Prof. dr. A.W. Hoes

\section{Copromotoren:}

Dr. D.L.M. Zwart

Dr. E. de Groot 


\section{CONTENTS}

Chapter 1 General introduction $\quad 7$

Chapter 2 Optimisation of telephone triage of callers with symptoms suggestive of acute cardiovascular disease in out-of-hours primary care: observational design of the Safety First study

Chapter 3 Accuracy of telephone triage in primary care patients with 45 chest discomfort: A cross-sectional study

Chapter $4 \quad$ Tinkering and overruling the computer decision support system: working strategies of telephone triage-nurses who assess the urgency of callers suspected of having an acute cardiac event.

Chapter 5 Chest discomfort at night and risk of acute coronary syndrome: cross-sectional study of telephone conversations

Chapter 6 Gender differences in telephone triage of patients with chest discomfort in out-of-hours primary care

Chapter 7 Development of sex-specific prediction rules for early recognition of acute coronary syndrome in primary care: $\mathrm{A}$ cross-sectional study

Chapter 8 General discussion

Samenvatting

List of publications

Dankwoord 182

About the author 
(1)

B

m

Oo

c

(i)

(1)

c)

(c) 0

- (1) $\mathrm{O}_{0}$

())

c

(c)

(ิ)

Cos

0

10

60

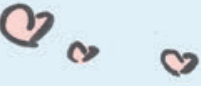

(c) 0 क हु ०

O 00

0

O 


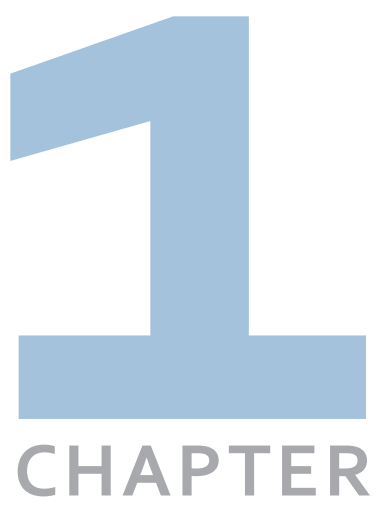

General introduction 
The following case concerns a true case that was judged by the Medical Disciplinary Court on the charge of insufficient medical actions by the general practitioner. ${ }^{1}$ On the basis of this case we introduce the problems with telephone triage of patients with chest discomfort in out-of-hours services for primary care (OHS-PC, in Dutch 'Huisartsenpost').

\begin{abstract}
"A woman with acute chest discomfort at the OHS-PC 1
Mrs. Brown*, a 65-year-old woman, contacted the OHS-PC because of symptoms of chest discomfort. The telephone triage nurse assessed the urgency of her condition with the help of a decision support tool, the Netherlands Triage Standard (NTS). In the electronic medical file (EMF), the nurse noted that Mrs. Brown had been experiencing for two hours (i) a tightening chest pain, (ii) which radiated to her back, (iii) with vomiting (without blood) and (iv) sweating. Mrs. Brown experienced similar symptoms before, but then during exercise, and subsiding in rest (how long such periods usually lasted was not notified). The triage nurse allocated an urgency $U_{2}$ (patient should be seen within one hour) with a consultation at the OHS-PC."
\end{abstract}

*Fictional name

Had the triage nurse chosen, within the NTS, 'chest pain' (in Dutch 'thoracale pijn') as the 'main complaint' (in Dutch 'ingangsklacht') among the 56 available options, then the very first pop-up question of the 'chest pain' hierarchically ordered algorithm would have been 'what is the severity of chest pain?' on a numeric rating scale (NRS) ranging from 0-10. ${ }^{2}$ If Mrs. Brown had answered with a pain severity score of eight or higher and answered 'yes' to the second question 'Does the pain last for less than 12 hours?', the NTS would have immediately recommended an urgency $U_{1}$, which means that the patient should be seen at home within 15 minutes by an ambulance (see table 1 for all NTS urgency levels, response times and recommended help). ${ }^{3}$ The NTS algorithm behind the main complaint 'chest pain' is programmed as such that in that case no additional questions need to be asked. If the triage nurse classifies the severity of pain as moderate (NRS 5 to 7 ) or light (NRS 4 or less), additional questions pop-up to gather further information on symptoms. The triage nurse should have answered 'yes' to at least one of the linked pop-up questions about (i) tightening or pressing chest pain, (ii) radiation of pain and (iii) autonomous nervous system related symptoms (nausea, vomiting, sweating, feeling of fainting), which would also result in the NTS generating an $U_{1}$ urgency level. Appendix-Figures 1-6 show the combinations of Mrs. Brown's symptoms if filled out in the pop-up questions of the main complaint 'chest pain' and which corresponding urgencies would automatically have been generated by the NTS. 
Appendix-Table 1 and 2 give an overview of the 'chest pain' related questions, and of more NTS main complaints that are commonly used for telephone triage of patients with chest discomfort.

Table 1. NTS levels of urgency

\begin{tabular}{|c|c|c|c|}
\hline NTS Urgency level & Definition & Response time & Medical help \\
\hline Uo-Resuscitation & Loss of vital functions & Immediately & Ambulance \\
\hline$U_{1}$ - Life threatening & $\begin{array}{l}\text { Unstable vital } \\
\text { functions }\end{array}$ & $\begin{array}{l}\text { Immediately, } \\
\text { within } 15 \text { minutes }\end{array}$ & Ambulance \\
\hline$U_{2}$ - Emergent & $\begin{array}{l}\text { Vital functions in } \\
\text { danger or organ } \\
\text { damage }\end{array}$ & $\begin{array}{l}\text { As soon as } \\
\text { possible, within } \\
1 \text { hour }\end{array}$ & $\begin{array}{l}\text { Home visit by GP or } \\
\text { consultation at } \mathrm{OHS}-\mathrm{PC}\end{array}$ \\
\hline$U_{3}$-Urgent & $\begin{array}{l}\text { Possible risk of } \\
\text { damage, human } \\
\text { reasons }\end{array}$ & $\begin{array}{l}\text { A few hours (<3 } \\
\text { hours) }\end{array}$ & $\begin{array}{l}\text { Home visit by GP or } \\
\text { consultation at } \mathrm{OHS}-\mathrm{PC}\end{array}$ \\
\hline$U_{4}$ - Non-urgent & $\begin{array}{l}\text { Marginal risk of } \\
\text { damage }\end{array}$ & 24 hours & $\begin{array}{l}\text { Consultation at OHS-PC } \\
\text { or telephone advice }\end{array}$ \\
\hline$U_{5}$-Advice & No risk of damage & $\begin{array}{l}\text { Advice, no time } \\
\text { related }\end{array}$ & Telephone advice \\
\hline
\end{tabular}

GP: General practitioner

NTS: Netherlands Triage Standard

OHS-PC: Out-of-hours services for primary care

We do, however, not know what main complaint the triage nurse used for Mrs. Brown. We also do not know what the nurse exactly filled out in the NTS system. Moreover, the triage nurse may have overruled and downscaled the NTS-generated urgency, on her own or after consultation of the supervising general practitioner (GP). ${ }^{4}$ Still, in the case of Mrs. Brown, an ambulance should have been sent directly ( $\mathrm{U}_{1}$ according to the NTS) aimed at initiating treatment at the patient's home within 15 minutes. An urgency level $\mathrm{U}_{2}$ (patient seen within one hour) is the second best option in her case, because this still implies high urgency with a fast response. Importantly, Mrs. Brown should have been seen at her home, and not at the OHS-PC. Probably unwillingly, the triage nurse took a major risk because an acute coronary syndrome (ACS) could be the underlying cause, with the risk of life-threatening ventricular arrhythmias during the first hours. ${ }^{6}$ Moreover, patients with ACS gain much by early treatment which can only be delivered in the hospital after safe transportation by an ambulance. ${ }^{7}$ 


\section{Continuation of case:}

"When Mrs. Brown arrived at the OHS-PC, she vomited in the waiting room, and the triage nurse asks the GP to see the patient with priority.

The GP immediately sees the patient and includes her findings in the EMF which was already partly filled out by the triage nurse. She notified that Mrs. Brown was anxious. The tightening chest pain was located on both the left and right side of the thorax and radiated to the back. She had vomited, but had no shortness of breath. She had gone beyond her limits during exercise the previous day. Her medical history reported asthma, hypertension and a stoma, and she used antihypertensive drugs and a proton pump inhibitor. On physical examination, Mrs. Brown was not short of breath (breaths per minute not notified) and neither clammy nor sweaty, which was in contrast to what the triage nurse had notified in the EMF. Her blood pressure was $150 / 90 \mathrm{mmHg}$, the pulse rate 74 beats per minute and her temperature $36.8^{\circ} \mathrm{C}$. Lung auscultation and abdominal examination did not reveal abnormalities, and palpation of the chest wall was painful. The GP concluded that Mrs. Brown had musculoskeletal thoracic pain and advised her to take pain killers.

Mrs. Brown's chest discomfort continued for the next days, and after one week she ended in a resuscitation setting and died in the hospital. Autopsy revealed cardiac insufficiency due to an anteroseptal myocardial infarction with anterior wall rupture and cardiac tamponade. It was estimated that the myocardial infarction was 1 to 1.5 weeks old.

The family mentioned that a few days before her death, the patient had written an e-mail (but had not sent it) in which she notified that she felt she was not taken seriously by the GP at the OHS-PC.

The GP received an official warning (In Dutch 'waarschuwing') from the Medical Disciplinary Court. The court judged that the GP should have paid more attention to the nurse's triage report. From that report in the EMF suspicion of an ACS should have arisen. The GP answered "I read the report, but relied more on my own observations." The court also judged that the distress of Mrs. Brown should have been taken more seriously. The GP indicated that she has learned from this case that women often have 'atypical' cardiac symptoms and that distress is an important symptom to recognize and act upon. Furthermore, she had learned that she needed to explain her findings and chosen therapy more 
clearly to the patient and to check whether this was understood and agreed upon by the patient."

This true story of Mrs. Brown shows that telephone triage of patients with chest discomfort may be the starting point of a serious adverse event. We do not exactly know how the triage nurse filled out the NTS, but if she had answered a 'yes' in the NTS to the symptoms she notified in the EMF, it certainly would have generated an $U_{1}$ urgency, which might have triggered more sense of urgency for the next care providers in line. In this case the GP's assessment of the patient's physical condition together with the nurse's notes unfortunately did not lead to the adequate interpretation of presenting symptoms, resulting in the fatal outcome for Mrs. Brown.

Interestingly, both the GP and female journalist who wrote down the court case wrote that Mrs. Brown had 'atypical' cardiac symptoms. Yet, what is 'atypical' about 'tightening chest pain, radiating to the back, and experiencing sweating and vomiting'? Has the dominating medical and lay opinion that women are more likely to have 'atypical' cardiac symptoms resulted in an underestimation of the value of classical symptomatology of ACS? Notably, the poor telephone triage in this case of Mrs. Brown was not taken into consideration by the court.

This thesis focuses on the first part of the case; on how telephone triage of patients with chest discomfort at the OHS-PC is done and how it could be improved. But first I will provide some background knowledge on ACS and the history of triage that is relevant for the telephone triage of patients with chest discomfort at the OHS-PC. 


\section{Acute coronary syndrome}

\section{Definitions and pathophysiology}

ACS is an umbrella term for myocardial infarction (MI) and unstable angina pectoris (UAP). In the domain of patients with acute symptoms suggestive of cardiac ischemia, e.g. chest discomfort, $\mathrm{MI}$ is defined as cardiomyocyte necrosis, which can be detected with elevated cardiac biomarkers of (high sensitivity) troponin I or T. ${ }^{8}$ When there are repolarization abnormalities (ST and/or T wave) on the 12-lead electrocardiogram (ECG), the MI is called ST-elevated myocardial infarction (STEMI) and without these ECG abnormalities, non-ST-elevated myocardial infarction (NSTEMI). ${ }^{8}$ Patients in the same domain are classified as UAP if troponin levels are not elevated and thus cardiomyocyte necrosis is lacking. ${ }^{9}$ Currently, such an assessment with troponin and ECG is done in the hospital, although, point-of-care tests of high sensitivity troponin are being developed for use in primary care. ${ }^{10}$

The pathophysiology of most Mls is characterized by atherosclerotic plaque rupture, ulceration, fissure, erosion or dissection resulting in intraluminal thrombus in one or more of the epicardial coronary arteries leading to decreased myocardial blood flow and/or distal embolization and subsequent myocardial necrosis (type $1 \mathrm{MI}$ ). ${ }^{11}$ Most of these patients have underlying coronary artery disease (CAD) visible with imaging, but occasionally (5-20\% of cases), there may be an MI with non-obstructive epicardial coronary atherosclerosis (MINOCA) or no angiographic evidence of CAD (NOCAD) in the epicardial vessels. These two latter types are more common in women than men. ${ }^{12}$ ${ }^{13}$ Type $2 \mathrm{Ml}$ is caused by myocardial necrosis due to an imbalance between myocardial oxygen supply and demand. Mechanisms include coronary artery spasm, coronary microvascular dysfunction, tachyarrhythmias, bradycardia, anemia, respiratory failure, hypotension and severe hypertension. ${ }^{11}$ Type 3 concerns MI without available biomarker investigation (acute cardiac death), and type 4 and $5 \mathrm{MI}$ are related to coronary interventions and are out of the scope of this thesis. ${ }^{11}$

\section{Clinical presentation of patients with ACS}

The main symptom caused by myocardial ischemia is acute chest discomfort (i.e. chest pain, tightness, or pressure), which usually lasts more than 20 minutes and often the discomfort radiates to the arms, neck or jaws. ${ }^{81415}$ Additionally shortness of breath and autonomous nervous system (ANS) related symptoms may be present, e.g. sweating, nausea, pale face and (near) collapse. ${ }^{8}$ Life-threatening ventricular arrhythmias may occur in up to $6 \%$ of patients with ACS within the first hours after the onset of symptoms, most often before arrival at the hospital. 5 
Incidence and prevalence of ACS

In 2018 in the Netherlands, 49,200 men and 21,110 women were newly diagnosed with an acute $\mathrm{MI}$, and $\mathrm{MI}$ is in the top five causes of death. ${ }^{1617}$ Worldwide, ACS was ranked as the leading cause of death in 2017 for both sexes. ${ }^{18}$ The prevalence of ACS among patients with chest discomfort who call OHS-PC or emergency medical service (EMS or ambulance dispatch center) is about $10 \%$, and at the emergency department (ED) visits between 10 to $30 \% .^{19-21}$

\section{Management of ACS}

Early diagnosis of ACS is of vital importance to initiate lifesaving interventions in order to prevent or reduce myocardial necrosis ('time is muscle'). ${ }^{22}$ Patients with ACS should as soon as possible be treated, to restore cardiac blood flow. Treatment options include (rescue) percutaneous coronary intervention $(\mathrm{PCI})$, coronary artery bypass surgery (CABG) and/or pharmacological treatment. ${ }^{8}$ The role of the GP in this process is to adequately assess which chest discomfort patients have a high risk of ACS and therefore should immediately be referred to the hospital and in which patients ACS can be safely excluded and thus do not require referral. This is a difficult task.

\section{The history of triage}

The word triage is derived from the French verb 'trier', which means to sort, separate, and select. ${ }^{23}$ The original concept was developed around 1800 for use in warfare, where in mass casualty situations the need for medical attention exceeds the availability of resources. Patients who needed surgery and had a chance to survive needed to be sorted out at the battlefield. ${ }^{24}$ In modern healthcare systems there are three stages of triage (i) pre-hospital telephone triage by OHS-PC or EMS (ii) physical triage at the scene by the first clinician attending the patient and (iii) physical triage at the ED. ${ }^{3}$ ${ }^{24}$ Most commonly used digital triage systems automatically generate five levels of urgency, which are linked to a certain time period within which the patient should be seen by a physician. ${ }^{25}$ Worldwide, different triage systems are used, with ED triage systems being the most studied (stage 3, physical triage). Most used and studied in the ED are the Manchester Triage Standard (MTS), the Canadian Triage and Acuity Scale (CTAS), the Emergency Severity Index (ESI), and the Australasian Triage System (ATS). 2325 In the pre-hospital setting there is more diversity in telephone triage systems, and these are less studied. ${ }^{26}$

\section{The Netherlands Triage Standard}

Since 2011, most Dutch OHS-PC and half of the EMS have been using the NTS for urgency assessment. ${ }^{3}$ In EDs, both the NTS and MTS are used. ${ }^{27}$ The aim of the NTS 
and other triage systems is to establish both efficient and safe care, by standardizing urgency decision. ${ }^{262829}$ The NTS is constructed with lists of hierarchically ordered questions related to main complaints, and the answers filled out in the system automatically generate an urgency level linked to a certain time frame within which the patient should be seen by a physician or ambulance personnel. ${ }^{3}$ Triage nurses are supervised by GPs in the OHS-PC who have the final responsibility for the urgency allocation. 4

The NTS was implemented straightaway in the OHS-PC setting, although, the system has never been validated against clinical outcomes. ${ }^{3}$ Therefore, the NTS' accuracy of urgency allocation is unknown. The NTS was developed by an expert panel who integrated knowledge from (i) the MTS, (ii) the Dutch national clinical guidelines for general practice ('NHG triage index') and (iii) the Dutch national standard for ambulance dispatch centers ('LSMA'). ${ }^{3} \mathrm{~A}$ national report showed an increase in high urgency allocations after the implementation of the NTS at the OHS-PC, which was not related to a change in distribution of diseases, and thus suggests a more defensive triage strategy by the introduction of the NTS. ${ }^{30}$ Also, a survey among 428 GPs reported that the majority (83.9\%) was convinced that telephone triage with NTS had resulted in (i) increase in unnecessary consultations and home visits in patients with non-urgent problems, and (ii) a higher workload at the OHS-PC. 4

Triage nurses are trained to 'reason in urgencies' (and not consider diagnoses!), which would, according to experts, increase the NTS guided safety of urgency allocations. ${ }^{31-33}$ Focusing on urgency originates from the 'ABCD-approach', taught in Advanced Trauma Life Support (ATLS ${ }^{\circledR}$ ) courses for the initial assessment and treatment of critical ill patients in amongst others ED-setting. ${ }^{34}$ When the triage nurse starts the telephone triage with the NTS, the system requires a mandatory 'ABCD-check'; i.e. the triage nurse has to ask questions to assess whether the patient has life-threatening problems concerning the Airway, Breathing, Circulation and Disability for which an ambulance should be sent immediately. ${ }^{3435}$ The argumentation for 'reasoning in urgencies' is that clinical signs and symptoms of critical conditions are similar for all underlying causes of life-threatening situations, and this renders knowledge of the underlying cause redundant for the initial assessment and treatment. ${ }^{4}$ This may be true for the initial assessment of critically ill patients in the ED setting, but the usefulness of applying the 'reasoning in urgencies' to anybody calling the OHS-PC is at least questionable, simply because only $2.3 \%$ of all callers is ABCD-unstable. ${ }^{36}$ 
When the triage nurse has assessed the patient as ABCD-stable, the triage nurse has to choose out of 56 main complaints and follow the hierarchically ordered pop-up questions generated by the NTS that often require a 'yes' or 'no' answer. Triage nurses must choose an option, while often patients answer with 'a little bit' or 'doubtful', or patients describe their chest pain as 'burning' or 'uncomfortable' which are no answer options in the NTS. This rigidity of the NTS seems to prevent personalized patient assessment and easily results in 'interactional workability dilemmas'; i.e. difficulties for the triage nurse caused by applying a rigid system structure in the wider context of the patients' narrative. ${ }^{378}$ In conclusion, general triage rules may hamper tailored management of a specific case. ${ }^{8} 39$ Understanding how triage nurses are reasoning while working with the NTS and what interactional workability dilemmas they might experience may help to develop adequate education material for telephone triage of patients with chest discomfort and improve patient management.

\section{Current telephone triage of patients with chest discomfort at the OHS-PC}

Chest discomfort accounts for $2.1 \%$ of all telephone consultations at the OHS PC, and is included in the top five reasons for telephone contact in this setting. ${ }^{4041}$ In the Netherlands, the majority (80\%) of patient who seek medical help for chest discomfort call their own general practitioner (GP) or OHS-PC, the other $20 \%$ either directly calls the ambulance (112) or are self-referrals to the ED. ${ }^{42}$

Telephone triage of patients with chest discomfort at OHS-PC is notoriously challenging, because it is difficult to differentiate ACS from other causes of chest discomfort based on symptoms only. ${ }^{434}$ Chest discomfort may also be caused by a wide range of non-life-threatening conditions such as musculoskeletal, gastrointestinal and psychological conditions that together account for the majority of underlying causes. ${ }^{45}$ Diagnostic predictions models for acute chest discomfort and applicable for telephone triage at the OHS-PC are scarce, and are at best characterized by a moderate predictive performance. 4647

There are indications that both efficiency and safety need improvement for telephone triage of patients with chest discomfort at the OHS-PC. Efficiency is limited, because chest discomfort is the most common reason (60.7\%) for allocating ambulances to patients calling OHS-PC, but only 1 out of 10 patients has an ACS or other lifethreatening event. ${ }^{45}{ }^{48}$ Moreover, a missed ACS with as a result death or severe impairment is the most common cause (30.4\%) for a serious adverse event at the OHS-PC setting with an incidence of approximately 2 per 100.000 consultations. 4950 
Thus, there is an urgent need to improve both efficiency and safety of the telephone triage of patients with chest discomfort in the OHS-PC setting.

\section{Should telephone triage be different in men compared to women with chest discomfort?}

In the last decade, much scientific and public attention was paid to possible differences between men and women with ACS. ${ }^{152}$ Hospital based studies showed a delayed recognition of ACS in woman compared to men and it was suggested this delay was related to a less specific presentation in women. 5354 The 'atypical-symptoms' message gained much dominance, despite that most studies had methodological limitations, due to recall- and hindsight bias, and several other studies found no gender differences. ${ }^{55}{ }^{6}$ More importantly, nearly all studies evaluated the wrong comparison; comparing women with confirmed ACS to men with confirmed ACS. However, for clinically relevant information, one should compare diagnostic predictors of ACS in men and women. This should ideally be done by comparing symptom presentation of ACS-suspected women that are eventually diagnosed with ACS to suspected women without ACS, and compare suspected men with ACS with those without ACS. ${ }^{57} 5^{8} \mathrm{Just}$ one study performed such an analysis in patients with chest discomfort seen at the ED, and one additional study in the OHS-PC setting. ${ }^{5960}$ Both studies stressed that there were more similarities than differences in symptom predictors of ACS for women and men. ${ }^{5960}$ Unbalanced attention to differences, neglecting the much larger overlap may even introduce new blind spots in recognizing ACS in women. ${ }^{61}$

In conclusion, telephone triage of patients with acute chest discomfort comes with many challenges. Yet, it is currently still unknown how the NTS really performs because it was never validated on clinical outcomes. In addition, knowledge is needed about how triage nurses use the NTS tool and how they reason during telephone triage of patients with chest discomfort. Furthermore, much is unknown about sex differences in symptoms predictive for ACS and whether triage assessment should be different for women and men. The studies published in this thesis were carried out to fill some of these knowledge gaps.

\section{Objectives and outline of this thesis}

This thesis focuses on:

(i) Gaining insights into how the telephone triage of patients with chest discomfort in OHS-PC is currently done.

(ii) Discovering leads for improvement of triage, both in terms of patient safety and efficiency. 
(iii) Assessing whether triage of patients with chest discomfort should be different in women and in men.

In Chapter 2, we present the design and study protocol of the mixed-method Safety First project, which consists of multiple quantitative and qualitative studies, each with their own design. The aim of the Safety First project is to describe, understand and improve the diagnostic process and urgency allocation of telephone triage of patients suspected for acute cardiovascular diseases calling the OHS-PC.

In Chapter 3, we describe how we assessed the accuracy of telephone triage in patients with chest discomfort with as the reference the combined outcome ACS or other lifethreatening events. We calculate the accuracy of both the NTS tool and the 'final' urgency allocation, including the overruled urgency allocations and discuss the clinical implications of these findings.

Chapter 4 describes the results of an interview study among 24 triage nurses, who were asked to reflect on their reasoning while using the NTS for patients suspected of ACS. Recent audiotapes (<14 days old) of each of the nurse's triage conversations were used to stimulate the reflection.

In Chapter 5, we investigate whether the time of calling is associated with the risk of ACS in patients suspected of ACS who call the OHS-PC. Are there certain time periods in which the risk is higher? If so, this knowledge could be helpful in improving the telephone triage.

In Chapter 6, we assess whether there are gender-specific differences in symptoms predictive of ACS by comparing symptom presentation of women and men with ACS to women and men without ACS, in the domain of patients with chest discomfort who call the OHS-PC.

In Chapter 7 we developed novel sex-specific symptom-based prediction models for diagnosing ACS in patients with chest discomfort who call the OHS-PC.

Finally, in Chapter 8, the main findings and conclusions of this thesis are presented and we will discuss about the relevance of considering the patient's eventual diagnosis in triage system research and telephone triage in clinical practice. At the end, we reflect on the clinical case presented in the introduction of the thesis. 


\section{REFERENCES}

1. Broersen S, Rube A. Vrouw met atypische hartklachten op een overvolle huisartsenpost. Medisch Contact 2018;16(19 april):34-36.

2. Williamson A, Hoggart B. Pain: a review of three commonly used pain rating scales. Journal of Clinical Nursing 2005;14(7):798-804. doi: 10.1111/j.1365-2702.2005.01121.X

3. van lerland $Y$, van Veen $M$, Huibers $L$, et al. Validity of telephone and physical triage in emergency care: the Netherlands Triage System. Family Practice 2011;28(3):334-41. doi: 10.1093/fampra/cmq097

4. Keizer E, Maassen I, Smits M, et al. Reducing the use of out-of-hours primary care services: A survey among Dutch general practitioners. The European Journal of General Practice 2016;22(3):189-95. doi: 10.1080/13814788.2016.1178718

5. Kalarus Z, Svendsen JH, Capodanno D, et al. Cardiac arrhythmias in the emergency settings of acute coronary syndrome and revascularization: an European Heart Rhythm Association (EHRA) consensus document, endorsed by the European Association of Percutaneous Cardiovascular Interventions (EAPCI), and European Acute Cardiovascular Care Association (ACCA). Europace 2019;21(10):1603-04. doi: 10.1093/europace/euz163

6. Frans Rutten CB, Madeleine Bruins Slot, Bernadette van Casteren, Con Derks, Ravee Rambharose, Jako Burgers, Tjerk Wiersma, Paul Mensink, Margriet Bouma. NHGstandaard Acuut coronair syndroom. 2012

7. Task Force on the management of STseamiotESoC, Steg PG, James SK, et al. ESC Guidelines for the management of acute myocardial infarction in patients presenting with ST-segment elevation. European Heart Journal 2012;33(20):2569-619. doi: 10.1093/ eurheartj/ehs215 [published Online First: 2012/08/28]

8. Roffi M, Patrono C, Collet JP, et al. 2015 ESC Guidelines for the management of acute coronary syndromes in patients presenting without persistent ST-segment elevation: Task Force for the Management of Acute Coronary Syndromes in Patients Presenting without Persistent ST-Segment Elevation of the European Society of Cardiology (ESC). European Heart Journal 2016;37(3):267-315. doi: 10.1093/eurheartj/ehv320

9. Mueller C. Biomarkers and acute coronary syndromes: an update. European Heart Journal 2014;35(9):552-6. doi: 10.1093/eurheartj/eht530

10. Nilsson S, Andersson PO, Borgquist $\mathrm{L}$, et al. Point-of-Care Troponin T Testing in the Management of Patients with Chest Pain in the Swedish Primary Care. International Journal of Family Medicine 2013;2013:532093. doi: 10.1155/2013/532093

11. Thygesen K, Alpert JS, Jaffe AS, et al. Third universal definition of myocardial infarction. Global Heart 2012;7(4):275-95. doi: 10.1016/j.gheart.2012.08.001

12. Reynolds HR, Srichai MB, Iqbal SN, et al. Mechanisms of myocardial infarction in women without angiographically obstructive coronary artery disease. Circulation 2011;124(13):1414-25. doi: 10.1161/CIRCULATIONAHA.111.026542

13. Larsen Al, Galbraith PD, Ghali WA, et al. Characteristics and outcomes of patients with acute myocardial infarction and angiographically normal coronary arteries. The American Journal of Cardiology 2005;95(2):261-3. doi: 10.1016/j.amjcard.2004.09.014

14. Assaad MC, Calle-Muller C, Dahu M, et al. The relationship between chest pain duration and the incidence of acute myocardial infarction among patients with acute chest pain. Critical Pathways Cardiol 2013;12(3):150-3. doi: 10.1097/HPC.obo13e31829274ff 
15. O'Gara PT, Kushner FG, Ascheim DD, et al. 2013 ACCF/AHA guideline for the management of ST-elevation myocardial infarction: executive summary: a report of the American College of Cardiology Foundation/American Heart Association Task Force on Practice Guidelines: developed in collaboration with the American College of Emergency Physicians and Society for Cardiovascular Angiography and Interventions. Catheter Cardiovascular Interventions 2013;82(1):E1-27. doi: 10.1002/ccd.24776

16. https://www.volksgezondheidenzorg.info/onderwerp/coronaire-hartziekten/cijfers-context/

17. https://www.volksgezondheidenzorg.info/ranglijst/ranglijst-doodsoorzaken-op-basisvan-sterfte

18. Collaborators GBDM. Global, regional, and national age-sex-specific mortality and life expectancy, 1950-2017: a systematic analysis for the Global Burden of Disease Study 2017. Lancet 2018;392(10159):1684-735. doi: 10.1016/S0140-6736(18)31891-9

19. Rawshani A, Larsson A, Gelang C, et al. Characteristics and outcome among patients who dial for the EMS due to chest pain. International Journal of Cardiology 2014;176(3):859-65. doi: 10.1016/j.ijcard.2014.08.004

20. Buntinx $F$, Knockaert $D$, Bruyninckx $R$, et al. Chest pain in general practice or in the hospital emergency department: is it the same? Family Practice 2001;18(6):586-9.

21. Leite L, Baptista R, Leitao J, et al. Chest pain in the emergency department: risk stratification with Manchester triage system and HEART score. BMC Cardiovascular Disorders 2015;15:48. doi: 10.1186/s12872-015-0049-6

22. Wibring K, Herlitz J, Christensson L, et al. Prehospital factors associated with an acute life-threatening condition in non-traumatic chest pain patients - A systematic review. International Journal of Cardiology 2016;219:373-9. doi: 10.1016/j.ijcard.2016.06.066

23. Steiner D, Renetseder F, Kutz A, et al. Performance of the Manchester Triage System in Adult Medical Emergency Patients: A Prospective Cohort Study. Journal of Emergency Medicine 2016;50(4):678-89. doi: 10.1016/j.jemermed.2015.09.008

24. Robertson-Steel I. Evolution of triage systems. Emergency Medicine Journal 2006;23(2):154-5. doi: 10.1136/emj. 2005.030270

25. Kuriyama A, Urushidani S, Nakayama T. Five-level emergency triage systems: variation in assessment of validity. Emergency Medicine Journal 2017;34(11):703-10. doi: 10.1136/ emermed-2016-206295

26. Lake R, Georgiou A, Li J, et al. The quality, safety and governance of telephone triage and advice services - an overview of evidence from systematic reviews. BMC Health Services Research 2017;17(1):614. doi: 10.1186/s12913-017-2564-X

27. Zachariasse JM, Seiger N, Rood PP, et al. Validity of the Manchester Triage System in emergency care: A prospective observational study. PloS one 2017;12(2):e0170811. doi: 10.1371/journal.pone.0170811

28. Huibers L, Smits M, Renaud V, et al. Safety of telephone triage in out-of-hours care: a systematic review. Scandinavian Journal of Primary Health Care 2011;29(4):198-209. doi: 10.3109/02813432.2011.629150

29. Parenti N, Reggiani ML, lannone $P$, et al. A systematic review on the validity and reliability of an emergency department triage scale, the Manchester Triage System. International Journal of Nursing Studies 2014;51(7):1062-9. doi: 10.1016/j.ijnurstu.2014.01.013

30. Jansen T, de Hoon S, Hek K, et al. Developments at the out-of-hours services in primary care. Changes in care demand and health care issues in 2013-2015. [Ontwikkelingen op de huisartsenpost. Veranderingen in zorgvraag en gezondheidsproblemen in 20132015.]: NIVEL, 2017. 
31. Dijk EJv. Telefonische triage: laat diagnostische denktrant los. Huisarts \& Wetenschap 2013;Oktober

32. Dijk EJV. Denken in termen van urgentie bij triage. Medisch Contact 2010

33. Giesen $P$, Smits $M$, Huibers L, et al. Quality of after-hours primary care in the Netherlands: a narrative review. Annals of Internal Medicine 2011;155(2):108-13. doi: 10.7326/0003-4819-155-2-201107190-00006

34. Thim $\mathrm{T}$, Krarup NH, Grove EL, et al. Initial assessment and treatment with the Airway, Breathing, Circulation, Disability, Exposure (ABCDE) approach. International Journal of General Medicine 2012;5:117-21. doi: 10.2147/IJGM.S28478

35. Smits M, Keizer E, Ram P, et al. Development and testing of the KERNset: an instrument to assess the quality of telephone triage in out-of-hours primary care services. $B M C$ Health Services Research 2017;17(1):798. doi: 10.1186/s12913-017-2686-1

36. Ineen. Benchmarkbulletin huisartsenposten 2015. 2016

37. Murdoch J, Barnes R, Pooler J, et al. The impact of using computer decision-support software in primary care nurse-led telephone triage: interactional dilemmas and conversational consequences. Social Science and Medicine 2015;126:36-47. doi: 10.1016/j.socscimed.2014.12.013

38. Johannessen LEF. How triage nurses use discretion: a literature review. Professions and Professionalism 2016;6 (1):1446. doi: 10.7577

39. Noon AJ. The cognitive processes underpinning clinical decision in triage assessment: a theoretical conundrum? International Emergency Nursing 2014;22(1):40-6. doi: 10.1016/j.ienj.2013.01.003

40. Jansen T, Ramerman L, Verheij R. Zorg op de huisartsenpost - gezondheidsproblemen. Nivel zorgregistraties eerste lijn 11 februari 2020

41. Jansen $T$, Hek K, Schellevis $F$, et al. Income-related inequalities in out-of-hours primary care telephone-triad: using national registration data. Emergency Medicine Journal 2020

42. Mol KA, Smoczynska A, Rahel BM, et al. Non-cardiac chest pain: prognosis and secondary healthcare utilisation. Open Heart 2018;5(2):eooo859. doi: 10.1136/ openhrt-2018-000859

43. Burman RA, Zakariassen E, Hunskaar S. Management of chest pain: a prospective study from Norwegian out-of-hours primary care. BMC Family Practice 2014;15:51. doi: 10.1186/1471-2296-15-51

44. Rawshani N, Rawshani A, Gelang C, et al. Could ten questions asked by the dispatch center predict the outcome for patients with chest discomfort? International Journal of Cardiology 2016;209:223-5. doi: 10.1016/j.ijcard.2016.02.011

45. Hoorweg BB, Willemsen RT, Cleef LE, et al. Frequency of chest pain in primary care, diagnostic tests performed and final diagnoses. Heart 2017;103(21):1727-32. doi: 10.1136/heartjnl-2016-310905

46. Grijseels EW, Deckers JW, Hoes AW, et al. Implementation of a pre-hospital decision rule in general practice. Triage of patients with suspected myocardial infarction. European Heart Journal 1996;17(1):89-95.

47. Bruins Slot MH, Rutten FH, van der Heijden GJ, et al. Diagnosing acute coronary syndrome in primary care: comparison of the physicians' risk estimation and a clinical decision rule. Family Practice 2011;28(3):323-8. doi: 10.1093/fampra/cmq116

48. Plat FM, Peters YAS, Loots FJ, et al. Ambulance dispatch versus general practitioner home visit for highly urgent out-of-hours primary care. Family Practice 2017(Dec 20) doi: 10.1093/fampra/cm $\times 121$ 
49. Rutten MH, Kant J, Giesen P. What can we learn from calamities at out-of-hours services in primary care? [Wat kunnen we leren van calamiteiten op de huisartsenpost?]. Huisarts Wet 2018;6(61) doi: 10.1007/s12445-018-0155-7

50. Annual reports of 2014-2017. [Jaarverslagen 2014-2017.] Utrecht, The Netherlands: Foundation Primair out-of-hours services in primary care [Stichting Primair Huisartsenposten]

51. Regitz-Zagrosek V, Oertelt-Prigione S, Prescott E, et al. Gender in cardiovascular diseases: impact on clinical manifestations, management, and outcomes. European Heart Journal 2016;37(1):24-+. doi: 10.1093/eurheartj/ehv598

52. Canto JG, Canto EA, Goldberg RJ. Time to standardize and broaden the criteria of acute coronary syndrome symptom presentations in women. Canadian Journal of Cardiology 2014;30(7):721-8. doi: 10.1016/j.cjca.2013.10.015

53. Stehli J, Martin C, Brennan A, et al. Sex Differences Persist in Time to Presentation, Revascularization, and Mortality in Myocardial Infarction Treated With Percutaneous Coronary Intervention. Journal of American Heart Association 2019;8(10):e012161. doi: 10.1161/JAHA.119.012161

54. Canto JG, Rogers WJ, Goldberg RJ, et al. Association of age and sex with myocardial infarction symptom presentation and in-hospital mortality. Journal of American Heart Association 2012;307(8):813-22. doi: 10.1001/jama.2012.199

55. Canto JG, Goldberg RJ, Hand MM, et al. Symptom presentation of women with acute coronary syndromes: myth vs reality. Archives of Internal Medicine 2007;167(22):240513. doi: 10.1001/archinte.167.22.2405

56. Mackay MH, Ratner PA, Johnson JL, et al. Gender differences in symptoms of myocardial ischaemia. European Heart Journal 2011;32(24):3107-14. doi: 10.1093/eurheartj/ehr358

57. Araujo $\mathrm{C}$, Laszczynska $\mathrm{O}$, Viana $\mathrm{M}$, et al. Sex differences in presenting symptoms of acute coronary syndrome: the EPIHeart cohort study. BMJ Open 2018;8(2):e018798. doi: 10.1136/bmjopen-2017-018798

58. Mehta LS, Beckie TM, DeVon HA, et al. Acute Myocardial Infarction in Women: A Scientific Statement From the American Heart Association. Circulation 2016;133(9):91647. doi: $10.1161 / C I R .0000000000000351$

59. Devon HA, Rosenfeld A, Steffen AD, et al. Sensitivity, specificity, and sex differences in symptoms reported on the 13 -item acute coronary syndrome checklist. Journal of American Heart Association 2014;3(2):e000586. doi: 10.1161/JAHA.113.000586

6o. van der Meer MG, Appelman Y, Rutten KHG, et al. Are there gender disparities in symptom presentation or triage of patients with chest discomfort at primary care outof-hours services? An observational study. BMJ Open 2019;9(11):e031613. doi: 10.1136/ bmjopen-2019-031613]

61. Amalberti R. Navigating safety: necessary compromises and trade-offs - theory and practice. Heidelberg: Springer 2013. 


\section{Appendix- Figure 1. NTS fragment of triage criteria within main complaint 'chest pain' with combination of symptoms of Mrs. Brown.}

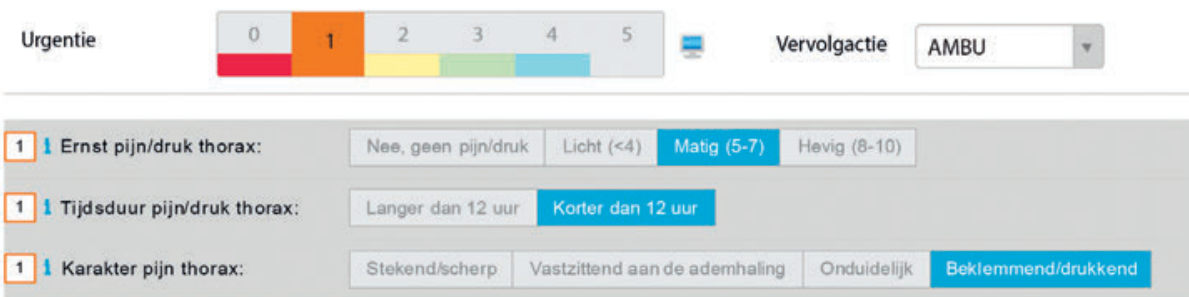

English translation; The combination of moderate intensity pain (NRS 5-7), lasting for less than 12 hours and a tightening or pressing character generates an urgency $\mathrm{U}_{1}$.

\section{Appendix-Figure 2. NTS information pop-up about triage criterion character of pain.}

Karakter pijn thorax

? Kunt u de pijn beschrijven (beklemmend, scherp/stekend, vastzittend aan de ademhaling, onduidelijk)?

i Beklemmende pijn is verdacht voor cardiale pijn. Typische cardiale pijn is krampende, beklemmende of drukkende pijn op het midden van de thorax, dat vooral optreedt bij inspanning. Het kan aanvoelen als een druk op de borst of knijpen in de borstkas.

English translation; when the patient describes the character of pain as cramping, tightening, pressing or feels as squeezing of the chest wall, the triage nurse should be aware the pain may be caused by a cardiac problem. 
Appendix-Figure 3. NTS fragment of triage criteria within main complaint 'chest pain' with combination of symptoms of Mrs. Brown.

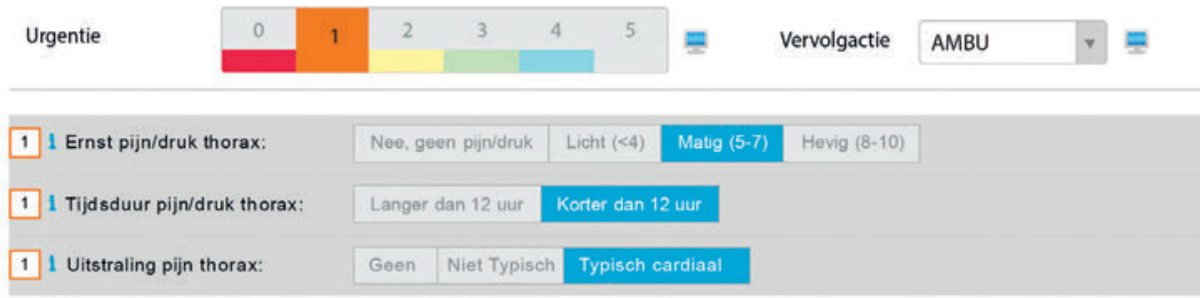

English translation; the combination of moderate intensity pain (NRS 5-7), lasting for less than 12 hours and 'typical' cardiac radiation generates an urgency $U_{1}$.

\section{Appendix-Figure 4. NTS information pop-up about triage criterion} radiation.

Uitstraling pijn/druk thorax

? Straalt de pijn of druk uit? Waarheen?

i Typisch is passend bij cardiale pijn zoals uitstraling naar de kaak, arm of rug. Zie afbeelding

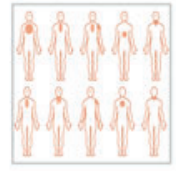

English translation; When the patient describes the chest pain radiates to the jaws, arm or the back, the triage nurse should consider the radiation to be 'typically' cardiac. 


\section{Appendix- Figure 5. NTS fragment of triage criteria within main complaint 'chest pain' with combination of symptoms of Mrs. Brown.}

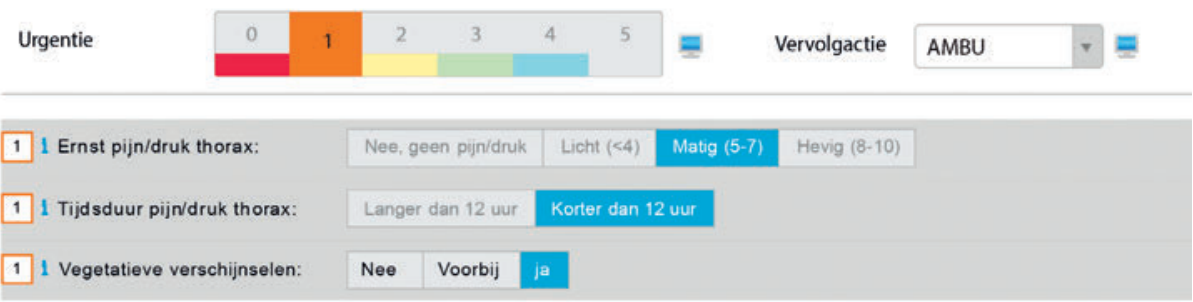

English translation; the combination of moderate intensity pain (NRS 5-7), lasting for less than 12 hours and present or past (not shown in this figure) autonomous nervous system-related symptoms generates an urgency $\mathrm{U}_{1}$.

\section{Appendix-Figure 6. NTS information pop-up about triage criterion autonomous nervous system-related symptoms.}

Vegetatieve verschijnselen

? Heeft u het gevoel flauw te vallen? Transpireert u? Bent u bleek, misselijk of duizelig?

i Vegetatieve verschijnselen zijn misselijkheid, transpireren, klam en/of gevoel flauw te vallen, bij een verdenking op een cardiovasculair event dreigende shock. Niet bij hevige pijn door een trauma.

Voorbij is vegetatieve verschijnselen in de afgelopen uren (max.6).

English translation; When the patient reports nausea, sweating, clamminess or feels like fainting the triage nurse should be aware about the possibility of a cardiovascular event or shock. Past autonomous nervous system-related symptoms are defined as the presence of these symptoms within the last 6 hours. 
Appendix-Table 1: NTS main complaints with triage criteria that generate an urgency $\mathrm{U}_{1}$ level, within the domain chest discomfort.

\begin{tabular}{|c|c|c|c|}
\hline \multicolumn{3}{|c|}{$\rightarrow A B C D$ unstable (no main complaint is selected) } & \\
\hline \multicolumn{3}{|c|}{ Main complaint 'Chest pain' } & \\
\hline$\rightarrow$ ABCD stable & \multicolumn{2}{|c|}{$\begin{array}{l}\text { AND severe chest pain (Numeric Rating Scale } 2 \text { (NRS)-score } \geq 8 \text { ) } \\
\text { lasting less than } 12 \text { hours }\end{array}$} & \\
\hline$\rightarrow \mathrm{ABCD}$ stable & $\begin{array}{l}\text { AND mild (NRS } \\
\leq 4 \text { ) to moderate } \\
\text { (NRS 5-7) chest } \\
\text { pain lasting for less } \\
\text { than } 12 \text { hours }\end{array}$ & $\begin{array}{l}\text { AND one of the following: } \\
\text { - retrosternal located pain } \\
\text { - tightening or pressing } \\
\text { - radiation to jaw, arm or upper back } \\
\text { - progressive pain intensity in short time } \\
\text { - past or present autonomous nervous system- } \\
\text { related symptoms } \\
\text { - dizziness }\end{array}$ & \\
\hline \multicolumn{3}{|c|}{ Main complaint 'Collapse' } & \\
\hline$\rightarrow$ ABCD stable & AND collapse & AND chest pain of any severity & \\
\hline \multicolumn{3}{|c|}{ Main complaint 'Back complaints' } & \\
\hline$\rightarrow \mathrm{ABCD}$ stable & $\begin{array}{l}\text { AND severe upper } \\
\text { back pain }(N R S \geq 8)\end{array}$ & $\begin{array}{l}\text { AND past or present autonomous nervous } \\
\text { system-related symptoms }\end{array}$ & \\
\hline
\end{tabular}

Appendix-Table 2: NTS main complaints with triage criteria that generate an urgency $\mathrm{U}_{2}$ level, within the domain chest discomfort.

\begin{tabular}{|c|c|c|c|}
\hline \multicolumn{3}{|c|}{ Main complaint 'Chest pain' } & \\
\hline $\begin{array}{l}\rightarrow \text { ABCD } \\
\text { stable }\end{array}$ & $\begin{array}{l}\text { AND severe chest } \\
\text { than } 12 \text { hours }\end{array}$ & t pain (Numeric Rating Scale (NRS)-score $\geq 8$ ) lasting longer & \\
\hline $\begin{array}{l}\rightarrow \text { ABCD } \\
\text { stable }\end{array}$ & $\begin{array}{l}\text { AND mild (NRS } \\
\leq 4 \text { ) to moderate } \\
\text { (VRS 5-7) chest } \\
\text { lasting longer } \\
\text { than } 12 \text { hours }\end{array}$ & $\begin{array}{l}\text { AND one of the following: } \\
\text { - retrosternal located } \\
\text { - oppressive or tight } \\
\text { - radiation to jaw, arm or upper back } \\
\text { - pain intensity being quickly progressive } \\
\text { - past or present autonomous nervous system-related } \\
\text { - } \text { dizzminems }\end{array}$ & \\
\hline \multicolumn{3}{|c|}{ Main complaint 'Arm complaints' } & \\
\hline $\begin{array}{l}\rightarrow \text { ABCD } \\
\text { stable }\end{array}$ & $\begin{array}{l}\text { AND severe arm } \\
\text { pain }(N R S \geq 8)\end{array}$ & $\begin{array}{l}\text { AND past or present autonomous nervous system-related } \\
\text { symptoms }\end{array}$ & \\
\hline \multicolumn{3}{|c|}{ Main complaint 'Abdominal complaints' } & \\
\hline $\begin{array}{l}\rightarrow \text { ABCD } \\
\text { stable }\end{array}$ & $\begin{array}{l}\text { AND severe } \\
\text { abdominal pain } \\
(\mathrm{NRS} \geq 8)\end{array}$ & $\begin{array}{l}\text { AND past or present autonomous nervous system-related } \\
\text { symptoms }\end{array}$ & \\
\hline
\end{tabular}


(1)

B

m

Oo

c

(i)

(1)

c)

(c) 0

- (1) $\mathrm{O}_{0}$

())

c

(c)

(ิ)

Cos

0

10

60

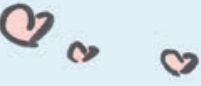

(c) 0 क हु ०

O 00

0

O 


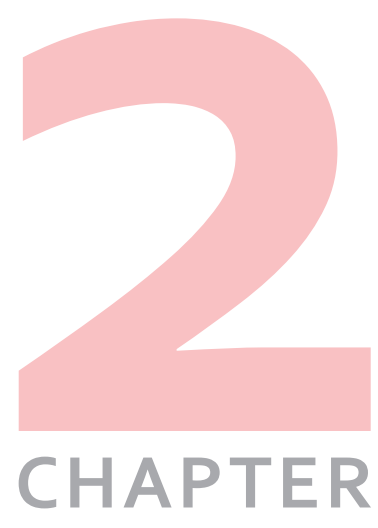

Optimisation of telephone triage of callers with symptoms suggestive of acute cardiovascular disease in out of hours primary care: observational design of the Safety First study

Daphne CA Erkelens*, Loes TCM Wouters*, Dorien LM Zwart, Roger AMJ Damoiseaux, E de Groot, Arno W Hoes, Frans H Rutten

*Both authors contributed equally 


\begin{abstract}
Introduction In the Netherlands, the "Netherlands Triage Standard" (NTS) is frequently used as digital decision support system for telephone triage at out-of-hours primary care services (OHS-PC). Aim of NTS is to guarantee accessible, efficient and safe care. However, there are indications that current triage is inefficient, with overestimation of urgency, notably in suspected acute cardiovascular disease. In addition, in primary care setting the NTS has only been validated against surrogate markers, and diagnostic accuracy with clinical outcomes as the reference is unknown. In the Safety First study, we address this gap in knowledge by describing, understanding and improving the diagnostic process and urgency allocation in callers with symptoms suggestive of acute cardiovascular disease, in order to improve both efficiency and safety of telephone triage in this domain.
\end{abstract}

Methods and analysis An observational study in which 3,000 telephone triage recordings (period 2014-2016) will be analysed. Information is collected from the recordings including caller- and symptom characteristics and urgency allocation. The callers' own general practitioners are contacted for the final diagnosis of each contact. We included recordings of callers with symptoms suggestive of acute coronary syndrome (ACS) or transient ischemic attack (TIA)/stroke. With univariable and multivariable logistic regression analyses the diagnostic accuracy of caller- and symptom characteristics will be analysed in terms of predictive values with urgency level, and ACS and TIA/stroke as outcomes, respectively. To further improve our understanding of the triage process at OHS-PC, we will carry out additional studies applying both quantitative and qualitative methods; (i) case-control study on calamities, (ii) conversation analysis study, and (iii) interview study with triage nurses.

Ethics and dissemination The Medical Ethics Committee of the University Medical Centre Utrecht, the Netherlands endorsed this study (National Trial Register identification: NTR7331). Results will be disseminated at scientific conferences, regional educational sessions, and publication in peer-reviewed journals. 


\section{INTRODUCTION}

Digital decision support systems for telephone triage are widely used, also in primary care out of hours settings. For these settings, telephone triage systems were derived from triage systems applied in emergency department (ED) settings. An important difference, however, is that telephone triage systems do not include items related to face-to-face contact and physical examination. ${ }^{1}$ In the Netherlands, a digital decision support system for telephone triage called the "Netherlands Triage Standard" (NTS) was introduced in 2011. ${ }^{2}$ The NTS was constructed by an expert panel using (i) the Dutch national telephone guidelines for office hours in family practice ('NHG triage index') and (ii) a modified version of the Manchester Triage System (MTS) developed in the ED setting. ${ }^{3}$ Since its introduction in 2011, the NTS has been used by most out-ofhours services in primary care (OHS-PC), and by approximately half of the ambulance dispatch centres in the Netherlands. ${ }^{4}$ An important argument for using the same system within the 'critical care chain' was that it would facilitate communication during care transitions, and potentially improve transitional safety. ${ }^{5}$

Many studies assessed the diagnostic accuracy of triage systems in the ED setting. 6-9 Yet, comparable studies on validity of telephone triage systems in primary care settings are limited. ${ }^{5}$ The validity of the five-level triage system for physical triage in the ED setting was evaluated in a systematic review of 57 studies. ${ }^{1}$ Various reference standards for the assessment of validity were used; researchers' own creation of a reference standard or combining severity with resource measures, e.g. hospital admissions. ${ }^{1}$ Only one of the included studies in this review assessed the validity of the NTS, for both physical triage in the ED and for telephone triage in the OHS-PC. ${ }^{5}$ For the assessment of telephone triage in OHS-PC, 6,668 patients were evaluated. Referrals to the ED and self-care advices were the two surrogate markers used as best proxies for adequate urgency allocation. Consequently, patients referred to the ED were considered as being correctly labelled as high urgency and those receiving a self-care advice as correctly low urgency, independent of the final diagnosis related to the episode. Not surprisingly, the researchers found an association between high urgencies and ED referrals and between low urgency level allocation by the triage nurse and self-care advices. Information on whether the urgency allocation was in line with the clinical outcomes is lacking. ${ }^{5}$ There are no other studies available that assessed the validity of the NTS for telephone triage in the OHS-PC setting or validated the NTS to the final diagnosis instead of to surrogate markers. ${ }^{510}$ Our study addresses this current knowledge gap. 
Over the last decade, out of hours primary care in the Netherlands has been reorganised from small practices into larger OHS-PC. ${ }^{4}$ Patients primarily contact the OHS-PC when they need medical help outside office hours. In case of life-threatening symptoms, however, patients can also directly contact the emergency number of the ambulance dispatch centres or directly visit the ED. At the OHS-PC, triage nurses trained in using the NTS handle all incoming calls, under supervision of a general practitioner (GP). ${ }^{4}$ The goal of this telephone triage is to identify callers with the most urgent need of care. ${ }^{11}$ With urgent clinical situations in mind the experts formulated the NTS questions in a hierarchically ordered algorithm; questions focusing on the symptoms and circumstances considered most critical first, followed by questions about less critical symptoms. ${ }^{2}$ The triage nurse fills out the caller's responses in the semi-automatic NTS system, which then automatically generates urgency allocations. Within the NTS six possible urgency levels can be distinguished that are linked to the response time within which a caller should receive medical help (see table 1). The urgency level generated by the NTS can be adjusted by the triage nurse if the nurse disagrees with the NTS allocation (upgrading or downgrading). ${ }^{11}$ Most often such adjustments are preceded by consultation of the supervising GP, who has the final responsibility for the urgency level allocation.

Table 1. NTS urgency levels

\begin{tabular}{|c|c|c|c|}
\hline NTS Urgency level & Definition & Response time & Medical help \\
\hline Uo-Resuscitation & Loss of vital functions & Immediately & Ambulance \\
\hline$U_{1}$ - Life threatening & $\begin{array}{l}\text { Unstable vital } \\
\text { functions }\end{array}$ & $\begin{array}{l}\text { Immediately, } \\
\text { within } 15 \text { minutes }\end{array}$ & Ambulance \\
\hline$U_{2}$ - Emergent & $\begin{array}{l}\text { Vital functions in } \\
\text { danger or organ } \\
\text { damage }\end{array}$ & $\begin{array}{l}\text { As soon as } \\
\text { possible, within } \\
1 \text { hour }\end{array}$ & $\begin{array}{l}\text { Home visit by GP or } \\
\text { consultation at OHS-PC }\end{array}$ \\
\hline$U_{3}$-Urgent & $\begin{array}{l}\text { Possible risk of } \\
\text { damage, human } \\
\text { reasons }\end{array}$ & $\begin{array}{l}\text { A few hours ( }<3 \\
\text { hours) }\end{array}$ & $\begin{array}{l}\text { Home visit by GP or } \\
\text { consultation at OHS-PC }\end{array}$ \\
\hline$U_{4}$ - Non-urgent & $\begin{array}{l}\text { Marginal risk of } \\
\text { damage }\end{array}$ & 24 hours & $\begin{array}{l}\text { Consultation at OHS-PC } \\
\text { or telephone advice }\end{array}$ \\
\hline$U_{5}$ - Advice & No risk of damage & $\begin{array}{l}\text { Advice, no time } \\
\text { related }\end{array}$ & Telephone advice \\
\hline
\end{tabular}

GP: General practitioner

NTS: Netherlands Triage Standard

OHS-PC: Out-of-hours services for primary care

The aim of the NTS is to guarantee both efficient and safe care. Questions have been raised, however, about the current efficiency. ${ }^{4} \mathrm{~A}$ national report showed an increase in high urgency allocations after the implementation of the NTS at the Dutch OHS-PC, 
notably $U_{2}$ urgencies. ${ }^{12}$ This is in contrast to the unchanged distribution of diseases, and suggests an increase of a more defensive triage strategy. In addition, a survey in 2016 among GPs revealed that the large majority (83.9\%) believed that telephone triage with NTS resulted in (i) many unnecessary consultations and home visits in patients with non-urgent problems, and (ii) a high workload at the OHS-PC. ${ }^{13}$ The authors of this survey speculated that overconsumption of care at the OHS-PC was attributable to certain characteristics of the users of the NTS. Previous studies on OHS-PC telephone triage in the United Kingdom described that the clinical background of triage nurses, the range of their experience, their gender and their attitudes to risk did not affect the triage decisions made. ${ }^{14} 15$ More insight in the users of the NTS (triage nurse) could help improve the system. Yet, it is currently unknown how triage nurses actually use the NTS in their clinical reasoning process and how this affects the performance of the triage system. Also, media coverage of (fatal) adverse events has grown, and adverse event reports and investigation by the Dutch Health and Youth Care Inspectorate have been made publically available. ${ }^{16}$ The increasing attention for (fatal) adverse events might possibly be related to more defensive triage to avoid such (fatal) adverse events, which could potentially worsen efficiency. Thus, thorough research on the accuracy and use of the NTS is needed in order to assess whether improvements in the balance between efficiency and safety are required.

Callers with symptoms suggestive of acute cardiovascular diseases, e.g. acute coronary syndrome (ACS), or transient ischemic attack (TIA)/stroke generally receive high urgency allocations. ${ }^{17}$ Chest pain is the most common reason for dispatching an ambulance ( $\left.U_{1}\right)$ with $60.7 \%$ of all ambulance rides deployed from the OHS-PC. ${ }^{18}$ However, the incidence of ACS among patients experiencing chest discomfort in the Dutch primary care setting and referred to the hospital is low with around 10\%. ${ }^{19-21}$ The trade-off between efficiency and patient safety of telephone triage is particularly challenging in these cases. On the one hand, prompt detection of ACS or TIA/stroke is crucial to initiate interventions as early as possible and prevent myocardial or brain necrosis, and improve prognosis. ${ }^{22-24}$ On the other hand, overestimation of urgency results in unnecessary high workload, high referral rates, high costs, and potentially in iatrogenic damage of the caller. ${ }^{25}$ The discussion about balancing efficiency and safety is especially complicated because missing an acute myocardial infarction is the most common reason for malpractice claims worldwide. ${ }^{26-28}$

Our ultimate goal is to improve the efficiency and safety of the triage of callers with symptoms suggestive of ACS or TIA/stroke who contact the OHS-PC, and to improve diagnosis. In the Safety First study we will evaluate real-life telephone triage recordings 
with corresponding urgency allocations, and patients' final clinical outcomes. Our research questions are (i) what is the diagnostic accuracy of the urgency allocation in callers with symptoms suggestive of ACS or TIA/stroke, (ii) which (clinical) determinants are predictive of an ACS or TIA/stroke diagnosis, and (iii) how is the NTS triage system used and how can it be improved in view of balancing efficiency and safety.

\section{METHODS AND ANALYSIS}

\section{Design}

An observational study in which telephone triage recordings from nine OHS-PC will be evaluated against the clinical outcomes. The researchers will listen to 3,000 real-life recordings, and collect information on the medical history (e.g. history of heart failure, hypertension, ACS, TIA/stroke, diabetes, etc.), caller and symptom characteristics (e.g. onset, duration and severity of symptom(s), additional symptoms (e.g. transpiration, nausea, vomiting, pale skin), pain score in case of chest discomfort, etc.) discussed between the caller and triage nurse during the telephone triage conversations. We will also collect call characteristics (i.e. time of calling, duration of the call, and who calls) and triage information such as the urgency allocation, available from the registered notes of the OHS-PC (i.e. notes from both triage nurses and the supervising GP). All information will be collected on an electronic case record form. Because there is no national Dutch database containing information about diagnoses, we will ask the callers' own GPs to provide the final diagnosis related to the OHS-PC contact, which is based on the patient's medical record, and includes medical specialists' and hospital discharge letters.

\section{Setting}

The foundation 'Primair Huisartsenposten' is a collaboration of six different OHS-PC locations in the central part of the Netherlands that provides out-of-hours primary care for approximately 1,5 million residents. It is one of the largest OHS-PC collaborations in the Netherlands and it covers both rural and urban areas. Every OHS-PC location has its own telephone triage centre.

\section{Data collection}

All telephone calls are routinely recorded and archived for training, quality control, and research purposes in a computer program called 'Callmanager' (i.e. electronic patient record of the OHS-PC). Archiving is based on the International Classification of Primary Care (ICPC) code. ${ }^{29}$ ICPC codes allow for classification of symptoms and diagnoses in the electronic patient records. The standardisation of the coding facilitates (inter)national 
comparison of primary care diagnoses. At Dutch OHS-PC both triage nurses and GPs assign ICPC codes to patient contacts manually. The study sample will be derived retrospectively from all triage recordings in the years 2014 to 2016 and will contain calls linked to the ICPC codes reflecting our study domain: symptoms suggestive of ACS (i.e. Ko1, Ko2, Ko3, K24, $\mathrm{K}_{74}, \mathrm{~K}_{75}, \mathrm{~K}_{76}, \mathrm{~K}_{77}, \mathrm{~K}_{93}$, L04, P74, Ro2, R98) and symptoms suggestive of TIA/stroke (i.e. $\left.\mathrm{K} 89, \mathrm{~K} 90, \mathrm{~N}_{17}, \mathrm{~N}_{18}, \mathrm{~N}_{19}, \mathrm{~N}_{29}, \mathrm{~N} 89, \mathrm{~N} 91\right)$. The distribution of sampling of ICPC codes within our study was based on the actual distribution of ICPC codes at the OHS-PC in 2014, and thus best reflects current practice. Per ICPC code a random sample will be taken.

\section{Inclusion and exclusion criteria}

Telephone triage recordings of callers of the OHS-PC with complaints that lead to suspicion of ACS or TIA/stroke will be included. The selection of recordings is based on (i) specific ICPC codes and (ii) a selection of keywords used in Callmanager (figure 1). As the specific ICPC codes may not cover all eligible callers due to inter-rater variability as a result of ICPC coding by different triage nurses and GPS ${ }^{30}{ }^{31}$, we choose to select cases not only on ICPC codes, but also on keywords in the free text, in order to include a broad but nevertheless clinically realistic' range of patients with possibly typical and less typical symptoms that could be considered to be caused by underlying ACS or TIA/ stroke. A major exclusion criterion is other recordings than triage conversations, e.g. calls between colleagues. All exclusion criteria are displayed in table 2 .

Table 2. Inclusion and exclusion criteria for participation in the Safety First study

\begin{tabular}{|c|c|}
\hline Inclusion criteria & Exclusion criteria \\
\hline $\begin{array}{l}\text { - Recordings of triage conversations of } \\
\text { callers with symptoms suggestive of ACS } \\
\text { based on (i) the following ICPC codes in } \\
\text { 'Callmanager': K01, K02, K03, K24, K74, } \\
\text { K75, K76, K77, K93, L04, P74, Ro2, R98; and } \\
\text { (ii) key word selection: thoracic pain, chest } \\
\text { pain, myocardial infarction, heart attack and } \\
\text { their common abbreviations. } \\
\text { - Recordings of triage conversations of callers } \\
\text { with symptoms suggestive of TIA or stroke } \\
\text { based on (i) the following ICPC codes in } \\
\text { 'Callmanager': K89, K9o, N17, N18, N19, } \\
\text { N29, N89, N91; and (ii) key word selection: } \\
\text { TIA, stroke, cerebral or brain bleeding or } \\
\text { haemorrhage or infarction, neurological } \\
\text { deficit, arm or leg weakness, face or mouth } \\
\text { drooping, speech or visual problems or } \\
\text { sensory disturbances. }\end{array}$ & $\begin{array}{l}\text { - No triage conversation, but consultation } \\
\text { between colleagues or questions about } \\
\text { medication use } \\
\text { - Poor quality recordings } \\
\text { - Callers younger than } 18 \text { years } \\
\text { - Callers not living in the catchment area } \\
\text { of the OHS-PC } \\
\text { - Callers enlisted with a GP who refused } \\
\text { to provide information on the final } \\
\text { clinical outcome }\end{array}$ \\
\hline
\end{tabular}


Figure 1. Flowchart of the Safety First study

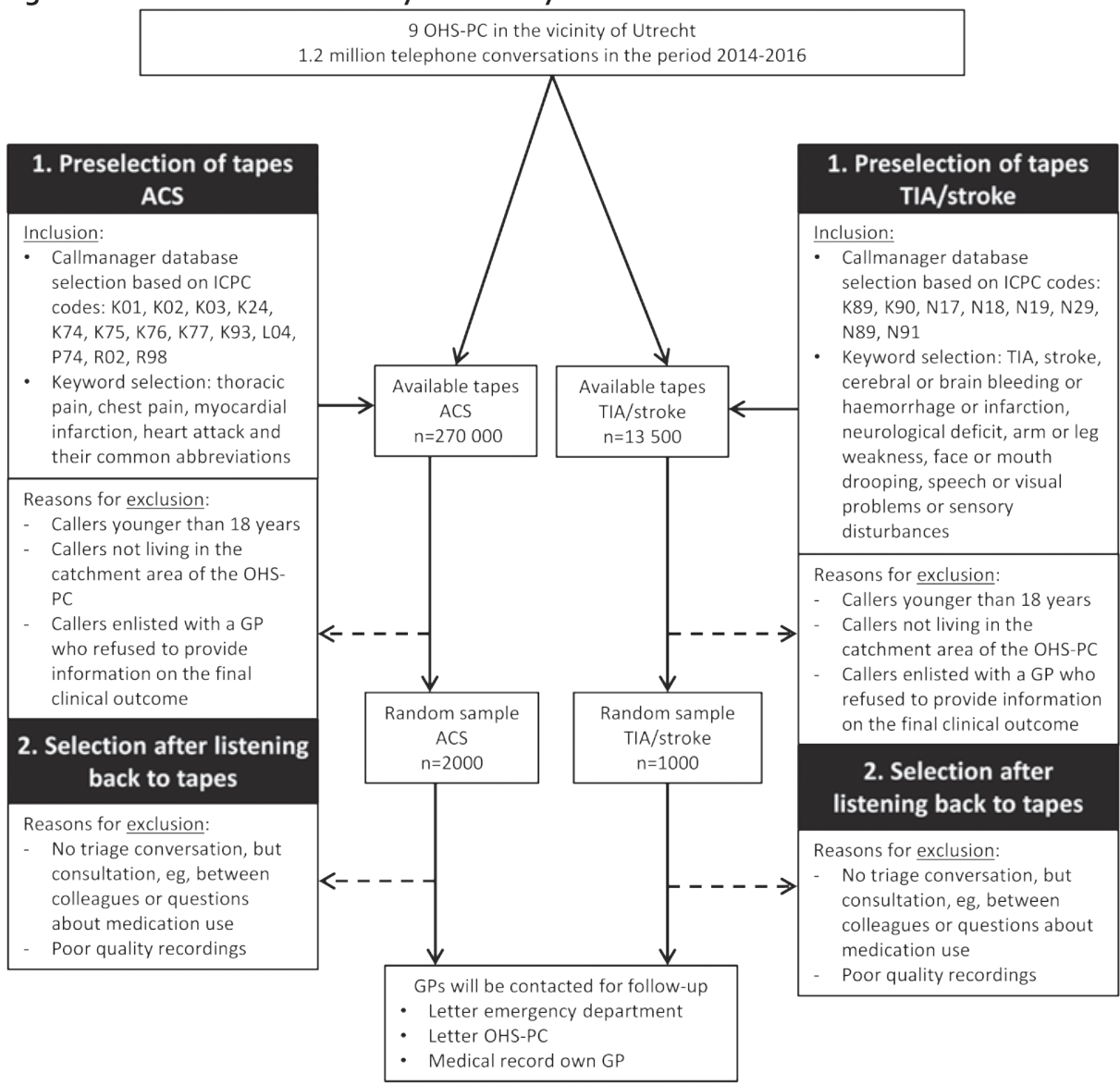

\section{Data analysis}

(i) The diagnostic accuracy of the urgency allocation on two separate outcomes: ACS, or TIA/stroke, will be calculated in terms of sensitivity, specificity, positive and negative predictive values. In addition, we will perform sensitivity analyses; a) also considering other emergency cases with chest discomfort, e.g. pulmonary embolism, acute heart failure, and thoracic aortic dissection, or in the domain symptoms suggestive of TIA/stroke; b) other emergency cases with neurological symptoms, e.g. subarachnoidal haemorrhage (SAH), epilepsy.

(ii) Multivariable logistic regression analysis will be applied to identify history items or caller characteristics that independently predict either ACS or TIA/ stroke. In addition, multivariable models will be developed that predict the 
presence of respectively ACS, or TIA/stroke, and the C-statistic with the $95 \%$ confidence interval will be calculated after bootstrapping to correct for overoptimism. ${ }^{32}$ Before multivariable analysis, multiple imputation techniques will be applied for missing values. Variables with more than $50 \%$ missings will not be considered. Variable selection will be based on literature review (known diagnostic predictors in both domains) and on univariable analysis (inclusion of variables with $\mathrm{p}<0.15$. Special attention will be paid to gender and age, either as interaction term or by calculating gender and/or agespecific prediction models. All data analyses will be performed using SPSS statistical software program version 25.0.

\section{Blinding of researchers}

All researchers listening to the recordings, and filling out the electronic case record forms or who are otherwise involved in the Safety First study, e.g. the expert panel of one of our additional studies, will be blinded to the callers' clinical outcomes.

\section{Power calculation}

For the power calculation we used the recommendations that apply to diagnostic studies. Records of 2014-2016 were used and after application of the exclusion criteria two random samples of 2,000 recordings with 'symptoms suggestive of ACS' and 1,000 recordings with 'symptoms suggestive of TIA/stroke' will be drawn. A prior pilot study showed that 1 out of 9 callers symptoms suggestive of ACS is, after diagnostic workup, diagnosed with ACS and 1 out of 2 callers symptoms suggestive for TIA-stroke is diagnosed with TIA or stroke. Based on Harrell's rule of thumb, for ACS 2,000 audiotapes allow for the analysis of 22 variables and for TIA-stroke 1,000 audio tapes allow for the analysis of 50 diagnostic items. We speculated that more variables would be needed to evaluate suspected TIA/stroke cases than patients in the domain 'suspicion of ACS' because the former patients may present themselves with a larger variety of symptoms. ${ }^{33}$

\section{ADDITIONAL STUDIES}

We explicitly chose to describe the observational cross-sectional study in more detail and not the other three studies because it is the largest study within the Safety First project, and for readability. As part of the Safety First project, three additional but smaller studies will be carried out to further expand the knowledge about the triage process at OHS-PC. 


\section{(i) A case-control study on calamities}

A calamity is defined as an adverse event with serious permanent patient harm or death as a consequence. ${ }^{34}$ By Dutch law, root cause analysis (RCA) of every single calamity is required. RCA often points at flaws in the triage process as root causes for such calamities ${ }^{35}$, resulting in an array of improvement measures for daily practice. However, it is unknown whether cases that result in a calamity really differ from those not evolving into a calamity, as all only have been evaluated as individual cases by experts knowing they evaluated a calamity and their assessment is thus prone to hindsight bias. ${ }^{36} 37$ In the OHS-PC setting calamities are very rare (0.006\%) and the majority is of cardiovascular origin, e.g. missed acute myocardial infarction (AMI). 35 The aim of this additional study is to provide a more thorough view on missed or too late diagnosed AMIs that resulted in calamities by comparing these cases with matched controls in the domain of callers with chest pain, either due to ACS or not. The main question is whether the calamity cases actually differ from controls with respect to call and patient characteristics. For this additional study we will collect new data (calamity cases) and use data from the larger observational study described earlier for sampling our controls. Archived triage conversations from the period January $2013-$ December 2017 of the calamity cases (defined as a missed diagnosis of AMI) will be compared with triage conversations of controls not meeting the calamity definition but also contacting the OHS-PC with symptoms suggestive of ACS. Per calamity case 8 controls will be matched to the case according to age, gender and symptom presentation. A researcher blinded to the outcome will extract information regarding call characteristics, caller and symptom characteristics (including medical history) and urgency allocation, by re-listening the archived triage calls and by using the registered information. All data will be inserted in a database. An expert panel of experienced GPs blinded to the final outcome (calamity or no calamity), thus without case specific hindsight bias, will evaluate the quality and safety of triage conversations, and the diagnostic accuracy (sensitivity, specificity, predictive values) of safe triage handling according to the expert panel will be calculated against the final outcome (calamity or no calamity).

\section{(ii) Conversation analysis study}

In this additional study we will assess how conversation aspects may affect the urgency allocation during telephone triage. The ways in which obligatory NTS questions and other questions are formulated by the triage nurse (i.e. suggestive questions), and responded to by the conversation partner may provide more thorough insight into question-answer sequences at the OHS-PC that can be helpful to improve the (use of) the NTS. We will transcribe a sample of the conversations from the case-control 
study following the Jefferson conventions. These transcripts that can be considered as new data will then be qualitatively analysed with established conversation analysis techniques. ${ }^{38-40}$ We will specifically focus on either/or questions and their various formats (e.g. two-choice, multiple choice, open-ended or tag format) in the urgency decision phase of the triage calls.

\section{(iii) Interview study with triage nurses}

Finally, we will perform a qualitative interview study of triage nurses with the aim to gain more knowledge on triage nurses' reasoning during telephone triage of callers with symptoms suggestive of ACS or TIA/stroke, and how they use the NTS for decision making in these two domains. We will conduct semi-structured audio-stimulated recall interviews. ${ }^{41}$ Per interview one or two recordings from a recent shift at the OHS-PC will be used to stimulate triage nurses' reflections. The interviews will be transcribed and the transcripts will be qualitatively analysed according to the principles of the grounded theory approach. ${ }^{42}$

\section{Patient and public involvement}

Patients were not directly involved in the design of this study, but representatives participate in the stakeholders meetings every 6 months together with other representatives, i.e. of the local and national OHS-PC organization and the Dutch Health and Youth Care Inspectorate. They provide crucial input that helps us with formulating additional, clinically relevant research questions.

\section{Ethics and dissemination}

The Medical Ethics Committee of the University Medical Centre Utrecht, the Netherlands endorsed this study (National Trial Register (NTR) identification number: NTR7331). All personal data, as well as all research data were stored anonymized according to the European General Data Protection Regulation. Data collection started in January 2016 and will last until December 2020. Communications and publications on the results will not enable identification of individual callers. Results will be disseminated to relevant primary care communities in peer-reviewed journals, and at scientific conferences. In addition, this research project will also result in two PhD theses. 


\section{DISCUSSION}

The Safety First study will provide diagnostic accuracy data on ACS and TIA/stroke in the primary care setting. The efficiency and safety of the NTS in the out-of-hours primary care setting will be evaluated for callers with symptoms suggestive of ACS or TIA/stroke. In a case-control study we will explore calamities (missed acute myocardial infarctions) and assess whether they differ from controls (other patients with symptoms suggestive of ACS but not fulfilling the calamity criteria) with respect to call and patient characteristics. With qualitative studies we will generate more thorough knowledge on how triage nurses work and how the NTS is used.

\section{Efficiency and patient safety}

A systematic review about patient safety in the OHS-PC setting concluded that $10 \%$ of all OHS-PC calls could be considered as 'unsafe'. ${ }^{43}$ However, the claim of 'unsafe' calls was based on surrogate markers, and not on patients' clinical outcomes, and clearly contrasts with the very low incidence of calamities (0.006\%). 35 By using the patients' final clinical outcomes as the reference, the Safety First study will address an important knowledge gap on diagnostic accuracy of telephone triage. In addition, our study will provide a more complete view on the patient safety of the NTS than can be achieved with root cause analysis of individual cases only, often resulting in the conclusion that the urgency level is underestimated. ${ }^{354} \mathrm{It}$ is difficult to define when telephone triage at the OHS-PC is safe. Our case-control study will provide deeper knowledge on telephone conversations that resulted in calamities and their matched controls. This knowledge might put the general view on (i) analysing calamities, and (ii) the weight that is assigned to improvement measures in a different perspective.

\section{Users of the NTS}

A questionnaire among Dutch GPs working at the OHS-PCs reported that a majority of GPs (83.9\%) believe that nowadays telephone triage contributes to overconsumption of care at OHS-PC. About $85 \%$ of responders consider this to be at least partly attributable to the level of experience and education, and the attitude and personality of the triage nurses. ${ }^{13}$ As the performance of the NTS is inextricably linked to its users, we want to include conversation analysis and interview studies with triage nurses. The quality of telephone triage is highly dependent on the quality of communication between the triage nurse and the caller, and therefore the communication skills of triage nurses. ${ }^{27} 45$ Moreover, they have to deal with callers who greatly vary in their ability to communicate effectively and coherently. ${ }^{46} 47$ Additionally, the telephone triage is necessarily only based on oral information provided by the caller, lacking 
any visual cues or diagnostic information from physical examination. Our additional study on conversation analysis will add knowledge on the ways in which questions and answers are formulated by triage nurses and callers, and how this affects the triage conversation.

Secondly, we will also focus on the obligatory question structure within the NTS, and how this affects the users. The NTS is a semi-automatic support system that is heavily dependent on the input of the triage nurses themselves; which 'main presenting problem' he/she chooses is based on the initial information from the caller, and each of the in total 57 'presenting problems' are linked to a separate algorithm of hierarchically organized, pre-specified questions. These questions need to be filled out before the NTS generates an urgency allocation. ${ }^{8}$ Previous studies suggested that triage nurses may experience interactional dilemmas while working with a computer decision support. ${ }^{49}$ Our interview study will provide more insight into triage nurses' clinical reasoning process during telephone triage, and how they use the NTS for decision making within the domains of callers with symptoms suggestive of ACS or TIA/stroke. This information can help improve the workability of NTS in daily practice. Furthermore, in these domains the knowledge that 'time is muscle' or 'time is brain' puts extra strain on the triage nurse, because unnecessary delays directly affect morbidity and mortality of patients who actually show to have ACS or TIA/stroke. 2223 Beside this stress factor, other factors such as shift work, fatigue, multitasking and understaffing can attribute to the risk of errors during the triage process. ${ }^{27}$ In our interview study we want to include these risk factors, and their possible influence on the reasoning process of triage nurses.

\section{CONCLUSION}

Our Safety First study will provide diagnostic accuracy data on ACS and TIA/stroke, and new insights on efficiency, patient safety and the use of the NTS by triage nurses during telephone triage of callers with symptoms suggestive of ACS or TIA/stroke at the OHS-PC. Results from our study will help to improve the telephone triage in these important domains and improve both efficiency and safety for callers. 


\section{ACKNOWLEDGEMENTS}

The authors would like to thank the OHS-PC foundation 'Primair Huisartsenposten' and all employees of the participating locations for their cooperation in this study, notably for providing data and technical support.

\section{FUNDING}

This work was supported by the Department of General Practice of the University Medical Centre Utrecht, Associate Professorship-promotion grant of DLMZ, MD, PhD, the foundation 'Netherlands Triage Standard' and the foundation 'Stoffels-Hornstra'. 


\section{REFERENCES}

1. Kuriyama A, Urushidani S, Nakayama T. Five-level emergency triage systems: variation in assessment of validity. Emergency Medicine Journal. 2017;34(11):703-10.

2. Netherlands Triage Standard [cited 2018 June 22]. Available from: http://de-nts.nl/.

3. National guidelines for telephone triage and advice in Family Practice. Available from: https://www.nhg.org/winkel/producten/nhg-triagewijzer-versie-2016.

4. Smits M, Rutten M, Keizer E, Wensing M, Westert G, Giesen P. The Development and Performance of After-Hours Primary Care in the Netherlands: A Narrative Review. Annals of Internal Medicine. 2017;166(10):737-42.

5. van lerland $Y$, van Veen $M$, Huibers $L$, Giesen $P$, Moll HA. Validity of telephone and physical triage in emergency care: the Netherlands Triage System. Family Practice. 2011;28(3):334-41.

6. Nishi F, de Oliveira Motta Maia F, de Souza Santos I, de Almeida Lopes Monteiro da Cruz D. Assessing sensitivity and specificity of the Manchester Triage System in the evaluation of acute coronary syndrome in adult patients in emergency care: a systematic review. JBI Database of Systematic Reviews and Implementation Reports. 2017;15(6):1747-61.

7. Steiner D, Renetseder F, Kutz A, Haubitz S, Faessler L, Anderson JB, et al. Performance of the Manchester Triage System in Adult Medical Emergency Patients: A Prospective Cohort Study. Journal of Emergency Medicine. 2016;50(4):678-89.

8. Grouse Al, Bishop RO, Bannon AM. The Manchester Triage System provides good reliability in an Australian emergency department. Emergency Medicine Journal. 2009;26(7):484-6.

9. Jimenez JG, Murray MJ, Beveridge R, Pons JP, Cortes EA, Garrigos JB, et al. Implementation of the Canadian Emergency Department Triage and Acuity Scale (CTAS) in the Principality of Andorra: Can triage parameters serve as emergency department quality indicators? Canadian Journal of Emergency Medicine. 2003;5(5):315-22.

10. Lake R, Georgiou A, Li J, Li L, Byrne M, Robinson M, et al. The quality, safety and governance of telephone triage and advice services - an overview of evidence from systematic reviews. BMC Health Services Research. 2017;17(1):614.

11. Blank L, Coster J, O'Cathain A, Knowles E, Tosh J, Turner J, et al. The appropriateness of, and compliance with, telephone triage decisions: a systematic review and narrative synthesis. Journal of Advanced Nursing. 2012;68(12):2610-21.

12. Jansen T, de Hoon S, Hek K, Verheij R. Developments at the out-of-hours services in primary care. Changes in care demand and health care issues in 20132015. [Ontwikkelingen op de huisartsenpost. Veranderingen in zorgvraag en gezondheidsproblemen in 2013-2015]. NIVEL, 2017.

13. Keizer E, Maassen I, Smits M, Wensing M, Giesen P. Reducing the use of out-of-hours primary care services: A survey among Dutch general practitioners. The European Journal of General Practice. 2016;22(3):189-95.

14. O'Cathain A, Munro J, Armstrong I, O'Donnell C, Heaney D. The effect of attitude to risk on decisions made by nurses using computerised decision support software in telephone clinical assessment: an observational study. BMC Medical Informatics and Decision Making. 2007;7:39.

15. O'Cathain A, Nicholl J, Sampson F, Walters S, McDonnell A, Munro J. Do different types of nurses give different triage decisions in NHS Direct? A mixed methods study. Journal of Health Services Research \& Policy. 2004;9(4):226-33. 
16. Dutch Health and Youth Care Inspectorate, IGJ. Learning from incident reports in openness. Learn and improve, working together on further improvement of quality of care. [In openheid leren van meldingen. Leren en verbeteren, samen werken aan verdere verbetering van kwaliteit van zorg.]. Dutch Ministry of Health, Welfare and Sport; 2016.

17. Smits $M$, Verheij R. Changes in urgency of contacts with the out-of-hours services in primary care 2013-2016. [Veranderingen in de urgentie van contacten met de huisartsenpost 2013-2016]. NIVEL, 2017.

18. Plat FM, Peters YAS, Loots FJ, de Groot CJA, Eckhardt T, Keizer E, et al. Ambulance dispatch versus general practitioner home visit for highly urgent out-of-hours primary care. Family Practice. 2017(Dec 20).

19. Hoorweg BB, Willemsen RT, Cleef LE, Boogaerts T, Buntinx F, Glatz JF, et al. Frequency of chest pain in primary care, diagnostic tests performed and final diagnoses. Heart. 2017;103(21):1727-32.

20. Wibring K, Herlitz J, Christensson L, Lingman M, Bang A. Prehospital factors associated with an acute life-threatening condition in non-traumatic chest pain patients - A systematic review. International Journal of Cardiology. 2016;219:373-9.

21. Rawshani A, Larsson A, Gelang C, Lindqvist J, Gellerstedt M, Bang A, et al. Characteristics and outcome among patients who dial for the EMS due to chest pain. International Journal of Cardiology. 2014;176(3):859-65.

22. Bosner S, Haasenritter J, Becker A, Karatolios K, Vaucher P, Gencer B, et al. Ruling out coronary artery disease in primary care: development and validation of a simple prediction rule. Canadian Medical Association journal. 2010;182(12):1295-300.

23. Berglund A, von Euler M, Schenck-Gustafsson K, Castren M, Bohm K. Identification of stroke during the emergency call: a descriptive study of callers' presentation of stroke. British Medical Journal Open. 2015;5(4):e007661.

24. Leathley MJ, Jones SP, Gibson JM, Ford GA, McAdam JJ, Quinn T, et al. "Can you send an ambulance please?": a comparison of callers' requests for emergency medical dispatch in non-stroke and stroke calls. Emergency Medicine Journal. 2014;31(e1):e25-8.

25. Coster JE, Turner JK, Bradbury D, Cantrell A. Why Do People Choose Emergency and Urgent Care Services? A Rapid Review Utilizing a Systematic Literature Search and Narrative Synthesis. Academic Emergency Medicine. 2017;24(9):1137-49.

26. Ernesater A, Winblad U, Engstrom M, Holmstrom IK. Malpractice claims regarding calls to Swedish telephone advice nursing: what went wrong and why? Journal of Telemedicine and Telecare. 2012;18(7):379-83.

27. Roing $M$, Holmstrom IK. Malpractice claims in Swedish telenursing: lessons learned from interviews with telenurses and managers. Nursing Research. 2015;64(1):35-43.

28. Katz HP, Kaltsounis D, Halloran L, Mondor M. Patient safety and telephone medicine : some lessons from closed claim case review. Journal of General Internal Medicine. 2008;23(5):517-22.

29. The Dutch College of General Practitioners, NHG. The International Classification of Primary Care (ICPC). Version 6 (Dutch translation derived from ICPC-1 by the WONCA International Classification Committee). 2018. Available from: https://www.nhg.org/themas/artikelen/icpc.

30. Zwaanswijk M, Hek K. ICPC coding at the out-of-hours service in primary care [ICPCcodering op de huisartsenpost]. Huisarts \& Wetenschap. 2013;56(11).

31. Rosendal M, Carlsen A, Rask M, Moth G. Symptoms as the main problem in primary care: A cross-sectional study of frequency and characteristics. Scandinavian Journal of Primary Health Care. 2015;33(2):91-9. 
32. Efron BT, R. An introduction to the bootstrap. Monographs on statistics and applied probability. New York: Chapman \& Hall; 1993.

33. Harrell FE, Jr., Lee KL, Califf RM, Pryor DB, Rosati RA. Regression modelling strategies for improved prognostic prediction. Statistics in Medicine. 1984;3(2):143-52.

34. Healthcare Quality, Complaints and Disputes Act (WKKGZ), (2016).

35. Rutten $\mathrm{MH}$, Kant J, Giesen P. What can we learn from calamities at out-of-hours services in primary care? [Wat kunnen we leren van calamiteiten op de huisartsenpost?]. Huisarts \& Wetenschap. 2018;6(61).

36. Henriksen K, Kaplan H. Hindsight bias, outcome knowledge and adaptive learning. Quality \& Safety in Health Care. 2003;12 Suppl 2:ii46-50.

37. Zwaan L, Monteiro S, Sherbino J, Ilgen J, Howey B, Norman G. Is bias in the eye of the beholder? A vignette study to assess recognition of cognitive biases in clinical case workups. British Medical Journal Quality \& Safety. 2017;26(2):104-10.

38. Jefferson $G$. A technique for inviting laughter and its subsequent acceptance/declination. In: Psathas G, editor. Everyday language: Studies in ethnomethodology. New York, London: Irvington; 1979. p. 79-96.

39. Jefferson G. On a failed hypothesis: conjunctionals as overlap-vulnerable. In: Brabant $\mathrm{KU}$, editor. Tilburg papers in language and literature. Tilburg 1983. p. 1-33.

40. Jefferson $G$. Notes on a possible metric which provides for a 'standard maximum' silence of approximately one second in conversation. In: Brabant KU, editor. Tilburg papers in language and literature. Tilburg1983. p. 1-83.

41. Dempsey N. Stimulated recall interviews in ethnography. Qualitative Sociology. 2010;33(3):349-67.

42. Kolb SM. Grounded theory and the constant comparative method: valid research strategies for educators. Journal of Emerging Trends in Educational Research and Policy Studies. 2012;3:83-6.

43. Huibers L, Smits M, Renaud V, Giesen P, Wensing M. Safety of telephone triage in out-of-hours care: a systematic review. Scandinavian Journal of Primary Health Care. 2011;29(4):198-209.

44. Annual reports of 2014 and 2015. [Jaarverslagen 2014 en 2015.]. Utrecht, The Netherlands: Foundation Primair out-of-hours services in primary care [Stichting Primair Huisartsenposten]

45. Holmstrom I. Decision aid software programs in telenursing: not used as intended? Experiences of Swedish telenurses. Nursing Health Sciences. 2007;9(1):23-8.

46. Pettinari CJ, Jessopp L. "Your ears become your eyes": managing the absence of visibility in NHS Direct. Journal of Advanced Nursing. 2001;36(5):668-75.

47. Roing $M$, Rosenqvist $U$, Holmstrom IK. Threats to patient safety in telenursing as revealed in Swedish telenurses' reflections on their dialogues. Scand J Caring Sci. 2013;27(4):969-76.

48. Smits M, Keizer E, Ram P, Giesen P. Development and testing of the KERNset: an instrument to assess the quality of telephone triage in out-of-hours primary care services. BMC Health Services Research. 2017;17(1):798.

49. Murdoch J, Barnes R, Pooler J, Lattimer V, Fletcher E, Campbell JL. The impact of using computer decision-support software in primary care nurse-led telephone triage: interactional dilemmas and conversational consequences. Social Science \& Medicine. 2015;126:36-47. 
(1)

B

m

Oo

c

(i)

(1)

c)

(c) 0

- (1) $\mathrm{O}_{0}$

())

c

(c)

(ิ)

Cos

0

10

60

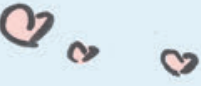

(c) 0 क हु ०

O 00

0

O 


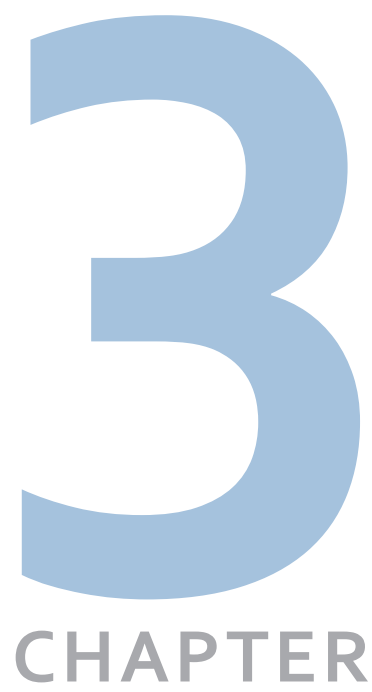

\section{Accuracy of telephone triage in primary care patients with chest discomfort: a cross-sectional study}

Loes TCM Wouters, Frans H Rutten, Daphne CA Erkelens, Esther De Groot, Roger AMJ Damoiseaux, Dorien LM Zwart 


\section{ABSTRACT}

Objectives To assess the accuracy of semi-automatic assisted telephone triage in patients with acute chest discomfort against the diagnosis acute coronary syndrome (ACS) or other life threatening events (LTEs).

Methods Cross-sectional study with telephone conversations of 2,023 patients with acute chest discomfort (pain, pressure, tightness, or discomfort) who called outof-hours services for primary care (OHS-PC) between 2014 and 2016. Sensitivity, specificity, positive and negative predicted values were calculated for a high urgency (patient seen within one hour) against the diagnoses ACS and other LTEs. Diagnoses were retrieved from the patient's medical records in general practice, including hospital specialists discharge letters.

Results Of 2,023 patients who called for chest discomfort, 227 (11.2\%) had an ACS (men 14.9\%, women $8.2 \%$ ) and 58 (2.9\%) had another LTE (men 3.6\%, women 2.3\%). The sensitivity and specificity of a high Netherlands Triage Standard (NTS) urgency allocation against ACS/other LTEs were $0.73(95 \% \mathrm{Cl} 0.68-0.78)$ and $0.43(95 \% \mathrm{Cl}$ $0.40-0.45) \cdot \ln 13.2 \%$ of the calls, the triage nurse overruled the NTS urgency, mostly by upscaling (11.0\%). The sensitivity and specificity of the final urgency allocation were 0.86 ( $95 \% \mathrm{Cl} 0.81-0.90)$ and $0.34(95 \% \mathrm{Cl} 0.32-0.37)$. The positive and negative predictive values of the final urgency were $0.18(95 \% \mathrm{Cl} 0.17-0.19)$ and $0.94(95 \% \mathrm{Cl}$ 0.92-0.95).

Conclusions The semi-automatic triage NTS tool underestimated the urgency in $27 \%$ of patients with ACS/other LTEs. Overruling by triage nurses improved safety, but still $14 \%$ of men and women with ACS/other LTEs received a too low urgency, while efficiency remained poor. 


\section{INTRODUCTION}

Adequate triage followed by early diagnosis is vital in patients with acute chest discomfort. They might have an acute coronary syndrome (ACS) or other lifethreatening event (LTE), e.g. pulmonary embolism. Telephone triage of such patients as done in out-of-hours services primary care (OHS-PC) and emergency medical services (EMS or ambulance dispatch centres) is however challenging, because based on symptoms only it is difficult to differentiate ACS/other LTEs from other causes of chest pain. ${ }^{1}$ In the Netherlands $80 \%$ of people with chest discomfort first calls the general practitioner (GP) or OHS-PC and $20 \%$ directly calls EMS (call 112) for an ambulance or are self-referrals to the emergency department (ED). ${ }^{2}$

In most Western countries, semi-automatic computer triage systems are used to support telephone decision making. ${ }^{3}$ Triage nurses fill out a standard list of hierarchically ordered questions that pops up after the triage nurse choose the patient's main complaint in the computer system, and herewith the computer automatically generates a recommended urgency (one out of six urgency levels). ${ }^{34}$ These triage systems have never been validated in the OHS-PC setting against clinical outcomes as the reference. ${ }^{4}$

Since 2011, most OHS-PC in the Netherlands and half of the EMS use the Netherlands Triage Standard (NTS). ${ }^{5}$ In Dutch EDs, both the NTS and the Manchester Triage Standard (MTS) are used. ${ }^{6}$ The NTS was developed by an expert panel who integrated knowledge from (i) the MTS, (ii) the Dutch national guidelines for general practice ('NHG triage index') and (iii) the Dutch national standard for ambulance dispatch centres ('LSMA'). ${ }^{4}$ The aim of the NTS was similar to other triage systems to guarantee efficient and safe care. ${ }^{7}$ The NTS seems safe with $0.006 \%$ serious adverse events (SAEs) a year at OHS-PCs (SAE is an unintended or unexpected event resulting in death or a severe harmful event). ${ }^{8}$ Still, most SAEs are of cardiovascular origin (46.2\%), most often missed myocardial infarctions and sudden cardiac death. ${ }^{910}$ More questions are asked about the NTS' efficiency for patients with chest pain. It is the most common reason for allocating an ambulance within 15 minutes ( $\left.\mathrm{U}_{1}\right)$ to patients calling OHS-PC (60.7\% of all dispatches), but only around $10 \%$ actually has an ACS..$^{11-13}$

The aim of our study was to assess the accuracy of telephone triage for patients with chest discomfort who call the OHS-PC with the clinical outcome ACS/other LTE as the reference. Both the accuracy of the NTS tool, and the 'final' urgency including overruling of the triage nurses were evaluated. 


\section{METHODS}

The study design and data collection have been published in our study design paper. ${ }^{14}$ In short, we performed a cross-sectional study in 2,023 patients who contacted one of nine OHS-PCs in the Netherlands with acute chest discomfort (pain, pressure, tightness, or discomfort) between 2014 and 2016. We selected calls on the basis of International Classification of Primary Care (ICPC; a WHO world-wide code system for primary care) codes (K01, K02, K03, K24, K74, K75, K76, K77, K93, L04, P74, Ro2, R98) and keywords (thoracic pain, chest pain, myocardial infarction, heart attack and their common abbreviations). ${ }^{15}{ }^{16}$ On purpose, we sampled broadly to capture the entire domain of patients that could be suspected of ACS.

We used electronic health record (EHR) data of OHS-PC ('Callmanager') and relistened telephone triage recordings in order to collect information about symptoms, patient and conversation characteristics of patients, and urgency allocation. The final diagnoses were retrieved from the patients' GP, and these were based on hospital specialist discharge letters or GP's diagnoses. For the diagnosis of ACS we used the cardiologist's diagnosis. Patient without elevated levels of (high-sensitivity) troponin were classified as unstable angina pectoris (UAP), and those with elevated levels as myocardial infarction, divided in STEMI (ST-elevation MI) and NSTEMI (non-ST elevation myocardial infarction). Other life-threatening diagnoses were classified by an expert panel of experienced GPs (DZ, FR, RD) based on medical specialist letters (majority of votes).

\section{Context}

Triage assessment with the NTS starts with a mandatory 'ABCD-check' (Airway, Breathing, Circulation and Disability); this check determines whether there are direct life-threatening problems for which an ambulance must be sent straight away. ${ }^{17}$ When the patient is 'ABCD-stable', the triage nurse has to choose one out of 56 main complaints to continue the urgency assessment. Based on the triage nurses' input, the NTS automatically generates an urgency allocation ranging from $U o$ (reanimation) to $U_{5}$ (telephone self-care advice) (Appendix - table 1). The triage nurse can overrule this recommendation and up- or downscale the urgency allocation, often after consulting the supervising GP. ${ }^{5}$ For clarification of the work process in the OHS-PC see an adapted SEIPS (Systems Engineering Initiative for Patient Safety) framework (Appendix - figure 1). ${ }^{18}$ In the Netherlands there is a strong primary care, and general practitioners (GPs) take care of $93 \%$ of all health care problems for $3 \%$ of the total health care budget. ${ }^{19}$ 
The GP has a gatekeeper's role to hospital care, although, people may call EMS (112) in case they suspect is a life-threatening situation. ${ }^{19}$

\section{The NTS and final urgency}

The NTS urgency was the automatically NTS generated urgency based on the input of the triage nurse. The final urgency was the 'overruled' urgency or the NTS urgency, when not adjusted. In around 15\% the final urgency allocation was unclear because of incomplete registration of overruled urgencies. For these cases, an expert panel of three experienced GPs (DZ, FR, IK) independently decided on the final urgency blinded for the outcome (majority of votes) (See also Appendix - figure 2).

\section{Data analyses}

We dichotomized urgency allocation in high ( $U_{1}$ and $\left.U_{2}\right)$ and low $\left(U_{3}, U_{4}\right.$ and $U_{5}$ ) urgency, and calculated the accuracy of the (i) NTS and (ii) final urgency for allocating a high urgency to patients with the outcome ACS/other LTEs in terms of sensitivity, specificity, positive and negative predictive values. For patient and call characteristics we used the $\mathrm{Chi}^{2}$ test for comparison of dichotomous variables and the independent sample t-test or Mann-Whitney $U$ test for continuous variables. We compared baseline characteristics between patients in whom the eventual diagnosis was retrieved to those in whom the GP did not provide these outcomes, to get an impression on whether selection bias could have occurred. Sample size was calculated using Harrell's rule of thumb, which can be found our study design paper. ${ }^{14}$ All data analyses were performed using SPSS statistical software program version 25.0.

\section{Patient and public involvement}

No patients were involved in setting the research question or the outcome measures, or in developing plans for design, however, they were involved in the implementation of the study. In addition, they were asked to advise on interpretation and writing up of results. Results will be shared and discussed with the national patient community of cardiovascular diseases ('Harteraad').

\section{Ethical approval}

The Medical Ethics Committee Utrecht, the Netherlands (reference number WAG/ mb/16/003208; National Trial Register identification number: NTR7331) approved this study. In addition, a waiver of informed consent was given as our study involves no more than minimal risk to subjects and this study could not be carried out practicably without the waiver. All personal and research data were handled and stored according to the European General Data Protection Regulation (GDPR). 


\section{RESULTS}

\section{Baseline characteristics}

Of the 2,023 patients with acute chest discomfort and a retrieved diagnosis, 227 (11.2\%) had an ACS (women 8.2\%, men 14.9\%), and 57 (2.8\%) had another LTE (women 2.3\%, and men 3.5\%) (Figure 1). The mean age was 58.9 (SD 19.5) years, and $54.9 \%$ were women. The NTS allocated $59.7 \%$ (men $57.6 \%$, women $61.5 \%$ ) to a high urgency $\left(\mathrm{U}_{1} / \mathrm{U}_{2}\right)$ and this was $68.5 \%$ (men $68.2 \%$, women $68.7 \%$ ) for the final urgency. Triage nurses overruled in $13.2 \%$ of patients the NTS urgency, mostly upscaling (11.0\% of all calls) (Figure 2).

Figure 1. Flowchart of study population.

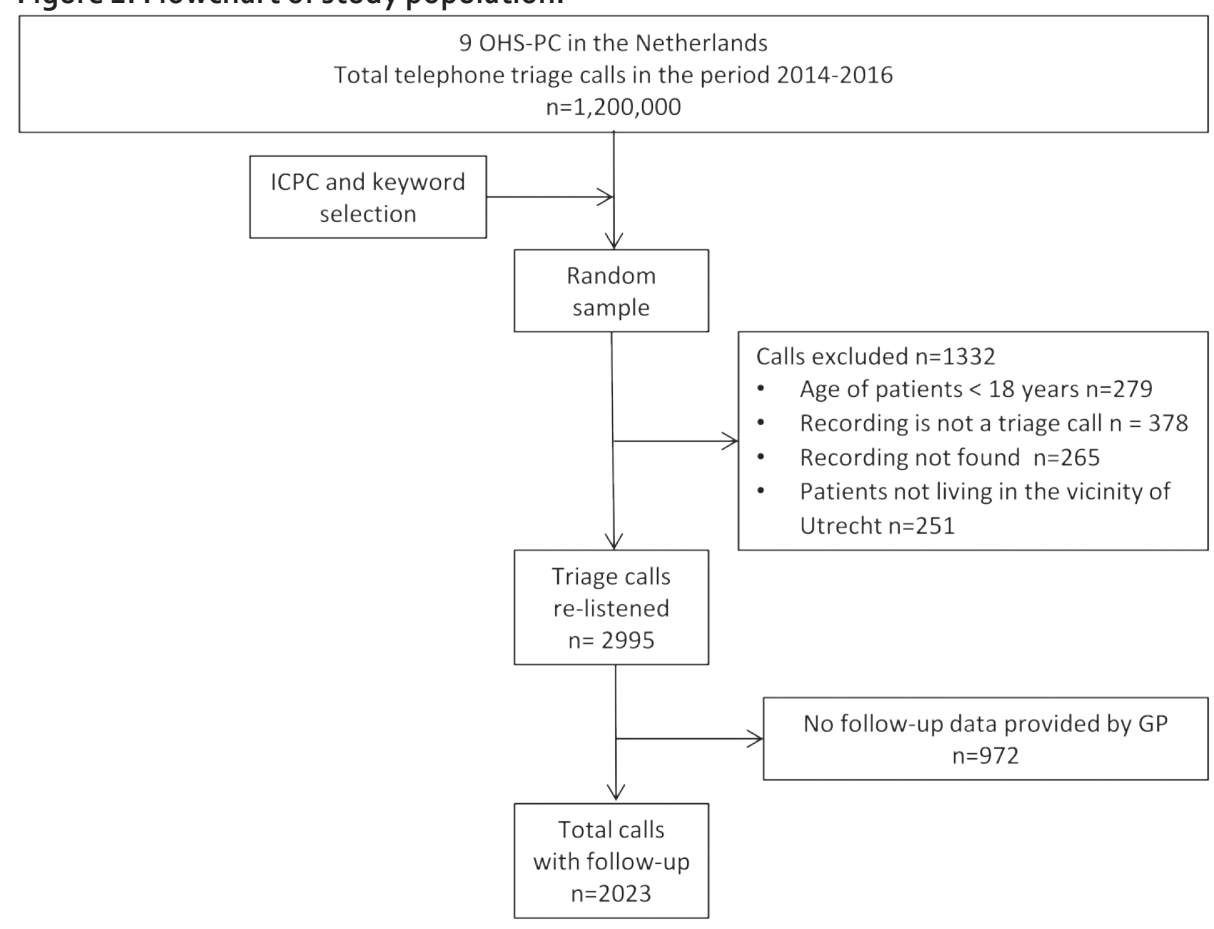




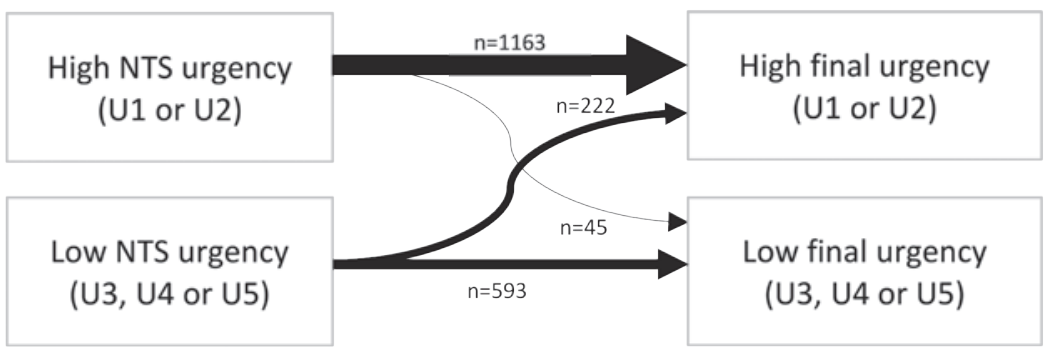

Patients allocated a high urgency were significantly older (62.7 (SD 18.2) years vs. 53.1 (SD 19.9) years, $p<0.001)$, had a shorter mean duration of calls (6:57 min vs. 8:30 $\min , \mathrm{p}<0.001)$, and more often someone else called on behalf of the patient $(58.9 \%$ vs. $38.9 \%, p<0.001$ ) than those allocated a low urgency. Nearly all callers expressed concerns ( $92.1 \%$ vs. $86.4 \%, p=0.003$ ). In $2.1 \%$ of the patients labelled as 'ABCDunstable' the NTS urgency allocation was downgraded by the triage nurse/GP. When the triage nurse chose for 'shortness of breath' as the main complaint, relatively more patients received a high urgency than when 'chest pain' was the main complaint $(73.8 \%$ vs. $56.5 \%, p<0.001)$.

Patients classified as high urgent had more often acute shortness of breath ( $71.0 \% \mathrm{vs}$. $53.9 \%, \mathrm{p}<0.001)$, chest pain lasting for less than 12 hours ( $81.3 \%$ vs. $62.5 \%, p<0.001)$, heavier chest pain (Numeric Rating Scale $>7,46.7 \%$ vs. $22.1 \%$, p<0.001) and sweating $(47.7 \%$ vs. $31.5 \%, \mathrm{p}<0.001)$. They also more often recognized their symptoms from a previous cardiac event than those who received a low urgency (30.9\% vs. $21.5 \%$, $\mathrm{p}=0.002$ ). Patients with stabbing pain ( $33.8 \%$ vs. $15.0 \%, \mathrm{p}<0.001$ ) or pain located on either the left or right side of the thorax ( $53.4 \%$ vs. $28.6 \%, p<0.001$ ) were more often classified as low urgent.

There were no clinically meaningful differences in patient or call characteristics between the 2,023 patients with a retrieved diagnosis and 972 patients without a diagnosis (Appendix-table 2). 
Table 1. Baseline characteristics of 2,023 patients with chest discomfort (chest pain, pressure, tightness, discomfort) calling OHS-PC, divided in high (U1-U2) and low $\left(U_{3}-U_{5}\right)$ NTS urgency.

\begin{tabular}{|c|c|c|c|}
\hline Characteristics & $\begin{array}{c}\text { NTS High } \\
\text { urgency } \\
\mathrm{n}=1208 \\
(59.7 \%)\end{array}$ & $\begin{array}{c}\text { NTS Low } \\
\text { urgency } \\
n=815 \\
(40.3 \%)\end{array}$ & p-value \\
\hline \multicolumn{4}{|l|}{ Patient characteristics } \\
\hline Mean age in years (SD) & $62.7(18.2)$ & $53.1(19.9)$ & $<0.001$ \\
\hline Female sex & $683(56.5)$ & $428(52.5)$ & 0.074 \\
\hline \multicolumn{4}{|l|}{ Call characteristics } \\
\hline Mean total call duration in min (SD) & $6: 57(3: 42)$ & $8: 30(3: 48)$ & $<0.001$ \\
\hline Mean patients' introduction duration in $\min (S D)$ & $0: 18(0: 12)$ & $0: 21(0: 14)$ & $<0.001$ \\
\hline Triage nurse consulted the GP & $643(53.2)$ & $418(51.3)$ & 0.391 \\
\hline Someone else called on behalf of patient & $711(58.9)$ & $317(38.9)$ & $<0.001$ \\
\hline Caller has expressed concerns & $500(92.1)$ & $413(86.4)$ & 0.003 \\
\hline \multicolumn{4}{|l|}{ NTS main complaints } \\
\hline ABCD-unstable & $93(7.7)$ & $2(0.2)$ & $<0.001$ \\
\hline Chest pain & $867(71.8)$ & $668(82.0)$ & $<0.001$ \\
\hline Shortness of breath & $121(10.0)$ & $43(5 \cdot 3)$ & $<0.001$ \\
\hline Palpitations & $33(2.7)$ & $27(3 \cdot 3)$ & 0.450 \\
\hline Back pain & $19(1.6)$ & $7(0.9)$ & 0.162 \\
\hline Dizziness & $11(0.9)$ & $8(1.0)$ & 0.871 \\
\hline Arm problems & $2(0.2)$ & $8(1.0)$ & 0.010 \\
\hline Other & $62(5.1)$ & $52(6.4)$ & 0.233 \\
\hline \multicolumn{4}{|l|}{ NTS triage criteria } \\
\hline Chest pain & $1088(93.5)$ & $738(93.5)$ & 0.954 \\
\hline Shortness of breath & $664(71.0)$ & $337(53.9)$ & $<0.001$ \\
\hline Chest pain duration $<12$ hours & $843(81.3)$ & $453(62.5)$ & $<0.001$ \\
\hline Pain intensity severe (NRS $>7$, range $1-10$ ) & $224(46.7)$ & $83(22.1)$ & $<0.001$ \\
\hline Pressing heavy chest pain* & $623(73 \cdot 4)$ & $309(47.5)$ & $<0.001$ \\
\hline Stabbing chest pain* & $127(15.0)$ & $220(33.8)$ & $<0.001$ \\
\hline Chest pain located retrosternal** & $401(51.2)$ & $196(30.0)$ & $<0.001$ \\
\hline Chest pain located left or right on thorax** & $224(28.6)$ & $349(53 \cdot 4)$ & $<0.001$ \\
\hline Radiation of chest pain to any location & $662(71.5)$ & $341(54 \cdot 3)$ & $<0.001$ \\
\hline Radiation to the arm & $273(50.8)$ & $151(34 \cdot 5)$ & $<0.001$ \\
\hline Radiation to the shoulder blades & $206(43.8)$ & $102(26.2)$ & $<0.001$ \\
\hline Radiation to the jaws & $93(26.1)$ & $22(7.1)$ & $<0.001$ \\
\hline Sweating & $363(47.7)$ & $159(31.5)$ & $<0.001$ \\
\hline Nausea or vomiting & $308(55 \cdot 3)$ & $137(39 \cdot 4)$ & $<0.001$ \\
\hline Pallor & $187(39.0)$ & $55(22.8)$ & $<0.001$ \\
\hline Dizziness or (feelings of nearly) fainting & $274(26.6)$ & $113(14.8)$ & $<0.001$ \\
\hline History of coronary artery disease & $234(38.6)$ & $127(27.1)$ & $<0.001$ \\
\hline Diabetes mellitus & $98(23.1)$ & $62(14.8)$ & 0.002 \\
\hline
\end{tabular}


Table 1. (Continued)

\begin{tabular}{|c|c|c|c|}
\hline Characteristics & $\begin{array}{c}\text { NTS High } \\
\text { urgency } \\
n=1208 \\
(59.7 \%)\end{array}$ & $\begin{array}{c}\text { NTS Low } \\
\text { urgency } \\
n=815 \\
(40.3 \%)\end{array}$ & p-value \\
\hline \multicolumn{4}{|c|}{ Other than NTS items, if they were discussed in triage call } \\
\hline Coin size area of chest pain & $77(45 \cdot 3)$ & $154(48.0)$ & 0.571 \\
\hline Tingling sensations on chest, hands or elsewhere & $112(86.8)$ & $97(79 \cdot 5)$ & 0.121 \\
\hline $\begin{array}{l}\text { Patient recognized symptoms from previous cardiac } \\
\text { event }\end{array}$ & $152(30.9)$ & $76(21.5)$ & 0.002 \\
\hline \multicolumn{4}{|l|}{ CVD risk factors other than diabetes } \\
\hline Hypertension & $190(43.0)$ & $116(28.6)$ & $<0.001$ \\
\hline Hypercholesterolemia/statin use & $103(28.0)$ & $89(22.0)$ & 0.056 \\
\hline
\end{tabular}

*Pain described by patient. Pressing heavy pain: pressing, heavy or tightening pain vs. other types of pain (stabbing, burning, cramping, tearing) Stabbing pain: stabbing vs. other types of pain (pressing, heavy, tightening, burning, cramping, tearing)

** P-value comparing retrosternal or left/right side thorax vs. others locations of pain together (retrosternal, left/right side thorax, back/shoulder, epigastric region)

Coronary artery disease: History of $\mathrm{MI}, \mathrm{PCl}, \mathrm{CABG}$, stable or unstable angina pectoris (patient reported)

\section{Diagnoses}

Of the 227 patients with an ACS ( 91 women, 136 men), 67 (29.5\%) patients had a STEMI (women 22.1\%, men 33.8\%), 93 (40.0\%) a NSTEMI (women 46.2\%, men 37.5\%), 52 (22.9\%) unstable angina pectoris (UAP) (women 20.9\%, men 24.3\%) and 15 (6.6\%) unspecified ACS, including three sudden cardiac deaths in women (women 9.9\%, men $4.4 \%$ ) (Table 2). In nearly all cases (97.0\%) the ACS diagnosis was from the cardiologist and based on symptom presentation, troponin levels and electrocardiography. Three patients died before arrival of the ambulance (they were classified as acute cardiac death), one patient died after resuscitation at the ED. Three patients were classified as ACS by the GP, while not referred because of short life expectancy due to cancer. Of the 58 patients with other LTEs (2.9\%), 13 had a pulmonary embolism, five an acute abdominal aneurysm, five a thoracic aortic dissection and 35 other diagnoses (amongst others diabetic ketoacidosis, sepsis). The majority of patients had non-urgent medical conditions (85.9\%); non-urgent cardiovascular diseases (18.7\%), non-cardiac chest pain (not further specified) (17.3\%), musculoskeletal pain (17.9\%), psychogenic disorder $(11.2 \%)$, gastrointestinal disorders (7.1\%), respiratory disorders (5.5\%) and other nonurgent diagnoses (8.4\%). 
Table 2. Diagnosis of 2,023 patients who contacted the OHS-PC for chest discomfort (pain, pressure, tightness, or discomfort), divided in NTS high (U1-U2) and low urgency $\left(U_{3}-U_{5}\right)$.

\begin{tabular}{lccc}
\hline Diagnosis, $\mathrm{n}(\%)$ & $\begin{array}{c}\text { NTS High } \\
\text { urgency } \\
\mathrm{n}=1208\end{array}$ & $\begin{array}{c}\text { NTS Low } \\
\text { urgency } \\
\mathrm{n}=815\end{array}$ & $\mathrm{p}$-value \\
& $\mathbf{( 5 9 . 7 \% )}$ & $(\mathbf{4 0 . 3 \% )}$ & \\
\hline Acute coronary syndrome & $171(14.2)$ & $56(5.6)$ & $<0.001$ \\
STEMI & $51(29.8)$ & $16(28.6)$ & 0.858 \\
NSTEMI & $71(41.5)$ & $22(39.3)$ & 0.768 \\
UAP & $38(22.2)$ & $14(25.0)$ & 0.668 \\
Non-classified ACS & $11(6.4)$ & $4(7.1)$ & 0.853 \\
Other life threatening events (LTEs) & $38(3.1)$ & $20(2.5)$ & 0.361 \\
Pulmonary embolism & $6(15.8)$ & $7(35.0)$ & 0.095 \\
Acute abdominal aneurysm & $5(13.2)$ & $0(0.0)$ & 0.151 \\
Thoracic aortic dissection & $3(7.9)$ & $2(10.0)$ & 0.786 \\
Other* & $24(63.2)$ & $11(55.0)$ & 0.546 \\
Non-urgent cardiovascular diseases** & $257(21.3)$ & $121(14.8)$ & $<0.001$ \\
Non-cardiac chest pain, not further specified *** & $180(14.9)$ & $169(20.7)$ & 0.001 \\
Musculoskeletal pain & $173(14.3)$ & $189(23.2)$ & $<0.001$ \\
Psychogenic disorders & $116(9.6)$ & $110(13.5)$ & 0.006 \\
Gastrointestinal tract disorders & $97(8.0)$ & $46(5.6)$ & 0.040 \\
Respiratory tract disorders & $66(5.5)$ & $45(5.5)$ & 0.955 \\
Other non-urgent diagnoses**** & $110(9.1)$ & $59(7.2)$ & 0.137 \\
\hline
\end{tabular}

* Stroke, severe COPD exacerbation, acute severe heart failure, sepsis, coronary spasm caused by hypokalaemia, diabetic ketoacidosis, epileptic insult, bleeding from oesophageal varices, ovarian torsion, ventricular fibrillation.

** Stable angina pectoris (including atypical chest pain), stable heart failure, arrhythmias, hypertension

*** Cardiac pathology unlikely after cardiologist's or GP's diagnostic work-up, but without differential diagnosis

$* * * *$ Amongst others: anaemia, carcinoma, vasovagal collapse, side effects medication, dermatologic diseases

\section{Relation diagnosis and urgency allocation}

Patients with an ACS had received a NTS high urgency in $75.3 \%$ (women $74.7 \%$, men $75.7 \%$ ), and final high urgency in $88.5 \%$ (women $89.0 \%$, men $88.2 \%$ ). Patients with another LTE received a NTS high urgency in $65.5 \%$ (women $76.0 \%$, men $57.6 \%$ ), and a final high urgency in $74.1 \%$ (women $84.0 \%$, men $66.7 \%$ ). Of the 41 ACS/other LTE patients who had received a final low urgency most were categorized as $\mathrm{U}_{3}(87.8 \%)$, and a minority as $U_{4}(7.3 \%)$ or $U_{5}(4.9 \%)$ (Table 3 ). 
Patients with non-urgent cardiovascular diseases were more often classified as highurgent $(21.3 \%$ vs. $14.8 \%, \mathrm{p}<0.001)$ and patients with psychogenic disorder as lowurgent ( $9.6 \%$ vs. $13.5 \%, p=0.006)$.

Table 3. Overview of the NTS and final urgency allocation of 285 patients with ACS or LTES

\begin{tabular}{|c|c|c|c|c|c|c|}
\hline & Final U1 & Final $U_{2}$ & Final $U_{3}$ & Final $U_{4}$ & Final $U_{5}$ & Total \\
\hline NTS U1 & 153 & 14 & 1 & 0 & 0 & 168 \\
\hline NTS U 2 & 16 & 24 & 0 & 0 & 1 & 41 \\
\hline $\mathrm{NTS} \mathrm{U}_{3}$ & 20 & 9 & 34 & 0 & 0 & 63 \\
\hline NTS U4 & 0 & 0 & 0 & 0 & 0 & 0 \\
\hline NTS U 5 & 4 & 4 & 1 & 3 & 1 & 13 \\
\hline Total & 193 & 51 & 36 & 3 & 2 & 285 \\
\hline
\end{tabular}

NTS urgency: NTS urgency allocation, retrieved from electronic health record

Final urgency: the overruled urgency, retrieved from re-listening calls

Black: the NTS urgency and final urgency were the same

Blue: the user (triage nurse in coordination with the GP) has scaled up the urgency

Red: the user (triage nurse in coordination with the GP) has scaled down the urgency

\section{Accuracy NTS and final urgency}

The NTS high urgency had a sensitivity of 0.73 ( $95 \% \mathrm{Cl} 0.68-0.78)$, specificity of 0.43 ( $95 \% \mathrm{Cl} 0.40-0.45)$, positive predictive value of 0.17 ( $95 \% \mathrm{Cl} 0.16-0.19$ ), and negative predictive value of 0.91 ( $95 \% \mathrm{Cl} 0.89$-0.92) for the outcome ACS/other LTE (Table 4). For the final urgency this was: sensitivity 0.86 ( $95 \% \mathrm{Cl} 0.81-0.90)$, specificity 0.34 ( $95 \%$ $\mathrm{Cl} 0.32-0.37)$, positive predictive value 0.18 (95\% Cl 0.17-0.19) and negative predictive value 0.94 ( $95 \% \mathrm{Cl} 0.92-0.95)$.

Table 4. Accuracy outcomes of the NTS and final high urgency allocation $\left(U_{1} / U_{2}\right)$ against ACS or other LTEs.

\begin{tabular}{lll}
\hline $\begin{array}{l}\text { Accuracy outcomes } \\
\text { Value }(95 \% \mathrm{CI})\end{array}$ & NTS high urgency & Final high urgency \\
ACS - LTE prevalence 14.1\% & & \\
\hline Sensitivity & $0.73(0.68-0.78)$ & $0.86(0.81-0.90)$ \\
Specificity & $0.43(0.40-0.45)$ & $0.34(0.32-0.37)$ \\
Positive predictive value & $0.17(0.16-0.19)$ & $0.18(0.17-0.19)$ \\
Negative predictive value & $0.91(0.89-0.92)$ & $0.94(0.92-0.95)$ \\
\hline
\end{tabular}




\section{DISCUSSION}

The safety and efficiency of the Dutch NTS decision support tool were rather poor for telephone triage at OHS-PC in patients with acute chest discomfort, given the sensitivity (0.73) and specificity (0.43) for high urgency allocation of patients who had an ACS/other LTE. Safety improved after intervening of the triage nurse; the final high urgency had a sensitivity of 0.86 and specificity of $0.34 .{ }^{20}$ Women and men with ACS/ other LTE received equally high urgencies. At a prevalence of ACS/other LTE of $14.1 \%$ (11.2\% and $2.9 \%$, respectively), the positive predictive value for both the NTS and final urgency was low ( 0.17 and 0.18 , respectively) and the high negative predictive value high (0.91 and 0.94 , respectively).

Clearly, the triage system is calibrated on the safe side. Most GPs highlight the over triage, but in our opinion, in the critical domain of patients with chest discomfort under triage should receive more attention. ${ }^{19,521}$ It is evident that patients with an ACS and those classified with other LTEs should receive a high urgency allocation, but the NTS classified $27 \%$ of the ACS/LTE patients as low urgent, and this was still rather high for the final urgency (14\%).

We were able to analyse the original and very first conversation with patients, and these conversations were assessed without knowledge of the diagnosis; the assessment of symptoms was not affected by recall or hindsight bias. Moreover, we were able to include a large sample of patients and missing outcome data did not lead to patient or call selection. We therefore are confident our results are well generalizable, not only to Dutch settings but also to similar OHS-PC settings, e.g. UK and Scandinavian countries. ${ }^{1}$ Our results may also be generalizable to EMS settings, because the prior chance of having an ACS among those calling for chest discomfort is rather similar in the EMS setting as in the OHS-PC setting. ${ }^{1322}$

A limitation is that in $15 \%$ of calls the overruled urgency was unclear. In these cases, an expert panel (blinded to the clinical outcome) decided on all available information to be heard in the calls.

We could not find studies evaluating the accuracy of telephone triage in the OHS-PC among patients with chest discomfort against clinical outcomes. A systematic review of six studies evaluating the Manchester Triage Standard (MTS) in the ED setting reported that the MTS had allocated a high urgency in patients who showed to have an ACS with a sensitivity of $0.70-0.80 .{ }^{23}$ One of these six studies also reported specificity 
(0.59) among patients with chest pain referred to a Portuguese ED. ${ }^{24}$ Thus, the MTS, with the advantage of face-to-face contact seems to have a similar sensitivity and somewhat higher specificity as seen in our study. Interestingly, the prevalence of ACS among the 233 patients with chest pain in the Portuguese study was lower than in our study (9.4\% vs. 11.2\%). ${ }^{24}$ None of the studies reported positive and negative predictive values, which prevented us from comparing these to ours. The prior risk of ACS and LTEs of $14.1 \%$ changed only marginally with $17 \%$ and $18 \%$, for the NTS and final high urgency, respectively, and to $9 \%$ and $6 \%$ for the NTS and final low urgency allocation. To the best of our knowledge, there are no accuracy studies performed in the EMS-setting in which urgency allocation with EMS (112 or 911) telephone triage was compared to presence or absence of ACS. In an observational Swedish study among 14,454 patients calling EMS for chest discomfort, 63.5\% received an urgency 1 ambulance and $11.5 \%$ turned out to have an ACS (women 9\% and men $14 \%$ ). ${ }^{22}$ An EMS study from USA with 3,007 calls of patients with acute chest pain to the Medical Priority Dispatch System (MPDS) for decision support reported a prevalence of $8.7 \%$ of acute myocardial infarction. ${ }^{25}$

In a primary care study, the GP's clinical gestalt was more accurate in predicting ACS than a prediction rule (c-statistic 0.75 vs. 0.66 ) in patient with acute chest discomfort. ${ }^{20}$ This is in line with our finding that the sensitivity of the final urgency (including overruled cases) was higher than that of the NTS alone (0.86 vs. 0.73). Previous studies reported that the risk of ACS in women was underestimated, a finding in contrast to our result in which women and men with ACS received similarly high urgency allocation. 2627 One of the former mentioned EMS studies also found women and men received similarly high urgency allocation, the other EMS study did not report sex-stratified analyses. 2225

Missing an ACS is the most common reason for malpractice claims worldwide. ${ }^{2} 28$ There are no generally accepted guidelines that define what rate of missed ACS is considered acceptable, and this threshold will likely differ among different health care providers. A survey performed among 1,029 ED doctors in the US, New Zealand and Australia showed that they considered on average a missing rate between $0.1-1 \%$ (range $0-10 \%$ ) as acceptable. ${ }^{29}$ We do not have such information from GPs or lay people, but we suspect that this will be rather similar in the Netherlands. Alarmingly, this number is not in line with our finding that $27 \%$ of patients with ACS/other LTES received a NTS' low urgency allocation and a 14\% final low urgency allocation. Indeed, a low urgency allocation does not necessarily mean the ACS is being missed, yet still an undesirable patient safety risk has been taken for the hazard of life-threatening 
ventricular arrhythmias and sudden death due to severe pumping failure of the heart in those with AMI. ${ }^{30} 3^{1}$ On the other hand, triage nurses and their supervising GPs increased triage safety by overruling the decision support system adequately, though with significantly increasing over triage. Apparently, the 'human factor' remains conducive for safety in the current telephone triage process. ${ }^{1832}$ Nonetheless, potential room for improvement should be studied, both of the decision support tool itself by developing better diagnostic prediction rules as well as by improving its use by triage nurses and management. 33

\section{CONCLUSION}

The semi-automatic triage NTS tool underestimated the urgency in $27 \%$ of patients with ACS/other LTEs. Overruling by triage nurses improved safety, but still $14 \%$ of men and women with ACS/other LTEs received a too low urgency, while efficiency remained poor.

\section{ACKNOWLEDGEMENTS}

The authors would like to thank the OHS-PC foundation 'Primair Huisartsenposten' and all employees of the participating locations for their cooperation in this study, notably for providing data and technical support. We thank general practitioner I Kagenaar for her contribution to the expert panel.

\section{FUNDING}

This study was funded by an unrestricted grant from (i) the Department of General Practice of the University Medical Centre Utrecht, (ii) a personal promotion grant to DZ, (iii) the The Netherlands Triage Standard Foundation and (iv) the Stoffels-Hornstra Foundation. 


\section{REFERENCES}

1. Burman RA, Zakariassen E, Hunskaar S. Management of chest pain: a prospective study from Norwegian out-of-hours primary care. BMC Family Practice 2014;15:51. doi: 10.1186/1471-2296-15-51

2. Mol KA, Smoczynska A, Rahel BM, et al. Non-cardiac chest pain: prognosis and secondary healthcare utilisation. Open Heart 2018;5(2):eooo859. doi: 10.1136/ openhrt-2018-000859

3. Kuriyama A, Urushidani S, Nakayama T. Five-level emergency triage systems: variation in assessment of validity. Emergency Medicine Journal. 2017;34(11):703-10. doi: 10.1136/ emermed-2016-206295

4. van lerland $Y$, van Veen $M$, Huibers $L$, et al. Validity of telephone and physical triage in emergency care: the Netherlands Triage System. Family Practice 2011;28(3):334-41. doi: 10.1093/fampra/cmq097

5. Keizer E, Maassen I, Smits M, et al. Reducing the use of out-of-hours primary care services: A survey among Dutch general practitioners. The European Journal of General Practice 2016;22(3):189-95. doi: 10.1080/13814788.2016.1178718

6. Zachariasse JM, Seiger N, Rood PP, et al. Validity of the Manchester Triage System in emergency care: A prospective observational study. PloS one 2017;12(2):e0170811. doi: 10.1371/journal.pone.0170811

7. Huibers L, Smits M, Renaud V, et al. Safety of telephone triage in out-of-hours care: a systematic review. Scandinavian Journal of Primary Health Care 2011;29(4):198-209. doi: 10.3109/02813432.2011.629150

8. Healthcare Quality, Complaints and Disputes Act (WKKGZ), 2016.

9. Rutten MH, Kant J, Giesen P. What can we learn from calamities at out-of-hours services in primary care? [Wat kunnen we leren van calamiteiten op de huisartsenpost?]. Huisarts \& Wetenschap 2018;6(61) doi: 10.1007/s12445-018-0155-7

10. Annual reports of 2014-2017. [Jaarverslagen 2014-2017.] Utrecht, The Netherlands: Foundation Primair out-of-hours services in primary care [Stichting Primair Huisartsenposten]

11. Plat FM, Peters YAS, Loots FJ, et al. Ambulance dispatch versus general practitioner home visit for highly urgent out-of-hours primary care. Family Practice 2017(Dec 20) doi: 10.1093/fampra/cm $\times 121$

12. Hoorweg BB, Willemsen RT, Cleef LE, et al. Frequency of chest pain in primary care, diagnostic tests performed and final diagnoses. Heart 2017;103(21):1727-32. doi: 10.1136/heartjnl-2016-310905

13. van der Meer MG, Appelman Y, Rutten KHG, et al. Are there gender disparities in symptom presentation or triage of patients with chest discomfort at primary care out-of-hours services? An observational study. British Medical Journal Open 2019;9(11):e031613. doi: 10.1136/bmjopen-2019-031613

14. Erkelens DC, Wouters LT, Zwart DL, et al. Optimisation of telephone triage of callers with symptoms suggestive of acute cardiovascular disease in out-of-hours primary care: observational design of the Safety First study. British Medical Journal Open 2019;9(7):e027477. doi: 10.1136/bmjopen-2018-027477 
15. Soler JK, Okkes I, Wood M, et al. The coming of age of ICPC: celebrating the 21st birthday of the International Classification of Primary Care. Family Practice 2008;25(4):312-7. doi: 10.1093/fampra/cmno28

16. Olagundoye OA, Malan Z, Mash B, et al. Reliability measurement and ICD-10 validation of ICPC-2 for coding/classification of diagnoses/health problems in an African primary care setting. Family Practice 2018;35(4):406-11. doi: 10.1093/fampra/cm×132

17. Thim T, Krarup NH, Grove EL, et al. Initial assessment and treatment with the Airway, Breathing, Circulation, Disability, Exposure (ABCDE) approach. International Journal of General Medicine 2012;5:117-21. doi: 10.2147/IJGM.S28478

18. Carayon P, Schoofs Hundt A, Karsh BT, et al. Work system design for patient safety: the SEIPS model. Quality \& Safety in Health Care 2006;15 Suppl 1:i50-8. doi: 10.1136/ qshc. 2005.015842

19. Kroneman M, Boerma W, van den Berg M, et al. Netherlands: Health System Review. Health Systems in Transition 2016;18(2):1-240.

20. Bruins Slot $\mathrm{MH}$, Rutten $\mathrm{FH}$, van der Heijden GJ, et al. Diagnosing acute coronary syndrome in primary care: comparison of the physicians' risk estimation and a clinical decision rule. Family Practice 2011;28(3):323-8. doi: 10.1093/fampra/cmq116

21. Moll HA. Challenges in the validation of triage systems at emergency departments. Journal of Clinical Epidemiology 2010;63(4):384-8. doi: 10.1016/j.jclinepi.2009.07.009

22. Rawshani A, Larsson A, Gelang C, et al. Characteristics and outcome among patients who dial for the EMS due to chest pain. International Journal of Cardiology 2014;176(3):859-65. doi: 10.1016/j.ijcard.2014.08.004

23. Nishi F, de Oliveira Motta Maia F, de Souza Santos I, et al. Assessing sensitivity and specificity of the Manchester Triage System in the evaluation of acute coronary syndrome in adult patients in emergency care: a systematic review. JBI Database of Systematic Reviews and Implementation Reports 2017;15(6):1747-61. doi: 10.11124/ JBISRIR-2016-003139

24. Leite L, Baptista R, Leitao J, et al. Chest pain in the emergency department: risk stratification with Manchester triage system and HEART score. BMC Cardiovascular Disorders 2015;15:48. doi: 10.1186/s12872-015-0049-6

25. Scott G, Clawson JJ, Gardett I, et al. 9-1-1 Triage of Non-Traumatic Chest Pain: Association with Hospital Diagnosis. Prehospital Emergency Care 2017;21(4):525-34. doi: 10.1080/10903127.2017.1302530

26. Canto JG, Rogers WJ, Goldberg RJ, et al. Association of age and sex with myocardial infarction symptom presentation and in-hospital mortality. Journal of American Medical Association 2012;307(8):813-22. doi: 10.1001/jama.2012.199

27. Stehli J, Martin C, Brennan A, et al. Sex Differences Persist in Time to Presentation, Revascularization, and Mortality in Myocardial Infarction Treated With Percutaneous Coronary Intervention. Journal of American Heart Association 2019;8(10):e012161. doi: 10.1161/JAHA.119.012161

28. Ernesater A, Winblad U, Engstrom M, et al. Malpractice claims regarding calls to Swedish telephone advice nursing: what went wrong and why? Journal of Telemedicine \& Telecare 2012;18(7):379-83. doi: 10.1258/jtt.2012.120416

29. Than $M$, Herbert $M$, Flaws $D$, et al. What is an acceptable risk of major adverse cardiac event in chest pain patients soon after discharge from the Emergency Department?: a clinical survey. International Journal of Cardiology 2013;166(3):752-4. doi: 10.1016/j. ijcard.2012.09.171 
30. Kalarus Z, Svendsen JH, Capodanno D, et al. Cardiac arrhythmias in the emergency settings of acute coronary syndrome and revascularization: an European Heart Rhythm Association (EHRA) consensus document, endorsed by the European Association of Percutaneous Cardiovascular Interventions (EAPCI), and European Acute Cardiovascular Care Association (ACCA). Europace 2019;21(10):1603-04. doi: 10.1093/europace/euz163

31. Driscoll A, Barnes EH, Blankenberg S, et al. Predictors of incident heart failure in patients after an acute coronary syndrome: The LIPID heart failure risk-prediction model. International Journal of Cardiology 2017;248:361-68. doi: 10.1016/j.ijcard.2017.06.098

32. Wooldridge AR, Carayon P, Hundt AS, et al. SEIPS-based process modeling in primary care. Applied Ergonomics 2017;60:240-54. doi: 10.1016/j.apergo.2016.11.010

33. Wouters LT, Zwart DL, Erkelens DC, et al. Tinkering and overruling the computer decision support system: Working strategies of telephone triage nurses who assess the urgency of callers suspected of having an acute cardiac event. Journal of Clinical Nursing 2019 doi: 10.1111/jocn.15168 


\section{APPENDICES}

\section{Appendix - table 1. NTS urgency levels}

\begin{tabular}{|c|c|c|c|}
\hline NTS Urgency level & Definition & Response time & Medical help \\
\hline Uo-Resuscitation & Loss of vital functions & Immediately & Ambulance \\
\hline$U_{1}$ - Life threatening & $\begin{array}{l}\text { Unstable vital } \\
\text { functions }\end{array}$ & $\begin{array}{l}\text { Immediately, } \\
\text { within } 15 \text { minutes }\end{array}$ & Ambulance \\
\hline$U_{2}$ - Emergent & $\begin{array}{l}\text { Vital functions in } \\
\text { danger or organ } \\
\text { damage }\end{array}$ & $\begin{array}{l}\text { As soon as } \\
\text { possible, within } \\
1 \text { hour }\end{array}$ & $\begin{array}{l}\text { Home visit by GP or } \\
\text { consultation at OHS-PC }\end{array}$ \\
\hline$U_{3}$ - Urgent & $\begin{array}{l}\text { Possible risk of } \\
\text { damage, human } \\
\text { reasons }\end{array}$ & $\begin{array}{l}\text { A few hours ( }<3 \\
\text { hours) }\end{array}$ & $\begin{array}{l}\text { Home visit by GP or } \\
\text { consultation at OHS-PC }\end{array}$ \\
\hline$U_{4}$-Non-urgent & $\begin{array}{l}\text { Marginal risk of } \\
\text { damage }\end{array}$ & 24 hours & $\begin{array}{l}\text { Consultation at OHS-PC } \\
\text { or telephone advice }\end{array}$ \\
\hline$U_{5}$-Advice & No risk of damage & $\begin{array}{l}\text { Advice, no time } \\
\text { related }\end{array}$ & Telephone advice \\
\hline
\end{tabular}

GP: General practitioner

NTS: Netherlands Triage Standard

OHS-PC: Out-of-hours services for primary care

\section{Appendix - Table 2. Patient and call characteristics of 2,995 patients with chest discomfort calling OHS-PC, comparing patients with and without follow-up information on diagnosis}

\begin{tabular}{|c|c|c|c|}
\hline Characteristics & $\begin{array}{c}\text { Follow-up } \\
\mathrm{n}=2023 \\
(\%)\end{array}$ & $\begin{array}{c}\text { No follow- } \\
\text { up } \\
n=972(\%)\end{array}$ & P-value \\
\hline \multicolumn{4}{|l|}{ Patient characteristics } \\
\hline Mean age in years (SD) & $58.9(19.5)$ & $57.4(20.2)$ & 0.055 \\
\hline Female sex & $1111(54.9)$ & $533(54.8)$ & 0.966 \\
\hline \multicolumn{4}{|l|}{ Urgency } \\
\hline NTS urgency high & $1208(59.7)$ & $540(55.6)$ & 0.031 \\
\hline Final urgency high & $1384(68.5)$ & $625(64.7)$ & 0.038 \\
\hline \multicolumn{4}{|l|}{ Call characteristics } \\
\hline Mean total call duration in min (SD) & $7: 34(3: 49)$ & $7: 31(3: 37)$ & 0.093 \\
\hline Mean patients' introduction duration in $\min (S D)$ & $0: 19(0: 13)$ & $0: 19(0: 14)$ & 0.370 \\
\hline Triage nurse consulted the GP & $1061(52.4)$ & $509(52.4)$ & 0.967 \\
\hline Someone else called on behalf of patient & $1028(50.8)$ & $458(47.1)$ & 0.058 \\
\hline The person who calls expressed concerns & $913(89.4)$ & $402(89.3)$ & 0.959 \\
\hline \multicolumn{4}{|l|}{ NTS entry complaints } \\
\hline Breathing & $58(2.9)$ & $32(3 \cdot 3)$ & 0.523 \\
\hline Circulation & $37(1.8)$ & $11(1.1)$ & 0.155 \\
\hline Chest pain & 1535 (75.9) & $731(75.2)$ & 0.688 \\
\hline
\end{tabular}




\section{Appendix - Table 2. (Continued)}

\begin{tabular}{|c|c|c|c|}
\hline Characteristics & $\begin{array}{c}\text { Follow-up } \\
\mathrm{n}=2023 \\
(\%)\end{array}$ & $\begin{array}{l}\text { No follow- } \\
\text { up } \\
n=972(\%)\end{array}$ & P-value \\
\hline Shortness of breath & $164(8.1)$ & $95(9.8)$ & 0.129 \\
\hline Palpitations & $60(3.0)$ & $29(3.0)$ & 0.979 \\
\hline Back pain & $26(1.3)$ & $6(0.6)$ & 0.096 \\
\hline Dizziness & $19(0.9)$ & $8(0.8)$ & 0.753 \\
\hline Arm complaints & $10(0.5)$ & $6(0.6)$ & 0.666 \\
\hline Other & $114(5.6)$ & $54(5.6)$ & 0.929 \\
\hline \multicolumn{4}{|l|}{ NTS triage criteria } \\
\hline Chest pain & $1826(93.5)$ & $856(92.3)$ & 0.252 \\
\hline Shortness of breath & $1001(64.2)$ & $509(65.7)$ & 0.472 \\
\hline Chest pain duration $<12$ hours & $1296(73.6)$ & $569(68.7)$ & 0.011 \\
\hline Pain intensity severe (NRS >7) & $307(35.9)$ & $172(42.5)$ & 0.024 \\
\hline Pressing chest pain* & $771(51.4)$ & $354(50.9)$ & 0.828 \\
\hline Stabbing chest pain* & $347(23.1)$ & $167(24.0)$ & 0.651 \\
\hline Chest pain located retrosternal** & $597(41.6)$ & $283(40.7)$ & 0.688 \\
\hline Chest pain located left or right on thorax** & $573(39.9)$ & $265(38.1)$ & 0.418 \\
\hline Radiation of chest pain to any location & $1003(64 \cdot 5)$ & $439(59.6)$ & 0.021 \\
\hline Radiation to the arm & $424(43.5)$ & $175(37.0)$ & 0.019 \\
\hline Radiation to the shoulder blades & $308(35.9)$ & $124(29.4)$ & 0.021 \\
\hline Radiation to the jaws & $115(17 \cdot 3)$ & $45(13.1)$ & 0.088 \\
\hline Sweating & $522(41.2)$ & $239(40.7)$ & 0.833 \\
\hline Nausea or vomiting & $445(49.2)$ & $211(47.6)$ & 0.595 \\
\hline Pallor & $242(33.6)$ & $107(29.2)$ & 0.137 \\
\hline Dizziness or (feelings of nearly) fainting & $387(21.6)$ & $211(23.5)$ & 0.260 \\
\hline Coronary artery disease & $361(33.6)$ & $157(32.0)$ & 0.531 \\
\hline Diabetes mellitus & $160(19.0)$ & $72(18.8)$ & 0.933 \\
\hline \multicolumn{4}{|c|}{ Other than NTS items, if they were discussed in triage call } \\
\hline Point or coin size area of chest pain & $231(47.0)$ & $99(41.9)$ & 0.196 \\
\hline Tingling sensations on chest, arm or else & $209(83 \cdot 3)$ & $71(78.9)$ & 0.352 \\
\hline $\begin{array}{l}\text { Patient recognized symptoms from previous cardiac } \\
\text { events }\end{array}$ & $228(27.0)$ & $86(24 \cdot 3)$ & 0.340 \\
\hline \multicolumn{4}{|l|}{ CVD risk factors other than diabetes } \\
\hline Hypertension & $306(36.1)$ & $117(31.7)$ & 0.140 \\
\hline Hypercholesterolemia/statin use & $192(24.9)$ & $87(24.9)$ & 0.996 \\
\hline
\end{tabular}

* P-value comparing pressing or stabbing vs. the others types of pain together (pressing, stabbing, burning, cramping, gnawing)

** P-value comparing retrosternal or left/right side thorax vs. others locations of pain together (retrosternal, left/right side thorax, back/shoulder, epigastric region)

Coronary artery disease: patient reported history of myocardial infarction, stable or unstable angina pectoris 
Appendix-Figure 1. The Systems Engineering Initiative for Patient Safety (SEIPS) model, adapted from Carayon ${ }^{18}$

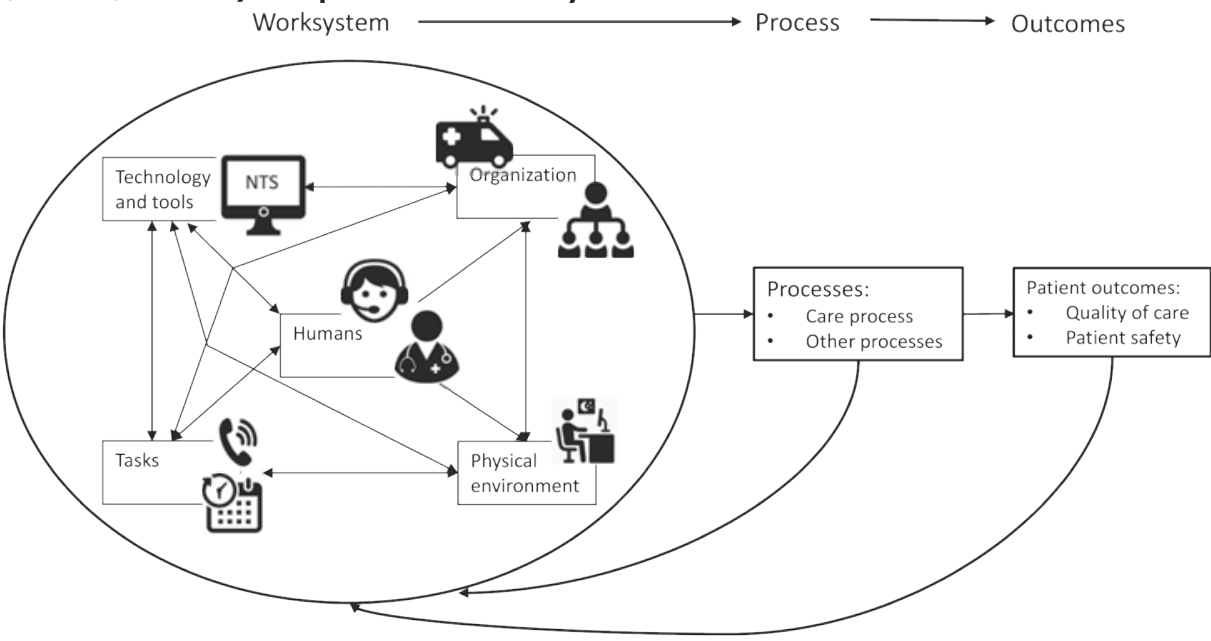




\section{Appendix-Figure 2. Examples of urgency adjustments and process of expert panel defining the final urgency.}
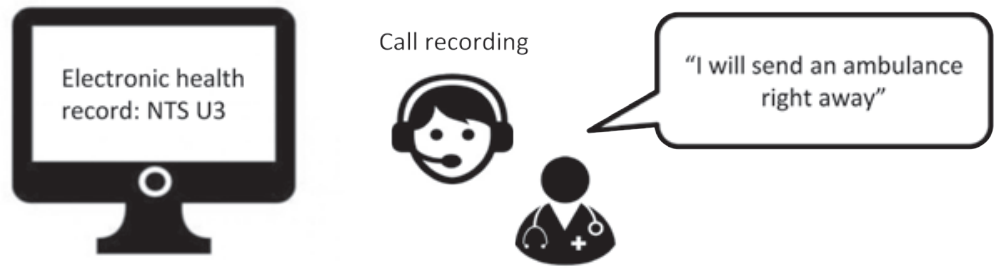

Example 1. NTS urgency: U3

Final urgency: U1

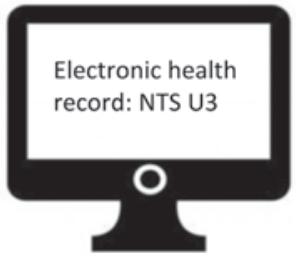

Example 2. NTS urgency: U3

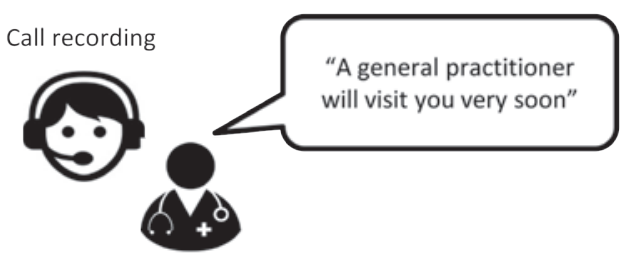

Final urgency: U2 (expert panel decision*)

*Comments expert panel: "Since the nurse says the general practitioner is coming very soon, I think the urgency is meant to be U2. I hear it's an urgent matter.. "

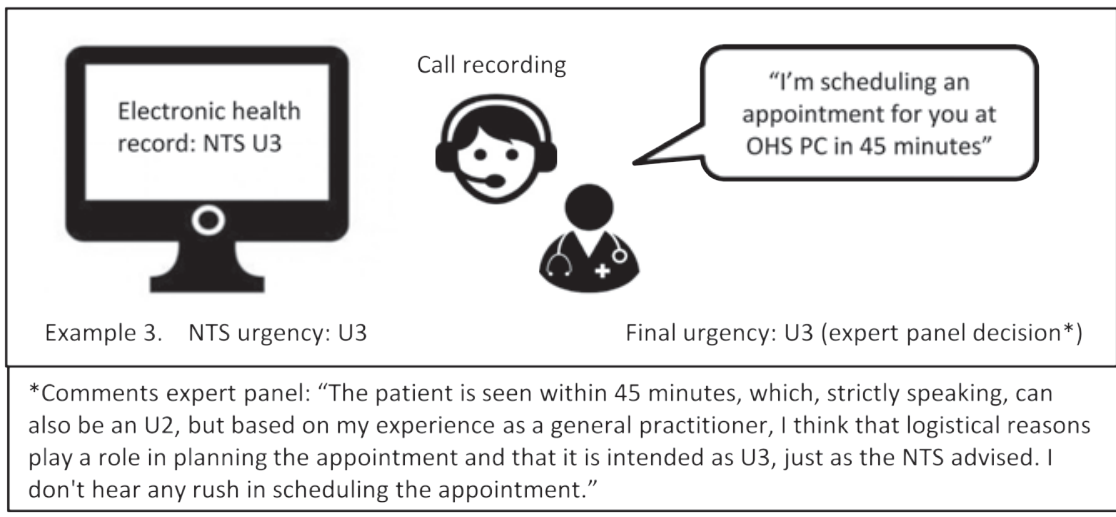


(1)

B

m

Oo

c

(i)

(1)

c)

(c) 0

- (1) $\mathrm{O}_{0}$

())

c

(c)

(ิ)

Cos

0

10

60

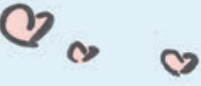

(c) 0 क हु ०

O 00

0

O 


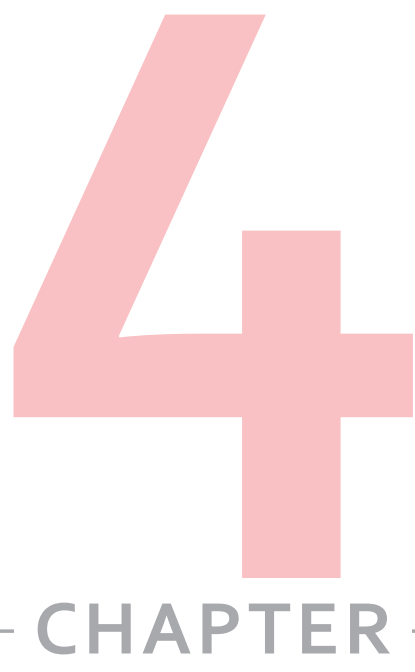

Tinkering and overruling the computer decision support system: working strategies of telephone triage-nurses who assess the urgency of callers suspected of having an acute cardiac event

Loes TCM Wouters, Dorien LM Zwart, Daphne CA Erkelens, Marlies Huijsmans, Arno W Hoes, Roger AMJ

Damoiseaux, Frans H Rutten, Esther de Groot 


\section{ABSTRACT}

Aims and objectives Our aim is to understand clinical reasoning and decision making of triage-nurses during telephone conversations with callers suspected of having acute cardiac events, and support from a computer decision support system (CDSS) herewith.

Background In telephone triage, nurses assess the urgency of callers' conditions with clinical reasoning, often supported by CDSS. The use of CDSS may trigger interactional workability dilemmas.

Design Qualitative study using principles of a grounded theory approach following COREQ-criteria for qualitative research.

Methods Audio-stimulated recall interviews were conducted amongst twenty-four telephone triage-nurses at nine out-of-hours primary care centers (OHS-PC).

Results Telephone triage-nurses use clinical reasoning elements for urgency assessment. Typically in telephone triage, they interpret the vocal - but not wordedelements in communication (paralanguage) such as tone of voice and shortness of breath and create a mental image in order to compensate for lack of visual information. We confirmed that interactional workability dilemmas occur. Congruence, established when the CDSS supports the triage-nurses' decision making, is essential for the CDSS' value. If congruence is absent, triage-nurses may apply four working strategies: (i) tinker to make CDSS final recommendation align with their own assessment, (ii) overrule the CDSS recommendation, (iii) comply with the CDSS recommendation or (iv) transfer responsibility to the GP.

Conclusion Triage-nurses who assess urgency may experience absence of congruence between the CDSS and their decision making. Awareness how triage-nurses reason and make decisions about urgency and what aspects influence their working strategies can help in achieving optimal triage of callers suspected of acute cardiac events at OHS-PC.

Relevance to clinical practice Triage-nurses' reasoning and their working strategies are vital for outcome of triage decisions. Understanding these processes is essential for CDSS developers and OHS-PC managers, who should value how triage-nurses interact with the CDSS, while they have the benefit of callers in mind. 


\section{INTRODUCTION}

Telephone triage is the gateway to medical help for patients in primary care in the Netherlands ${ }^{1}$. Accurate triage is of vital importance, specifically for the identification of highly urgent cases, such as patients who are suspected of having an acute cardiac event. ${ }^{23}$ Triage-nurses assess the urgency of the patient's health problem; should an ambulance be sent right away or is consultation at the out-of-hours service sufficient? Urgency assessment may be seen as a clinical reasoning process of triagenurses. ${ }^{4}$ Clinical reasoning has been studied in physical triage. ${ }^{5}$ However, clinical reasoning during telephone triage, a situation where triage-nurses have limited clinical information, is not well investigated. ${ }^{78}$

In most Western countries, computer decision support systems (CDSS) are used to support telephone triage decision making. ${ }^{9}$ Commonly used CDSS are constructed as a list of questions; starting with questions that ask for an immediate medical response, and gradually questions come up about symptoms which allow for a longer response time. ${ }^{10}$ The use of CDSS in telephone triage has a complex dynamic which can induce many, so-called, 'interactional workability dilemmas'. ${ }^{112}{ }^{12}$ Interactional workability dilemmas may be described as difficulties between the rigid CDSS structure and the wider context of the patients' narrative. ${ }^{12}$ The use of CDSS in telephone triage has been investigated during day practice of general practitioners and in a study about telenurses handling calls patients with chronic obstructive pulmonary disease (COPD). ${ }^{1213}$ These situations differ from the triage of patients suspected of acute cardiac events 3 because urgency and time pressures may specifically trigger interactional dilemmas with CDSS in the triage assessment.

Out-of-hours primary care (OHS-PC) are general practice cooperatives which were set up for urgent help requests that could not wait until the daytime consulting hours of the patient's general practitioner (GP). ${ }^{14}$ In the Netherlands, triage-nurses handle calls independently with a GP stand-by to consult in difficult situations. In the OHS-PC, the GP stand-by and the triage-nurses are not familiar with the callers and their medical history. In the Netherlands, the triage system is overall safe, with only $0.006 \%$ serious adverse events a year. ${ }^{15} \mathrm{~A}$ serious adverse event is defined as an unintended or unexpected event related to the quality of care and resulting in death or a severe harmful event for the patient. ${ }^{16}$ The majority of serious adverse events is of cardiovascular origin, such as missed myocardial infarction. ${ }^{15}$ 
It is unknown how triage-nurses reason during their out-of-office hour's telephone conversations. These conversations are under time-pressure when callers are suspected of having acute cardiac events.

\section{Rationale and research questions}

Our aim is to understand clinical reasoning and decision making of triage-nurses during telephone conversations, under time-pressure with callers suspected of having acute cardiac events, and support of these processes from a CDSS. Such understanding is necessary to improve the workability of the CDSS and to optimize support for triagenurses.

\section{Our research questions are:}

1. How do triage-nurses reflect on their reasoning elements and decisions which took place during their telephone conversations for triage of callers suspected of having acute cardiac events?

2. How do triage-nurses use a CDSS to support their clinical reasoning and decision making during these telephone conversations?

Given our interest in clinical reasoning, relevant theories were the hypotheticodeductive approach, the intuitive humanistic approach and the dual-process theory. ${ }^{417}$ For the use of the CDSS and interactional aspects, we employ the interactional workability theory. ${ }^{1112}$

\section{Clinical reasoning}

The hypothetico-deductive approach aims to understand how clinicians make decisions and hypotheses as if they are logical, rational decision-makers. ${ }^{18}$ It assumes that reasoning starts with gathering information, from which cues are used to generate preliminary hypotheses about a specific diagnosis or list of differential diagnoses. The professional interprets and classifies cues as confirmatory, negative or noncontributory to the hypotheses. The professional weighs each alternative hypothesis and then chooses the one supported by evidence. ${ }^{1920}$ Knowledge and experience are required to process information into reliable hypotheses successfully.

The hypothetico-deductive approach was found to be abstract and difficult to apply in real-life decisions, and hence, the importance of intuition was recognized. ${ }^{21}$ The intuition-humanistic approach was defined in six key aspects: pattern recognition, similarity recognition, common sense understanding, skilled know-how, sense of salience, and deliberate rationality. ${ }^{4}$ Intuitive judgments are said to be unaware and 
intrinsic, often referred to as a 'gut-feeling', 'hunch' or 'sixth-sense'. ${ }^{22}$ However, intuition was never seen as in opposition to traditional analytical reasoning. Although one is considered to be unaware of intuitive judgments, the process involves rational elements of knowledge. ${ }^{23} 24$ For example, the assessment of the vital sign pain, an indicator of a patient's acuity, entails both intuitive and rational elements. ${ }^{25}$

The concurrent use of rational and intuitive decision elements comes together in the dual-process theory. ${ }^{17}$ The dual-process theory consists of system one reasoning, which is automatic, fast and intuitive, and system two reasoning, which is deliberate, reliable and analytical. ${ }^{26}$ Croskerry suggested that these reasoning systems work separate from one another, in stages. ${ }^{26}$ In contrast, Norman said the systems work together in a continuum, and the reasoning processes are parallel and complementary. 2027 Furthermore, Croskerry argued that system one reasoning is more susceptible to cognitive biases, because it heavily relies on heuristics, and he suggested that cognitive biases may be reduced by slowing down the reasoning. ${ }^{28}$ The evidence for the effect of slowing down strategies is scarce: in contrast, several studies show that faster response times are more often associated with a correct diagnosis. ${ }^{24}$ Norman proposed that prior experience and knowledge is more important to reduce cognitive biases. ${ }^{24} 27$

\section{Reasoning during triage}

In assessing the urgency, the triage-nurse uses the caller's response to the CDSS questions and the CDSS recommendation, which consists of one out of six possible urgency levels (Appendix-Table 1). ${ }^{10}$ Previous studies assessing physical triage by nurses identified that decisions were based both on analytical and non-analytical reasoning strategies. ${ }^{629}$ With an increase in experience, triage-nurses' decisions became more based on intuition. ${ }^{4}$ Experienced nurses relied more on behavioural cues, time factors and medical, social and contextual factors to judge the patients' complaints. ${ }^{30} 3^{1}$ During telephone triage, nurses have to deal with the absence of physical parameters and compensate for this lack of information, by creating a mental image of the patient and the situation from which the call is made. ${ }^{732}$

\section{Interactional workability}

The aim of using a CDSS is to standardize and thereby presumably increase the accuracy and reliability of nurses' urgency decisions. ${ }^{43^{1}}$ However, there are limits to standardization because general rules may underdetermine what should be done in a specific case. ${ }^{33}$ Interactional workability is the way that a complex intervention, such as a CDSS, affects interactions between people and their work processes. ${ }^{11}$ During telephone triage, the interaction is between the patient, the triage-nurse and 
the CDSS. ${ }^{12}$ Interactional workability is characterized by the dimensions congruence and disposal of work. ${ }^{11}$ Congruence in the interactions between the intervention, the users' role, and the context is key to promote the ease of use and efficiency of the intervention. Disposal of work considers how the interactions with (technical) interventions, such as the CDSS, contribute to the fulfilment of the purpose of the intervention (e.g. following a guideline). ${ }^{11}$ Congruence in the interactions gives rise to disposal of work. The introduction of a CDSS for triage systems seems to reduce the nurses' opportunities for making their own judgments. ${ }^{31}$ In practice, triage-nurses rarely use the recommendations from the CDSS in isolation. Instead, they combine and compare digital, clinical and subjective patient information to identify any conflicts. ${ }^{13}$ 34 The level of experience influences how nurses use decision support. Novice nurses said they carefully followed the guidelines, whereas more senior triage-nurses said they have internalized the guidelines and use these alongside their own judgment. ${ }^{6}$

\section{METHODOLOGY}

We designed a qualitative study using the principles of a grounded theory approach. ${ }_{35}{ }^{6}$ Twenty-four triage-nurses from nine OHS-PC locations were invited for semistructured audio stimulated recall interviews. ${ }^{37}$ The Consolidated criteria for Reporting Qualitative Research (COREQ) were used to report the findings of this study (see supplementary file 1$)$.

\section{Context}

The study was conducted at nine OHS-PC locations in the Netherlands, who collaborate in the foundation 'Primair Huisartsenposten'. ${ }^{38}$ This foundation provides care for approximately 1.5 million residents in the Netherlands, covering both rural and urban areas. The triage-nurses working at the OHS-PC are required to have a 3-year education for certified primary care nursing assistant and a specific training for telephone triage about how to use the CDSS the Netherlands Triage Standard (NTS, a modified version of the Manchester Triage Standard). ${ }^{9} 44^{\circ}$ Since the introduction of the NTS in 2011 in the Netherlands, this system has been used by most OHS-PC, by approximately half of the ambulance dispatch centers and by an increasing number of emergency departments. ${ }^{1}$ The triage-nurse fills out the caller's responses in the semiautomatic NTS system, which then automatically generates urgency allocations. The urgency level generated by the NTS can be adjusted by the triage-nurse if the nurse disagrees with the NTS advice. Most often, adjustments are preceded by consultation of the supervising GP, who has the final responsibility for the urgency level decision. 
${ }^{14}$ All telephone calls to the OHS-PC locations are routinely recorded and archived for training and quality control purposes.

\section{Recruitment procedures}

Recruitment of participants was done by the research team members, who initially contacted the triage-nurses managers. The manager asked the triage-nurses in their team who was interested in reflecting on their clinical reasoning during telephone triage. We encouraged the managers to maximise variation of sampling, to gather triage-nurses with varying levels of experience in telephone triage and experience in health care elsewhere. We have no insight in how many triage-nurses refused to participate, but as the triage-nurses were enabled to participate within working hours, we assume there were no other than practical reasons to refuse. Triage-nurses who expressed themselves as senior in general had at least six years of working experience in telephone triage in the OHS-PC. When a triage-nurse was recruited by the manager, the research team members made an appointment for an interview of one hour at their OHS-PC. Before the interview, the triage-nurses were asked to focus on triage conversations in which they suspected that the caller had an acute cardiac event, during telephone shifts in the two weeks before the interview. We encouraged them specifically to bring forward not only conversations of 'clear' cases, but also cases in which the triage-nurse was uncertain about his or her urgency assessment. The research team members retrieved the recordings of these conversations from the recording archive. All interviews were conducted between July 2016 and July 2018 by three researchers ( $L W, M H, D E)$. The researchers introduced themselves to the triage-nurses as GP-trainees and researchers in the field of telephone triage of acute cardiac events.

\section{Design}

We performed face-to-face semi-structured interviews, using audio stimulated recall technique. Every interview, we started with listening to an audio tape of a telephone triage conversation. This technique helps the participant to give meaning to and reflect on their behavior in a real life situation. ${ }^{41} \mathrm{~A}$ topic list comprised of open questions about clinical reasoning and working with the CDSS was used as a framework (appendix 2). All interviews were audio-taped and subsequently transcribed verbatim for analysis. In addition, triage-nurses completed a 6-question questionnaire about their education, working experience at the OHS-PC and whether they had working experience in patient care elsewhere. 


\section{Research team}

Our research included three female GPs in training ( $\mathrm{LW}, \mathrm{MH}, \mathrm{DE})$, of which two clinician-scientists who combine the GP specialty training with a PhD-project (LW, $D E)$ about telephone triage. Since these researchers were in training and had limited clinical experience, they had no assumptions beforehand about clinical reasoning and workability with the NTS. Four members of the team were experienced researchers in primary care clinical research (female $D Z$ and males $F R, A H, R D$ ) of which one a practicing GP who has a special interest in mixed methods studies on quality and patient safety (DZ) and two with a special interest in cardiovascular diseases ( $F R, A H)$. $\mathrm{RD}$ is a practicing GP and the director of the GP specialty training. Finally, in the team was one female researcher qualified in the learning sciences and qualitative research (EdG).

\section{Ethical approval}

This interview study is part of a mixed-method study about telephone triage in patients suspected of having acute cardiac events ${ }^{38} ;$ the study was approved by the Ethical Review Board of the UMC Utrecht. Anonymity was guaranteed and participation was voluntary. Informed consent of the participants was obtained at the beginning of each interview.

\section{Data-analysis}

Data were analyzed with constant comparison within and between cases, using both deductive and inductive approaches. ${ }^{35}{ }^{6}$ We took an approach according to the principles of a grounded theory (iterative and focused on theory development) for the inductive analysis of the data about the CDSS use, and we took a deductive approach for the analysis of reasoning strategies. Coding was done using NVivo version 11, qualitative data analysis software. Two researchers (LW, MH) studied independently in iterative cycles of four transcripts and started with open coding. They discussed their findings with a third researcher (EdG) until consensus was achieved. The codes were identified through active interaction with the data by carefully reading each line and memo writing. The initial codebook was developed through reading and coding the first nine transcripts and discussed with a third and fourth researcher (EdG, DZ). The codes were categorized, and each theme was compared across all participants, in order to investigate, clinical reasoning strategies and working with the CDSS. Sixteen interviews were independently coded by two researchers ( $\mathrm{LW}, \mathrm{MH})$ and five interviews were coded by one researcher (LW). From then on, a framework was developed and improved through axial and thematic coding. The final coding was then applied to the last three transcripts by three researchers to confirm the emergent theory (EdG, 
$\mathrm{DZ}, \mathrm{DE})$. The remaining research team members discussed and approved the analysis during the development of the final manuscript ( $F R, A H, R D)$. Researcher triangulation was achieved through discussions about our findings with a research team with diverse research and working backgrounds. In addition, we discussed our results with members of the national association of primary care organizations, and with GPs with additional training and skills in acute care; the attending triage-nurses and GPs in these meetings recognized our findings as relevant and representative for daily practice at OHS-PC.

\section{RESULTS}

Baseline characteristics of the participants are presented in Table 1. Variety was achieved in all the relevant characteristics such as education level, telephone triage working experience and other working experience in health care with direct patient observations. Most of the respondents were women (91.6\%).

Table 1. Baseline characteristics of triage-nurse participants $(n=24)$

\begin{tabular}{|c|c|}
\hline Median age (IQR) in years & $46(36.5-53 \cdot 5)$ \\
\hline Gender & 22 women, 2 men \\
\hline Education level & $\begin{array}{l}20 \text { nursing assistants, } 2 \text { nurses, } 1 \text { medical student and } \\
1 \text { nurse practitioner }\end{array}$ \\
\hline $\begin{array}{l}\text { Education for telephone triage } \\
\text { assessment }\end{array}$ & $\begin{array}{l}17 \text { triage-nurses have completed the formal education } \\
\text { for telephone triage assessment, } 7 \text { are in training }\end{array}$ \\
\hline $\begin{array}{l}\text { Working experience as telephone } \\
\text { triage-nurse in the OHS-PC }\end{array}$ & $\begin{array}{l}1<\text { one year, } 9 \text { one-three years, } 5 \text { four-six years, } 9>\operatorname{six} \\
\text { years }\end{array}$ \\
\hline $\begin{array}{l}\text { Previous working experience } \\
\text { elsewhere with direct patient } \\
\text { observations }\end{array}$ & $\begin{array}{l}14 \text { triage-nurses have worked or currently work with } \\
\text { direct patient observations, } 10 \text { have never worked } \\
\text { with direct patient observations }\end{array}$ \\
\hline $\begin{array}{l}\text { Present working experience } \\
\text { elsewhere with direct patient } \\
\text { observations }\end{array}$ & $\begin{array}{l}12 \text { triage-nurses currently work with direct patient } \\
\text { observations, at the following settings: } \\
\text { - } 8 \text { in GP daycare practice } \\
\text { - } 3 \text { in hospital } \\
\text { - } 1 \text { in homecare }\end{array}$ \\
\hline
\end{tabular}

\section{Clinical reasoning}

The analyses showed that triage-nurses combined elements of the hypotheticodeductive approach with elements of the humanistic-intuitive approach in their clinical reasoning. Triage-nurses gathered information, use their knowledge about diseases and test hypotheses about the disease(s) of concern. Within the humanistic-intuitive approach, triage-nurses used pattern recognition, intuition, and they created a mental 
image of the patient to compensate for the lack of visuals during telephone triage. The more senior triage-nurses tended to ask more questions beyond the required CDSS' questions during the telephone conversations. They aimed to gather in-depth information about the symptoms and the patient's context and wishes. In our analyses, there were no remarkable differences in clinical reasoning between nurses who work or have worked elsewhere in health care with direct patient contact. Furthermore, we found triage-nurses were aware of potential cognitive biases in their reasoning, described in the literature about the dual-process theory. ${ }^{17}$

"She said straight off that she was sweating because of the heat and the menopause, but I don't agree with her explanation, though it could be, of course. It can be a real pitfall, getting distracted. You stop having a clear view of the situation." (T8)

"Yesterday the ECG was okay. The E.R. doctor thought the symptoms were stomach-related but I don't want to be influenced by that. I want to know why this patient is phoning now. What has changed?" (T18)

Triage-nurses strongly included the patient's sound of voice in their clinical reasoning. They used the non-verbal, paralinguistic, aspects of the conversations, such as talking and breathing speed, gasping and tone of the voice. The vocal elements in communication, such as the intensity of voice or volume were in previous studies defined as paralanguage. ${ }^{42}$ Interpreting paralanguage was particularly adapted to judge the credibility of the degree of pain and dyspnea that the patients communicate. Both senior and novice triage-nurses interpreted paralanguage, but senior nurses were more confident, they said it is a skill that improved with experience.

"I can tell by the sound of her voice that she's anxious. She's breathing fast and she can't hear or answer my questions. There's a certain haste in her voice." (T13)

"Experience teaches you when someone sounds sick. You can really hear if someone's in pain, or feeling worried, or that it's serious.... It's also a gut feeling." (T18)

Interpreting paralanguage is combined with other reasoning processes to create a mental image of the patient, with the aim to judge the clinical status of the patient. 
"I make a mental image of the patient's physical state: how is she doing at the moment, what's the color of her skin, how is her breathing...?" (T6)

\section{Interactional workability with the CDSS}

The support that the CDSS provides for the urgency decision making was dependent on whether the CDSS's recommendation is congruent to the triage-nurses' based on their assessment of the caller's narrative. Triage-nurses considered the CDSS supportive for the registration of patient's name, date of birth, location and the gathering of clinical information.

"It was quite clear what to do for this patient. He'd had pain in the middle of his chest for under twelve hours and vegetative symptoms. The NTS advice was a $U_{1}$, so I sent for the ambulance." (T14)

Interactional workability dilemmas occured when the CDSS does not support the triage-nurse's clinical reasoning or decision making: then the CDSS constrains the decision-making process. This occured, for example, when in the CDSS there is a mandatory choice for a main presenting symptom which misaligns with the clinical situation. As a result of the CDSS' construction, the triage-nurse is forced to continue with the list of questions to be able to complete the triage assessment in the CDSS.

"If you have a patient who is breastfeeding and has chest pain, the main presenting symptom 'chest pain' doesn't fit the clinical condition. It's an inflammation of the breast, nothing cardiac is happening. But you have to tick all the boxes in the list of questions to complete the triage assessment." (T4)

Another example of an interactional dilemma is when the answer options within the CDSS are too restrictive in conjunction with the caller's narrative.

"You have to choose between oppressive, stabbing or unclear pain, but some people have both pressing and stabbing pain. In that case I go for unclear, but actually I don't think that's appropriate." (T13)

\section{Strategies of triage-nurses}

To deal with absence of congruence of the CDSS with the triage-nurses' decision making, triage-nurse applied four working strategies. These strategies were labeled by us as tinkering, overruling, complying and transferring responsibility to the GP. Tinkering was often practiced when the CDSS does not support the decision making 
of the triage-nurse. With tinkering the triage-nurse strived for a certain CDSS urgency recommendation which fitted her own decision through, amongst others, switching between main presenting symptoms and up- or downgrading pain or dyspnea scores.

"She'd had oppressive pain for under twelve hours... but I needed more to get $U_{1}$ urgency, so I looked for symptoms that could increase the urgency. Finally I set the pain score to 'severe'. Then the NTS advice is U1 so I don't have to explain why to the GP." (T10)

In overruling, the triage-nurse entered the symptoms according to how the patient responds, but the triage-nurse did not comply with the CDSS recommended urgency, because she thought a higher or lower urgency was appropriate for the patient. In overruling, the triage-nurse involved the supervising GP as is required according to the triage protocol of the OHS-PC.

"Some patients say they're having severe dyspnea. Then the NTS advises immediate $U_{1}$. But if the patient doesn't sound dyspneic on the phone ... then I'll go to the GP and ask if I can give it less urgency." (T13)

Complying was the third strategy of triage-nurses. In complying, the triage-nurse complied with the urgency recommendation given by the CDSS despite the fact that the CDSS recommendation was not in line with his or her own decision making. Some triage-nurses indicated that management demands make them decide as such. Managers audit the triage-nurses' telephone conversation recordings on a regular basis to establish whether the triage-nurses complies with a certain conversation format, based on the CDSS structure. Triage-nurses expressed that they feel the tension between performing triage assessment which is accurate according to their professional convictions, and what is expected from them to meet the audit demands.

"But then they say you don't perform well... that your conversations should be different, that you should comply more to the NTS and you should change your way of questioning.. " (T3)

The fourth working strategy was to transfer the responsibility to the supervising GP of duty. The triage-nurse asked the supervising GP to take over and let him or her take the decision. 
"This elderly patient had so much going on. It began with dizziness and falling over, which led to a head wound of uncertain size. He had a long medical history, including diabetes, and besides that lived alone. Every question I asked seemed to turn up more problems. It got so confusing for me that I decided the GP should take over." (T1)

In figure 1, a full model is presented with the clinical reasoning elements, centrally the congruence with the CDSS and the four working strategies.

Figure 1. Model of telephone triage nurses' urgency assessment while working with the CDSS

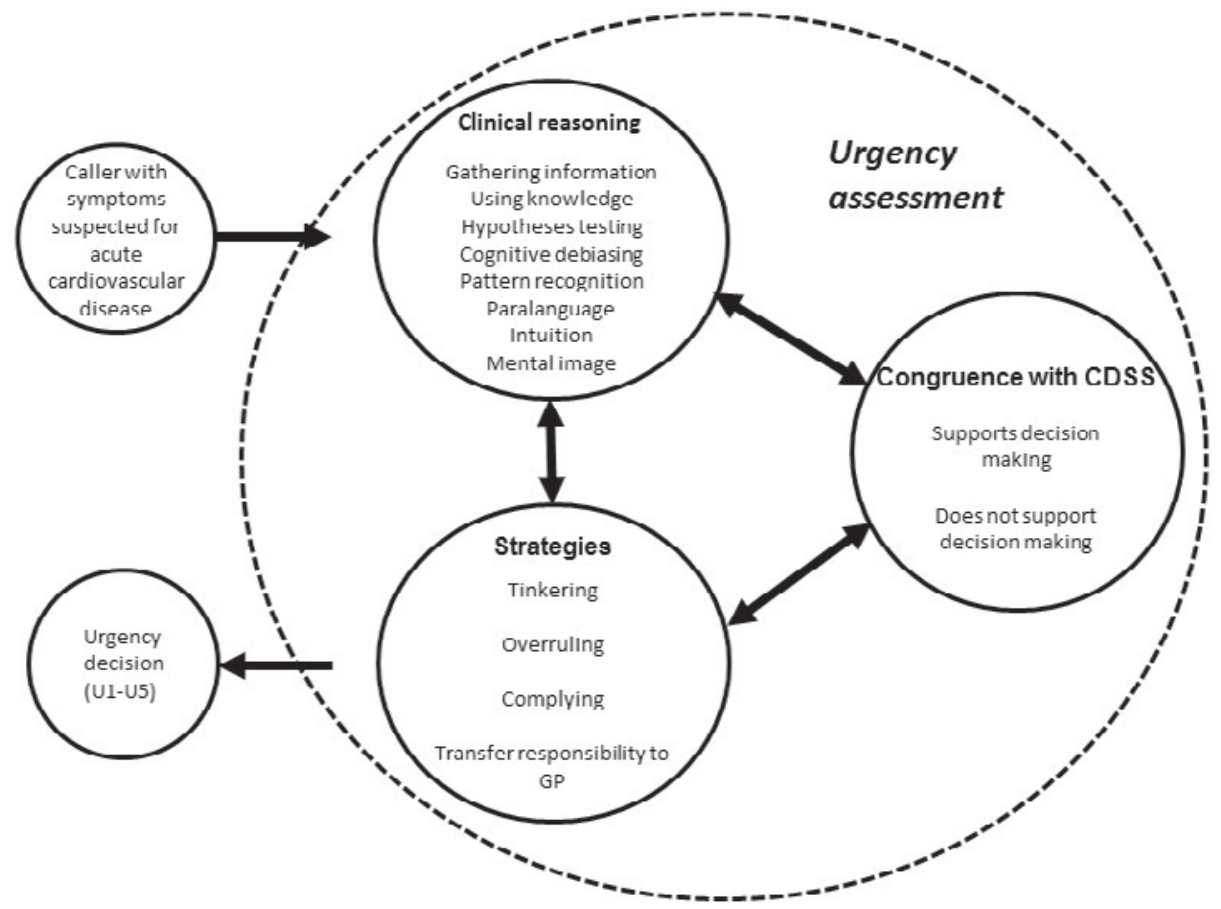

Results indicate that the triage-nurses' experience, the patient's context, feelings of uncertainty and management demands influenced their choice for the strategies. In general, novice nurses may experience more feelings of uncertainty and be more likely to comply or ask the GP to take over responsibility. Senior triage-nurses expressed to feel more confident about their decision making and therefore they tended more to overrule and tinker. 
"I didn't know what effect a pacemaker has on chest pain... so that's why I asked the GP. In general I tend to consult the GP fairly quickly, just to be sure, since I'm still in training." (T17)

Senior triage-nurses told that they used the context to support their decision making. Context may be about patient characteristics, cultural background, caller history or behavior on the telephone.

"People in this area code rarely call for help. They don't have medical insurance, so if they do call, you know it's serious." (T12)

Uncertainty was mentioned by all triage-nurses, meaning they perceived the patient to be giving too limited or too much information or conflicting information. Conversations with callers who had limited language skills or showed strong emotions were also mentioned to trigger uncertainty. Triage-nurses mentioned that their uncertainty was sometimes enhanced by the CDSS, which constrains them because the CDSS necessitates them to reduce the patient's problem to one or more individual measurable symptoms that can be administrated within the CDSS structure. For patients with potentially urgent conditions triage-nurses tended to go for the safest strategy.

"I asked five or six times if he was unconscious, but the son didn't seem to understand what I meant. I thought it was serious because the patient had a history of stroke and cardiac bypasses. Meanwhile the call had already gone on for five minutes, so I decided not to wait for more clarity and just sent an ambulance." ( $\left.T_{1} 6\right)$

\section{DISCUSSION}

With the principles of a grounded theory approach we analyzed the reflections of telephone triage-nurses and we identified that triage-nurses use diverse known reasoning elements for their urgency assessment. In combining elements of the hypothetico-deductive approach with elements of the humanistic-intuitive approach, they adjust to the patient's narrative. Triage-nurses assess the urgency by creating a mental image and interpreting the callers' paralanguage. Whether the CDSS supports the decision making of the triage-nurse is important in choosing the triage-nurses' working strategies. We distinguished four working strategies triage-nurses apply 
while using CDSS: tinkering to make the final advice align with their own assessment, overruling the CDSS advice, complying with the CDSS advice and transferring responsibility to the GP. We found that the triage-nurses' work experience, the patient's context (such as patient characteristics, caller history), feelings of uncertainty and management demands influence their choice for a strategy.

Interactional dilemmas, earlier reported in the literature, are present in our study and described as the feeling of negotiating between the CDSS questions and the patient's narrative which may include diverse symptoms. ${ }^{12}$ In the few studies about interactional workability, which are not specifically about telephone triage-nurses, the telemedicine setting both enabled and constrained the nurses' reasoning and decision making. ${ }^{12}$ ${ }^{13}$ When the CDSS does not support the triage-nurses' decision making, this may lead to time delay, which worsens the patient's prognosis when having acute cardiac event. ${ }^{3}$ The technical design of the CDSS in our study supports in a certain manner the purpose of the intervention; triage-nurses consider the CDSS supportive for the registrations of patient's name, date of birth and gathering clinical information with the help of the question lists that pop-up after choosing a main presenting symptom in the CDSS. However, triage-nurses consider the CDSS only supportive for gathering clinical information when the main presenting symptom and corresponding questions align with the clinical condition. In the case of absence of congruence, triage-nurses will apply strategies which will not fulfil the purpose of the CDSS (such as following the guideline) and therefore the CDSS does not accomplish disposal of work. Studies about interactional dilemmas are scarce and knowledge is lacking on what strategies triagenurses apply when they experience absence of congruence. In one Swedish interview study about working environment, it was briefly mentioned that some triage-nurses complied to the CDSS because they were afraid of making a wrong assessment. ${ }^{3} \mathrm{We}$ also found that management demands was one of the aspects that influenced the choice for the working strategies. Given telephone triage in the Netherlands is very safe ${ }^{15}$, it is a shortcoming when managers should limit their audits' focus on complying to the CDSS. We argue that it would be more relevant for managers to use feedback on clinical outcomes, which will be helpful for the triage- nurse to improve their urgency assessment performance, given the fact that providing feedback improves accuracy of new tasks. 44

In our study, interpreting paralanguage showed to be important for urgency assessment. Triage-nurses combine interpreting paralanguage with other reasoning elements and create therewith a mental image to compensate for the lack of visual information. Paralanguage is studied within linguistics, but there is limited research 
about interpreting paralanguage in telephone triage conversations. ${ }^{42}$ In one study, senior triage-nurses used caller self-tests and listened carefully to detect physical signs. ${ }^{7}$ In this study, the concept interpreting paralanguage was not mentioned, but 'listening for physical signs' suggests that triage-nurses use the paralinguistic aspects of the conversation. In a study performed at the emergency department, telephone triage-nurses said they judged the credibility of patient's symptoms on how they narrate their story, how they behave or speak and imagine what the patient's physical appearance looks like. ${ }^{\circ}$ Detailed information was, however, lacking in these studies on how triage-nurses listened for physical signs and how they interpreted these for their urgency assessment. 'Knowing the patient' was the cornerstone of reasoning in the prior mentioned Swedisch study about tele-nurses who managed patients with COPD; such familiarity with the patients enabled tele-nurses to value the clinical symptoms as either normal for the patient or as a warning sign. ${ }^{13}$ In this way the triage-nurses of acquired in-depth knowledge that empowered them to see past the CDSS and adapt their decision to the clinical situation. In our study, triage-nurses were not familiar with the callers, which implicates that they have to rely stronger on other reasoning elements for urgency assessment. Our study indicates that interpreting paralanguage and creating a mental image may be keystones for urgency assessment when triagenurses are not familiar with and cannot see the caller. Further research in exploring how triage-nurses interpret paralanguage in their urgency assessment may help to acquire additional knowledge for improving telephone triage training.

\section{Strengths}

We interviewed twenty-four triage-nurses with a variety of work experience and training. By using the audio stimulated recall interview technique, we obtained an accurate view of triage-nurses' reasoning elements. This method is considered reliable to understand participants' implicit theories and reflections on key events in a real situation of interest. ${ }^{41}$ Findings were discussed with the members of the research team, who have diverse research backgrounds, to optimize transparency and researcher triangulation. Understanding how clinical reasoning takes place in telephone triage of patients suspected of potential urgent conditions while working with a CDSS is important to improve workability with the CDSS and improve the training of triagenurses. As these interviews were performed in an open, non-judging, and confidential atmosphere, we had rich data to analyze and achieved a good understanding of triagenurses' clinical reasoning. 


\section{Limitations}

At the time of the interviews, the telephone conversations that were used for listening during the interview, were performed at a maximum of two weeks before the interview. However, because the nurses perform a large number of calls every shift, some nurses may have found it hard to remember their reasoning during these specific conservations used during the interview. The literature about audio-stimulated recall recommends that an interview should be conducted as soon as possible after the recording, but does not indicate a specific period. ${ }^{37}$ For future research, a (video) observation study might give additional information on how triage-nurses use the CDSS by observing exactly how they use the options provided by the interface of the CDSS. Also, a think-a-loud study with triage-nurses during telephone conversations, although very difficult to realize in an urgency setting, could contribute to our understanding. ${ }^{45}$

\section{CONCLUSION}

Telephone triage-nurses use clinical reasoning elements for urgency assessment of callers suspected of potentially acute cardiac events. They interpret paralanguage and create a mental image to compensate for the lack of visual information. Congruence with the CDSS is a key aspect, which in this study is established when the CDSS supports the triage-nurses' decision making. If congruence is absent, triage-nurses apply four working strategies, which are (i) tinkering to make the final recommendation align with their own assessment, (ii) overruling the CDSS recommendation, (iii) complying with the CDSS recommendation or (iv) transferring responsibility to the GP.

\section{RELEVANCE TO CLINICAL PRACTICE}

This study confirms triage-nurses have to deal with interactional dilemmas while working with CDSS, with lists of questions that may misalign to the clinical condition or have too restrictive answer options. Understanding triage-nurses' working strategies with CDSS and what influences their choices herewith, may help to develop improved education and also may add to a constructive safety culture in the workplace. Telephone triage training may benefit by sharing how interpreting paralanguage and creating a mental image is done. Awareness that triage-nurses' reasoning and their working strategies are vital for the outcome of triage decisions is important for CDSS developers and managers. CDSS developers may benefit by involving the triagenurses' input to improve interactional workability. About implications for managers, 
we argue that it would be counter-effective when managers solely focus their audits of triage-nurses on complying with the CDSS. Given that in the Netherlands, current telephone triage is very safe, managers better shift the focus of audits more to clinical outcomes of triage decisions.

\section{ACKNOWLEDGEMENTS}

We would like to thank the telephone triage nurses of primary care OHS foundation "Primair Huisartsenposten" in Utrecht for their participation.

\section{FUNDING}

This study was funded by the department of general practice of the University Medical Center Utrecht, the Associate Professorship-Promotion Grant of D.L. Zwart, MD, $\mathrm{PhD}$, the foundation "TheNetherlands Triage Standard" and the foundation "StoffelsHornstra." 


\section{REFERENCES}

1. Smits M, Rutten M, Keizer E, et al. The Development and Performance of After-Hours Primary Care in the Netherlands: A Narrative Review. Annals of Internal Medicine 2017;166(10):737-42. doi: 10.7326/M16-2776

2. Bosner S, Becker A, Abu Hani M, et al. Accuracy of symptoms and signs for coronary heart disease assessed in primary care. The British Journal of General Practice 2010;6o(575):e246-57. doi: 10.3399/bjgp10X502137 [published Online First: 2010/06/10]

3. Rawshani A, Larsson A, Gelang C, et al. Characteristics and outcome among patients who dial for the EMS due to chest pain. International Journal of Cardiology 2014;176(3):859-65. doi: 10.1016/j.ijcard.2014.08.004

4. Noon AJ. The cognitive processes underpinning clinical decision in triage assessment: a theoretical conundrum? International Emergency Nursing 2014;22(1):40-6. doi: 10.1016/j.ienj.2013.01.003

5. Goransson KE, Ehnfors M, Fonteyn ME, et al. Thinking strategies used by Registered Nurses during emergency department triage. Journal of Advanced Nursing 2008;61(2):163-72. doi: 10.1111/j.1365-2648.2007.04473.x

6. Patel VL, Gutnik LA, Karlin DR, et al. Calibrating urgency: triage decision-making in a pediatric emergency department. Adv Health Sciences Education Theory Pract 2008;13(4):503-20. doi: 10.1007/s10459-007-9062-6

7. Pettinari CJ, Jessopp L. "Your ears become your eyes": managing the absence of visibility in NHS Direct. Journal of Advanced Nursing 2001;36(5):668-75.

8. Wahlberg AC, Cedersund E, Wredling R. Telephone nurses' experience of problems with telephone advice in Sweden. Journal of Clinical Nursing 2003;12(1):37-45.

9. Lake R, Georgiou A, Li J, et al. The quality, safety and governance of telephone triage and advice services - an overview of evidence from systematic reviews. BMC Health Services Research 2017;17(1):614. doi: 10.1186/s12913-017-2564-x

10. Kuriyama A, Urushidani S, Nakayama T. Five-level emergency triage systems: variation in assessment of validity. Emergency Medicine Journal 2017;34(11):703-10. doi: 10.1136/ emermed-2016-206295

11. May C, Finch T, Mair F, et al. Understanding the implementation of complex interventions in health care: the normalization process model. BMC Health Services Research 2007;7:148. doi: 10.1186/1472-6963-7-148

12. Murdoch J, Barnes R, Pooler J, et al. The impact of using computer decision-support software in primary care nurse-led telephone triage: interactional dilemmas and conversational consequences. Social Science \& Medicine 2015;126:36-47. doi: 10.1016/j. socscimed.2014.12.013

13. Barken $T L$, Thygesen E, Soderhamn U. Advancing beyond the system: telemedicine nurses' clinical reasoning using a computerised decision support system for patients with COPD - an ethnographic study. Bmc Medical Informatics and Decision Making 2017;17 doi: ARTN 181 10.1186/s12911-017-0573-7

14. Keizer E, Maassen I, Smits M, et al. Reducing the use of out-of-hours primary care services: A survey among Dutch general practitioners. The European Journal of General Practice 2016;22(3):189-95. doi: 10.1080/13814788.2016.1178718 
15. Rutten MH, Kant J, Giesen P. What can we learn from calamities at out-of-hours services in primary care? [Wat kunnen we leren van calamiteiten op de huisartsenpost?]. Huisarts \& Wetenschap 2018;6(61) doi: 10.1007/s12445-018-0155-7

16. Healthcare Quality, Complaints and Disputes Act (WKKGZ), 2016.

17. Croskerry P. A universal model of diagnostic reasoning. Academic Medicine 2009;84(8):1022-8. doi: 10.1097/ACM.obo13e3181ace703

18. Dowding $D$, Thompson C. Using judgement to improve accuracy in decision-making. Nursing Times 2004;100(22):42-4.

19. Elstein AS, Schwartz A. Clinical problem solving and diagnostic decision making: selective review of the cognitive literature. British Medical Journal 2002;324(7339):72932.

20. Monteiro SM, Norman G. Diagnostic reasoning: where we've been, where we're going. Teach Learn Med 2013;25 Suppl 1:S26-32. doi: 10.1080/10401334.2013.842911

21. Carper B. Fundamental patterns of knowing in nursing. Advacned Nurse Sciences 1978;1(1):13-23.

22. Cioff J. Heuristics, servants to intuition, in clinical decision-making. Journal of Advanced Nursing 1997;26(1):203-8.

23. Croskerry P, Nimmo GR. Better clinical decision making and reducing diagnostic error. Journal of the Royal College of Physicians of Edinbrugh 2011;41(2):155-62. doi: 10.4997/ JRCPE.2011.208

24. Brush JE, Jr., Sherbino J, Norman GR. How Expert Clinicians Intuitively Recognize a Medical Diagnosis. Am J Med 2017;130(6):629-34. doi: 10.1016/j.amjmed.2017.01.045

25. Wood S. Assessment of pain. Nursing Times 2008:10042-47.

26. Croskerry P. Clinical cognition and diagnostic error: applications of a dual process model of reasoning. Advances in Health Science Education: Theory and Practice 2009;14 Suppl 1:27-35. doi: 10.1007/s10459-009-9182-2

27. Norman GR, Monteiro SD, Sherbino J, et al. The Causes of Errors in Clinical Reasoning: Cognitive Biases, Knowledge Deficits, and Dual Process Thinking. Academic Medicine 2017;92(1):23-30. doi: 10.1097/ACM.0000000000001421

28. Croskerry $P$, Singhal G, Mamede $S$. Cognitive debiasing 1: origins of bias and theory of debiasing. BMJ Quality \& Safety 2013;22 Suppl 2:ii58-ii64. doi: 10.1136/bmjqs-2012001712

29. Benner P. Using the Dreyfus model of skill acquisition to describe and interpret skill acquisition and clinical judgment in nursing practice education. Bulletin of science, technology \& society 2004;24(3):188-99. doi: 10.1177/0270467604265061

30. Edwards B, Sines D. Passing the audition - the appraisal of client credibility and assessment by nurses at triage. Journal of Clinical Nursing 2008;17(18):2444-51. doi: $10.1111 / \mathrm{j} .1365-2702.2007 .01970 . x$

31. Johannessen LEF. How triage nurses use discretion: a literature review. Professions and Professionalism 2016;6 (1):1446. doi: 10.7577

32. Edwards B. Seeing is believing--picture building: a key component of telephone triage. Journal of Clinical Nursing 1998;7(1):51-7.

33. Dong SL, Bullard MJ, Meurer DP, et al. The effect of training on nurse agreement using an electronic triage system. Canadian Journal of Emergency Medicine 2007;9(4):260-6.

34. Dowding $D$, Mitchell $N$, Randell $R$, et al. Nurses' use of computerised clinical decision support systems: a case site analysis. Journal of Clinical Nursing 2009;18(8):1159-67. doi: $10.1111 / j .1365-2702.2008 .02607 . x$ 
35. Kolb SM. Grounded theory and the constant comparative method: valid research strategies for educators. Journal of Emerging Trends in Educational Research and Policy Studies 2012;3:83-86.

36. Kennedy TJL, L.A. Making sense of grounded theory in medical education. Medical Education 2006;40:101-08.

37. Dempsey N. Stimulated recall interviews in ethnography. Qualitative Sociology 2010;33(3):349-67. doi: 10.1007/s11133-010-9157

38. Erkelens DC, Wouters LT, Zwart DL, et al. Optimisation of telephone triage of callers with symptoms suggestive of acute cardiovascular disease in out-of-hours primary care: observational design of the Safety First study. British Medical Journal Open 2019;9(7):e027477. doi: 10.1136/bmjopen-2018-027477

39. Kroneman M, Boerma W, van den Berg M, et al. Netherlands: Health System Review. Health Systems in Transition 2016;18(2):1-240.

40. Huibers $L$, Giesen $P$, Smits $M$, et al. Nurse telephone triage in Dutch out-of-hours primary care: the relation between history taking and urgency estimation. European Journal of Emergency Medicine 2012;19(5):309-15. doi: 10.1097/MEJ.obo13e32834d3e67

41. van Braak M, de Groot $E$, Veen $M$, et al. Eliciting tacit knowledge: The potential of a reflective approach to video-stimulated interviewing. Perspectives on Medical Education 2018;7(6):386-93. doi: 10.1007/s40037-018-0487-9

42. Ephratt M. Linguistic, paralinguistic and extralinguistic speech and silence. Journal of Pragmatics 2011;43(9):2286-307.

43. Wahlberg AC, Bjorkman A. Expert in nursing care but sometimes disrespectedTelenurses' reflections on their work environment and nursing care. Journal of Clinical Nursing 2018;27(21-22):4203-11. doi: 10.1111/jocn.14622

44. Nederhand T, Splinter, Rikers. The effect of performance standards and medical experience on diagnostic calibration accuracy. Health Professions Education 2018;4:30007. doi: https://doi.org/10.1016/j.hpe.2017.12.008

45. Lyle J. Stimulated recall: a report on its use in naturalistic research. British Educational Research Journal 2003;29(6):861-78. doi: 10.1080/0141192032000137349 


\section{APPENDICES}

\section{Appendix- Table 1. NTS urgency levels}

\begin{tabular}{|c|c|c|c|}
\hline NTS Urgency level & Definition & Response time & Medical help \\
\hline Uo-Resuscitation & Loss of vital functions & Immediately & Ambulance \\
\hline$U_{1}-$ Life threatening & $\begin{array}{l}\text { Unstable vital } \\
\text { functions }\end{array}$ & $\begin{array}{l}\text { Immediately, } \\
\text { within } 15 \text { minutes }\end{array}$ & Ambulance \\
\hline$U_{2}$ - Emergent & $\begin{array}{l}\text { Vital functions in } \\
\text { danger or organ } \\
\text { damage }\end{array}$ & $\begin{array}{l}\text { As soon as } \\
\text { possible, within } \\
1 \text { hour }\end{array}$ & $\begin{array}{l}\text { Home visit by GP or } \\
\text { consultation at OHS-PC }\end{array}$ \\
\hline$U_{3}$-Urgent & $\begin{array}{l}\text { Possible risk of } \\
\text { damage, human } \\
\text { reasons }\end{array}$ & $\begin{array}{l}\text { A few hours }(<3 \\
\text { hours) }\end{array}$ & $\begin{array}{l}\text { Home visit by GP or } \\
\text { consultation at OHS-PC }\end{array}$ \\
\hline$U_{4}-$ Non-urgent & $\begin{array}{l}\text { Marginal risk of } \\
\text { damage }\end{array}$ & 24 hours & $\begin{array}{l}\text { Consultation at OHS-PC } \\
\text { or telephone advice }\end{array}$ \\
\hline$U_{5}$ - Advice & No risk of damage & $\begin{array}{l}\text { Advice, no time } \\
\text { related }\end{array}$ & Telephone advice \\
\hline
\end{tabular}

GP: General practitioner

NTS: Netherlands Triage Standard

OHS-PC: Out-of-hours services for primary care

\section{Appendix 2. Questionnaires}

\section{Original version questionnaire, August 2016}

Topic: clinical reasoning

- Which moment or moments in the call was/were important for your reasoning? We will listen to the fragment/fragments again.

- Why was this fragment important for your reasoning?

- What did you take into consideration here?

- What made it striking for you?

- What did it mean to your reasoning process that the patient said this (......)?

- Here you asked the following question (...?) What made you think of that question?

Topic: interactional workability

- $\quad$ Does the NTS support the decision (s) you made in this fragment?

- Where in this fragment did the NTS decision supporter help you? Can you say more about that?

- $\quad$ Are the questions you asked here based on the NTS, or did you also have questions that come from outside the NTS? 
- Why did you ask those questions? And why did you ask those questions right here?

- Do you often ask questions that go beyond the NTS?

- Do you remember the main presenting symptoms that the NTS suggests?

- Which main presenting symptom did you choose? Why?

- What is / are the most important reason/s that led to this choice?

- Did you answer all the questions related to this presenting complaint? Why or why not?

- $\quad$ Did you switch to another main presenting symptom while asking questions? Why did you?

- Do you remember what the NTS recommended level of urgency was?

- What do you think of the urgency the NTS recommends? Why do you agree or disagree?

Topic: acute cardiac events

- $\quad$ Are there any special features in the triage of these patients? What makes the triage special or difficult or easy?

- Is the triage of patients with suspected acute cardiac event (compared to other types of triage phone calls) generally very clear or do you also get conversations where it is not so clear?

Topic: uncertainty

- How sure of your reasoning were you in this call?

- What were you unsure about and why?

- How did you deal with this uncertainty?

- How did this doubt / uncertainty influence your determination of urgency?

- Consultation with general practitioner: why did you or why did you not consult the GP? What did you expect from this consultation?

Topic: context

- Did anything else influence your reasoning process (other than the patient's characteristics) in this call? Things in yourself, in the environment?

- Can you imagine the circumstances to this call?

- How did that influence your reasoning during the triage call? 


\section{Supplementary topics, February 2017}

Topic: interactional workability (adapted questions)

- When does the NTS work for you and when does it get in your way?

- In your opinion, when is the NTS suitable for a particular case, and when is it not?

- If the NTS is not "working" for you, how do you do the triage? What do you base your decisions on?

- Have you noticed if using the NTS has any influence on the conversation with the patient? Do the questions match, or not? Have you noticed any clashes? What do you do if the questions do not fit the patient's story very well?

- What do you do if the patient gives unclear answers? The NTS requires a yes / no choice. Do you fill it in, or leave it open?

Topic: paralanguage

- $\quad$ You say the patient sounds sick ... what do you mean by that? What precisely do you base this on?

- Can you state explicitly what you hear then, in this fragment?

- How decisive for the triage is it for you, that the patient sounds like that?

Topic: patient's personality

- You indicate that this patient is a ... type of person. What do you mean? What kind of influence does this have on your reasoning process?

- How decisive for the triage is it for you that this patient is a ... type? 
AUDIO STIMULATED RECALL INTERVIEW STUDY WITH TRIAGE NURSES 
(1)

B

m

Oo

c

(i)

(1)

c)

(c) 0

- (1) $\mathrm{O}_{0}$

())

c

(c)

(ิ)

Cos

0

10

60

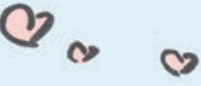

(c) 0 क हु ०

O 00

0

O 


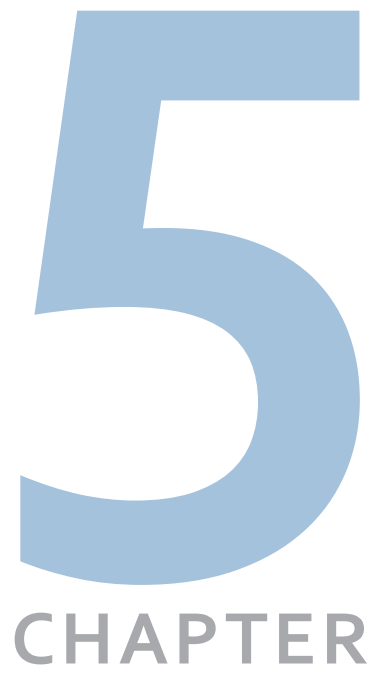

Chest discomfort at night and risk of acute coronary syndrome: cross-sectional study of telephone conversations

Loes TCM Wouters, Dorien LM Zwart, Daphne CA Erkelens, Noël S Cheung, Esther de Groot, Roger AMJ

Damoiseaux, Arno W Hoes, Frans H Rutten 


\section{ABSTRACT}

Background During telephone triage it is difficult to assign the adequate urgency to patients with chest discomfort. Considering the time of calling could be helpful.

Objective To assess the risk of acute coronary syndrome (ACS) in certain time periods and whether sex influences this risk.

Methods Cross-sectional study of 1,655 recordings of telephone conversations of patients who called the out-of-hours services primary care (OHS-PC) for chest discomfort. Call time, patient characteristics, symptoms, medical history and urgency allocation of the triage conversations were collected. The final diagnosis of each call was retrieved at the patient's general practice. Absolute numbers of patients with and without ACS were plotted and risks per hour were calculated. The risk ratio of ACS at night (oam to gam) was calculated by comparing to the risk at other hours, and was adjusted for gender and age.

Results The mean age of callers was 58.9 (SD \pm 19.5 ) years, $55.5 \%$ were women and in total 199 (12.0\%) had an ACS. The crude risk ratio for an ACS at night was 1.80 (CI 1.39-2.34, $p<0.001) ; 2.33$ (1.68-3.22, $p<0.001)$ for men, and 1.29 (0.83-1.99, $p=0.256)$ for women. The adjusted risk ratio for ACS of all people at night was 1.82 (1.07-3.10, $\mathrm{p}=0.039$ ).

Conclusions Patients calling the OHS-PC for chest discomfort between o-gam have almost twice a higher risk of ACS than those calling other hours, a phenomenon more evident in men than in women. At night, dispatching ambulances more 'straightaway' could be considered for these patients with chest discomfort. 


\section{BACKGROUND}

Adequate triage of patients with chest discomfort and timely diagnosis of those with ACS is crucial for initiation of lifesaving early interventions in order to prevent or reduce myocardial necrosis ('time is muscle'), and thus improve outcome and prognosis. ${ }^{1}$ Urgency allocation of patients with chest discomfort based on telephone triage as done in out-of-hours services for primary care (OHS-PC) and emergency medical dispatch centers is, however, challenging because it is very difficult to differentiate ACS from other reasons for chest discomfort. For the diagnosis of ACS an abnormal electrocardiogram (repolarization abnormalities (ST and/or T wave)) and/or elevated blood levels of troponin I or T are needed. ACS may than be further subdivided in STelevated myocardial infarction (STEMI) and non-ST-elevated myocardial infarction (NSTEMI) if the troponin levels are elevated ${ }^{2}$. If troponin levels are not elevated (or increased over time), it is called unstable angina pectoris (UAP)².

In the Netherlands, around $80 \%$ of patients with chest pain first call the general practitioner (GP) or OHS-PC, while $20 \%$ directly calls the ambulance (112) or are selfreferrals ${ }^{3}$. In the $20 \%$ who called directly the emergency medical dispatch center, $63 \%$ received a priority 1 ambulance, and $10 \%$ had an ACS. ${ }^{4}$ In people who first called the OHS-PC, $70 \%$ received a priority 1 ambulance, and also $10 \%$ had an ACS. 5-7

Previous studies in the emergency department setting showed circadian variability in the occurrence of acute coronary events, with a peak early mornings which was twice as high as in the evening. ${ }^{8-10}$ This early morning peak of acute myocardial infarction is considered related to physiological changes in these hours such as a rise in blood pressure and plasma adrenaline levels that could possibly trigger plaque rupture and thrombosis. ${ }^{8,9,11}$ Studies in primary care setting are lacking and studies dividing the absolute numbers of ACS by the number of patient who contacted because of chest pain are limited. ${ }^{11}$ Also studies about sex differences in circadian rhythm of ACS are limited. If there were a high incidence of ACS relative to the number of callers for chest discomfort during certain hours, this would facilitate triage at the OHS-PC.

In the Netherlands, the OHS-PC is organized in large services, similar to the United Kingdom and Scandinavian countries. ${ }^{12}$ Dutch triage nurses use the Netherlands Triage Standard (NTS) to assess the urgency and use five priority levels related to the time within which the patients should be seen. The NTS is a semi-automatic computerized decision support system that is based on the Manchester Triage Standard. ${ }^{13}$ Previous studies showed that chest discomfort is the most common reason (60.7\%) for allocating 
the highest priority $\left(U_{1}\right.$; ambulance dispatched, patient should be seen within 15 minutes) for those contacting the OHS-PC. On the second place came respiratory tract symptoms with just $8.1 \%$ ambulances dispatched. ${ }^{7}$ The Dutch triage system is overall safe with only $0.006 \%$ calamities a year, but this incidence is higher with around $0.03 \%$ in the domain of chest discomfort. ${ }^{14,15}$ Besides safety, also efficiency could very likely be improved in the domain chest discomfort because only one out of ten of the referred patients actually has an ACS. ${ }^{5-7,14}$

For better safety and efficiency, there is an urgent need for determinants that improve prediction and thus help triage nurses in their task. ${ }^{7}$ If there are hours with a high incidence of ACS as compared to the total number of telephone calls, then considering the time of calling could help to improve the triage. Therefore we assessed whether there are certain time periods in which there is a higher risk ratio of ACS and whether sex differences influence this risk ratio.

\section{METHODS}

The study design and data collection are published before in our study design paper. ${ }^{15}$ In short, we performed a cross-sectional study with a random sample of 1,655 calls of people calling the OHS-PC for chest discomfort between 2014 and 2016. We selected calls on the basis of ICPC codes (Ko1, Ko2, Ko3, K24, K74, K75, K76, K77, K93, Lo4, $\mathrm{P}_{74}, \mathrm{Ro2}, \mathrm{R} 98$ ) and keywords (thoracic pain, chest pain, myocardial infarction, heart attack and their common abbreviations). On purpose, we sampled broad to capture the entire domain of patients that could be suspected of ACS. We drew a random sample of all available calls of these patients (270,000 between 2014-2016) with the Random Number Generator (RAND) function in Microsoft Excel.

We re-listened telephone triage recordings in order to collect information about characteristics of patients and their conversation, on symptoms, medical history, urgency allocation, and whether a supervising GP was involved in the triage. Nine OHS-PC in the Netherlands participated, serving a total population of 1.5 million people. The final diagnoses were provided by the patients' GP, and this was based on the electronic medical file and cardiologist discharge letters. An ACS was based on the cardiologist's diagnosis, including information on levels of (high-sensitivity) troponin and electrocardiography. 
In the OHS-PC, trained triage nurses used the NTS to generate an urgency allocation. The NTS is hierarchically ordered with key questions, and answers are linked to urgency recommendations. Linked to the nurse's urgency allocation is the time frame within which a physician should see the patient. ${ }^{17}$ Direct, within 15 minutes (by ambulance or GP $\left.\left(U_{1}\right)\right)$, urgently within one hour $\left(U_{2}\right)$, less urgent within three hours $\left(U_{3}\right)$, nonurgent the same day $\left(U_{4}\right)$, or telephone advice $\left(U_{5}\right)$. The GP may see the patient at the patient's home or at the OHS-PC. Triage nurses can always consult the supervising GP on call. ${ }^{18}$

\section{Data-analyses}

We plotted the absolute numbers of patients calling for chest discomfort hourly, subdivided in patients with and without a final diagnoses ACS, and we calculated the risks of ACS per hour by dividing the absolute number of ACS by the total numbers of callers with chest discomfort per hour. The risk ratio of ACS was calculated over several time periods. The aim was to find a time period in which the risk of ACS was high, and also practical in use. We performed separate analyses for men and women, and used the likelihood ratio test to assess the difference. Adjusted risk ratios for ACS were calculated after correction for gender and age below and over forty years.

We compared patient and call characteristics, and urgency allocation between callers at night and callers at others hours. For comparison of dichotomous variables we used the $\mathrm{Chi}^{2}$ test, and for continuous variables the independent sample t-test. Finally, we compared the correlation between urgency allocation and the final diagnosis ACS. Data analysis was performed using SPSS, IBM version 21.

\section{RESULTS}

Of the 1,655 patients with chest discomfort the mean age was 58.9 ( $S D \pm 19.5$ ) years, and 919 (55.5\%) were women. In total, 199 (12.0\%) had an ACS; 82 (8.9\%) women and 117 (15.9\%) men, $\mathrm{p}<0.001)$; in $41.7 \%$ a NSTEMI, $26.6 \%$ a STEMI, $24.1 \%$ UAP and $7.5 \%$ a non-classified ACS.

Variation was small in the absolute numbers of ACS during 24 hours, see figure 1 . The incidence of ACS varied with a peak from o-gam of $17.7 \%$ compared to $9.8 \%$ at the remaining hours. The highest risk of ACS was between 2-5am with 21.5\%, and lowest between 4-7pm with 6.8\%. In figure 2 the distribution of risks for ACS per hour are plotted, subdivided for men and women. The risk ratio for an ACS from o-gam was 1.80 ( $\mathrm{Cl}$ 1.39- 
2.34, $\mathrm{p}<0.001)$ compared to other hours; for men $2.33(\mathrm{Cl} 1.68-3.22, \mathrm{p}<0.001)$ and for women 1.29 ( $\mathrm{Cl} 0.83-1.99, \mathrm{p}=0.256)$. The difference in risk ratios for men and women was statistically significant $(p=0.030)$. The adjusted risk ratio for ACS from o-gam compared to other hours was $1.82(1.07-3.10, p<0.001)$ after correction for both age and sex.

Figure 1. Call time of 1,655 patients with chest discomfort calling the OHS-PC between 2014-2016, subdivided in those with and without ACS.

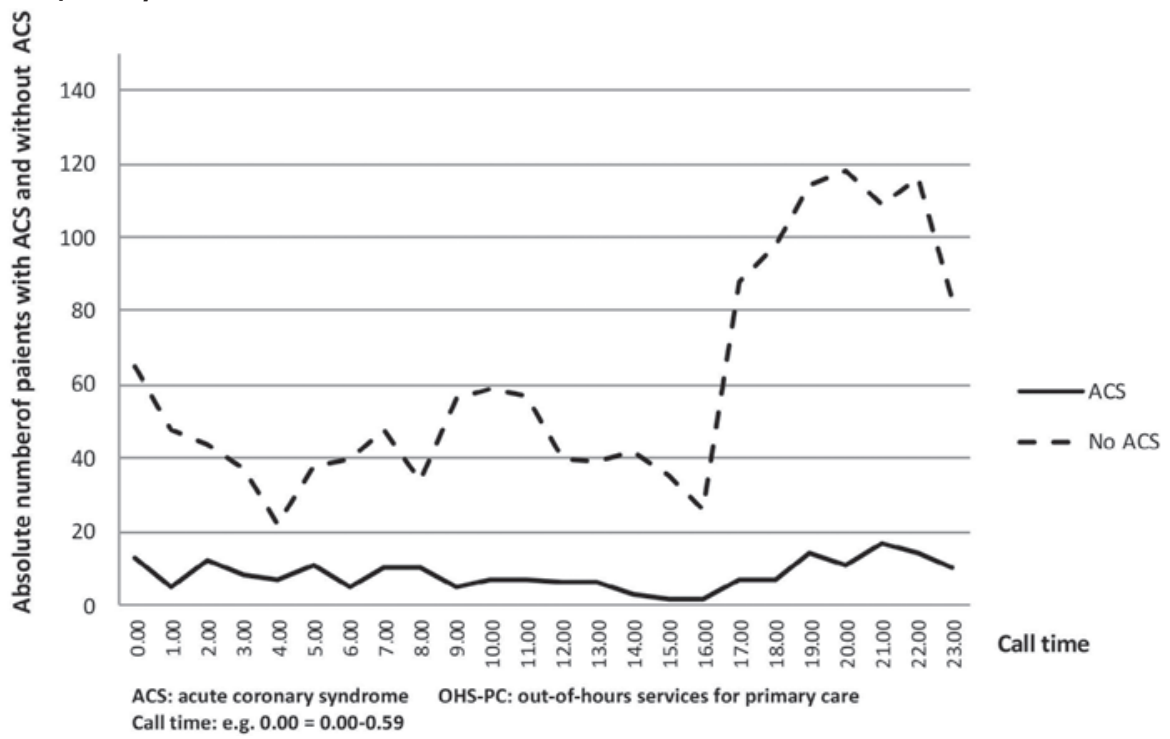

Figure 2. Risk of ACS per hour of 1,655 patients with chest discomfort calling the OHS-PC between 2014-2016, subdivided for men and women.

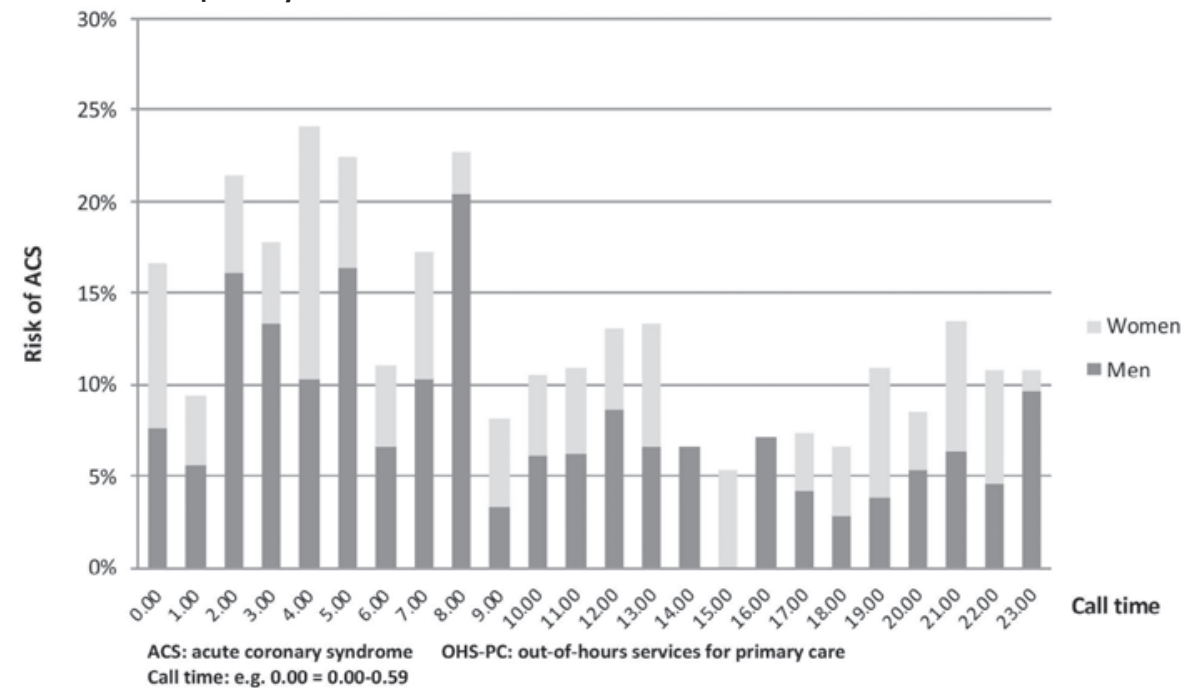


Table 1. Baseline characteristics of 1,655 patients calling the OHS-PC with chest discomfort between 2014-2016, divided into those who called between oam-9am and other hours.

\begin{tabular}{|c|c|c|c|c|c|}
\hline Characteristics & & $\begin{array}{l}\text { Total } \\
1655\end{array}$ & $\begin{array}{c}\text { oam-gam } \\
\text { No. (\%) } \\
n=457 \\
\end{array}$ & $\begin{array}{c}\text { Other hours } \\
\text { No. (\%) } \\
n=1198 \\
\end{array}$ & $\mathrm{p}$-value \\
\hline Patient & Mean age (SD) & 1655 & $61.4(19.7)$ & $57.9(19.3)$ & 0.001 \\
\hline characteristics & Male sex & 736 & $193 / 457(42.2)$ & $543 / 1198(45 \cdot 3)$ & 0.759 \\
\hline $\begin{array}{l}\text { Call } \\
\text { characteristics }\end{array}$ & $\begin{array}{l}\text { Call duration in } \\
\text { min:sec (SD) }\end{array}$ & 1655 & $7: 02(3: 40)$ & $7: 42(3: 47)$ & 0.001 \\
\hline \multirow[t]{4}{*}{ Medical History } & $\begin{array}{l}\text { Cardiovascular } \\
\text { disease }\end{array}$ & $1350 *$ & $227 / 365(62.2)$ & $592 / 985(60.1)$ & 0.485 \\
\hline & $\begin{array}{l}\text { Coronary artery } \\
\text { disease }\end{array}$ & $902 *$ & $88 / 251(35.1)$ & $225 / 651(34.6)$ & 0.888 \\
\hline & Hypertension & $701^{*}$ & $70 / 188(37.2)$ & $189 / 513(36.8)$ & 0.924 \\
\hline & Diabetes mellitus & $686 *$ & $32 / 185(17 \cdot 3)$ & $89 / 501(17.8)$ & 0.887 \\
\hline \multirow[t]{5}{*}{ Symptoms } & Chest pain & $1601 *$ & $412 / 442(93.2)$ & $1090 / 1159(94.0)$ & 0.536 \\
\hline & $\begin{array}{l}\text { Pain lasting }<12 \\
\text { hours }\end{array}$ & $1438 *$ & $320 / 385(83.1)$ & $741 / 1053(70.4)$ & $<0.001$ \\
\hline & Radiation of pain & $1283^{*}$ & $239 / 348(68.7)$ & $593 / 935(63.4)$ & 0.080 \\
\hline & $\begin{array}{l}\text { Autonomous } \\
\text { nervous system } \\
\text { related symptoms } \\
* *\end{array}$ & $1599^{*}$ & $257 / 434(59.2)$ & $658 / 1165(56.5)$ & 0.325 \\
\hline & $\begin{array}{l}\text { Shortness of } \\
\text { breath }\end{array}$ & $1260 *$ & $214 / 333(64 \cdot 3)$ & $610 / 927(65.8)$ & 0.612 \\
\hline $\begin{array}{l}\text { GP participated } \\
\text { in triage }\end{array}$ & $\begin{array}{l}\text { In consultation or } \\
\text { taking over the call }\end{array}$ & 1655 & $233 / 457(51.0)$ & $650 / 1198(54 \cdot 3)$ & 0.233 \\
\hline Urgency & $U_{1}$ & 753 & $249 / 457(54 \cdot 5)$ & $504 / 1198(42.1)$ & $<0.001$ \\
\hline \multirow[t]{2}{*}{ allocation } & $U_{2}$ & 371 & $85 / 457(18.6)$ & $286 / 1198$ (23.9) & $* * *$ \\
\hline & $U_{3}, U_{4}, U_{5}$ & 531 & $123 / 457(26.9)$ & $408 / 1198(34.1)$ & $\begin{array}{l}0.005 \\
* * * *\end{array}$ \\
\hline Diagnosis ACS & & 1655 & $81 / 457(17.7)$ & $118 / 1198(9.8)$ & $<0.001$ \\
\hline
\end{tabular}

Notes: * For these variables there were missing data.

** Autonomous nervous system (ANS) related symptoms consist of one or more of the following: nausea and/or vomiting, sweating, pallor/ashen skin, (near) collapse.

$* * * \mathrm{p}$-value comparing $U_{1}$ vs. $U_{2}-U_{5}$

$* * * * p$-value comparing $U_{1}, U_{2}$ vs. $U_{3}, U_{4}, U_{5}$

OHS-PC: out-of-hours services for primary care GP: general practitioner ACS: acute coronary syndrome

The baseline characteristics for those calling at night and those calling the other hours are presented in table 1. Patients calling between o-gam were significantly older (61.4 (SD \pm 19.7 ) years vs. 57.9 ( \pm 19.3 ) years, $p=0.001)$, had less patient decision delay (calling 
$<12$ hours after symptom onset $83.1 \%$ vs. $70.4 \%$, $p<0.001$ ), and received more often the highest urgency 1 ( $54.5 \%$ vs. $42.1 \%$, p<0.001) than those calling other hours.

In table 2 the correlations between urgency allocation and diagnosis of ACS are presented. Triage nurses dispatched significantly more ambulances to patients who turned out to have an ACS than no ACS (70.4\% vs. $42.1 \%$, p<0.001) and this was more so at night ( $80.2 \%$ vs. $48.9 \%, p<0.001)$.

Table 2. Correlation between urgency allocation and final diagnosis ACS of 1,655 patients with chest discomfort calling the OHS-PC between 2014-2016.

\begin{tabular}{lcccr}
\hline Total calls & ACS $n=199(\%)$ & No ACS $n=1,456(\%)$ & p-value 1* & p-value $2 * *$ \\
\hline$U_{1}$ & $140(70.3)$ & $613(42.1)$ & $<0.001$ & $<0.001$ \\
$U_{2}$ & $31(15.6)$ & $340(23.4)$ & & \\
$U_{3}, U_{4}$ and $U_{5}$ & $28(14.1)$ & $503(34.5)$ & & \\
\hline oam-9am & ACS $n=81(\%)$ & No ACS $n=376(\%)$ & & \\
\hline$U_{1}$ & $65(80.2)$ & $184(48.9)$ & $<0.001$ & $<0.001$ \\
$U_{2}$ & $11(13.6)$ & $74(19.7)$ & & \\
$U_{3}, U_{4}$ and $U_{5}$ & $5(6.2)$ & $118(31.4)$ & & \\
\hline Other hours & ACS $n=118(\%)$ & No ACS $n=1,080(\%)$ & & \\
\hline$U_{1}$ & $75(63.6)$ & $429(39.7)$ & $<0.001$ & \\
$U_{2}$ & $20(17.0)$ & $266(24.6)$ & & \\
$U_{3}, U_{4}$ and $U_{5}$ & $23(19.4)$ & $385(35.7)$ & & \\
\hline
\end{tabular}

* p-value 1: U1 vs. U2-U5

** p-value $2: U_{1} / U_{2}$ vs. $\cup_{3}-U_{5}$

ACS: acute coronary syndrome

OHS-PC: out-of-hours services for primary care

The final diagnoses of patients without ACS $(n=1,456)$ were in $2.6 \%$ diseases that need urgent treatment (e.g. thoracic aortic dissection, acute severe heart failure, pulmonary embolism), and in the remaining $85.4 \%$ non-urgent disorders (e.g. musculoskeletal, pulmonary, psychiatric or gastrointestinal causes).

\section{DISCUSSION}

Patients with chest discomfort who called the OHS-PC between o-gam had almost twice as high a risk of an ACS than patients calling at other hours. This effect remained after adjustment for sex and age, but the risk was highest for men and less evident for women. 
An important strength of our study is that we analyzed all patients calling for chest discomfort, not selectively those with ACS. Another strength is that the original and very first conversations with patients were available, and analyzed before knowledge of the eventual diagnosis, which assures our results are not affected by recall bias, as was possibly in many of the previous studies. A limitation is missing values on some clinical variables; a phenomenon common for research with routine care data. Importantly, however, we had no missing data for the time of calling, sex category, age, or the outcome (ACS/no ACS), and thus we could perform our multivariable analysis without the need of imputing data. Finally, the less pronounced circadian effects among women compared to men should be interpreted carefully, because our study could be under-powered for this subgroup analysis.

To the best of our knowledge, this is the first study in the OHS-PC setting assessing risks of ACS over 24 hours of patients with chest discomfort. Most previous studies analyzed patients with established ACS and reported absolute numbers, not risks or risk ratios. They reported a peak of ACS early mornings if considering the time of arrival at the hospital. ${ }^{8,10,19} \mathrm{~A}$ Swedish study reported likelihoods for ACS among patients with chest pain seen at the emergency department (ED), and reported a peak incidence from 8 -10am of $10.6 \%$ and a trough between 6 -8pm of $5.6 \%$, based on arrival time at the ED ${ }^{9}$. The incidence peak of ACS o-gam in our study could at least partly be explained by the fact that we used time of calling. ${ }^{9}$ Interestingly, in the Swedish study the incidence peak of ACS at the ED was lower than in our study, and the contrast between peak and trough less. In another Swedish study among 2,205 patients with chest pain calling the dispatcher center, the odds ratio among patients with an ACS for calls arriving before lunch at the dispatch center was $2.02(95 \% \mathrm{Cl}$ 1.22-3.43) compared with midnight. ${ }^{11}$ Possibly, differences in patient decision delay and organization of health care between Sweden and the Netherlands could have played a role.

We found a significant lower risk of ACS among women than men (8.9\% vs. 15.9\%, $\mathrm{p}<0.001)$, and among women there was less difference in ACS between 0-gam and other hours; $1.29(\mathrm{Cl} 0.83-1.99)$ vs. $2.33(\mathrm{Cl}$ 1.68-3.22) among men. In the aforementioned Swedish study in emergency department setting, women also had a lower likelihood for ACS than men, but they did not find a sex difference in the circadian pattern of ACS. 9

To appreciate our findings; presence of radiation of chest pain to the left arm had a likelihood ratio of ACS of 1.30 (Cl 1.13-1.47), presence of sweating 1.34 (1.09-1.65) and nausea and/or vomiting $1.32\left(\mathrm{Cl}_{1.09-1.65)}\right.$ in a meta-analyses of 16 studies with 
non-selected patients. ${ }^{20}$ These symptoms typically are considered important items during triage op patients with chest discomfort, but their impact is fairly low. Currently, pre-hospital decision rules do not consider time of calling as a valuable triage item and there seems to be no awareness among lay people about these 'critical hours'. ${ }^{21-23}$ Some awareness about a higher risk of ACS at night seems to be present among triage nurses and GPs working at the OHS-PC, as ACS patients received more often priority 1 with ambulance straightaway if calls arrived o-gam than during other hours $(80.2 \%$ vs. $63.6 \%, \mathrm{p}<0.001)$. A previous study reported that missed diagnoses of ACS most often occurred at night. ${ }^{14}$ Also this study stresses the importance of considering the time of calling with triage of patients with chest discomfort; it helps improve patient safety and accuracy of pre-hospital telephone triage.

\section{CONCLUSION}

Patients calling the OHS-PC for chest discomfort between o-gam have almost twice a higher risk of ACS than those calling other hours, a phenomenon more evident in men than in women. At night, dispatching ambulances more 'straightaway' than during daytime could be considered for these patients with chest discomfort.

\section{ACKNOWLEDGEMENTS}

We would like to thank the primary care OHS foundation 'Primair Huisartsenposten' in Utrecht for their willingness to participate and Peter Zuithoff for statistical help.

\section{FUNDING}

We received an unrestricted grant from (i) the Department of General Practice of the University Medical Center Utrecht, (ii) a personal promotion grant of DLZ, (iii) an unrestricted grant from the foundation 'The Netherlands Triage Standard' and (iv) the foundation 'Stoffels-Hornstra'. 


\section{REFERENCES}

1. Bosner S, Haasenritter J, Becker A, et al. Ruling out coronary artery disease in primary care: development and validation of a simple prediction rule. Canadian Medical Association Journal. 2010;182(12):1295-1300.

2. Roffi M, Patrono C, Collet JP, et al. 2015 ESC Guidelines for the management of acute coronary syndromes in patients presenting without persistent ST-segment elevation: Task Force for the Management of Acute Coronary Syndromes in Patients Presenting without Persistent ST-Segment Elevation of the European Society of Cardiology (ESC). European Heart Journal. 2016;37(3):267-315.

3. Mol KA, Smoczynska A, Rahel BM, et al. Non-cardiac chest pain: prognosis and secondary healthcare utilisation. Open Heart. 2018;5(2):e000859.

4. Rawshani A, Larsson A, Gelang $C$, et al. Characteristics and outcome among patients who dial for the EMS due to chest pain. International Journal of Cardiology. 2014;176(3):859-865.

5. Hoorweg BB, Willemsen RT, Cleef LE, et al. Frequency of chest pain in primary care, diagnostic tests performed and final diagnoses. Heart. 2017;103(21):1727-1732.

6. Frese $T$, Mahlmeister J, Heitzer M, Sandholzer H. Chest pain in general practice: Frequency, management, and results of encounter. Journal of Family Medicine and Primary Care. 2016;5(1):61-66.

7. Plat FM, Peters YAS, Loots FJ, et al. Ambulance dispatch versus general practitioner home visit for highly urgent out-of-hours primary care. Family Practice. 2017(Dec 20).

8. Bhalla A, Sachdev A, Lehl SS, Singh R, D'Cruz S. Ageing and circadian variation in cardiovascular events. Singapore Medical Journal. 2006;47(4):305-308.

9. Ekelund U, Akbarzadeh M, Khoshnood A, Bjork J, Ohlsson M. Likelihood of acute coronary syndrome in emergency department chest pain patients varies with time of presentation. BMC Research Notes. 2012;5:420.

10. Leiza JR, de Llano JM, Messa JB, Lopez CA, Fernandez JA, Group AS. New insights into the circadian rhythm of acute myocardial infarction in subgroups. Chronobiology International. 2007;24(1):129-141.

11. Rawshani A, Rawshani N, Gelang C, et al. Emergency medical dispatch priority in chest pain patients due to life threatening conditions: A cohort study examining circadian variations and impact of the education. International Journal of Cardiology. 2017;236:4348.

12. Kroneman $\mathrm{M}$, Boerma W, van den Berg $\mathrm{M}$, Groenewegen $\mathrm{P}$, de Jong J, van Ginneken $\mathrm{E}$. Netherlands: Health System Review. Health Systems in Transition. 2016;18(2):1-240.

13. van lerland $Y$, van Veen $M$, Huibers $L$, Giesen $P$, Moll HA. Validity of telephone and physical triage in emergency care: the Netherlands Triage System. Family Practice. 2011;28(3):334-341.

14. Rutten $\mathrm{MH}$, Kant J, Giesen P. What can we learn from calamities at out-of-hours services in primary care? [Wat kunnen we leren van calamiteiten op de huisartsenpost?]. Huisarts \& Wetenschap. 2018;6(61).

15. Erkelens DC, Wouters LT, Zwart DL, et al. Optimisation of telephone triage of callers with symptoms suggestive of acute cardiovascular disease in out-of-hours primary care: observational design of the Safety First study. British Medical Journal Open. 2019;9(7):e027477. 
16. Zwaanswijk M, Hek K. ICPC coding at the out-of-hours service in primary care [ICPCcodering op de huisartsenpost]. Huisarts \& Wetenschap. 2013;56(11).

17. Smits M, Keizer E, Ram P, Giesen P. Development and testing of the KERNset: an instrument to assess the quality of telephone triage in out-of-hours primary care services. BMC Health Services Research. 2017;17(1):798.

18. Keizer E, Maassen I, Smits M, Wensing M, Giesen P. Reducing the use of out-of-hours primary care services: A survey among Dutch general practitioners. European Journal of General Practice. 2016;22(3):189-195.

19. Cohen MC, Rohtla KM, Lavery CE, Muller JE, Mittleman MA. Meta-analysis of the morning excess of acute myocardial infarction and sudden cardiac death. American Journal of Cardiology. 1997;79(11):1512-1516.

20. Bruyninckx R, Aertgeerts B, Bruyninckx P, Buntinx F. Signs and symptoms in diagnosing acute myocardial infarction and acute coronary syndrome: a diagnostic meta-analysis. British Journal of General Practice. 2008;58(547):105-111.

21. Bruins Slot $\mathrm{MH}$, Rutten $\mathrm{FH}$, van der Heijden GJ, et al. Gender differences in prehospital time delay and symptom presentation in patients suspected of acute coronary syndrome in primary care. Family Practice. 2012;29(3):332-337.

22. Grijseels EW, Deckers JW, Hoes AW, et al. Implementation of a pre-hospital decision rule in general practice. Triage of patients with suspected myocardial infarction. European Heart Journal . 1996;17(1):89-95.

23. Haasenritter J, Donner-Banzhoff N, Bosner S. Chest pain for coronary heart disease in general practice: clinical judgement and a clinical decision rule. British Journal of General Practice. 2015;65(640):e748-753. 
- $0^{0} \circ \quad a_{0}$

(1) 0 (1) 0 C 0

0 कर 0 है

(1)<smiles>[O]OCO</smiles> 


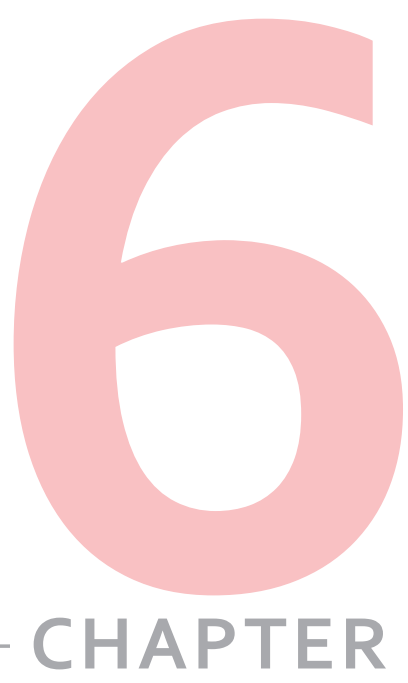

Gender differences in telephone triage of patients with chest discomfort in out-of-hours primary

care

Loes TCM Wouters, Dorien LM Zwart, Daphne CA Erkelens, Esther De Groot, Arno W Hoes, Roger AMJ

Damoiseaux, Frans H Rutten 


\section{ABSTRACT}

Objectives To assess differences in symptoms predictive of acute coronary syndrome (ACS) between women and men presenting with chest discomfort in out-of-hours primary care (OHS-PC).

Design Cross-sectional study.

Setting Nine OHS-PC in the Netherlands.

Participants 993 women and 802 men who called OHS-PC for acute chest discomfort (pain, pressure, tightness, or discomfort) between 2014 and 2017.

Primary outcome measure Diagnosis of acute coronary syndrome (ACS). We compared patient and call characteristics of triage call recordings between women with and without ACS, and men with and without ACS. Diagnoses were retrieved from the patient's medical record in general practice, including hospital specialists' discharge letters.

Results Among 1,795 patients (mean age 58.8 (SD 19.5) years, 55.3\% women), $15.0 \%$ of men and $8.6 \%$ of women had an ACS. In both sexes, retrosternal chest pain was discriminative for ACS (women with ACS vs. without $62.3 \%$ vs. 40.3\%, $p=0.002$, men with ACS vs. without $52.5 \%$ vs. $39.7 \%, p=0.032)$, as was pressing/tightening pain (women $78.6 \%$ vs. $61.5 \%, p=0.011$, men $82.1 \%$ vs. $57.4 \%, p=<0.001$ ) and radiation to arm (women $75.6 \%$ vs. $45.9 \%$, $p<0.001$, men $56.0 \%$ vs. $34.8 \%, p<0.001$ ). In women, severe pain $(65.4 \%$ vs. $38.1 \%, p=0.006)$, a pale face $(50.0 \%$ vs. $22.9 \%, p=0.007)$ and radiation to jaw ( $50.0 \%$ vs. $29.8 \%, p=0.017$ ) were also discriminative for $A C S$, while in men this was sweating ( $52.4 \%$ vs. $38.1 \%, p=0.015)$, and against ACS stabbing pain (8.4\% vs. $26.5 \%, p<0.001)$.

Ambulances were dispatched equally in women (72.9\%) and men with ACS (70.0\%).

Conclusion Symptoms predictive of ACS were rather similar for women and men with chest discomfort, with some important exceptions, such as severity, type, and radiation of pain, and some autonomous nervous system related symptoms. 


\section{INTRODUCTION}

Adequate triage and early diagnosis is key in patients with acute chest discomfort because they might have an acute coronary syndrome (ACS) for which lifesaving early interventions are available. ACS is an umbrella term including ST-elevated myocardial infarction (STEMI), non-ST-elevated myocardial infarction (NSTEMI) and unstable angina pectoris (UAP). ${ }^{1}$ Increased preventive measures and development of (timely) effective therapeutic interventions ('time is muscle') have resulted in improved outcomes and prognosis in ACS. ${ }^{2}$ Telephone triage of patients with chest discomfort, as done in out-of-hours service primary care (OHS-PC) and emergency medical services (EMS or ambulance dispatch centres) is, however, challenging because it is difficult to differentiate ACS from other causes of chest discomfort based on symptoms only. 3,4 Importantly, the majority of patients with chest discomfort (80\%) in the Netherlands first approach the general practitioner (GP) or OHS-PC, and 20\% directly calls the ambulance (112) or are self-referrals to the emergency department (ED). ${ }^{5}$

Previous hospital-based studies reported a delayed recognition of ACS in women compared to men. ${ }^{6,7}$ It was suggested that this delayed recognition was related to a less specific presentation in women. ${ }^{8,9}$ This caused an ongoing debate on whether women with ACS, compared to men, present with less specific symptoms, and how this affects diagnosis, but also treatment, and prognosis. ${ }^{10,11} \mathrm{~A}$ recent meta-analysis of 27 studies showed that women with ACS, compared to men with ACS, had higher odds of presenting with pain between the shoulder blades (OR 2.15, 95\% Cl 1.95-2.37), nausea or vomiting (OR 1.64, 95\% Cl 1.48-1.82) and shortness of breath (OR 1.34 (95\% $\mathrm{Cl}_{1.21-1.48) .}{ }^{12}$ Women with ACS had lower odds of sweating (OR $0.84,95 \% \mathrm{Cl} 0.76$ 0.94 ) and presenting with chest pain (OR $0.70,95 \% \mathrm{Cl} 0.63-0.78)$, but in both sexes chest pain remained the most common symptom (pooled prevalence men $79 \%$ and women $74 \%$ ). ${ }^{12}$ Importantly, researchers suggested standardization in methods of symptoms assessment is needed, because of the difficulties to formulate any definitive statements about symptom presentation, as studies assessed symptoms in different ways (questionnaires or abstracting from medical records). ${ }^{9,13-15}$ Abstracting symptoms from medical records may dilute symptom presentation, as they are translated by the clinician in medical terminology. ${ }^{16}$ Moreover, many studies suffer from recall or hindsight bias of both patient and researcher as they know the outcome (ACS).

For the clinician or telephone triage nurse it is crucial to differentiate ACS from other causes of chest discomfort. For that, studies are needed that include female and male patients presenting with chest discomfort, in which women and men who turn out to 
have ACS are compared to those who do not have ACS. Such studies are scarce. In a study performed among patients with chest discomfort seen at the ED in the USA (77 women and 244 men with ACS, and 195 women and 240 men without ACS were compared. Women with ACS more often reported arm pain than women without ACS ( $47 \%$ vs. $32 \%, p=0.021)$, while men with ACS reported pressing heavy feelings on the chest $(63 \%$ vs. $54 \%, p=0.035)$ and chest pain ( $72 \%$ vs $60 \%, p=0.005)$ more often than men without ACS. ${ }^{13}$ In a recent Dutch OHS-PC study among 23 women and 34 men with ACS, and 253 women and 208 men without ACS, differences in symptom presentation between women and men were small. ${ }^{17}$ In men, radiation of pain ( $89.3 \%$ vs. $64.9 \%$, p-value $\left.=0.011\right)$ was discriminative for ACS, while stabbing chest pain (3.7\% vs. 24.0\%, p-value $=0.014$ ) was discriminative for the absence of ACS. Both these symptoms were not discriminative in women ( $90.0 \%$ vs $78.6 \%, p=0.227$, and $15.8 \%$ vs. $18.8 \%, p=0.743$ ), respectively. ${ }^{17}$

We aimed to assess symptoms predictive of ACS in women and men separately, among patients presenting with acute chest discomfort to OHS-PC based on analyses of recorded telephone triage conversations.

\section{METHODS}

We performed a cross-sectional study with a random sample of 1,795 OHS-PC calls for chest discomfort (chest pain, pressure, tightness, or discomfort) between 2014 and 2016. ${ }^{18}$ We first selected calls on the basis of International Code for Primary Care (ICPC; a WHO world-wide code system for primary care) codes (Ko1, Ko2, Ko3, K24, $\mathrm{K}_{74}, \mathrm{~K}_{75}, \mathrm{~K}_{76}, \mathrm{~K}_{77}, \mathrm{~K}_{93}, \mathrm{~L}_{4}, \mathrm{P}_{74}, \mathrm{Ro2}, \mathrm{R} 98$ ) and keywords (thoracic pain, chest pain, myocardial infarction, heart attack and their common abbreviations). ${ }^{19,20}$ On purpose, we sampled a broad variety of symptoms to capture the entire domain of patients that could be suspected of ACS. We drew a random sample of all available calls of these patients with the Random Number Generator (RAND) function in Microsoft Excel. Calls were excluded from re-listening when the patients' age was below 18 years or when the patient did not live in the surrounding area of the OHS-PCs (because we could not retrieve a diagnosis from the general practitioner of patients living outside the area of the OHS-PCs). Calls were also excluded from re-listening when it did not concerned a triage call (e.g. inter-collegial consultation) or when the recording was of poor quality.

We re-listened the telephone triage recordings and collected information about patient and conversation characteristics, on symptom presentation, medical history, urgency allocation, and involvement of a supervising general practitioner (GP) in the triage. 
Nine OHS-PC in the Netherlands participated, serving a total population of 1.5 million people. The final diagnoses were provided by the patients' GP, and this was based on the electronic medical file including ED and cardiologist discharge letters, and notes from the OHS-PC. An ACS was based on the cardiologist's diagnosis, including information on levels of (high-sensitivity) troponin and electrocardiography results.

\section{Context}

In the Netherlands, OHS-PC covers primary care during $73 \%$ of week hours, and the initial contact is by telephone. In most OHS-PC and EMS, the 'Netherlands Triage Standard' (NTS) is used as a decision support to classify the urgency of the patients' conditions. ${ }^{21}$ Based on the patient's symptom presentation, the triage nurse needs to choose the most appropriate complaint out of 56 'main complaints'. Each NTS 'main complaint' incorporates a decision tree with hierarchically ordered questions, which are similar for men and women. Triage nurses fill out the caller's responses in the semiautomatic NTS system, which then generates urgency allocations (Uo (reanimation) to $U_{5}$ (self-care advice, see also appendix-table 1 ). The triage nurse can overrule this recommendation and up- or downscale the urgency allocation, often after consulting the supervising GP. ${ }^{22}$ Since its introduction in 2011, the NTS system has, however, never been formally validated by correlating the generated urgencies to clinical endpoints. ${ }^{21}$

\section{Data analyses}

We compared patient and call characteristics between women with and without ACS, and men with and without ACS. We analysed the association between urgency allocation and the final diagnosis ACS (with or without other life threatening events (LTEs)). We considered pulmonary embolism, thoracic aortic dissection and acute abdominal aneurysm as LTEs; patients with LTEs as well as those with ACS should receive an $\mathrm{U}_{1}$-level urgency (full list in table 2).

For comparison of dichotomous variables we used the $\mathrm{Chi}^{2}$ test or the Fisher exact test and for continuous variables the independent sample t-test or Mann-Whitney $U$ test. Data analysis was performed using SPSS, IBM version 25.

\section{Patient and public involvement}

No patients were involved in setting the research question or the outcome measures, or in developing plans for design, however, they were involved in the implementation of the study. In addition, patients were asked to advise on interpretation and writing up of results. Results will be shared and discussed with the national patient community of cardiovascular diseases ('Harteraad'). 


\section{Ethics}

The study (National Trial Register identification number: NTR7331) was approved by the Medical Ethics Committee Utrecht, the Netherlands (reference number WAG/ $\mathrm{mb} / 16 / 003208$ ) and complied with the Declaration of Helsinki. A waiver of informed consent was given because our study had minimal risk to subjects and could otherwise not be carried out logistically. Personal and research data were handled and stored according to the European General Data Protection Regulation (GDPR).

\section{RESULTS}

Among the 1,795 callers with chest discomfort (mean age 58.8 (SD 19.5) years, $55.3 \%$ women), $8.6 \%$ of women and $15.0 \%$ of men had an ACS. In women with an ACS, $18.8 \%$ had a STEMI, 48.2\% a NSTEMI, 20.0\% an UAP, and $13.0 \%$ non-classified ACS. In men with ACS, $32.5 \%$ had a STEMI, 36.7\% a NSTEMI, $27.5 \%$ an UAP, and $3.3 \%$ non-classified ACS.

A total of 22 (2.2\%) women and 23 men (2.9\%) had another LTE than ACS (e.g. pulmonary embolism, thoracic aortic dissection, acute abdominal aneurysm, acute heart failure).

\section{Patient and call characteristics}

In table 1, patient and call characteristics are presented for women and men with and without ACS.

Men and women with ACS were older than those without ACS (mean age of women 73.6 vs. 57.8 years, $p<0.001$, men 67.2 vs. 56.9 years, $p<0.001$ ), and the mean duration of the telephone calls shorter (women 6:47 vs. 7:47 minutes, $p=0.021$, men 6:31 vs. 7:33 minutes, $p=0.004)$.

The GP was consulted by the triage nurse in the majority of cases $(52.2 \%$ in women and $55.5 \%$ in men, $p=0.161$ ). However, in women with ACS, the GP was less often consulted than in women without ACS ( $41.2 \%$ vs. $53.2 \%, p=0.034)$. In men such a difference was not observed ( $53.3 \%$ vs. $55.9 \%, p=0.607$ ). In around half of the calls, someone else called on behalf of the patient; somewhat less often in women than in men ( $49.5 \%$ vs. $54.7 \%, p=0.029)$. In cases with ACS, for both sexes more often someone else called than in those without ACS (in women $69.4 \%$ vs. $47.7 \%, p<0.001$, in men $65.8 \%$ vs. $52.8 \%, p=0.008$ ). In men with ACS, most often their female partner $(53.3 \%)$ called, while in women with ACS, it was either their male partner (17.6\%), their daughter (20.0\%) or a nurse (17.6\%). See appendix-table 2. 


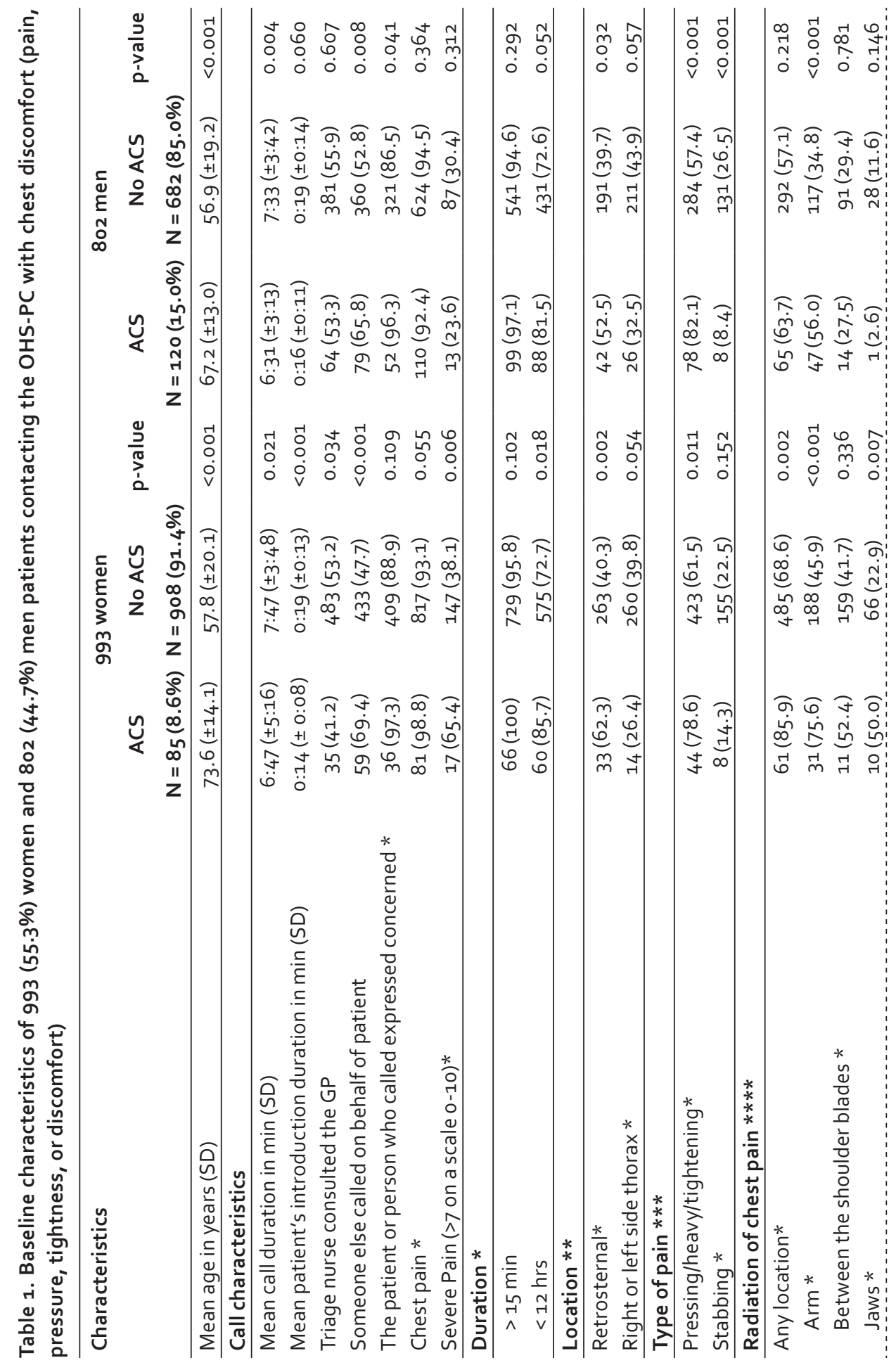




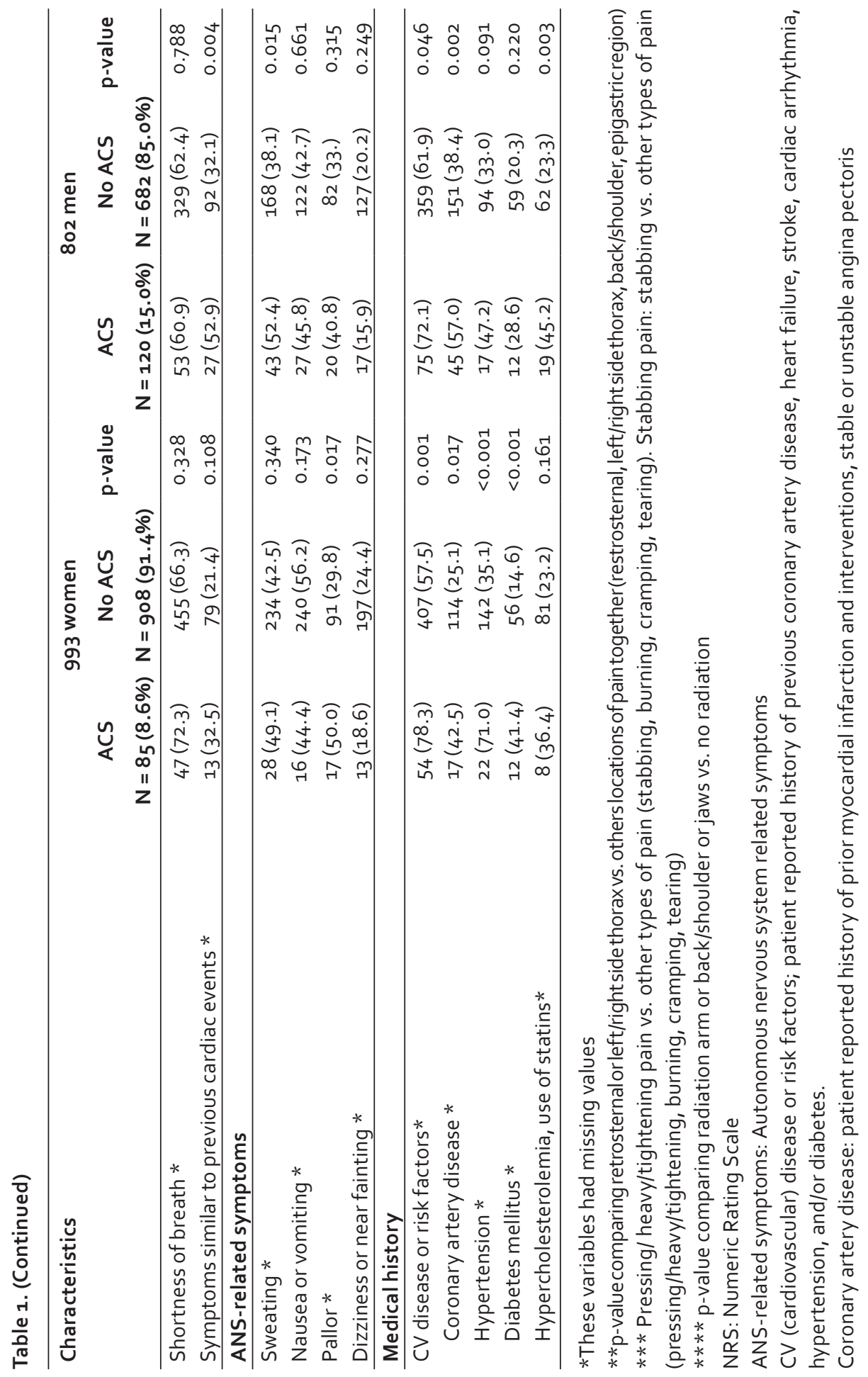


Callers expressed concerns about their symptoms in nearly all calls, also in those without an ACS; women with ACS vs. women without ACS 97.3\% vs. 88.9\% ( $p=0.109$ ), and men with ACS vs. men without ACS $96.3 \%$ vs. $86.5 \%(p=0.041)$.

Both women and men with ACS more often had a history of cardiovascular disease or cardiovascular risk factors (e.g. hypertension and diabetes) than those without (women $78.3 \%$ vs. 57.5\%, $p=0.001$, and in men these proportions were $72.1 \%$ vs. $61.9 \%$ $(p=0.046)$, respectively.

\section{Symptom presentation}

Chest pain was the most common complaint, both in those with and without an ACS; in women with and without ACS 98.8\% and 93.1\% ( $p=0.055)$, and in men $92.4 \%$ and $94.5 \%$, respectively $(p=0.364)$. Retrosternal located chest pain was more common in women and men with ACS than in those without ACS (women 62.3\% vs. 40.3\%, $\mathrm{p}=0.002$, and men $52.5 \%$ vs. $39.7 \%, p=0.032)$. Also, radiation of pain to the arms seemed indicative of ACS in both sexes (women with vs. without ACS $75.6 \%$ vs. $45.9 \%$, p<0.001, and men $56.0 \%$ vs. $34.8 \%$, $\mathrm{p}<0.001$ ), as was pressing/heavy/tightening chest pain (women with vs. without ACS $78.6 \%$ vs. $61.5 \%, p=0.011$ and men $82.1 \%$ vs. $57.4 \%, p=<0.001$ ). Only in women radiation to the jaw (50.0\% vs. 22.9\%, $\mathrm{p}=0.007$ ) and severe pain (8 or more on a Numeric Rating Scale 0-10) was indicative for ACS (65.4\% vs. $38.1 \%$, $\mathrm{p}=0.006)$. Only in men, stabbing pain was discriminative in that it was very rare in those with ACS (8.4\% vs. $26.5 \%, \mathrm{p}<0.001)$.

Of the autonomous nervous system (ANS)-related symptoms, nausea/vomiting and dizziness/near fainting were not indicative for ACS in either sex, with the exception of a pale face that was discriminative in women (50.0\% vs. 29.8\%, $\mathrm{p}=0.017)$, and sweating in men ( $52.4 \%$ vs. $38.1 \%, p=0.015)$.

Recognition of symptoms being similar to a previous cardiac event was discriminative for ACS in men ( $52.9 \%$ vs. $32.1 \%, p=0.004$ ), but not clearly for ACS in women ( $32.5 \%$ vs. $21.4 \%, p=0.108)$.

\section{Diagnoses}

The most common non-ACS diagnoses in both sexes were (i) non-urgent cardiovascular diseases such as stable angina pectoris, stable heart failure and arrhythmias (19.5\% of all female callers with chest discomfort vs. $21.2 \%$ of male callers, $p=0.384$ ) and (ii) noncardiac unspecified chest pain (women $16.4 \%$ vs. $19.8 \%$ men, $p=0.061$ ). Women more often than men were diagnosed with musculoskeletal problems (women $20.8 \%$ vs. men $14.1 \%, p=0.001$ ) and psychogenic conditions (women $14.0 \%$ vs. men $8.4 \%, p<0.001$ ). 
Table 2. Diagnosis of 1,795 patients who contacted the OHS-PC for chest discomfort (pain, pressure, tightness, or discomfort), divided in women and men

\begin{tabular}{lccc}
\hline Diagnosis, $\mathrm{n}(\%)$ & $\begin{array}{c}\text { Women } \\
\mathrm{n}=993(55.3 \%)\end{array}$ & $\begin{array}{c}\text { Men } \mathrm{n}=802 \\
(\mathbf{4 4 . 7 \%})\end{array}$ & $\mathrm{p}$-value \\
\hline Acute coronary syndrome & $85(8.6)$ & $120(15.0)$ & $<0.001$ \\
STEMI & $16(18.8)$ & $39(32.5)$ & 0.037 \\
NSTEMI & $41(48.2)$ & $44(36.7)$ & 0.114 \\
UAP & $17(20.0)$ & $33(27.5)$ & 0.250 \\
Non-classified ACS & $11(13.0)$ & $4(3.3)$ & 0.013 \\
Life threatening events (LTE's) & $22(2.2)$ & $23(2.9)$ & 0.448 \\
Pulmonary embolism & $6(27.3)$ & $7(30.4)$ & 0.815 \\
Thoracic aortic dissection & $4(18.2)$ & $2(8.7)$ & 0.349 \\
Acute abdominal aneurysm & $3(13.6)$ & $2(8.7)$ & 0.598 \\
Other* & $9(40.9)$ & $12(52.2)$ & 0.449 \\
Non-urgent cardiovascular diseases** & $194(19.5)$ & $170(21.2)$ & 0.384 \\
Non-cardiac chest pain, not further specified *** & $163(16.4)$ & $159(19.8)$ & 0.061 \\
Musculoskeletal pain & $199(20.0)$ & $113(14.1)$ & 0.001 \\
Psychogenic disorders & $139(14.0)$ & $67(8.4)$ & $<0.001$ \\
Gastrointestinal tract disorders & $76(7.7)$ & $62(7.7)$ & 0.951 \\
Respiratory tract disorders & $52(5.2)$ & $45(5.6)$ & 0.727 \\
Other non-urgent diagnoses*** & $63(6.3)$ & $43(5.4)$ & 0.380 \\
\hline
\end{tabular}

*Acute heart failure, stroke, severe COPD exacerbation, sepsis, coronary spasm probably caused by hypokalaemia, diabetic ketoacidosis, epileptic insult, bleeding from oesophageal varices, ovarian torsion, ventricular fibrillation.

** Stable angina pectoris (including atypical chest pain), stable heart failure, arrhythmias, hypertension

$* * *$ Cardiac pathology unlikely after cardiologist's diagnostic work-up, but without differential diagnosis

$* * * *$ Amongst others: anemia, malignancy, vasovagal collapse, side effects medication, dermatologic diseases

\section{Urgencies}

Women and men were equally sent an ambulance; overall ( $43.6 \%$ vs. $46.6 \%, p=0.200$ ). These proportions were in women compared to men with ACS or other LTEs $66.4 \%$ vs. $67.1 \%, p=0.897)$.

Women and men in whom ACS was diagnosed had more often ambulances dispatched than in those showed not to have an ACS (women $72.9 \%$ vs. 40.9\%, p<0.001, and men $70.0 \%$ vs. $42.5 \%, p<0.001)$. See table 3 . 
Table 3. Association between urgency allocation, diagnose ACS and other LTEs

\begin{tabular}{|c|c|c|c|c|}
\hline Women & $\begin{array}{c}\text { ACS } \\
n=85(8.6 \%)\end{array}$ & $\begin{array}{c}\text { No ACS } \\
\mathrm{n}=908(91.4 \%)\end{array}$ & $p$-value $1^{*}$ & p-value $2^{* *}$ \\
\hline$U_{1}$ & $62(72.9)$ & $371(40.9)$ & $<0.001$ & $<0.001$ \\
\hline$U_{2}$ & $12(14.1)$ & $231(25 \cdot 4)$ & & \\
\hline$U_{3}-U_{5}$ & $11(13.0)$ & $306(33.6)$ & & \\
\hline \multirow[t]{2}{*}{ Men } & ACS & No ACS & & \\
\hline & $\mathrm{n}=120(15.0 \%)$ & $n=682(85.0 \%)$ & & \\
\hline$U_{1}$ & $84(70.0)$ & $290(42.5)$ & $<0.001$ & $<0.001$ \\
\hline $\mathrm{U}_{2}$ & $19(15.8)$ & $142(20.8)$ & & \\
\hline$U_{3}-U_{5}$ & $17(14.2)$ & $250(36.7)$ & & \\
\hline \multirow[t]{2}{*}{ Women } & ACS or LTE & No ACS or LTE & & \\
\hline & $\mathrm{n}=107(10.8 \%)$ & $\mathrm{n}=886(89.2 \%)$ & & \\
\hline $\mathrm{U}_{1}$ & $71(66.4)$ & $362(40.9)$ & $<0.001$ & $<0.001$ \\
\hline$U_{2}$ & $21(19.6)$ & $222(25.1)$ & & \\
\hline$U_{3}-U_{5}$ & $15(14.0)$ & $302(34.0)$ & & \\
\hline \multirow[t]{2}{*}{ Men } & ACS or LTE & No ACS or LTE & & \\
\hline & $\mathrm{n}=143(17.8 \%)$ & $n=659(82.2 \%)$ & & \\
\hline $\mathrm{U}_{1}$ & $96(67.1)$ & $278(42.2)$ & $<0.001$ & $<0.001$ \\
\hline$U_{2}$ & $24(16.8)$ & $137(20.8)$ & & \\
\hline$U_{3}-U_{5}$ & $23(16.1)$ & $244(37.0)$ & & \\
\hline
\end{tabular}

* p-value 1: $U_{1}$ vs. $U_{2}, U_{3}, U_{4}$ and $U_{5}$

** p-value 2: $U_{1}, U_{2}$ vs. $U_{3}, U_{4}, U_{5}$

$* * *$ LTE $=$ life threatening event. Life threatening events consist of: ACS; pulmonary embolism; thoracic aortic dissection; acute heart failure; stroke; abdominal aortic aneurysm; severe COPD exacerbation; diabetic ketoacidosis; coronary spasm probably caused by hypokalaemia; epileptic insult; bleeding from oesophageal varices; ovarian torsion; ventricular fibrillation.

\section{DISCUSSION}

For both sexes, retrosternal pain, pain described as pressing, heavy or tightening, and radiation to the arm were indicative of ACS in patients presenting with chest discomfort to out-of-hours primary care (OHS-PC). Radiation of pain to the jaw, severe pain, and a pale face was indicative for ACS in women. In men with chest discomfort sweating was positive related to ACS and stabbing pain negatively. Women and men were equally often sent an ambulance.

Our finding that radiation of pain to the arm and chest pressure were discriminative for ACS in both sexes was not reported in the two previous studies that assessed ACS symptoms using the same methodology. The US study in ED-setting found that 
radiation to the arm was indicative for ACS in women but not for men, and chest pressure was distinctive for men but not for women. ${ }^{13}$ The OHS-PC study reported opposite to our study that radiation to the arm was indicative for ACS in men, but not in women, and reported similar to our study that stabbing pain is very uncommon in men with ACS. ${ }^{17}$

Regarding dispatching the ambulance, the aforementioned OHS-PC study and two EMS studies showed, similar to our findings, that there was no difference in dispatch priorities between men and women with ACS. 4,17,23 This is in contrast with studies that show delay in hospital presentation of women with ACS. 9, 24

We need to realize that focusing on differences may blur the large overlap in symptoms. Moreover, comparing selectively women with ACS to men with ACS as many previous studies did, is clinically irrelevant. 9, 14,25 Clinicians, including GPs, and triage nurses need to know whether and how women with ACS differ from women without ACS, with the same question for men. Nevertheless, even guidelines stick to comparing those with established disease, and express the view that women with ACS more likely present with less specific symptoms than men with ACS. ${ }^{1,26}$ Unfortunately, public awareness campaigns follow this reasoning, and over-emphasize sex differences in women awareness campaigns ('Go Red for Women' in the United States and 'Invisible me' in Australia). 7, 25, 27 Unbalanced attention to differences, neglecting the much larger overlap may even introduce new blind spots in recognizing ACS in women. ${ }^{28}$

A likely reason behind the predominant message that women present with other ACS symptoms than men is the difference in pathophysiology of coronary artery disease. Women, compared to men, more often have elongated plaques, located on bifurcations in epicardial coronaries, coronary spasm, microvascular dysfunction, and spontaneous coronary dissection. ${ }^{27,29}$ These pathophysiological differences have an effect on interventional treatment and prognosis. ${ }^{2,29}$ However, these differences do not necessarily imply an effect on symptom presentation because the pain pathway is equal in women and men: i.e. triggered by myocardial ischemia. ${ }^{30,31} \mathrm{~A}$ supply and demand mismatch of the myocardial oxygen consumption triggers sensory nerve endings in the myocardium and cause ischemia symptoms, and this is irrespective of the fact whether the ischemia is caused by a plaque rupture in an epicardial artery or spasm, or any other cause. ${ }^{31}$ The sex differences in pathophysiology of ACS do therefore not support the belief in differences in ACS symptoms between women and men. 
Another reason behind the belief of 'vague' symptom presentation in women with ACS might be that they seem to present a larger number of symptoms than men with ACS, and this may be interpreted as 'vague' by physicians. ${ }^{15,32}$ The presentation of multiple symptoms may influence the prompt recognition of heart disease and initial actions on the part of health care providers. ${ }^{32,33}$ In a study from 2018, 2009 women and 976 men hospitalized for myocardial infarction, healthcare providers initially thought symptoms of women (53.4\%) were less often heart-related than in men (36.7\%). ${ }^{32}$ Women and men had the same chest pain symptoms, but women reported more additional symptoms. ${ }^{32}$

In our study, the call duration and the number of GP consultations by the triage nurse were similar among women and men, suggesting that triage nurses seem not to experience more difficulties in interpreting symptoms in women than men. This is in line with a prospective study with 2,795 patients with chest discomfort in ED-setting that showed the physicians' diagnostic uncertainty for the presence of ACS in women was not more common as compared to men. ${ }^{34}$

Interestingly, in the majority of calls in our study someone else than the patient called the OHS-PC (women with ACS 69.4\%, without ACS 47.7\%, and men with ACS 65.8\%, and without ACS 52.8\%). This was also highlighted in an Australian study among 1,681 patients with an acute myocardial infarction; in $90.5 \%$ of the women with AMI someone else called on behalf of the patient and in $87.8 \%$ of the men with AMI. 35

\section{Strengths and limitations}

We analysed the very first conversations with symptom presentation of a large sample of patients calling the OHS-PC because of chest discomfort. We analysed the conversations without knowledge of the eventual diagnosis (no hindsight bias of the researcher or recall bias of the patient). Another strength is that our results are generalizable to comparable primary care settings, e.g. UK and Scandinavian countries, and some other European countries. Our results may even be generalizable to EMS settings, since the prior probability of having an ACS is comparable in EMS settings as in OHS-PC settings. ${ }^{4}$ We had missing values on some clinical variables, a phenomenon common in routine care data. 


\section{CONCLUSIONS}

Symptoms predictive of ACS were rather similar for women and men with chest discomfort, with some important exceptions, such as severity, type, and radiation of pain, and some autonomous nervous system related symptoms.

\section{ACKNOWLEDGEMENTS}

The authors would like to thank the OHS-PC foundation 'Primair Huisartsenposten' and all employees of the participating locations for their cooperation in this study, notably for providing data and technical support.

\section{FUNDING}

This study was funded by an unrestricted grant from (i) the Department of General Practice of the University Medical Centre Utrecht, (ii) a personal promotion grant to DZ, (iii) the The Netherlands Triage Standard Foundation and (iv) the Stoffels-Hornstra Foundation. 


\section{REFERENCES}

1. Roffi M, Patrono C, Collet JP, Mueller C, Valgimigli M, Andreotti F, Bax JJ, Borger MA, Brotons C, Chew DP, Gencer B, Hasenfuss G, Kjeldsen K, Lancellotti P, Landmesser U, Mehilli J, Mukherjee D, Storey RF, Windecker S and Group ESCSD. 2015 ESC Guidelines for the management of acute coronary syndromes in patients presenting without persistent ST-segment elevation: Task Force for the Management of Acute Coronary Syndromes in Patients Presenting without Persistent ST-Segment Elevation of the European Society of Cardiology (ESC). European Heart Journal. 2016;37:267-315.

2. Dey S, Flather MD, Devlin G, Brieger D, Gurfinkel EP, Steg PG, Fitzgerald G, Jackson EA and Eagle KA. Sex-related differences in the presentation, treatment and outcomes among patients with acute coronary syndromes: the Global Registry of Acute Coronary Events. Heart. 2009;95:20-6.

3. Burman RA, Zakariassen E and Hunskaar S. Management of chest pain: a prospective study from Norwegian out-of-hours primary care. BMC Family Practice. 2014;15:51.

4. Rawshani A, Larsson A, Gelang C, Lindqvist J, Gellerstedt M, Bang A and Herlitz J. Characteristics and outcome among patients who dial for the EMS due to chest pain. International Journal of Cardiology. 2014;176:859-65.

5. Mol KA, Smoczynska A, Rahel BM, Meeder JG, Janssen L, Doevendans PA and Cramer MJ. Non-cardiac chest pain: prognosis and secondary healthcare utilisation. Open Heart. 2018;5:e000859.

6. Ting HH, Chen AY, Roe MT, Chan PS, Spertus JA, Nallamothu BK, Sullivan MD, DeLong ER, Bradley EH, Krumholz HM and Peterson ED. Delay from symptom onset to hospital presentation for patients with non-ST-segment elevation myocardial infarction. Archives of Internal Medicine. 2010;170:1834-41.

7. Stehli J, Martin C, Brennan A, Dinh DT, Lefkovits J and Zaman S. Sex Differences Persist in Time to Presentation, Revascularization, and Mortality in Myocardial Infarction Treated With Percutaneous Coronary Intervention. Journal of American Heart Association. 2019;8:e012161.

8. Canto JG, Rogers WJ, Goldberg RJ, Peterson ED, Wenger NK, Vaccarino V, Kiefe Cl, Frederick PD, Sopko $G$ and Zheng ZJ. Association of age and sex with myocardial infarction symptom presentation and in-hospital mortality. Journal of American Medical Association. 2012;307:813-22.

9. Chen W, Woods SL and Puntillo KA. Gender differences in symptoms associated with acute myocardial infarction: a review of the research. Heart Lung. 2005;34:240-7.

10. Canto JG, Goldberg RJ, Hand MM, Bonow RO, Sopko G, Pepine CJ and Long T. Symptom presentation of women with acute coronary syndromes: myth vs reality. Archives of Internal Medicine. 2007;167:2405-13.

11. Sorensen NA, Neumann JT, Ojeda F, Schafer S, Magnussen C, Keller T, Lackner KJ, Zeller T, Karakas M, Munzel T, Blankenberg S, Westermann D and Schnabel RB. Relations of Sex to Diagnosis and Outcomes in Acute Coronary Syndrome. Journal of American Heart Association. 2018;7.

12. van Oosterhout REM, de Boer AR, Maas A, Rutten FH, Bots ML and Peters SAE. Sex Differences in Symptom Presentation in Acute Coronary Syndromes: A Systematic Review and Meta-analysis. Journal of American Heart Association. 2020;9:e014733. 
13. Devon HA, Rosenfeld A, Steffen AD and Daya M. Sensitivity, specificity, and sex differences in symptoms reported on the 13 -item acute coronary syndrome checklist. Journal of American Heart Association. 2014;3:e000586.

14. Araujo C, Laszczynska O, Viana M, Melao F, Henriques A, Borges A, Severo M, Maciel MJ, Moreira I and Azevedo A. Sex differences in presenting symptoms of acute coronary syndrome: the EPIHeart cohort study. British Medical Journal Open. 2018;8:e018798.

15. Canto JG, Canto EA and Goldberg RJ. Time to standardize and broaden the criteria of acute coronary syndrome symptom presentations in women. Canadian Journal of Cardiology. 2014;30:7218.

16. Ferry AV, Anand A, Strachan FE, Mooney L, Stewart SD, Marshall L, Chapman AR, Lee KK, Jones S, Orme K, Shah ASV and Mills NL. Presenting Symptoms in Men and Women Diagnosed With Myocardial Infarction Using Sex-Specific Criteria. Journal of American Heart Association. 2019;8:e012307.

17. van der Meer MG, Appelman Y, Rutten KHG, van der GraafY, Nathoe HM, Doevendans PA, Smit M, Verheij E, Botermans A and Rutten FH. Are there gender disparities in symptom presentation or triage of patients with chest discomfort at primary care outof-hours services? An observational study. BMJ open. 2019;9:e031613.

18. Erkelens DC, Wouters LT, Zwart DL, Damoiseaux RA, De Groot E, Hoes AW and Rutten $\mathrm{FH}$. Optimisation of telephone triage of callers with symptoms suggestive of acute cardiovascular disease in out-of-hours primary care: observational design of the Safety First study. British Medical Journal Open. 2019;9:e027477.

19. Soler JK, Okkes I, Wood M and Lamberts H. The coming of age of ICPC: celebrating the 21st birthday of the International Classification of Primary Care. Family Practice. 2008;25:312-7.

20. Olagundoye OA, Malan Z, Mash B, van Boven K, Gusso G and Ogunnaike A. Reliability measurement and ICD-10 validation of ICPC-2 for coding/classification of diagnoses/ health problems in an African primary care setting. Family Practice. 2018;35:406-411.

21. van lerland $Y$, van Veen $M$, Huibers $L$, Giesen $P$ and Moll HA. Validity of telephone and physical triage in emergency care: the Netherlands Triage System. Family Practice. 2011;28:334-41.

22. Keizer E, Maassen I, Smits M, Wensing M and Giesen P. Reducing the use of out-ofhours primary care services: A survey among Dutch general practitioners. The European Journal of General practice. 2016;22:189-95.

23. Herlitz J, Starke M, Hansson E, Ringvall E, Karlson BW and Waagstein L. Characteristics and outcome among women and men transported by ambulance due to symptoms arousing suspicion of acute coronary syndrome. Medical Science Monitor. 2002;8:CR2516.

24. Bugiardini R, Ricci B, Cenko E, Vasiljevic Z, Kedev S, Davidovic G, Zdravkovic M, Milicic D, Dilic M, Manfrini O, Koller A and Badimon L. Delayed Care and Mortality Among Women and Men With Myocardial Infarction. Journal of American Heart Association. 2017 ; 6 . 
25. Diercks DB, Owen KP, Kontos MC, Blomkalns A, Chen AY, Miller C, Wiviott S and Peterson ED. Gender differences in time to presentation for myocardial infarction before and after a national women's cardiovascular awareness campaign: a temporal analysis from the Can Rapid Risk Stratification of Unstable Angina Patients Suppress ADverse Outcomes with Early Implementation (CRUSADE) and the National Cardiovascular Data Registry Acute Coronary Treatment and Intervention Outcomes Network-Get with the Guidelines. American Heart Journal. 2010;160:80-87 e3.

26. Mehta LS, Beckie TM, DeVon HA, Grines CL, Krumholz HM, Johnson MN, Lindley KJ, Vaccarino V, Wang TY, Watson KE, Wenger NK, American Heart Association Cardiovascular Disease in W, Special Populations Committee of the Council on Clinical Cardiology CoE, Prevention CoC, Stroke N, Council on Quality of C and Outcomes R. Acute Myocardial Infarction in Women: A Scientific Statement From the American Heart Association. Circulation. 2016;133:916-47.

27. Khamis RY, Ammari T and Mikhail GW. Gender differences in coronary heart disease. Heart. 2016;102:1142-9.

28. Amalberti R. Navigating safety: necessary compromises and trade-offs - theory and practice. Heidelberg: Springer; 2013.

29. Regitz-Zagrosek V, Oertelt-Prigione $S$, Prescott E, Franconi F, Gerdts E, Foryst-Ludwig A, Maas AHEM, Kautzky-Willer A, Knappe-Wegner D, Kintscher U, Ladwig KH, SchenckGustafsson K, Stangl V, EUGenMed and Grp CCS. Gender in cardiovascular diseases: impact on clinical manifestations, management, and outcomes. European Heart Journal. 2016;37:24-+.

30. Leach A and Fisher M. Myocardial ischaemia and cardiac pain - a mysterious relationship. BrJ Pain. 2013;7:23-30.

31. Rosen SD. From heart to brain: the genesis and processing of cardiac pain. Canandian Journal of Cardiology. 2012;28:S7-19.

32. Lichtman JH, Leifheit EC, Safdar B, Bao H, Krumholz HM, Lorenze NP, Daneshvar M, Spertus JA and D'Onofrio G. Sex Differences in the Presentation and Perception of Symptoms Among Young Patients With Myocardial Infarction: Evidence from the VIRGO Study (Variation in Recovery: Role of Gender on Outcomes of Young AMI Patients). Circulation. 2018;137:781-790.

33. Goldberg R, Goff D, Cooper L, Luepker R, Zapka J, Bittner V, Osganian S, Lessard D, Cornell C, Meshack A, Mann C, Gilliland J and Feldman H. Age and sex differences in presentation of symptoms among patients with acute coronary disease: the REACT Trial. Rapid Early Action for Coronary Treatment. Coronary Artery Disease. 2000;11:399407.

34. Hillinger $P$, Twerenbold $R$, Wildi $K$, Rubini Gimenez $M$, Jaeger $C$, Boeddinghaus J, Nestelberger T, Grimm K, Reichlin T, Stallone F, Puelacher C, Sabti Z, Kozhuharov $\mathrm{N}$, Honegger U, Ballarino P, Miro O, Denhaerynck K, Ekrem T, Kohler C, Bingisser $\mathrm{R}$, Osswald $\mathrm{S}$ and Mueller $\mathrm{C}$. Gender-specific uncertainties in the diagnosis of acute coronary syndrome. Clinical Research in Cardiology. 2017;106:28-37.

35. Coventry LL, Bremner AP, Jacobs IG and Finn J. Myocardial infarction: sex differences in symptoms reported to emergency dispatch. Prehospital Emergency Care. 2013;17:193202. 


\section{APPENDICES}

\section{Appendix-Table 1: NTS urgency levels}

\begin{tabular}{|c|c|c|c|}
\hline NTS Urgency level & Definition & Response time & Medical help \\
\hline Uo-Resuscitation & Loss of vital functions & Immediately & Ambulance \\
\hline$U_{1}$ - Life threatening & $\begin{array}{l}\text { Unstable vital } \\
\text { functions }\end{array}$ & $\begin{array}{l}\text { Immediately, } \\
\text { within } 15 \text { minutes }\end{array}$ & Ambulance \\
\hline$U_{2}$-Emergent & $\begin{array}{l}\text { Vital functions in } \\
\text { danger or organ } \\
\text { damage }\end{array}$ & $\begin{array}{l}\text { As soon as } \\
\text { possible, within } \\
1 \text { hour }\end{array}$ & $\begin{array}{l}\text { Home visit by GP or } \\
\text { consultation at OHS-PC }\end{array}$ \\
\hline$U_{3}$ - Urgent & $\begin{array}{l}\text { Possible risk of } \\
\text { damage, human } \\
\text { reasons }\end{array}$ & $\begin{array}{l}\text { A few hours }(<3 \\
\text { hours) }\end{array}$ & $\begin{array}{l}\text { Home visit by GP or } \\
\text { consultation at OHS-PC }\end{array}$ \\
\hline$U_{4}-$ Non-urgent & $\begin{array}{l}\text { Marginal risk of } \\
\text { damage }\end{array}$ & 24 hours & $\begin{array}{l}\text { Consultation at OHS-PC } \\
\text { or telephone advice }\end{array}$ \\
\hline$U_{5}$ - Advice & No risk of damage & $\begin{array}{l}\text { Advice, no time } \\
\text { related }\end{array}$ & Telephone advice \\
\hline
\end{tabular}

GP: General practitioner

NTS: Netherlands Triage Standard

OHS-PC: Out-of-hours services for primary care

\section{Appendix-Table 2: Relation of caller to patient in women and men with ACS}

\begin{tabular}{lccc}
\hline Relationship caller & $\begin{array}{c}\text { Women } \\
\mathrm{n}=\mathbf{8 5}(\mathbf{8 . 6 \% )}\end{array}$ & $\begin{array}{c}\text { Men } \\
\mathrm{n}=\mathbf{1 2 0}(\mathbf{1 5 . 0 \% )})\end{array}$ & $\mathrm{p}$-value \\
\hline Someone else calls on behalf of patient & $59(69.4)$ & $79(65.8)$ & 0.590 \\
Partner & $16(18.8)$ & $64(53.3)$ & $<0.001$ \\
Son, daughter or other family member & $20(23.5)$ & $8(6.7)$ & 0.001 \\
Nurse & $15(17.6)$ & $4(3.3)$ & $<0.001$ \\
Other (neighbour, friend, colleague) & $8(9.4)$ & $3(2.5)$ & 0.030 \\
\hline
\end{tabular}


- $0^{0} \circ \quad a_{0}$

(1) 0 (1) 0 C 0

0 कर 0 है

(1)<smiles>[O]OCO</smiles> 


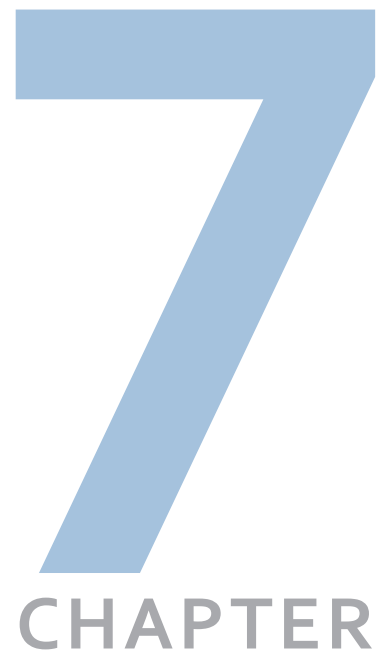

Development of sex-specific prediction rules for early recognition of acute coronary syndrome in primary care: a crosssectional study

Loes TCM Wouters, Dorien LM Zwart, Daphne CA Erkelens, Sanne AE Peters, Lisa Adriaansen, Hester M Den Ruijter, Esther de Groot, Roger AMJ Damoiseaux, Arno W Hoes, Maarten van Smeden, Frans HRutten 


\begin{abstract}
Objective To develop sex-specific symptom-based prediction rules for diagnosing acute coronary syndrome (ACS) in patients with acute chest discomfort who call outof-hours services for primary care (OHS-PC).
\end{abstract}

Design Cross-sectional study.

Setting Nine OHS-PCs in the Netherlands.

Participants 2,192 patients who called the OHS-PC for acute chest discomfort (pain, pressure, tightness, or discomfort) between 2014 and 2017.

Main outcomes measures Diagnosis of ACS.

Methods We collected symptoms and medical history by listening to the call recordings, and obtained the age of the patient and call characteristics from the electronic medical files of the OHS-PC. We retrieved diagnoses from the patient's medical records in general practice, including hospital specialists discharge letters. Multivariable logistic regression models were used to predict ACS, for women and men separately, and we calculated c-statistics to quantify the discriminative ability of the prediction rules. The prediction rules were internally validated using bootstrapping.

Results Among the 2,192 patients (mean age 59.1 years (SD 19.5), 55.3\% women) who called with complaints of acute chest discomfort, $8.3 \%$ of women and $15.3 \%$ of men had an ACS. Age, pressing heavy chest pain, sweating, and radiation of chest pain were the strongest predictors for the diagnosis ACS in both sexes. The prediction model for women included seven predictors and had a discriminative ability (c-statistic) of 0.76 (95\% Cl 0.71-0.80). The prediction model for men included eight predictors and had a discriminative ability (c-statistic) of 0.72 (95\% Cl 0.68-0.76).

Conclusion These sex-specific prediction models for ACS had moderate to good discrimination, and they could, after external validation, be applied in general practice and OHS-PC for telephone triage of patients with chest discomfort. 


\section{INTRODUCTION}

Chest discomfort is among the top five reasons for telephone contact in out-of-hours services for primary care (OHS-PC) and concerns $5 \%$ of all cases at the emergency department (ED) in the USA. ${ }^{12}$ In the Netherlands, around $80 \%$ of patients with chest discomfort first calls the general practitioner (GP) or OHS-PC while $20 \%$ directly calls the emergency medical service (EMS, or ambulance dispatch centre) or are self-referrals to the ED. ${ }^{34}$ Adequate triage and early diagnosis in these patients is vital, because in case of an underlying acute coronary syndrome (ACS) early effective therapeutic interventions ('time is muscle') improve the patient's outcome and prognosis. ${ }^{56}$ For the diagnosis of ACS, a 12-lead electrocardiogram (ECG) and troponin testing is needed. ${ }^{56}$ However, before the patient is referred to an ED where these diagnostic tests can be done, patient selection is needed on the basis of symptom presentation retrieved by telephone triage. ${ }^{78}$ Symptom-based differentiating ACS from other causes of chest discomfort is notoriously difficult. ${ }^{9}$ In contrast to the many prediction rules developed to diagnose ACS in the hospital, symptom-based prediction rules for diagnosing ACS in general practice and other prehospital settings are needed, but scarce. ${ }^{1011}$ The efficiency and safety of telephone triage in OHS-PC currently remains poor, because in this low prevalence setting a high urgency (patient seen within one hour, by ambulance or GP) is allocated to $68.7 \%$ of chest discomfort patients, but on the other hand $11 \%$ of patients diagnosed in the hospital with an ACS did not receive a high urgency. ${ }^{1213}$

Most prediction rules for diagnosing ACS were developed in the ED setting, and included results from ECG and troponin testing. ${ }^{114}$ Such prediction rules cannot be straightforward implemented for telephone triage or in general practice because in the latter setting (i) these diagnostic tests are not available, (ii) the a priori risk of ACS is lower, and (iii) disease severity is less, compared to those seen in the ED. ${ }^{15}{ }^{16}$ The prevalence of ACS among patients with chest discomfort who call OHS-PC or EMS is about 10\%, and among those seen at the ED between 10 to $30 \% .{ }^{1416}{ }^{17}$ Only one prediction rule was developed to predict ACS in primary care (the modified Grijseels prediction rule) and included male sex, radiation of chest pain to the neck or left arm, nausea or sweating, and history of coronary artery disease (CAD), which showed a moderate discriminative ability (c-statistic of 0.66 ) after external validation. ${ }^{1018}$ Five other primary care prediction rules were developed to predict CAD in general, not specifically for ACS, e.g. the Marburg Heart Score (MHS) and INTERCHEST prediction rule (International Working Group on Chest Pain in Primary Care). ${ }^{19}$ In these studies both patients with acute and non-acute chest discomfort were included and the 
prevalence of stable CAD showed to be $10.9 \%$ to $12.6 \%$, while that of ACS was $1.5 \%$ to $2.5 \%$. This, of course, limits their applicability for specifically diagnosing ACS in telephone triage of patients with acute chest discomfort. ${ }^{19}$

Interestingly, many studies report that women and men differ in reporting symptoms of ACS, but never have sex-specific prediction rules been developed. 420

The aim of this study was to develop and internally validate sex-specific prediction rules for diagnosing ACS in primary care, in women and men who call OHS-PC for acute chest discomfort.

\section{METHODS}

We performed a cross-sectional study among 2,192 patients who called one of nine participating OHS-PCs in the Netherlands with acute chest discomfort (pain, pressure, tightness, or discomfort) in the period 2014 and 2017. ${ }^{21}$ These OHS-PCs serve a total population of 1.5 million people, and cover around 300,000 calls a year. We first selected calls on the basis of the International Code for Primary Care (ICPC; a WHO world-wide code system for primary care) codes $\mathrm{Ko}_{1}, \mathrm{Ko}_{2}, \mathrm{Ko3}_{3}, \mathrm{~K}_{24}$, $\mathrm{K}_{74}$, $\mathrm{K}_{75}$, K76, K77, K93, L04, P74, Ro2, R98 and keywords thoracic pain, chest pain, myocardial infarction, heart attack and their common abbreviations (Figure 1). ${ }^{22} 23$ We included a broad variety of symptoms to capture the entire domain of patients that could be suspected of ACS. We drew a random sample of all available calls of these patients with the Random Number Generator (RAND) function in Microsoft Excel. Calls were excluded from re-listening when the patients' age was below 18 years or when the patient did not live in the surrounding area of the OHS-PC (because we could not retrieve a diagnosis from the general practitioner of patients living outside the area of the OHS-P(s). Calls were also excluded from re-listening when it did not concern a triage call (e.g. inter-collegial consultation) or when the recording was of poor quality (Figure 1).

\section{Netherlands Triage Standard}

In the Netherlands, OHS-PC covers primary care during $73 \%$ of week hours, and the initial contact is by telephone. ${ }^{24}$ In most OHS-PCs, triage nurses use the 'Netherlands Triage Standard' (NTS) as a decision support tool to classify the urgency of the patient's condition. ${ }^{25}$ The NTS is a modified version of the Manchester Triage Standard developed in ED. ${ }^{25}$ Based on the patient's symptom presentation, the triage nurse 
needs to select the most appropriate complaint out of 56 'main complaints' and their answers are linked to urgency recommendations. In patients with acute chest discomfort triage nurses most often choose the NTS main complaint 'chest pain', but also other main complaints could be used (Appendix-table 2 NTS main complaints with triage criteria). ${ }^{13}$ The NTS generates urgency levels involving time frames within which a physician should see the patient: immediately, within 15 minutes by ambulance (U1); urgently, within one hour (U2); less urgent, within three hours (U3); non-urgent, the same day $\left(U_{4}\right)$, or telephone advice $\left(U_{5}\right)$ (Appendix-table 1 ). ${ }^{25}$ The GP may see the patient at the patient's home or at the OHS-PC. At any time, triage nurses can consult the supervising GP on call. ${ }^{26}$ In the Netherlands, GPs take care of $93 \%$ of all health care problems for $3 \%$ of the total health care budget. ${ }^{27}$ The GP has a gatekeeper's role to hospital care, although people may call EMS (112) in case they suspect a lifethreatening situation. ${ }^{27}$

Figure 1. Flowchart of study population

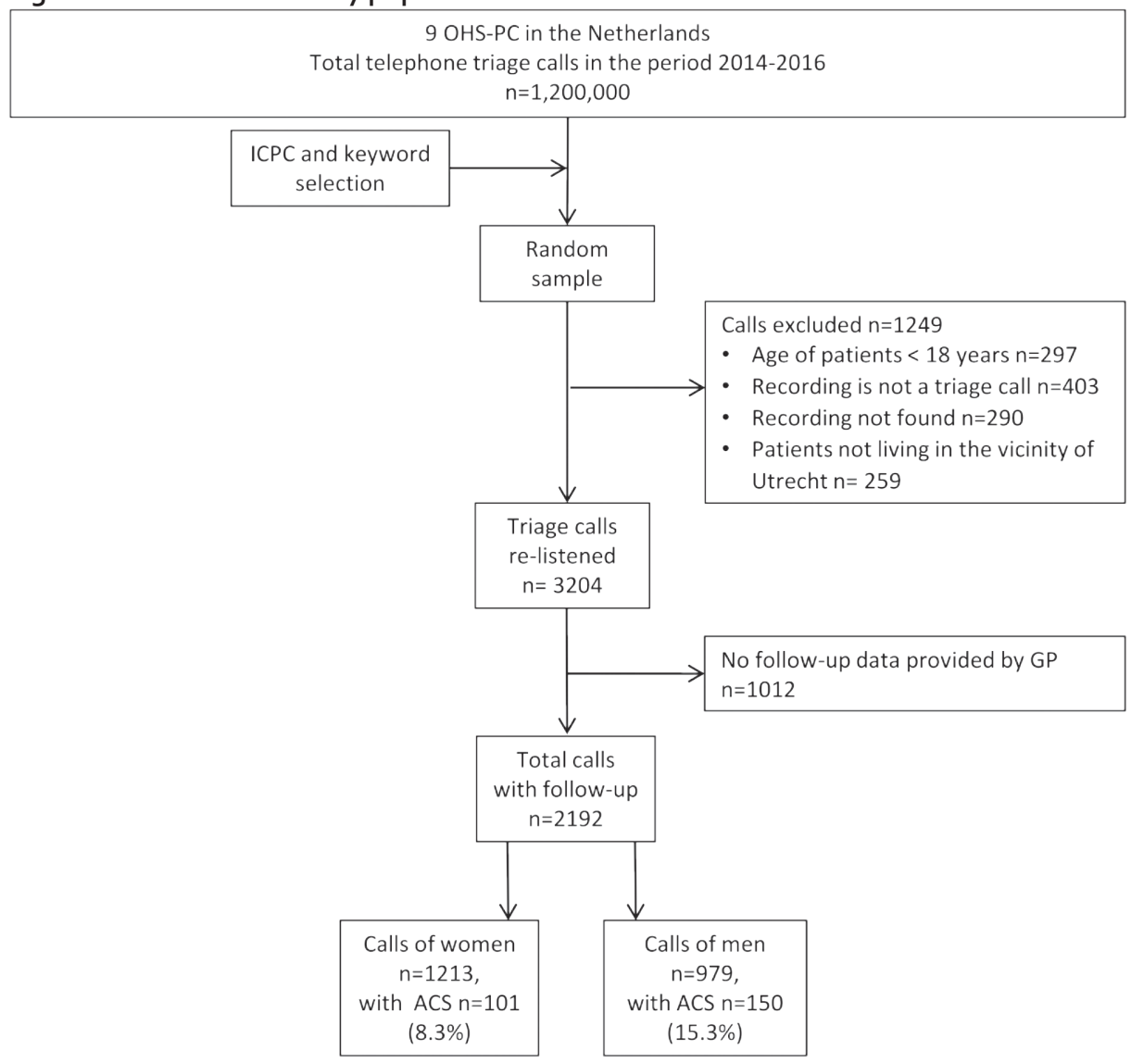




\section{Candidate predictors}

Research team members (LW, DE) and medical students listened to the call recordings, blinded for the outcome, to collect data about symptoms, medical history and urgency allocation. Patient (age, sex) and call characteristics (call time, call duration) were collected from the OHS-PC electronic medical files of the patients. As candidate predictors we included the ACS predictors from the modified Grijseels prediction model (radiation, nausea or vomiting, sweating and history of coronary artery disease), and we added the CAD predictors from MHS and INTERCHEST prediction models (age, pain feels like pressure, CAD history or risk factors, patient assumes cardiac origin of pain), and, based on a recent study in OHS-PC, call time during the night (oam-gam). ${ }^{10} 181928$ Furthermore, we selected the NTS triage criteria (shortness of breath, pain severity, pain duration, pain score > seven on a Numeric Rating Scale (NRS ${ }^{29}$, range 1-10) and (near) fainting) as candidate predictors.

\section{Outcome}

The primary outcome was the diagnosis ACS. The final diagnoses were retrieved from the patient's GP, and based on the GP's electronic medical files which include ED and cardiologist discharge letters, and notes from the OHS-PC contact. An ACS was based on the cardiologist's diagnosis, and included information on levels of (high-sensitivity) troponin and electrocardiography results.

\section{Sample size calculation}

We calculated the minimally required sample sizes to test twenty candidate predictors for women and men separately, with the criteria proposed by Riley et al, using the 'pmsampsize' package in R. ${ }^{30}$ Based on previous studies, we expected an ACS prevalence of $9 \%$ in women and $15 \%$ in men, and we used the modified Grijseels prediction model externally validated c-statistic of 0.66 to calculate an expected R-squared (0.169). ${ }^{18} 20283^{11}$ In women, the calculated minimum sample size was 962 suspected patients, including at least 87 patients diagnosed with ACS, and in men 962 suspected patients, with 145 patients with ACS. We decided to continue to include up to 100 women with ACS and 150 men with ACS.

\section{Statistical analyses}

Characteristics were compared between patients with and without information on the medical outcome - because some GPs refused diagnosis retrieval from their files - to allow for assessment of differences in characteristics between these patient groups (Appendix-table 3). There were no clinically meaningful differences in symptoms and patient or call characteristics between the 2,192 patients with information on the 
outcome, and the 1,012 patients without knowledge of the medical outcome related to the OHS-PC contact because of acute chest discomfort.

We developed our sex-specific prediction model with adherence to the Transparent Reporting of a multivariable prediction rules for Individual Prognosis Or Diagnosis (TRIPOD) criteria. ${ }^{32}$ We used multivariable logistic regression analysis to predict the presence of ACS, using backward elimination with a high cut-off $p$-value $<0.20$ for including predictors to minimize chances of overfitting. ${ }^{33} 34$ For missing data of predictors we carried out multiple imputation using the Multivariate Imputation via Chained Equation (MICE) package in $\mathrm{R}$, with 30 imputation rounds and 30 iterations (Appendix-table 4 for missing data). ${ }^{35}$ We pooled the results following Rubin's rules. ${ }^{36}$ Predictors with over $60 \%$ missing were excluded from the analyses. ${ }^{34}$

Internal validity of the models was assessed by means of bootstrapping, with replications of the analyses on 200 different samples in each of the 30 imputed sets, using the Regression Modelling Strategies ('rms') package in R. ${ }^{7}$ Because the regression coefficients were estimated in the development set, the estimates are often too optimistic resulting in overly extreme predicted probabilities when the model is applied in a new dataset. External validation of the prediction rules was however not possible, because no similar database was available as validation sample.

Descriptive statistics were performed with SPSS version 25.0.0.2, and multiple imputation, model development and performance testing were done in $\mathrm{R}$ studio version 1.2.5033.

\section{Patient and Public Involvement}

No patients were involved in defining the research question or the outcome measures and neither were they involved in developing plans for design. However, patients participated in the discussion on implications and the implementation strategy. In addition, patients were asked to advise on interpretation and writing up of results. Results will be shared and discussed in more detail with the Dutch national patient community of cardiovascular diseases ('Harteraad').

\section{Ethics}

The study (National Trial Register identification number: NTR7331) was approved by the Medical Ethics Committee Utrecht, the Netherlands (reference number WAG/ $\mathrm{mb} / 16 / 003208$ ) and complied with the Declaration of Helsinki. A waiver of informed consent was given because our study had minimal risk to subjects and could otherwise 
not be carried out logistically. Personal and research data were handled and stored according to the European General Data Protection Regulation (GDPR).

\section{RESULTS}

Among the 2,192 callers ( $55.3 \%$ women) with acute chest discomfort and a final diagnosis, 251 (11.5\%) had an ACS (women 8.3\%, men 15.3\%) (Table 1 and Table 2). The mean age was 59.1 (SD 19.5) years (women 59.4 (SD 20.2) years, men 58.7 (SD 18.6) years).

Women and men with ACS were significantly older than those without (mean age women with ACS 73.8 vs. women without ACS 58.1 years, $p<0.001$ and mean age in men with ACS 67.0 vs. men without ACS 57.2 years, $p<0.001$, respectively). The majority of patients $\left(68.2 \%\right.$ ) were allocated a high urgency (seen within one hour; $U_{1}$ or U2). For those with ACS, $88.4 \%$ had been allocated a high urgency (women $88.1 \%$, men $88.7 \%$ ) and for those without ACS $65.6 \%$ (women $66.5 \%$, men $64.4 \%$ ).

Calls of patients with ACS were shorter (median call duration 5:27 minutes for women with ACS vs. 6:59 minutes for women without ACS, $p<0.001$ and for men 6:04 vs. 6:56 minutes, $p<0.001$ ). The triage nurse consulted the GP for supervision in about half of the calls, similarly in both sexes. The majority of all patients had chest pain (94.5\%), without differences between women and men, with or without ACS.

Table 1. Characteristics of 1,213 women who called OHS PC with acute chest discomfort between 2014-2017, divided between patients with and without ACS.

\begin{tabular}{lccc}
\hline Characteristics & $\begin{array}{c}\text { ACS } \\
\mathrm{n=101}(\mathbf{8 . 3 \% )})\end{array}$ & $\begin{array}{c}\text { No ACS } \\
\mathrm{n=1112}(\mathbf{9 1 . 7 \% )}\end{array}$ & $\mathrm{p}$-value \\
\hline Patient characteristics & & & \\
\hline Mean age in years (SD) & $73.8(13.5)$ & $58.0(20.2)$ & $<0.001$ \\
\hline Call characteristics & & & \\
\hline Median call duration in min (IQR) & $5: 27(3: 57-8: 24)$ & $6: 59(5: 06-9: 47)$ & $<0.001$ \\
Mean introduction time in min (IQR) & $0: 13(0: 09-0: 18)$ & $0: 17(0: 11-0: 26)$ & $<0.001$ \\
Call during the night (oam-9am) & $34(33.7)$ & $304(27.3)$ & 0.175 \\
Triage nurse consulted the GP & $43(42.6)$ & $580(52.2)$ & 0.065 \\
Someone else called on behalf of patient & $69(68.3)$ & $515(46.3)$ & $<0.001$ \\
The person who calls expressed concerns & $42(95.5)$ & $507(90.5)$ & 0.275 \\
\hline
\end{tabular}


Table 1. (Continued)

\begin{tabular}{|c|c|c|c|}
\hline Characteristics & $\begin{array}{c}\text { ACS } \\
\mathrm{n}=101(8.3 \%)\end{array}$ & $\begin{array}{c}\text { No ACS } \\
\mathrm{n}=1112(91.7 \%)\end{array}$ & $\mathrm{p}$-value \\
\hline \multicolumn{4}{|l|}{ Medical history and risk factors } \\
\hline Cardiovascular disease or $\mathrm{CV}$ risk factors & $70(81.4)$ & $552(61.1)$ & $<0.001$ \\
\hline History of coronary artery disease & $23(47.9)$ & $131(24.2)$ & $<0.001$ \\
\hline Diabetes mellitus & $14(42.4)$ & $66(14 \cdot 3)$ & $<0.001$ \\
\hline Hypertension & $26(72.2)$ & $162(34.0)$ & $<0.001$ \\
\hline Hypercholesterolemia/statin use & $10(40.0)$ & $96(22.6)$ & 0.047 \\
\hline Cardiac arrhythmia & $4(14.8)$ & $125(26.2)$ & 0.189 \\
\hline \multicolumn{4}{|l|}{ Symptom presentation } \\
\hline Chest pain & $95(96.9)$ & $1007(94.1)$ & 0.246 \\
\hline Shortness of breath & $57(71.3)$ & $559(65.4)$ & 0.290 \\
\hline Chest pain duration $<12$ hours & $74(86.0)$ & $703(72.3)$ & 0.006 \\
\hline Pain intensity severe (NRS >7, range $1-10$ ) & $19(61.3)$ & $184(39.6)$ & 0.017 \\
\hline Pressing heavy chest pain* & $58(81.7)$ & $525(62.5)$ & 0.001 \\
\hline Stabbing chest pain* & $8(11.3)$ & $190(22.6)$ & 0.026 \\
\hline Chest pain located retrosternal** & $36(54 \cdot 5)$ & $326(40.0)$ & 0.020 \\
\hline Chest pain located left or right on thorax** & $19(28.8)$ & $318(39.0)$ & 0.102 \\
\hline Radiation of chest pain to any location & $74(86.0)$ & $575(67.8)$ & $<0.001$ \\
\hline Radiation to the arm *** & $37(43.0)$ & $218(25.7)$ & 0.001 \\
\hline Radiation to the shoulder blades $* * *$ & $14(16.3)$ & $190(22.4)$ & 0.190 \\
\hline Radiation to the jaws *** & $10(11.6)$ & $77(9.1)$ & 0.439 \\
\hline Sweating & $36(52.9)$ & $279(42.0)$ & 0.083 \\
\hline Nausea or vomiting & $24(52.2)$ & $295(56.6)$ & 0.560 \\
\hline Pallor or ashen skin & $22(59 \cdot 5)$ & $139(44 \cdot 3)$ & 0.079 \\
\hline (Near) fainting & $8(9 \cdot 5)$ & $76(7.7)$ & 0.562 \\
\hline Palpitations & $10(100.0)$ & $183(84.7)$ & 0.181 \\
\hline $\begin{array}{l}\text { Patient recognizes symptoms from previous } \\
\text { cardiac event }\end{array}$ & $17(35 \cdot 4)$ & $100(22.0)$ & 0.037 \\
\hline \multicolumn{4}{|l|}{ Urgency allocation } \\
\hline High urgency $\left(U_{1}\right.$ or $\left.U_{2}\right)$ & $89(88.1)$ & $740(66.5)$ & $<0.001$ \\
\hline$U_{1}$ & $75(74 \cdot 3)$ & $443(39.8)$ & \\
\hline$U_{2}$ & $14(13.9)$ & $297(26.7)$ & \\
\hline Low urgency $\left(\mathrm{U}_{3}\right.$ or $\mathrm{U}_{4}$ or $\left.\mathrm{U}_{5}\right)$ & $12(11.9)$ & $372(33.5)$ & \\
\hline
\end{tabular}

*Pain described by patient. Pressing heavy pain: pressing, heavy or tightening pain vs. other types of pain (stabbing, burning, cramping, tearing) Stabbing pain: stabbing vs. other types of pain (pressing, heavy, tightening, burning, cramping)

** Retrosternal location vs. other pain locations. Left or right side thorax vs. other pain locations *** Radiation location vs. no radiation and radiation other location 
Table 2. Characteristics of 979 men who called OHS PC with acute chest discomfort between 2014-2017, divided between patients with and without ACS.

\begin{tabular}{|c|c|c|c|}
\hline Characteristics & $\begin{array}{c}\text { ACS } \\
n=150(15 \cdot 3 \%)\end{array}$ & $\begin{array}{c}\text { No ACS } \\
\mathrm{n}=829(84.7 \%)\end{array}$ & $\mathrm{p}$-value \\
\hline \multicolumn{4}{|l|}{ Patient characteristics } \\
\hline Mean age in years (SD) & $67.0(12.6)$ & $57.2(19.2)$ & $<0.001$ \\
\hline \multicolumn{4}{|l|}{ Call characteristics } \\
\hline Median call duration in min (IQR) & $6: 04(4: 03-8: 17)$ & $6: 56(5: 10-9: 23)$ & $<0.001$ \\
\hline Mean introduction time in $\min (\mathrm{IQR})$ & $0: 14(0: 09-0: 21)$ & $0: 17(0: 11-0: 25)$ & 0.008 \\
\hline Call during the night (oam-gam) & $62(41.3)$ & $188(22.7)$ & $<0.001$ \\
\hline Triage nurse consulted the GP & $75(50.0)$ & $449(54.2)$ & 0.347 \\
\hline Someone else called on behalf of patient & $98(65 \cdot 3)$ & $432(52.1)$ & 0.003 \\
\hline The person who calls expressed concerns & $61(96.8)$ & $378(87.1)$ & 0.025 \\
\hline \multicolumn{4}{|l|}{ Medical history and risk factors } \\
\hline Cardiovascular disease or $\mathrm{CV}$ risk factor & $106(78.5)$ & $464(64.4)$ & 0.001 \\
\hline History of coronary artery disease & $54(56.3)$ & $181(38.8)$ & 0.002 \\
\hline Diabetes & $22(39.3)$ & $78(22.0)$ & 0.005 \\
\hline Hypertension & $22(51.2)$ & $113(33.3)$ & 0.021 \\
\hline Hypercholesterolemia/statin use & $27(50.0)$ & $79(24 \cdot 5)$ & $<0.001$ \\
\hline Cardiac arrhythmia & $12(25.0)$ & $89(25.2)$ & 0.975 \\
\hline \multicolumn{4}{|l|}{ Symptom presentation } \\
\hline Chest pain & $139(93.3)$ & 758 (94.9) & 0.433 \\
\hline Shortness of breath & $63(61.2)$ & $415(63.1)$ & 0.710 \\
\hline Chest pain duration $<12$ hours & $113(82.5)$ & $510(71.3)$ & 0.008 \\
\hline $\begin{array}{l}\text { Severe pain intensity severe (NRS }>7 \text {, range } \\
1-10 \text { ) }\end{array}$ & $18(25.4)$ & $116(33.0)$ & 0.209 \\
\hline Pressing/heavy chest pain* & $95(81.2)$ & $345(57.7)$ & $<0.001$ \\
\hline Stabbing chest pain* & $9(7.7)$ & $159(26.6)$ & $<0.001$ \\
\hline Chest pain located retrosternal** & $52(53.1)$ & $227(38.7)$ & 0.007 \\
\hline $\begin{array}{l}\text { Chest pain located on left or right of the } \\
\text { thorax** }\end{array}$ & $28(28.6)$ & $262(44.6)$ & 0.003 \\
\hline Radiation of chest pain to any location & $83(65 \cdot 4)$ & $347(56.2)$ & 0.058 \\
\hline Radiation to the arm *** & $54(42.5)$ & $143(23.2)$ & $<0.001$ \\
\hline Radiation to the shoulder blades *** & $19(15.0)$ & $103(16.7)$ & 0.631 \\
\hline Radiation to the jaws *** & $4(3.1)$ & $33(5 \cdot 3)$ & 0.299 \\
\hline Sweating & $54(51.9)$ & $190(35.8)$ & 0.002 \\
\hline Nausea or vomiting & $31(43.1)$ & 139 (39.9) & 0.624 \\
\hline Pallor or ashen skin & $36(64 \cdot 3)$ & $125(46.8)$ & 0.017 \\
\hline (Near) fainting & $9(6.7)$ & $50(6.7)$ & 0.996 \\
\hline Palpitations & $8(50.0)$ & $83(75 \cdot 5)$ & 0.034 \\
\hline $\begin{array}{l}\text { Patient recognizes symptoms from previous } \\
\text { cardiac event }\end{array}$ & $30(46.9)$ & $103(29.5)$ & 0.006 \\
\hline
\end{tabular}


Table 2. (Continued)

\begin{tabular}{lccc}
\hline Characteristics & ACS & No ACS & p-value \\
& $\mathbf{n = 1 5 0 ( 1 5 . 3 \% )}$ & $\mathbf{n = 8 2 9 ( 8 4 . 7 \% )}$ & \\
\hline Urgency allocation & & & \\
\hline High urgency $\left(U_{1}\right.$ or $\left.U_{2}\right)$ & $133(88.7)$ & $534(64.4)$ & $<0.001$ \\
$U_{1}$ & $106(70.7)$ & $350(42.2)$ & \\
$U_{2}$ & $27(18.0)$ & $184(22.2)$ & \\
Low urgency $\left(U_{3}\right.$ or $U_{4}$ or $\left.U_{5}\right)$ & $17(11.3)$ & $295(35.6)$ & \\
\hline
\end{tabular}

*Pain described by patient. Pressing heavy pain: pressing, heavy or tightening pain vs. other types of pain (stabbing, burning, cramping, tearing) Stabbing pain: stabbing vs. other types of pain (pressing, heavy, tightening, burning, cramping)

** Retrosternal location vs. other pain locations. Left or right side thorax vs. other pain locations $* * *$ Radiation location vs. no radiation and radiation other pain

\section{Diagnoses}

Of all women with ACS, $22.8 \%$ had a ST-segment elevation myocardial infarction (STEMI), 46.5\% had a non ST-segment elevation myocardial infarction (NSTEMI), $19.8 \%$ had unstable angina pectoris (UAP), and 10.9\% had non-classified ACS. In men with ACS, 33.3\% had a STEMI, 36.7\% had a NSTEMI, 26.0\% UAP, and $4.0 \%$ non-classified ACS (Table 3). The majority (96.0\%) of ACS patients was diagnosed by a cardiologist. Ten ACS patients (4.0\%) were not diagnosed by a cardiologist; four died before arrival of the ambulance, one patient died after resuscitation at the ED (all five were classified as acute cardiac death due to ACS), and in five patients the ACS diagnosis was solely based on the GP's interpretation and in all five it considered patients with a short life expectancy who were not referred to the hospital.

Twenty-eight (2.3\%) women and 38 men (3.9\%) had another life-threatening event than ACS, e.g. pulmonary embolism, thoracic aortic dissection, acute abdominal aneurysm or acute heart failure.

All other patients (85.6\%) had non-urgent medical conditions such as non-urgent cardiovascular disease (18.9\%), musculoskeletal pain (17.9\%), non-cardiac chest pain (not further specified) (16.9\%), psychogenic disorder (11.4\%), gastrointestinal disorders (7.2\%), respiratory disorders (5.3\%), and other non-urgent diagnoses (8.0\%). 
Table 3. Diagnoses of 2,192 patients who contacted the OHS-PC for acute chest discomfort between 2014-2017, by sex.

\begin{tabular}{lccc}
\hline Diagnosis, $\mathrm{n}(\%)$ & Women $\mathrm{n}=1213$ & Men $\mathrm{n}=979$ & $\mathrm{p}$-value \\
\hline Acute coronary syndrome & $101(8.3)$ & $150(15.3)$ & $<0.001$ \\
STEMI & $23(22.8)$ & $50(33.3)$ & 0.071 \\
NSTEMI & $47(46.5)$ & $55(36.7)$ & 0.119 \\
UAP & $20(19.8)$ & $39(26.0)$ & 0.256 \\
Non-classified ACS & $11(10.9)$ & $6(4.0)$ & 0.033 \\
Life threatening events (LTEs) & $28(2.3)$ & $37(3.8)$ & 0.043 \\
Pulmonary embolism & $8(28.6)$ & $10(27.0)$ & 0.890 \\
Acute abdominal aneurysm & $2(7.1)$ & $3(8.1)$ & 0.885 \\
Thoracic aortic dissection & $1(3.6)$ & $4(10.8)$ & 0.278 \\
Other* & $17(60.7)$ & $20(54.1)$ & 0.591 \\
Non-urgent cardiovascular diseases** & $223(18.4)$ & $191(19.5)$ & 0.069 \\
Musculoskeletal pain & $245(20.2)$ & $148(15.2)$ & 0.039 \\
Non-cardiac chest pain, not further specified *** & $191(15.7)$ & $179(18.3)$ & 0.012 \\
Psychogenic disorders & $165(13.6)$ & $85(8.7)$ & 0.005 \\
Gastrointestinal tract disorders & $89(7.3)$ & $68(6.9)$ & 0.776 \\
Respiratory tract disorders & $61(5.2)$ & $56(5.7)$ & 0.203 \\
Other non-urgent diagnoses**** & $110(9.1)$ & $65(6.6)$ & 0.152 \\
\hline
\end{tabular}

* Stroke, severe COPD exacerbation, acute severe heart failure, sepsis, coronary spasm caused by hypokalaemia, diabetic ketoacidosis, epileptic insult, bleeding from oesophageal varices, ovarian torsion, ventricular fibrillation.

** Stable angina pectoris (including atypical chest pain), stable heart failure, arrhythmias, hypertension

$* * *$ Cardiac pathology unlikely after cardiologist's or GP's diagnostic work-up, but without differential diagnosis

$* * * *$ Amongst others: anemia, carcinoma, vasovagal collapse, side effects medication, dermatologic diseases

\section{Model development, performance and internal validation}

In women, seven predictors were included in the final model; 1) age, 2) sweating, 3) radiation of chest pain, 4) pressing heavy chest pain, 5) severe pain intensity on NRS > seven, 6) pain duration shorter than twelve hours and 7) history of diabetes mellitus (Table 4$)$. The prediction model for ACS had an apparent c-statistic of $0.78(95 \% \mathrm{Cl}$ $0.74-0.83)$. After bootstrapping, the optimism corrected c-statistic was $0.76(95 \% \mathrm{Cl}$ $0.71-0.80)$. 
Table 4. Final multivariable logistic regression model with predictors for the diagnosis ACS in women

\begin{tabular}{lccc}
\hline Predictors & Beta (SE) & Odds ratio (95\% Cl) & p-value \\
\hline Intercept & $-7.297(0.712)$ & & \\
Age per year & $0.043(0.007)$ & 1.04 & $<0.001$ \\
Sweating & $0.434(0.249)$ & 1.54 & 0.082 \\
Radiation & $0.915(0.312)$ & 2.50 & 0.004 \\
Pressing heavy chest pain & $0.620(0.320)$ & 1.86 & 0.054 \\
Pain intensity severe (NRS >7, range 1-10) & $0.313(0.325)$ & 1.37 & 0.337 \\
Chest pain duration <12 hours & $0.429(0.334)$ & 1.54 & 0.200 \\
History of diabetes mellitus & $0.464(0.335)$ & 1.59 & 0.170 \\
\hline
\end{tabular}

Apparent c-statistic 0.78 ( $95 \% \mathrm{Cl} 0.74-0.83)$

Adjusted c-statistic $0.76(95 \% \mathrm{Cl} 0.71-0.80)$

Calibration slope 0.87

SE: standard error

$\mathrm{Cl}$ : confidence interval

In men, eight predictors were included in the final model; 1) age, 2) sweating, 3) radiation of chest pain, 4) pressing heavy chest pain, 5) history of diabetes mellitus, 6) calling during the night (oam-gam) 7) patient recognizes symptoms from previous cardiac events and 8) shortness of breath) (Table 5). The prediction model for ACS had an apparent c-statistic of 0.75 ( $95 \% \mathrm{Cl} 0.71-0.79)$. After bootstrapping, the optimism corrected c-statistic was $0.72(95 \% \mathrm{Cl} 0.68-0.76)$.

Table 5. Final multivariable logistic regression model with predictors for the diagnosis ACS in men

\begin{tabular}{lccc}
\hline Predictors & Beta (SE) & Odds Ratio $(95 \% \mathrm{Cl})$ & $\mathrm{p}$-value \\
\hline Intercept & $-4.756(0.493)$ & & \\
Age & $0.026(0.007)$ & 1.03 & $<0.001$ \\
Sweating & $0.599(0.238)$ & 1.82 & 0.013 \\
Radiation & $0.478(0.222)$ & 1.61 & 0.032 \\
Pressing heavy chest pain & $0.911(0.259)$ & 2.49 & $<0.001$ \\
History of diabetes mellitus & $0.284(0.274)$ & 1.33 & 0.303 \\
Patient calls during the night (oam-9am) & $0.770(0.201)$ & 2.16 & $<0.001$ \\
Patient recognizes symptoms from & $0.296(0.260)$ & 1.34 & 0.257 \\
previous cardiac event & & & \\
Shortness of breath & $-0.367(0.253)$ & 0.69 & 0.148 \\
\hline
\end{tabular}

Apparent c-statistic 0.75 ( $95 \% \mathrm{Cl} 0.71-0.79)$

Adjusted c-statistic $0.72(95 \% \mathrm{Cl} 0.68-0.76)$

Calibration slope 0.85

SE: standard error

$\mathrm{Cl}$ : confidence interval 


\section{DISCUSSION}

This is the first study to develop symptom-based, sex-specific prediction rules for the diagnosis ACS in patients calling OHS-PC with acute chest discomfort. Our prediction rule for women includes seven predictors that had an internal validated c-statistic of 0.76 (95\% Cl 0.71-0.80). Our prediction rule for men includes eight predictors with an internal validated c-statistic of 0.72 ( $95 \% \mathrm{Cl} 0.68-0.76)$.

\section{Strengths and limitations}

The major strength of this study is that we were able to analyse the original and very first conversations with health care providers of patients with acute chest discomfort without knowledge of the diagnosis; the assessment of symptoms was therefore not affected by bias caused by knowledge of the final diagnosis. Furthermore, a large sample size of unselected patients was available which allowed us to evaluate twenty candidate predictors in both women and men. We assessed the risk of selection due to missing outcome data, and our data suggest that this missingness was unlikely to bias our findings. For missing data on clinical characteristics, we carried out multiple imputation to obtain unbiased estimates of all the parameters. ${ }^{35}$ Prediction rule development was done with adherence to the universally accepted TRIPOD criteria. ${ }^{32}$ Because we used data from nine different OHS-PCs our results will be well generalizable to other OHS-PC in the Netherlands, but also to similar OHS-PC settings in for example the UK and Scandinavian countries. Our results may also be generalizable to EMS settings, because the a priori chance of having an ACS among those calling for chest discomfort is rather similar in the EMS setting as in the OHS-PC setting. ${ }^{17} 38$

A limitation of our study is that we were not able to perform external validation, because no similar database was available as validation sample. Our prediction rules therefore await further validation.

Another limitation is that we did not compare the performance of the sex-specific models to the performance of a generic model, alternatively with sex as statistical interaction term. However, we have chosen on clinical grounds to develop sex-specific models because the prevalence of ACS in OHS-PC is different in women and men and there are indications of differences in the pathophysiology of ACS, as well as differences in symptoms predictive for ACS. 203940 


\section{Comparison with other studies}

Our prediction rules show a higher discriminating ability for ACS than the modified Grijseels prediction rule, and they include more predictors. ${ }^{10}$ The higher discriminating ability can be largely explained by the addition of the strongest predictor age, which is in line with the notion that the prevalence of ACS increases with age. ${ }^{11} 194^{1}$ Similar to the modified Grijseels prediction rule our prediction rules include the predictors sweating and radiation, however, the modified Grijseels rule combined nausea and sweating to a single predictor (i.e., nausea or sweating). ${ }^{18}$ We found that only sweating (OR 1.54 women, OR 1.82 men), and not nausea, was a predictor for the diagnosis ACS. Age and patient's recognition of cardiac symptoms were common predictors in our model and in the MHS and INTERCHEST prediction models. ${ }^{42-45}$ Of the cardiovascular diseases (CVD) or CV risk factors, we found that a history of diabetes mellitus was a predictor for the diagnosis ACS in both women and men, while a history of CAD did not contribute to ACS prediction, in contrast to the modified Grijseels prediction rule, MHS and INTERCHEST studies. ${ }^{10} 4^{2}$

Our prediction rules included some new variables compared to the existing prediction rules. In women, we found that a severe pain intensity (NRS > seven) was associated with an increased risk of ACS (OR 1.37). Studies reporting on the predictive value of pain severity for the diagnosis ACS are scarce, but one ED study among 3,306 patients with potential ACS found contrasting results; a high pain score (NRS nine or ten) was not associated with an increased likelihood of ACS. ${ }^{4}{ }^{6}$ However, that study did not perform sex stratified analyses. In men, we found that calling at night (oam-gam) was associated with a doubled risk of ACS (OR 2.16). This finding is consistent with a previous study in OHS-PC, that analysed different time slots of calling and found that the risk ratio for ACS at night for men was 2.33 (1.68-3.22, p < 0.001) and for women 1.29 (0.83-1.99, $\mathrm{p}=0.256) .{ }^{28}$ Previous studies in the ED setting also showed circadian variability in the occurrence of acute coronary events, with an early morning peak of ACS patients. 47-49

We found a large overlap in symptoms in the men's and women's prediction rules. This is in contrast with studies - including guidelines - stressing differences in symptom presentation between women and men with ACS. ${ }^{5051}$ Others, however, also stress the overlap between symptoms predictive for ACS in women and men. 4205253 Importantly, however, most studies compared symptoms of men and women with confirmed ACS and did not include an evaluation of sex-specific comparison of symptom presentation of patients with chest discomfort, suspected of ACS, in whom ACS is diagnosed or not. ${ }^{5354}$ Such studies are needed to inform clinician and triage nurses about whether and how women with ACS differ from women without ACS, and similarly for men. 
Moreover, many previous studies suffer from recall or hindsight bias of both patient and researcher because patient interviews or questionnaires were taken when the outcome ACS was already known.

\section{Implications for clinical practice and future research}

Some of the findings of this study can be readily applied for improving diagnosis of ACS in OHS-PC. Although we do not know how well the models perform with external validation, we anticipate that the models will do better than the current decision support tool (the NTS) that is used in Dutch OHS-PC. The NTS performs poor because it underestimates the urgency (generated an $U_{3}$ to $U_{5}$ and not a $U_{1} / U_{2}$ ) in $27 \%$ of patients with ACS (sensitivity $0.73,95 \% \mathrm{Cl} 0.68-0.78$ ) and showed also poor efficiency (specificity $0.43,95 \% \mathrm{Cl}$ 0.40-0.45). ${ }^{13}$ Importantly, the NTS does not include age as a predictor and we recommend age to consider in the ACS risk assessment in OHS-PC. Furthermore, in men with acute chest discomfort who call at night (oamgam) dispatching an ambulance right away could be considered. Future research with external validation is recommended to further optimize the prediction models before application in OHS-PC, as well as application in EMS.

\section{CONCLUSION}

These first, mainly symptom-based, sex-specific prediction models for ACS have moderate to good discrimination, and they could, after external validation, be applied in general practice and OHS-PC for telephone triage of patients with chest discomfort.

\section{ACKNOWLEDGEMENTS}

The authors would like to thank the OHS-PC foundation 'Primair Huisartsenposten' and all employees of the participating locations for their cooperation in this study, notably for providing data and technical support.

\section{FUNDING}

This study was funded by an unrestricted grant from (i) the Department of General Practice of the University Medical Centre Utrecht, (ii) a personal promotion grant to DZ, (iii) the The Netherlands Triage Standard Foundation and (iv) the Stoffels-Hornstra Foundation. 


\section{REFERENCES}

1. Rui P, Kang K. National Hospital Ambulatory Medical Care Survey: 2017 Emergency Department Summary Tables. In: Statistics NCfH, ed., 2017.

2. Jansen T, Ramerman L, Verheij R. Zorg op de huisartsenpost - gezondheidsproblemen. Nivel zorgregistraties eerste lijn 11 februari 2020

3. Mol KA, Smoczynska A, Rahel BM, et al. Non-cardiac chest pain: prognosis and secondary healthcare utilisation. Open Heart 2018;5(2):e000859. doi: 10.1136/ openhrt-2018-000859

4. Devon HA, Rosenfeld A, Steffen AD, et al. Sensitivity, specificity, and sex differences in symptoms reported on the 13 -item acute coronary syndrome checklist. Journal American Heart Association 2014;3(2):e000586. doi: 10.1161/JAHA.113.000586

5. Roffi M, Patrono C, Collet JP, et al. 2015 ESC Guidelines for the management of acute coronary syndromes in patients presenting without persistent ST-segment elevation: Task Force for the Management of Acute Coronary Syndromes in Patients Presenting without Persistent ST-Segment Elevation of the European Society of Cardiology (ESC). European Heart Journal 2016;37(3):267-315. doi: 10.1093/eurheartj/ehv320

6. Ibanez B, James S, Agewall S, et al. 2017 ESC Guidelines for the management of acute myocardial infarction in patients presenting with ST-segment elevation. Revista Espanola Cardiologia 2017;70(12):1082. doi: 10.1016/j.rec.2017.11.010

7. Burman RA, Zakariassen E, Hunskaar S. Management of chest pain: a prospective study from Norwegian out-of-hours primary care. BMC Family Practice 2014;15:51. doi: 10.1186/1471-2296-15-51 [published Online First: 2014/03/26]

8. Deakin CD, Sherwood DM, Smith A, et al. Does telephone triage of emergency (999) calls using Advanced Medical Priority Dispatch (AMPDS) with Department of Health $(\mathrm{DH})$ call prioritisation effectively identify patients with an acute coronary syndrome? An audit of 42,657 emergency calls to Hampshire Ambulance Service NHS Trust. Emergency Medicine Journal 2006;23(3):232-5. doi: 10.1136/emj. 2004.022962

9. Bruyninckx R, Aertgeerts B, Bruyninckx $P$, et al. Signs and symptoms in diagnosing acute myocardial infarction and acute coronary syndrome: a diagnostic meta-analysis. The British journal of General Practice 2008;58(547):105-11. doi: 10.3399/bjgpo8X277014

10. Bruins Slot $\mathrm{MH}$, Rutten $\mathrm{FH}$, van der Heijden $\mathrm{GJ}$, et al. Diagnosing acute coronary syndrome in primary care: comparison of the physicians' risk estimation and a clinical decision rule. Family Practice 2011;28(3):323-8. doi: 10.1093/fampra/cmq116

11. Fanaroff AC, Rymer JA, Goldstein SA, et al. Does This Patient With Chest Pain Have Acute Coronary Syndrome?: The Rational Clinical Examination Systematic Review. Journal of American Medical Association 2015;314(18):1955-65. doi: 10.1001/ jama.2015.12735

12. Plat FM, Peters YAS, Loots FJ, et al. Ambulance dispatch versus general practitioner home visit for highly urgent out-of-hours primary care. Family Practice 2017(Dec 20) doi: 10.1093/fampra/cm×121

13. Wouters LT, Rutten FH, Erkelens DC, et al. Accuracy of telephone triage in primary care patients with chest discomfort: a cross-sectional study. Open Heart 2020;July

14. Leite L, Baptista R, Leitao J, et al. Chest pain in the emergency department: risk stratification with Manchester triage system and HEART score. BMC Cardiovascular Disorders 2015;15:48. doi: 10.1186/s12872-015-0049-6 
15. Leeflang MM, Rutjes AW, Reitsma JB, et al. Variation of a test's sensitivity and specificity with disease prevalence. Canadian Medical Association Journal 2013;185(11):E537-44. doi: $10.1503 / \mathrm{cmaj} .121286$

16. Buntinx $F$, Knockaert $D$, Bruyninckx $R$, et al. Chest pain in general practice or in the hospital emergency department: is it the same? Family Practice 2001;18(6):586-9.

17. Rawshani A, Larsson A, Gelang C, et al. Characteristics and outcome among patients who dial for the EMS due to chest pain. International Journal of Cardiology 2014;176(3):859-65. doi: 10.1016/j.ijcard.2014.08.004

18. Grijseels EW, Deckers JW, Hoes AW, et al. Implementation of a pre-hospital decision rule in general practice. Triage of patients with suspected myocardial infarction. European Heart Journal 1996;17(1):89-95.

19. Harskamp RE, Laeven SC, Himmelreich JC, et al. Chest pain in general practice: a systematic review of prediction rules. British Medical Journal Open 2019;9(2):e027081. doi: 10.1136/bmjopen-2018-027081

20. van der Meer MG, Appelman Y, Rutten KHG, et al. Are there gender disparities in symptom presentation or triage of patients with chest discomfort at primary care out-of-hours services? An observational study. British Medical Journal Open 2019;9(11):e031613. doi: 10.1136/bmjopen-2019-031613

21. Erkelens DC, Wouters LT, Zwart DL, et al. Optimisation of telephone triage of callers with symptoms suggestive of acute cardiovascular disease in out-of-hours primary care: observational design of the Safety First study. British Medical Journal Open 2019;9(7):e027477. doi: 10.1136/bmjopen-2018-027477

22. Soler JK, Okkes I, Wood M, et al. The coming of age of ICPC: celebrating the 21st birthday of the International Classification of Primary Care. Family Practice 2008;25(4):312-7. doi: 10.1093/fampra/cmno28

23. Olagundoye OA, Malan Z, Mash B, et al. Reliability measurement and ICD-10 validation of ICPC-2 for coding/classification of diagnoses/health problems in an African primary care setting. Family Practice 2018;35(4):406-11. doi: 10.1093/fampra/cm×132

24. Smits M, Rutten M, Keizer E, et al. The Development and Performance of After-Hours Primary Care in the Netherlands: A Narrative Review. Annals of Internal Medicine 2017;166(10):737-42. doi: 10.7326/M16-2776

25. van lerland $Y$, van Veen $M$, Huibers $L$, et al. Validity of telephone and physical triage in emergency care: the Netherlands Triage System. Family Practice 2011;28(3):334-41. doi: 10.1093/fampra/cmq097

26. Keizer E, Maassen I, Smits M, et al. Reducing the use of out-of-hours primary care services: A survey among Dutch general practitioners. The European Journal of General Practice 2016;22(3):189-95. doi: 10.1080/13814788.2016.1178718

27. Kroneman M, Boerma W, van den Berg M, et al. Netherlands: Health System Review. Health Systems in Transition 2016;18(2):1-240.

28. Wouters LT, Zwart DL, Erkelens DC, et al. Chest discomfort at night and risk of acute coronary syndrome: cross-sectional study of telephone conversations. Family Practice 2020 doi: 10.1093/fampra/cmaaoo5

29. Williamson A, Hoggart B. Pain: a review of three commonly used pain rating scales. Journal of Clinical Nursing 2005;14(7):798-804. doi: 10.1111/j.1365-2702.2005.01121.

30. Riley RD, Ensor J, Snell KIE, et al. Calculating the sample size required for developing a clinical prediction model. British Medical Journal 2020;368:m441. doi: 10.1136/bmj. $\mathrm{m} 441$ 
31. Riley RD, Snell KI, Ensor J, et al. Minimum sample size for developing a multivariable prediction model: PART II - binary and time-to-event outcomes. Statistics in Medicine 2019;38(7):1276-96. doi: 10.1002/sim.7992

32. Moons KG, Altman DG, Reitsma JB, et al. Transparent Reporting of a multivariable prediction model for Individual Prognosis or Diagnosis (TRIPOD): explanation and elaboration. Annals of Internal Medicine 2015;162(1):W1-73. doi: 10.7326/M14-0698

33. van Smeden M, Moons KG, de Groot JA, et al. Sample size for binary logistic prediction models: Beyond events per variable criteria. Statistical Methods in Medical Research 2019;28(8):2455-74. doi: 10.1177/og62280218784726

34. Steyerberg EW. Clinical prediction models2019.

35. Jolani S, Debray TP, Koffijberg H, et al. Imputation of systematically missing predictors in an individual participant data meta-analysis: a generalized approach using MICE. Statistics in Medicine 2015i34(11):1841-63. doi: 10.1002/sim.6451

36. Rubin DB. Multiple imputation for non response in surveys. John Wiley \& Sons, Hoboken, NJ 1987

37. Harrell FE, Jr. Regression Modeling Strategies: With Applications to Linear Models, Logistic and Ordinal Regression, and Survival Analysis. Second edition ed. Cham, Switzerland: Springer International 2015.

38. Scott G, Clawson JJ, Gardett I, et al. 9-1-1 Triage of Non-Traumatic Chest Pain: Association with Hospital Diagnosis. Prehospital Emergency Care 2017;21(4):525-34. doi: 10.1080/10903127.2017.1302530

39. Regitz-Zagrosek V, Oertelt-Prigione S, Prescott E, et al. Gender in cardiovascular diseases: impact on clinical manifestations, management, and outcomes. European Heart Journal 2016;37(1):24-+. doi: 10.1093/eurheartj/ehv598

40. Khamis RY, Ammari T, Mikhail GW. Gender differences in coronary heart disease. Heart 2016;102(14):1142-9. doi: 10.1136/heartjnl-2014-306463

41. Canto JG, Rogers WJ, Goldberg RJ, et al. Association of age and sex with myocardial infarction symptom presentation and in-hospital mortality. Journal of American Medical Association 2012;307(8):813-22. doi: 10.1001/jama.2012.199

42. Bosner $\mathrm{S}$, Haasenritter J, Becker $\mathrm{A}$, et al. Ruling out coronary artery disease in primary care: development and validation of a simple prediction rule. Canadian Medical Association Journal 2010;182(12):1295-300. doi: 10.1503/cmaj.100212

43. Haasenritter J, Bosner $\mathrm{S}$, Vaucher $\mathrm{P}$, et al. Ruling out coronary heart disease in primary care: external validation of a clinical prediction rule. The British Journal of General Practice 2012;62(599):e415-21. doi: 10.3399/bjgp12X649106

44. Haasenritter J, Donner-Banzhoff N, Bosner S. Chest pain for coronary heart disease in general practice: clinical judgement and a clinical decision rule. The British Journal of General Practice 2015;65(640):e748-53. doi: 10.3399/bjgp15X687385

45. International Working Group on Chest Pain in Primary C, Aerts M, Minalu G, et al. Pooled individual patient data from five countries were used to derive a clinical prediction rule for coronary artery disease in primary care. Journal of Clinical Epidemiology 2017;81:12028. doi: 10.1016/j.jclinepi.2016.09.011

46. Edwards M, Chang AM, Matsuura AC, et al. Relationship between pain severity and outcomes in patients presenting with potential acute coronary syndromes. Annals of Emergency Medicine 2011;58(6):501-7. doi: 10.1016/j.annemergmed.2011.05.036

47. Bhalla A, Sachdev A, Lehl SS, et al. Ageing and circadian variation in cardiovascular events. Singapore Medical Journal 2006;47(4):305-8. 
48. Ekelund $U$, Akbarzadeh M, Khoshnood A, et al. Likelihood of acute coronary syndrome in emergency department chest pain patients varies with time of presentation. $B M C$ Research Notes 2012;5:420. doi: 10.1186/1756-0500-5-420

49. Leiza JR, de Llano JM, Messa JB, et al. New insights into the circadian rhythm of acute myocardial infarction in subgroups. Chronobiology International 2007;24(1):129-41. doi: 10.1080/07420520601140027

50. Mehta LS, Beckie TM, DeVon HA, et al. Acute Myocardial Infarction in Women: A Scientific Statement From the American Heart Association. Circulation 2016;133(9):91647. doi: 10.1161/CIR.0000000000000351

51. Madonis SM, Skelding KA, Roberts M. Management of acute coronary syndromes: special considerations in women. Heart 2017;103(20):1638-46. doi: 10.1136/ heartjnl-2016-309938

52. Ferry AV, Anand A, Strachan FE, et al. Presenting Symptoms in Men and Women Diagnosed With Myocardial Infarction Using Sex-Specific Criteria. Journal of American Heart Association 2019;8(17):e012307. doi: 10.1161/JAHA.119.012307

53. van Oosterhout REM, de Boer AR, Maas A, et al. Sex Differences in Symptom Presentation in Acute Coronary Syndromes: A Systematic Review and Meta-analysis. Journal of American Heart Association 2020;9(9):e014733. doi: 10.1161/JAHA.119.014733

54. Araujo C, Laszczynska O, Viana M, et al. Sex differences in presenting symptoms of acute coronary syndrome: the EPIHeart cohort study. British Medical Journal Open 2018;8(2):e018798. doi: 10.1136/bmjopen-2017-018798

55. Thim T, Krarup NH, Grove EL, et al. Initial assessment and treatment with the Airway, Breathing, Circulation, Disability, Exposure (ABCDE) approach. International Journal of General Medicine 2012;5:117-21. doi: 10.2147/IJGM.S28478

56. Smits M, Keizer E, Ram P, et al. Development and testing of the KERNset: an instrument to assess the quality of telephone triage in out-of-hours primary care services. $B M C$ Health Services Research 2017;17(1):798. doi: 10.1186/s12913-017-2686-1 
Appendix-Table 1. NTS urgency levels

\begin{tabular}{|c|c|c|c|}
\hline NTS Urgency level & Definition & Response time & Medical help \\
\hline Uo-Resuscitation & Loss of vital functions & Immediately & Ambulance \\
\hline $\begin{array}{l}\text { U1-Life } \\
\text { threatening }\end{array}$ & Unstable vital functions & $\begin{array}{l}\text { Immediately, } \\
\text { within } 15 \text { minutes }\end{array}$ & Ambulance \\
\hline$U_{2}$ - Emergent & $\begin{array}{l}\text { Vital functions in } \\
\text { danger or organ } \\
\text { damage }\end{array}$ & $\begin{array}{l}\text { As soon as } \\
\text { possible, within } \\
1 \text { hour }\end{array}$ & $\begin{array}{l}\text { Home visit by GP or } \\
\text { consultation at OHS-PC }\end{array}$ \\
\hline$U_{3}-$ Urgent & $\begin{array}{l}\text { Possible risk of damage, } \\
\text { human reasons }\end{array}$ & $\begin{array}{l}\text { A few hours ( }<3 \\
\text { hours) }\end{array}$ & $\begin{array}{l}\text { Home visit by GP or } \\
\text { consultation at OHS-PC }\end{array}$ \\
\hline$U_{4}$ - Non-urgent & Marginal risk of damage & 24 hours & $\begin{array}{l}\text { Consultation at OHS-PC } \\
\text { or telephone advice }\end{array}$ \\
\hline$U_{5}$-Advice & No risk of damage & $\begin{array}{l}\text { Advice, no time } \\
\text { related }\end{array}$ & Telephone advice \\
\hline
\end{tabular}

GP: General practitioner

NTS: Netherlands Triage Standard

OHS-PC: Out-of-hours services for primary care

\section{Appendix-Table 2: NTS main complaints with triage criteria that generate an urgency $U_{1}$ level, within the domain chest discomfort.}

\begin{tabular}{|c|c|c|c|}
\hline$\rightarrow \mathrm{ABCD}$ unsta & le (no main compla & selected) & \\
\hline Main complain & 'Chest pain' & & \\
\hline$\rightarrow$ ABCD stable & $\begin{array}{l}\text { AND severe chest } p \\
\text { lasting less than } 12 \mathrm{H}\end{array}$ & $\begin{array}{l}\text { ain (Numeric Rating Scale }{ }^{29} \text { (NRS)-score } \geq 8 \text { ) } \\
\text { hours }\end{array}$ & \\
\hline$\rightarrow \mathrm{ABCD}$ stable & $\begin{array}{l}\text { AND mild (NRS } \\
\leq 4 \text { ) to moderate } \\
\text { (NRS 5-7) chest } \\
\text { pain lasting for less } \\
\text { than } 12 \text { hours }\end{array}$ & $\begin{array}{l}\text { AND one of the following: } \\
\text { - retrosternal located pain } \\
\text { - tightening or pressing } \\
\text { - radiation to jaw, arm or upper back } \\
\text { - progressive pain intensity in short time } \\
\text { - past or present autonomous nervous system- } \\
\text { related symptoms } \\
\text { - dizziness }\end{array}$ & \\
\hline Main complain & Collatse & & \\
\hline$\rightarrow$ ABCD stable & AND collapse & AND chest pain of any severity & \\
\hline Main complain & 'Back complaints' & & \\
\hline$\rightarrow$ ABCD stable & $\begin{array}{l}\text { AND severe upper } \\
\text { back pain (NRS } \geq 8 \text { ) }\end{array}$ & $\begin{array}{l}\text { AND past or present autonomous nervous } \\
\text { system-related symptoms }\end{array}$ & \\
\hline
\end{tabular}

$A B C D$ : acronym for Airway, Breathing, Circulation and Disability. ${ }^{55}$ When the triage nurse starts the telephone triage with the NTS, the system requires a mandatory 'ABCD-check'; i.e. the triage nurse has to ask questions to assess whether the patient has life-threatening problems concerning the Airway, Breathing, Circulation and Disability for which an ambulance should be sent immediately. ${ }^{6}$ 


\section{Appendix-Table 3. Patient and call characteristics of 3,204 patients with chest discomfort calling OHS-PC between 2014-2017, comparing patients with and without information on the study outcome.}

\begin{tabular}{|c|c|c|c|}
\hline Characteristics $\mathrm{N}=3204$ & $\begin{array}{c}\text { Follow-up } \\
\mathrm{n}=2192(68.4 \%)\end{array}$ & $\begin{array}{l}\text { No follow-up } \\
n=1012(31.6 \%)\end{array}$ & P-value \\
\hline \multicolumn{4}{|l|}{ Patient characteristics } \\
\hline Median age in years (IQR) & $59.1(19.5)$ & $57.3(20.4)$ & 0.020 \\
\hline Female sex & $1213(55 \cdot 3)$ & $565(55.8)$ & 0.794 \\
\hline \multicolumn{4}{|l|}{ Call characteristics } \\
\hline Median total call duration in min (IQR) & $6: 51(4: 59-9: 23)$ & $6: 56(5: 04-9: 15)$ & 0.836 \\
\hline Mean patient's introduction in min (IQR) & $0: 17(0: 11-0: 25)$ & $0: 17(0: 11-0: 26)$ & 0.052 \\
\hline Triage nurse consulted the GP & $1147(52.3)$ & $519(51.3)$ & 0.583 \\
\hline Someone else called on behalf of patient & $1114(50.8)$ & $479(47 \cdot 3)$ & 0.066 \\
\hline The person who calls expressed concerns & $988(89.7)$ & $430(90.1)$ & 0.804 \\
\hline \multicolumn{4}{|l|}{ Medical history and risk factors } \\
\hline $\begin{array}{l}\text { Cardiovascular disease or risk factor } \\
\text { combined }\end{array}$ & $1192(64.6)$ & $515(62.3)$ & 0.254 \\
\hline History of coronary artery disease & $389(33.8)$ & $166(32.4)$ & 0.573 \\
\hline Diabetes mellitus & $180(19.9)$ & $68(18.0)$ & 0.432 \\
\hline Hypertension & $323(36.1)$ & $121(31.9)$ & 0.150 \\
\hline Hypercholesterolemia/statin use & $212(25.7)$ & $88(25.1)$ & 0.842 \\
\hline Cardiac arrhythmia & $230(25.4)$ & $102(24 \cdot 3)$ & 0.684 \\
\hline \multicolumn{4}{|l|}{ Symptoms } \\
\hline Chest pain & $1981(93.6)$ & $894(92.8)$ & 0.417 \\
\hline Shortness of breath & $1094(64 \cdot 5)$ & $520(64 \cdot 3)$ & 0.911 \\
\hline Chest pain duration $<12$ hours & $1403(73.2)$ & $610(69.6)$ & 0.052 \\
\hline Pain intensity severe (NRS >7, range $1-10$ ) & $337(36.6)$ & $185(43.0)$ & 0.024 \\
\hline Pressing heavy chest pain* & $1023(62.9)$ & $444(61.6)$ & 0.538 \\
\hline Stabbing chest pain* & $366(22.5)$ & $177(24 \cdot 5)$ & 0.280 \\
\hline Chest pain located retrosternal** & $641(40.9)$ & $294(40.2)$ & 0.736 \\
\hline Chest pain located left or right on thorax** & $627(40.0)$ & $294(40.2)$ & 0.945 \\
\hline Radiation of chest pain to any location & $1077(64 \cdot 3)$ & $458(60.1)$ & 0.047 \\
\hline Radiation to the arm $* * *$ & $452(42.2)$ & $179(39.8)$ & 0.373 \\
\hline Radiation to the shoulder blades $* * *$ & $326(30.5)$ & $136(30.2)$ & 0.924 \\
\hline Radiation to the jaws $* * *$ & $124(11.6)$ & $41(9.1)$ & 0.156 \\
\hline Sweating & 559 (40.9) & $259(42.0)$ & 0.638 \\
\hline Nausea or vomiting & $489(49.5)$ & $229(47.1)$ & 0.381 \\
\hline Pallor or ashen skin & $322(47.8)$ & $136(40.8)$ & 0.038 \\
\hline (Near) fainting & $143(7.4)$ & $72(7.8)$ & 0.678 \\
\hline Palpitations & $284(80.7)$ & $125(83.9)$ & 0.396 \\
\hline $\begin{array}{l}\text { Patient recognizes symptoms from previous } \\
\text { cardiac event }\end{array}$ & $250(27.3)$ & $102(26.7)$ & 0.819 \\
\hline
\end{tabular}




\section{Appendix-Table 3. (Continued)}

\begin{tabular}{lccc}
\hline Characteristics $\mathrm{N}=\mathbf{3 2 0 4}$ & $\begin{array}{c}\text { Follow-up } \\
\mathbf{n}=\mathbf{2 1 9 2}(\mathbf{6 8 . 4 \% )})\end{array}$ & $\begin{array}{c}\text { No follow-up } \\
\mathbf{n}=\mathbf{1 0 1 2}(\mathbf{3 1 . 6 \% )}\end{array}$ & P-value \\
\hline Urgency allocation & & & \\
\hline High urgency $\left(\mathrm{U}_{1}\right.$ or $\left.\mathrm{U}_{2}\right)$ & $1497(68.3)$ & $695(31.7)$ & 0.095 \\
$\mathrm{U}_{1}$ & $974(44.5)$ & $390(38.6)$ & \\
$\mathrm{U}_{2}$ & $522(23.8)$ & $271(26.8)$ & \\
$\mathrm{U}_{3}, \mathrm{U}_{4}, \mathrm{U}_{5}$ & $696(31.8)$ & $351(17.4)$ & \\
\hline
\end{tabular}

\section{Appendix - table 4. Overview of the percentages of missing predictors, divided into patients with and without diagnosis ACS.}

\begin{tabular}{lcc}
\hline Characteristics, missing (\%) & $\begin{array}{c}\text { ACS } \mathbf{n}=\mathbf{2 5 1} \\
(\mathbf{1 1 . 5 \% )}\end{array}$ & $\begin{array}{c}\text { No ACS } \mathbf{n}=\mathbf{1 9 4 1} \\
\mathbf{( 8 8 . 5 \% )}\end{array}$ \\
\hline Mean in years age (SD) & 0 & 0 \\
Female sex & 0 & 0 \\
Median call duration in min (IQR) & 0 & 0 \\
Mean patient's introduction in min (IOR) & 0 & 0 \\
Triage nurse consulted the GP & 0 & 0 \\
Someone else called on behalf of patient & 0 & 0 \\
The person who calls expressed concerns & 57.3 & 48.6 \\
Cardiovascular disease or risk factor combined & 12.0 & 16.4 \\
History of coronary artery disease & 42.6 & 48.1 \\
Diabetes mellitus & 64.5 & 58.0 \\
Hypertension & 68.5 & 58.0 \\
Hypercholesterolemia/statin use & 68.5 & 61.6 \\
Cardiac arrhythmia & 70.1 & 57.2 \\
Chest pain & 1.6 & 3.7 \\
Shortness of breath & 27.1 & 22.1 \\
Chest pain duration <12 hours & 11.2 & 13.1 \\
Pain intensity severe (NRS >7, range 1-10) & 59.4 & 57.9 \\
Pressing heavy chest pain* & 25.1 & 25.9 \\
Stabbing chest pain* & 25.1 & 25.9 \\
Chest pain located retrosternal** & 34.7 & 27.7 \\
Chest pain located left or right on thorax** & 34.7 & 27.7 \\
Radiation of chest pain to any location & 15.1 & 24.5 \\
Radiation to the arm *** & 37.5 & 52.5 \\
Radiation to the shoulder blades *** & 37.5 & 52.5 \\
Radiation to the jaws *** & 37.5 & 52.5 \\
Sweating & 31.5 & 38.5 \\
Nausea or vomiting & 53.0 & 55.2 \\
Pallor or ashen skin & 62.9 & 70.1 \\
(Near) fainting & 13.1 & 11.2 \\
Palpitations & 89.6 & 83.2 \\
Patient recognizes symptoms from previous cardiac event & 55.4 & 58.6 \\
\hline & & \\
& & \\
\hline
\end{tabular}


(1)

B

m

Oo

c

(i)

(1)

c)

(c) 0

- (1) $\mathrm{O}_{0}$

())

c

(c)

(ิ)

Cos

0

10

60

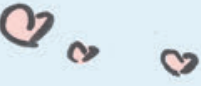

(c) 0 क हु ०

O 00

0

O 


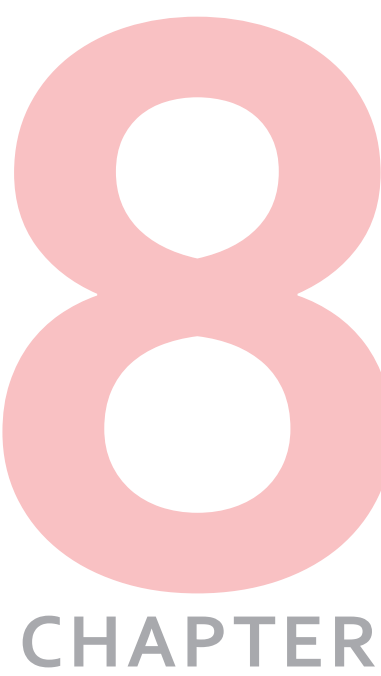

General discussion 
This thesis focused on telephone triage and diagnosis of patients presenting with chest discomfort in out-of-hours services for primary care (OHS-PC). In this general discussion we first summarize the main findings of the thesis, followed by a discussion about the relevance of considering the patient's eventual diagnosis in triage system research and telephone triage in clinical practice. For the latter topic we will elaborate on the overarching question: "Can we really reason in terms of urgencies during telephone triage at OHS-PC"? Finally, we reflect on the clinical case presented in the introduction of the thesis.

\section{Main findings of the studies in this thesis:}

- The Netherlands Triage Standard (NTS) decision support tool performed poorly regarding both safety and efficiency. Safety, because the NTS underestimated the urgency in $27 \%$ of patients who showed to have an acute coronary syndrome (ACS) or other life threatening events (LTEs), with a sensitivity of $0.73(95 \% \mathrm{Cl} 0.68-0.78)$. Efficiency, because the NTS overestimated the urgency in $57 \%$ of patients without ACS or other LTEs, with a specificity of $0.43(95 \% \mathrm{Cl} 0.40-0.45)$. Triage nurses' overruling of the NTS urgency increased the safety (sensitivity of $0.86,95 \% \mathrm{Cl} 0.81-0.90$ ) of telephone triage, but not the efficiency (specificity $0.34,95 \% \mathrm{Cl} 0.32-0.37$ ). (Chapter 3)

- $\quad$ Triage nurses create a 'mental image' of the patient; "what does the patient look like at the other end of the phone?" Furthermore, they use clinical reasoning strategies and interpret paralanguage (the vocal elements of communication such as tone of voice and breathing speed) to cope for the lack of visual information. 'Congruence' with the NTS is key for triage nurses, and if 'congruence' was absent, they applied four working strategies; i) tinkering, ii) overruling, iii) complying with the NTS urgency recommendation, or iv) transferring the responsibility of the urgency allocation by consulting the supervising general practitioner (GP). (Chapter 4 )

- $\quad$ The risk of ACS among patients with chest discomfort is almost twice as high for patients calling at night (between 0.00-9.00 a.m.) as compared to patients who call at other hours, evidently in men (risk ratio 2.33 (95\% Cl 1.68-3.22)) and less clearly in women (risk ratio 1.29 (95\% Cl 0.83-1.99)). (Chapter 5)

- $\quad$ Symptoms predictive of ACS were more similar than different for women and men with acute chest discomfort who called the OHS-PC, and ambulances were equally dispatched to women and men. (Chapter 6) 
- Age, pressing heavy chest pain, sweating, and radiation of pain were the strongest predictors for the diagnosis ACS in both sexes. The prediction model for women included also (i) severe pain $>7$ on a scale from 0-10, (ii) chest discomfort duration <12 hours, and (iii) history of diabetes, with as a result a discriminative ability (c-statistic) of 0.76 ( $95 \% \mathrm{Cl} 0.71-0.80$ ). The prediction model for men in addition included (i) history of diabetes, (ii) calling during the night, (iii) symptom recognition from a previous acute cardiac event, and (iv) shortness of breath, with as a result a discriminative ability (c-statistic) of 0.72 (95\% Cl 0.68-0.76). (Chapter 7)

\section{Triage systems should be validated on established diagnoses}

Today's decision support triage systems are developed on consensus opinion of experts, who based the triage criteria on physiological parameters, presumptive diagnoses and resource use. ${ }^{12}$ Remarkably, widely used triage systems are often not, or just partially, validated and often studies did not include the eventually established clinical diagnosis in the validation analyses. ${ }^{3}$ Only one study partially assessed the validity of the NTS for telephone triage in OHS-PC, but did not include the clinical diagnosis related to the call in the analyses. This study found that most patients with a high urgency allocation were referred to the ED (92.9\% of patients with an U1 urgency allocation and $29.3 \%$ of patients with an $U_{2}$ urgency) and patients allocated a low urgency received a self-care advice; on these results the authors concluded that the NTS seemed a 'feasible' triage system for use in OHS-PC. ${ }^{4}$ We argue that that the accuracy of triage decision support tools should always be validated against clinical diagnoses as the outcome.

To increase the accuracy of a triage decision support tool, first and foremost a proper evaluation of triage systems is required, involving assessment of validity (does the decision tool predict the 'true' urgency) and reliability (high degree of intra-observer and inter-observer variability). ${ }^{1}$ Information on the patient's clinical outcomes should be considered to allow for establishing the urgency and thus the assessment of validity. ${ }^{1}$ Defining a reference standard for 'true' urgency without knowledge on the clinical diagnosis is impossible; the best surrogate reference standard of urgency is the clinical diagnosis, because based on the diagnosis, and subsequently the average of diseaserelated morbidity and mortality, a 'true' urgency can be defined. Delay to effective, targeted, treatment is one of the most important predictors of outcomes for patients with serious medical conditions such as sepsis, pneumonia, stroke, and ACS. ${ }^{6} 7$ We validated the NTS for the outcomes ACS or other LTES, and found that the NTS tool underestimated the urgency in $27 \%$ of patients with ACS or other LTEs and this was 
$14 \%$ after triage nurses' overruling (usually upscaling) of the NTS urgency. ${ }^{8}$ This shows that the NTS urgency allocation in patients with acute chest discomfort is not safe enough, and triage nurses often need to correct for under-triaging by the tool. This poor safety performance we found in the important domain 'patients suspected of ACS' is in sharp contrast with the conclusion of the only previous NTS validation study, and subscribes the need of adequate validation of a decision support tool before it is widely implemented in clinical practice. Our study - around 10 years after the introduction of the NTS in the OHS-PC - shows that for patients suspected of ACS, safety of telephone triage should be improved. Importantly, we still do not know how well the NTS performs for the other domains than chest discomfort.

Triage decision support tools should be developed and validated in the setting for which they are intended. ${ }^{10}{ }^{11}$ However, the NTS is a modified version of the Manchester Triage Standard (MTS), which was developed for triage at the ED, including face-toface consultations and physical examination. ${ }^{34}$ One reason for using the same triage system in OHS-PC as at the ED is to create common situational awareness and facilitate communication among health care providers in 'the chain of emergency management'. ${ }^{41213}$ Although we agree with the importance of effective communication among health care providers, safe patient care should have a higher priority, which means having an accurate tool validated for the setting in which it is applied. Integrating or linking several triage systems can also overcome communication problems, while creating situational awareness. For example, in the USA, UK and Australia, pre-hospital telephone triage starts with primary triage ( 2 minutes protocolled $A B C D$-check) using the Advanced Medical Priority Dispatch System (AMPDS). ${ }^{14}$ If the patient is considered ABCD-stable, the call is transferred for secondary triage with the Emergency Communication Nurse System to assess probability diagnoses and make subsequent management plans. ${ }^{1415} 16$

Summarizing, triage decision support systems should be developed and validated against established clinical diagnoses in the setting for which they are intended, and this should be done before implementation of a decision support tool.

\section{Can we really 'reason in urgencies' during telephone triage at OHS-PC?}

While working on this research project, the question "Can we really reason in urgencies during telephone triage at OHS-PC?" recurrently came up. Urgency assessment and establishing a diagnosis are often considered as separate entities by clinicians as well as researchers. During our studies we incrementally realized that the two go handin-hand. 
Telephone triage nurses are currently trained to 'reason in urgencies' and not think about the potential underlying cause (diagnosis) of the patient's clinical condition. ${ }^{17}$ Indeed, the aim of triage is to prioritize which patients need urgent medical help and who don't, based on the clinical condition. Whereas the aim of diagnosing is to clarify the patient's clinical condition and increase certainty about the presence or absence of disease (with potential consequences for prognosis and targeted interventions). ${ }^{118}$ However, a patient's clinical condition is caused by a certain underlying disease or disorder. So, while knowing this, how can a triage nurse determine the patient's clinical condition based on 'reasoning in urgencies' only? We believe that the concept of 'reasoning in urgencies' creates problems for both triage nurses and supervising GPs at the OHS-PC for multiple reasons.

The concept of separating the urgency assessment from diagnosing seems useful in the very first minutes of the initial assessment and treatment of critically ill patients seen by the ambulance and in the ED. Then, first the ABCD-check (acronym for Airway, Breathing, Circulation and Disability) should be done, with stabilization of patients' vital functions. ${ }^{13}$ During the $A B C D$-check clinicians systematically assess the vital parameters of the patient in order to quickly find the most urgent life threatening unstable vital parameter. During this phase clinicians apply 'urgency reasoning', according to the rationale that the clinical signs of critical conditions are similar regardless of the underlying cause. ${ }^{13}$ After the $A B C D$-check in ED, the underlying diagnosis that can clarify the patient's clinical condition is further examined.

Firstly, we should realize that at the OHS-PC the number of contacts with critically ill patients is very low; in 2018, $2.5 \%$ of the OHS-PC contacts were considered in need of immediate care (urgency level $U_{1}$ ) and only a small portion of these few patients were considered to be 'ABCD-unstable'. ${ }^{19}$ The majority of all $U_{1}$ classified patients at OHS-PC were patients suspected of ACS, stroke, or having severe respiratory problems. ${ }^{20}$ In our own study among all patients with acute chest discomfort around $0.25 \%$ was considered 'ABCD-unstable' by the triage nurse ( $9.6 \%$ in those received the highest urgency level $U_{1}$ ). So, one may wonder on what evidence or arguments the decision was based that 'reasoning in urgencies' would be applicable in the OHSPC, while considering the underlying cause of the patient's condition as 'redundant'.

Secondly, we think that after the $A B C D$ check the rationale that clinical signs of critical conditions are similar regardless of the underlying cause is no longer valid. For example, the main reason for allocating a high urgency to patients with acute chest discomfort is that when an ACS is the underlying diagnosis, this inevitably carries the 
risk of life-threatening ventricular arrhythmias and severe loss of pumping function. ${ }^{21}$ ${ }^{22}$ In addition, managing patients with ACS as early as possible improves their prognosis considerably. ${ }^{23}$ We argue that in most cases in OHS-PC one has to anticipate the risk of $A B C D$-instability and to estimate this risk, we have to consider the consequences of the probability of the presence of a specific diagnoses that may underlie the patient's symptoms. Also their prognosis should be estimated on the probability of the specific diagnosis and consequently, one should not merely focus on determining the patient's clinical condition at that very moment of calling the OHS-PC.

Thirdly, the algorithms of each of the 56 NTS 'main complaints' consist of specific key questions that force the triage nurse to ask the patient for information about possible diagnoses and prognostic determinants anyway. ${ }^{1}$ E.g., the questions about type of pain and radiation of pain within the NTS' main complaint 'chest pain' are more directed at estimation of the risk of ACS, than at assessment of the patient's clinical condition. Moreover, the NTS pop-ups linked to the key questions provide background information about potential critical underlying diagnoses (Figure 1). We therefore think it is nearly impossible for a triage nurse to 'reason in urgencies' without considering underlying diagnoses, while going through these questions with their pop-ups. One could even argue that most of the NTS itself is not designed for urgency reasoning!

Fourthly, we argue that forcing triage nurses to adapt a simplified reasoning method, which acquires changes in the mind-set, and which does not fit the clinical context, will easily result in interactional problems with the decision support tool and with the supervising GPs. This is underpinned by qualitative studies which showed that triage nurses' reasoning is complex, and based on a variety of clinical reasoning strategies, including analytic reasoning and the use of intuition. ${ }^{2425}$ Also, for analytic reasoning, triage nurses start by gathering information, from which hypotheses are developed about probability diagnoses, which are then tested by asking confirmatory and nonconfirmatory questions. ${ }^{24}{ }^{26}$ Knowledge and experience are required to successfully process information into reliable hypotheses. ${ }^{27}$ Experienced triage nurses more often use their 'intuitive knowledge' and also 'tricks' in using a decision support tool, while novice triage nurses are prone to carefully follow the guidelines. ${ }^{28} 29$

Below, we further discuss this issue along with the history of the ABCD-approach, triage nurses' reflections on reasoning in telephone triage, and finally, we will return to the case description of Mrs. Brown from the introduction chapter of this thesis. 

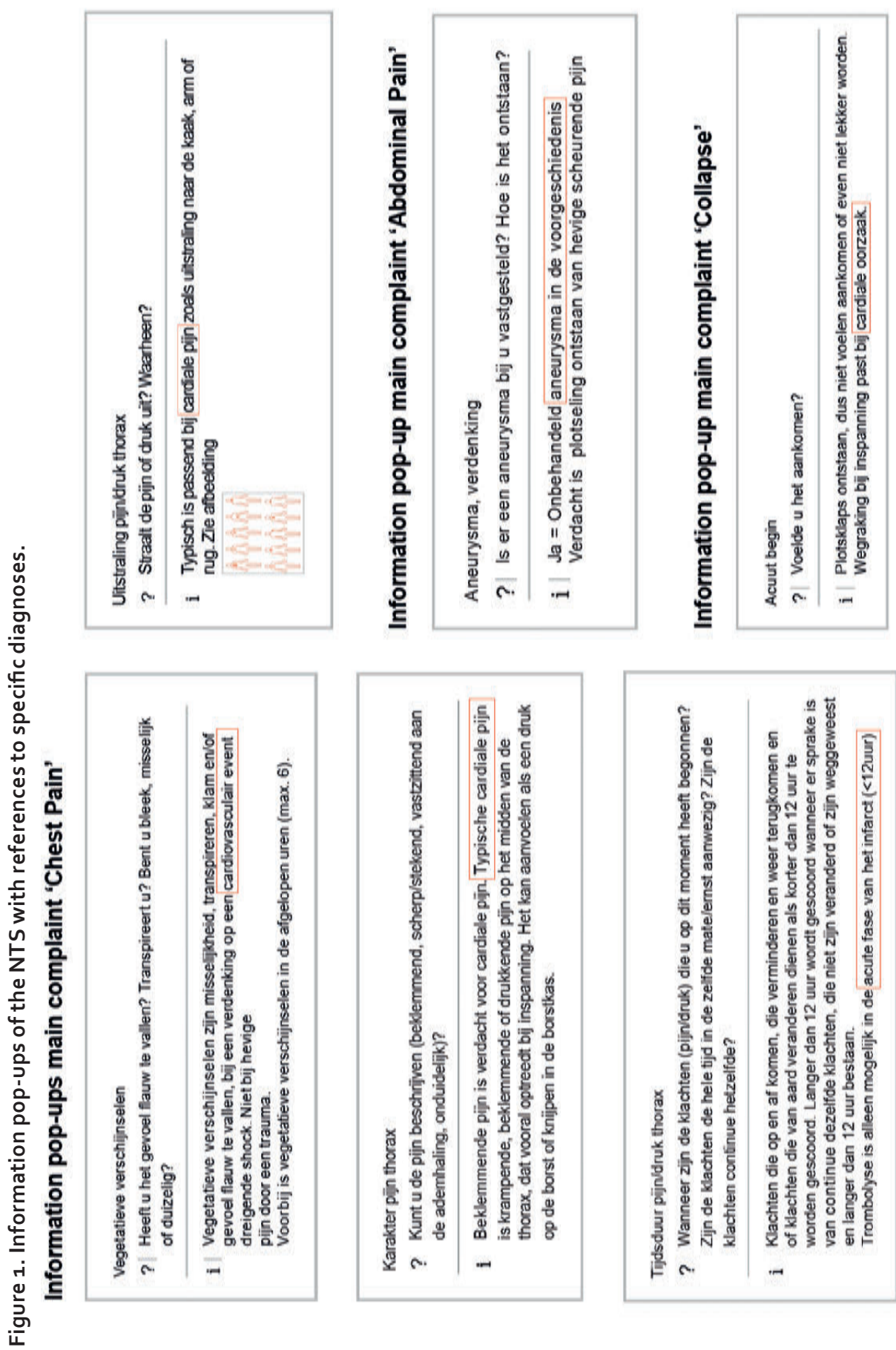


\section{History of the $A B C D$-approach and 'reasoning in urgencies'}

The concept of the ABCD-approach was developed in the 2oth century, and the first Advanced Trauma Life Support (ATLS ${ }^{\circledR}$ ) courses of teaching were held in $1978 .{ }^{13}$ The $A B C D$-approach is considered to be helpful for clinicians to systematically and completely assess the severely ill patient's clinical condition in a short amount of time. ${ }_{13}$ The aim of the ABCD-approach is to provide immediate life-saving treatment, to break down complex situations into more manageable parts, to establish common situational awareness among all treatment providers, and to buy time to establish a final diagnosis, prognosis and subsequent treatment. ${ }^{13}$ It was developed for the very first management of severely ill patients with life-threatening underlying diseases at the ED and intensive care units (ICU). ${ }^{30}{ }^{31}$ The ABCD approach can also be used in a first-aid pre-hospital setting for ambulance personnel and GPs when stabilizing the patient at home, and make the patient ready for transportation to the hospital. ${ }^{32}$ It was not developed for telephone triage, where inherently the assessment cannot be done completely due to lack of measurement of vital parameters. By applying the ABCDapproach, you can 'buy time' to establish a final diagnosis according to some authors, but how can this be done reliably with only telephone triage in the OHS-PC setting? ${ }^{1333}$

Thus, urgency reasoning, that underlies the $A B C D$-approach, with a focus on the very first minutes, is developed for situations when the patient is (i) seen and (ii) can be managed and (iii) is in a high casualty setting. This is completely opposite from telephone triage at in the OHS-PC setting with (i) no physical contact, (ii) no opportunity for direct management of the patient and (iii) in a domain of patients with predominantly non-urgent conditions, or in case of urgent conditions, with patients mostly (still) ABCD-stable at the time of calling.

\section{How do triage nurses reflect on 'reasoning in urgencies'?}

Telephone triage nurses are trained to 'reason in urgencies', for the underlying assumption that it would increase safety of triage decision. ${ }^{17} 34$ However, there is no evidence to support this hypothesis. Believers in this paradigm proclaim that 'reasoning in diagnoses' would increase the risk of making mistakes, because asking questions intended to make a diagnose would distract the telephone triage nurses from an adequate judgement about the patients' clinical condition. 3534

In our interview study among 24 triage nurses, we asked them to reflect on their own reasoning for urgency assessment when using the NTS. ${ }^{29}$ With grounded theory analysis we showed that triage nurses use clinical reasoning techniques for urgency assessment, which is the same sort of clinical reasoning that is used to come to a 
diagnosis. ${ }^{28} 26$ Triage nurses use their knowledge about diseases, they test hypothesis of probability diagnoses, they use pattern recognition and are aware of potential cognitive biases which they try to prevent with 'cognitive debiasing strategies'. Furthermore, intuition and 'paralanguage' interpretation (use of vocal elements in conversation) were important in their reasoning, and these elements were used to make a 'mental image' of the patient. Triage nurses expressed that they felt often confused about the separation of 'urgency reasoning from diagnostic reasoning', and the fact that they had to comply with a concept that often did not fit in their working method.

"We are not allowed to reason in diagnoses, but obviously I do. I take into consideration that this woman might have a myocardial infarction, given her symptom presentation, and I would like to gather more background information that would help me decide about whether or not to accept the recommended NTS urgency $U_{1}$. "

"They say we are not allowed to reason in diagnoses, but we do not get proper guidance how exactly we should reason in urgencies when applying the key questions of the NTS... they (OHS-PC management and the trainers of triage education programs) say we just should comply with the NTS."

The triage nurses indicated they had to deal with 'interactional workability dilemmas', which means difficulties in applying a rigid computer system in the wider context of the patients' narrative. They compared their own urgency considerations with the automatically generated urgency of the NTS. Based on the analysis we found that 'congruence' is key for triage nurses while working with the NTS, which is defined as whether the NTS supports their urgency decision making. If 'congruence' was absent, triage nurses applied four working strategies; (i) tinkering to make the NTS urgency align with their preferred urgency, (ii) overruling, (iii) complying with (but with 'resistance') to the NTS urgency recommendation, or (iv) transferring the responsibility about the urgency allocation to the GP. It is somewhat disturbing to realize that the training programs of triage nurses are completely based on the assumption of 'urgency reasoning'.

Even more disturbing is that Dutch OHS-PC managers use the 'core-set' to audit triage nurses for quality of their telephone triage. ${ }^{36}$ The core-set consists of 29 'quality' indicators of which ten are medical items (the other items concern communication, GP supervision and documentation). The medical items involve amongst others whether 
the correct 'main complaint' was chosen, and whether the urgency estimation was 'appropriate' according the 'expert opinion' of the OHS-PC manager. ${ }^{37}$ These items are assessed by just re-listening to the calls (without knowing the eventual diagnosis), and therefore essentially, this 'quality check' is only a check whether the triage nurse complies with the NTS. A Swedish qualitative study showed that telephone triage nurses often complied with the triage system because they were afraid to take the wrong decision should their performance be part of a formal 'quality' assessment. ${ }^{38}$ We argue that it is counter-effective when managers solely focus their audits of triage nurses on complying with the NTS. The triage nurses in our study pointed out they were eager to receive information about the diagnosis of the patients they spoke to on the phone, to know whether they made the correct urgency decision, and we suggest this should be incorporated in future quality assessments. A study about the influence of feedback confirms this, showing that the assessments of medical doctors and students improved when they received feedback about the diagnosis in various cases. 39

In summary, it is clear that triage nurses, besides the $A B C D$-check, generally do not 'reason in urgencies', and that this concept does not fit the OHS-PC setting. Furthermore, feedback to triage nurses should also include the clinical outcome of the patient.

\section{Return to the case of Mrs. Brown}

The triage nurse allocated an urgency $\mathrm{U}_{2}$ and scheduled a consultation at the OHS-PC for Mrs. Brown. Unfortunately, however, Mrs. Brown turned out to have an ACS.

We argue that 'diagnostic reasoning' could have helped the triage nurse to allocate a higher urgency, or at least would have recommended a home visit. We do not know what the triage nurse filled out in the NTS, and neither do we know whether she downscaled the NTS urgency, which is generally only done after consultation of the supervising GP. ${ }^{40}$ The triage nurse considered Mrs. Brown's clinical condition as 'ABCD-stable'. Thus, following the concept of urgency reasoning, indeed there was no life-threatening situation. But what about minutes to hours later? A life-threatening ventricular arrhythmia may have occurred only minutes after hanging up the telephone. When strictly applying the concept of urgency reasoning - still considered a key element of telephone triage - Mrs. Brown, as more patients with an ACS, would receive a low urgency because she passed the $A B C D$-check as 'stable'. Fortunately, however, Mrs. Brown would still have received a high urgency with ambulance dispatch if the triage nurse had filled out the key questions in the NTS 'main complaint chest 
pain' as follows; duration of chest pain less than 12 hours, in combination with one of the following items (i) severity of pain $>7 / 10$, or (ii) pressing tightening chest pain, or (iii) radiation to arm, neck or shoulders, or (iv) sweating. Strikingly, these four items have nothing to do with urgency reasoning, but merely with diagnostic reasoning (is an ACS likely?). Every triage nurse should know that when the suspicion of ACS is high, the patient must receive the highest urgency with ambulance dispatch, given the risk of life-threatening ventricular arrhythmias, and to enable starting treatment as early as possible. ${ }^{2123}$

We conclude that not only in the case of Mrs. Brown, but in anybody with symptoms of chest discomfort who is ABCD-stable at the time of calling the OHS-PC, urgency reasoning is at the very least incomplete and usually inadequate.

\section{Conclusions and recommendations based on the thesis}

- The NTS decision support tool performs rather poor in both terms of safety and efficiency, when it comes to allocating urgencies evaluated on the outcomes ACS or other LTEs.

- $\quad$ Triage nurses overruling of the NTS-system improves safety in patients presenting with chest discomfort at the OHS-PC, but not efficiency.

- Understanding that triage nurses' reasoning and working strategies with the NTS are vital for triage outcomes and knowing what influences their choices may help to develop improved education.

- Auditing of triage calls should include feedback on the patient's eventual clinical diagnosis.

- When patients with chest discomfort call at night, the risk of an ACS is increased and immediate dispatch of an ambulance should be considered, notably in men.

- $\quad$ There are more similarities than differences in symptoms predictive for ACS in women and men.

- $\quad$ Our sex-specific prediction rules for patients with chest discomfort should be implemented in the OHS-PC, once they have been externally validated.

- $\quad$ Reasoning in urgencies without considering the diagnosis is not adequate in telephone triage in OHS-PC. Moreover, not only the actual, but much more the anticipated risk of ABCD-instability and prognosis of probability diagnoses should be considered. 


\section{REFERENCES}

1. Moll HA. Challenges in the validation of triage systems at emergency departments. Journal of Clinical Epidemiology 2010;63(4):384-8. doi: 10.1016/j.jclinepi.2009.07.009

2. Zimmermann PG. The case for a universal, valid, reliable 5 -tier triage acuity scale for US emergency departments. Journal of Emergency Nursing 2001;27(3):246-54. doi: 10.1067/ men.2001.115284

3. Kuriyama A, Urushidani S, Nakayama T. Five-level emergency triage systems: variation in assessment of validity. Emergency Medicine Journal 2017;34(11):703-10. doi: 10.1136/ emermed-2016-206295

4. van lerland $Y$, van Veen $M$, Huibers $L$, et al. Validity of telephone and physical triage in emergency care: the Netherlands Triage System. Family Practice 2011;28(3):334-41. doi: 10.1093/fampra/cmq097

5. Nishi FA, Polak C, Cruz D. Sensitivity and specificity of the Manchester Triage System in risk prioritization of patients with acute myocardial infarction who present with chest pain. European Journal of Cardiovascular Nursing 2018;17(7):660-66. doi: 10.1177/1474515118777402

6. Graff I, Goldschmidt B, Glien P, et al. Validity of the Manchester Triage System in patients with sepsis presenting at the ED: a first assessment. Emergency Medicine Journal 2017;34(4):212-18. doi: 10.1136/emermed-2015-205309

7. Steiner D, Renetseder F, Kutz A, et al. Performance of the Manchester Triage System in Adult Medical Emergency Patients: A Prospective Cohort Study. Journa of Emergency Medicine 2016;50(4):678-89. doi: 10.1016/j.jemermed.2015.09.008

8. Wouters $\mathrm{LT}$, Rutten $\mathrm{FH}$, Erkelens $\mathrm{DC}$, et al. Accuracy of telephone triage in primary care patients with chest discomfort: a cross-sectional study. Open Heart 2020;September

9. Leeflang MM, Rutjes AW, Reitsma JB, et al. Variation of a test's sensitivity and specificity with disease prevalence. Canadian Medical Association journal 2013;185(11):E537-44. doi: $10.1503 / \mathrm{cmaj} .121286$

10. Bossuyt PM, Reitsma JB, Bruns DE, et al. STARD 2015: An Updated List of Essential Items for Reporting Diagnostic Accuracy Studies. Radiology 2015;277(3):826-32. doi: 10.1148/radiol.2015151516

11. Moons KG, Altman DG, Reitsma JB, et al. Transparent Reporting of a multivariable prediction model for Individual Prognosis or Diagnosis (TRIPOD): explanation and elaboration. Annals of Internal Medicine 2015;162(1):W1-73. doi: 10.7326/M14-0698

12. Huibers $L$, Giesen $P$, Wensing $M$, et al. Out-of-hours care in western countries: assessment of different organizational models. BMC Health Services Research 2009;9:105. doi: 10.1186/1472-6963-9-105

13. Thim T, Krarup NH, Grove EL, et al. Initial assessment and treatment with the Airway, Breathing, Circulation, Disability, Exposure (ABCDE) approach. International Journal of General Medicine 2012;5:117-21. doi: 10.2147/IJGM.S28478

14. Deakin CD, Sherwood DM, Smith A, et al. Does telephone triage of emergency (999) calls using Advanced Medical Priority Dispatch (AMPDS) with Department of Health $(\mathrm{DH})$ call prioritisation effectively identify patients with an acute coronary syndrome? An audit of 42,657 emergency calls to Hampshire Ambulance Service NHS Trust. Emergency Medicine Journal 2006;23(3):232-5. doi: 10.1136/emj. 2004.022962 
15. Flynn J, Archer F, Morgans A. Sensitivity and specificity of the medical priority dispatch system in detecting cardiac arrest emergency calls in Melbourne. Prehospital Disaster Medicine 2006;21(2):72-6. doi: 10.1017/s1049023×00003381

16. Eastwood K, Morgans A, Smith K, et al. Secondary triage in prehospital emergency ambulance services: a systematic review. Emergency Medicine Journal 2015;32(6):48692. doi: 10.1136/emermed-2013-203120

17. Dijk EJV. Denken in termen van urgentie bij triage. Medisch Contact 2010

18. Knottnerus JA, van Weel C, Muris JW. Evaluation of diagnostic procedures. British Medical Journal 2002;324(7335):477-80. doi: 10.1136/bmj.324.7335-477

19. Jansen T, Ramerman L, Verheij R. Cijfers huisartsenposten - aanmelding - urgentie. Nivel zorgregistraties eerste lijn 2020

20. Plat FM, Peters YAS, Loots FJ, et al. Ambulance dispatch versus general practitioner home visit for highly urgent out-of-hours primary care. Family Practice 2017(Dec 20) doi: 10.1093/fampra/cmx121

21. Kalarus Z, Svendsen JH, Capodanno D, et al. Cardiac arrhythmias in the emergency settings of acute coronary syndrome and revascularization: an European Heart Rhythm Association (EHRA) consensus document, endorsed by the European Association of Percutaneous Cardiovascular Interventions (EAPCI), and European Acute Cardiovascular Care Association (ACCA). Europace 2019;21(10):1603-04. doi: 10.1093/europace/euz163

22. Driscoll $\mathrm{A}$, Barnes $\mathrm{EH}$, Blankenberg $\mathrm{S}$, et al. Predictors of incident heart failure in patients after an acute coronary syndrome: The LIPID heart failure risk-prediction model. International Journal of Cardiology 2017;248:361-68. doi: 10.1016/j.ijcard.2017.06.098

23. Roffi M, Patrono C, Collet JP, et al. 2015 ESC Guidelines for the management of acute coronary syndromes in patients presenting without persistent ST-segment elevation: Task Force for the Management of Acute Coronary Syndromes in Patients Presenting without Persistent ST-Segment Elevation of the European Society of Cardiology (ESC). European Heart Journal 2016;37(3):267-315. doi: 10.1093/eurheartj/ehv320

24. Noon AJ. The cognitive processes underpinning clinical decision in triage assessment: a theoretical conundrum? Internal Emergency Nursing 2014;22(1):40-6. doi: 10.1016/j. ienj. 2013.01.003

25. Johannessen LEF. How triage nurses use discretion: a literature review. Professions and Professionalism 2016;6 (1):1446. doi: 10.7577

26. Leprohon J, Patel VL. Decision-making strategies for telephone triage in emergency medical services. Medical Decision Making 1995;15(3):240-53. doi: 10.1177/0272989X9501500307

27. Benner P. Using the Dreyfus model of skill acquisition to describe and interpret skill acquisition and clinical judgement in nursing practice and education. Bulletin of Science, Technology \& Society 2004;24:188-99.

28. Patel VL, Gutnik LA, Karlin DR, et al. Calibrating urgency: triage decision-making in a pediatric emergency department. Advances in Health Science Education and Theory Practice 2008;13(4):503-20. doi: 10.1007/s10459-007-9062-6

29. Wouters LT, Zwart DL, Erkelens DC, et al. Tinkering and overruling the computer decision support system: Working strategies of telephone triage nurses who assess the urgency of callers suspected of having an acute cardiac event. Journal of Clinical Nursing 2019 doi: 10.1111/jocn.15168

30. Thim $\mathrm{T}$, Krarup NH, Grove EL, et al. [ABCDE--a systematic approach to critically ill patients]. Ugeskr Laeger 2010;172(47):3264-6. 
31. Jayaraman $S$, Sethi $D$, Chinnock $P$, et al. Advanced trauma life support training for hospital staff. The Cochrane database of systematic reviews 2014(8):CDo04173. doi: 10.1002/14651858.CDo04173.pub4

32. Jayaraman $S$, Sethi $D$, Wong R. Advanced training in trauma life support for ambulance crews. The Cochrane database of systematic reviews 2014(8):CDo03109. doi: 10.1002/14651858.CDo03109.pub3

33. Nishi FA, de Motta Maia FO, de Lopes Monteiro da Cruz DA. Assessing sensitivity and specificity of the Manchester Triage System in the evaluation of acute coronary syndrome in adult patients in emergency care: a systematic review protocol. $J B I$ Database System Reviews and Implementation Reports 2015;13(11):64-73. doi: 10.11124/ jbisrir-2015-2213

34. Oomkens $\mathrm{S}$, Kar van de C. Leren van de top zes oorzaken van calamiteiten. INEEN ORGANISES PRIMARY CARE 2020

35. Dijk EJv. Telefonische triage: laat diagnostische denktrant los. Huisarts \& Wetenschap 2013; Oktober

36. Smits M, Keizer E, Ram P, et al. Development and testing of the KERNset: an instrument to assess the quality of telephone triage in out-of-hours primary care services. $B M C$ Health Services Research 2017;17(1):798. doi: 10.1186/s12913-017-2686-1

37. Handleiding KERNset - voor monitoren kwaliteit telefonische triage op huisartsenposten. INEEN organises primary care 2017

38. Wahlberg AC, Bjorkman A. Expert in nursing care but sometimes disrespectedTelenurses' reflections on their work environment and nursing care. Journal of Clinical Nursing 2018;27(21-22):4203-11. doi: 10.1111/jocn.14622

39. Nederhand T, Splinter, Rikers. The effect of performance standards and medical experience on diagnostic calibration accuracy. Health Professions Education 2018;4:30007. doi: https://doi.org/10.1016/j.hpe.2017.12.008

40. Keizer E, Maassen I, Smits M, et al. Reducing the use of out-of-hours primary care services: A survey among Dutch general practitioners. The European Journal of General Practice 2016;22(3):189-95. doi: 10.1080/13814788.2016.1178718 
(1)

B

m

Oo

c

(i)

(1)

c)

(c) 0

- (1) $\mathrm{O}_{0}$

())

c

(c)

(ิ)

Cos

0

10

60

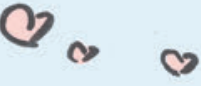

(c) 0 क हु ०

O 00

0

O 


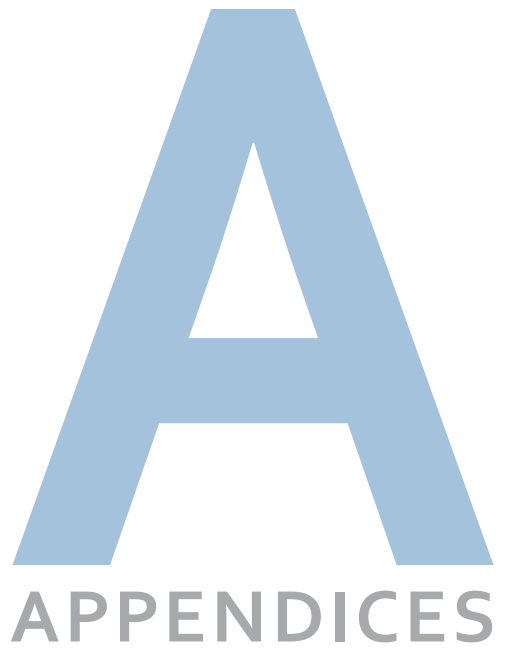

Summary

Samenvatting

List of publications

Dankwoord

About the author 


\section{SUMMARY}

\section{Introduction}

The aim of telephone triage in out-of-hours services for primary care (OHS-PC) is to prioritize callers based on symptom severity. For telephone triage of patients with chest discomfort diagnostic prediction is in play, which involves assessing the risk of acute coronary syndrome (ACS).

ACS is a life-threatening condition for which early life-saving therapeutic interventions are vital to improve the patient's outcome and prognosis. ${ }^{1}$ In the Netherlands, $80 \%$ of patients with chest discomfort first calls their general practitioner or OHS-PC, and chest discomfort is included in the top five reasons for telephone contact in the OHS-PC setting. ${ }^{23}$ The prevalence of ACS among these patients is however around 10\%, while the large majority has non-life-threatening conditions such as musculoskeletal, gastrointestinal or psychological disorders. ${ }^{45}$ Telephone triage of patients with chest discomfort at OHS-PC is notoriously challenging, because it is difficult to differentiate ACS from other causes of chest discomfort based on symptoms only. ${ }^{6}$

In 2011, an expert-based digital decision support system called the 'Netherlands Triage Standard' (NTS) was introduced in OHS-PC with the aim to ensure safe and efficient care. ${ }^{7}$ The NTS is constructed with lists of hierarchically ordered questions related to 56 'main complaints', and the answers filled out in the system automatically generate six urgency levels linked to a certain time frame within which the patient should be seen by a physician or ambulance personnel (from immediate ambulance (Uo) to telephone advice $\left.\left(U_{5}\right)\right) .{ }^{7}$ The automatically generated NTS urgency level can be scaled up or down ('overruled') by the triage nurse, which is usually done after consultation of the supervising GP, who has the final responsibility for the urgency allocation. ${ }^{8}$

There are indications that current efficiency, but also safety of telephone triage of patients with chest discomfort can be improved. Efficiency, because in $68.7 \%$ of patients who call the OHS-PC for chest discomfort a high urgency is allocated (patient seen within one hour, by ambulance or GP), and as already mentioned, around 10\% of them has an ACS. ${ }^{5}$ Safety, because on the other hand missing an ACS is the most common reason for malpractice claims in the OHS-PC setting. ${ }^{9}$ Remarkably, the NTS was never validated against clinical outcomes and therefore its diagnostic accuracy is unknown. Furthermore, it is unknown how triage nurse actually use the NTS and how they clinically reason during triage assessment of patients with chest discomfort. Therefore insights were needed about the performance of telephone triage, to help 
discover leads for improvement of safety and efficiency of triage of patients with chest discomfort.

Clinical decision rules for diagnosing ACS in the primary care setting are lacking, but very much needed. Interestingly, many studies report that women and men differ in symptoms of ACS, but never sex-specific prediction rules have been developed. Importantly, however, most studies compared symptoms of men and women with confirmed ACS ${ }^{10}$, and did not evaluate sex-specific symptom presentation of patients with chest discomfort; comparing patients with ACS versus those without, for men and women separately. Such studies are needed to inform general practitioners and triage nurses about whether and how women with ACS differ from women without ACS, and this similarly for men.

This thesis focused on:

(i) Gaining insights into how the telephone triage of patients with chest discomfort in OHS-PC is currently done.

(ii) Discovering leads for improvement of triage, both in terms of patient safety and efficiency.

(iii) Assessing whether triage of patients with chest discomfort should be different in women than in men.

\section{Insights into how telephone triage of patients with chest discomfort is currently done}

In Chapter 2, we described the rationale, aims and design of the Safety First study. We wanted to evaluate telephone triage at the OHS-PC in patients suspected of (i) acute coronary syndrome (ACS), and (ii) TIA or minor/major ischaemic stroke. We targeted on these two aforementioned domains because adequate triage is crucial given the potential benefit of early treatment ('time is muscle' and 'time is brain'). We designed a mixed-method research project using both quantitative and qualitative studies, with the aim to describe, understand and improve the triage process of patients suspected for either of these two acute cardiovascular diseases at OHS-PC.

For the quantitative studies we performed a cross-sectional study with data of more than 5,000 telephone triage recordings from the period 2014-2017, coming from nine OHS-PC locations in the Utrecht area. We re-listened the recordings to collect information of (i) call characteristics, (ii) patient characteristics and (iii) symptom presentation. The researchers who carried out the data collection were blinded to the final diagnosis of the patients. Final diagnoses were requested from the patient's 
own GP, and was based on information from specialists' discharge letters (i.e. the cardiologist or neurologist) or OHS-PC discharge letters. With this data we could evaluate the diagnostic accuracy of telephone triage (chapter 3), perform audio stimulated recall interviews (chapter 4 ), assess whether the time of calling was helpful (chapter 5), evaluate differences in symptom presentation between men and women with chest discomfort (chapter 6), and finally, develop new symptom-based diagnostic prediction rules for ACS, for men and women separately (chapter 7).

In Chapter 3, we assessed the accuracy of urgency allocation during telephone triage in 2,023 patients with chest discomfort who called the OHS-PC. We compared the patient's urgency allocation, categorized in high urgency level ( $U_{1}$ and $U_{2}$ ) and a low urgency level $\left(U_{3}, U_{4}\right.$ and $\left.U_{5}\right)$, to the outcomes acute ACS or other life threatening events (LTES), separately for the NTS tool and after overruling by the triage nurse. The NTS urgency was of poor safety; it underestimated the urgency in $27 \%$ of patients who showed to have an ACS or other LTEs (sensitivity of 0.73 ( $95 \% \mathrm{Cl} 0.68-0.78$ )). In $13.2 \%$ of the 2,023 calls, the triage nurse overruled the NTS urgency, mostly upscaling (in $11.0 \%)$. The final urgency, that is including the overruled urgencies, was safer than the urgency generated by the NTS, but still in $14 \%$ of patients with ACS or other LTEs the urgency was underestimated (sensitivity 0.86 ( $95 \% \mathrm{Cl} 0.81-0.90)$ ). For both situations, efficiency was low; a too high urgency was allocated by the NTS in $57 \%$ (specificity 0.43 ( $95 \% \mathrm{Cl} 0.40-0.45$ ) and final urgency in $67 \%$ (specificity 0.34 ( $95 \% \mathrm{Cl} 0.32-0.37$ ) of patients. These patients had non-urgent conditions, e.g. gastro esophageal reflux or musculoskeletal disorders.

In Chapter 4, we describe the results of an audio stimulated recall interview study among 24 triage nurses, who were asked to reflect on their reasoning while using the NTS for triage assessment for patients suspected of ACS. Recent audio-tapes (<14 days old) of each of the nurse's triage conversations were used to stimulate the reflection. It became clear that triage nurses create a 'mental image' of the patient; "How does the patient look like at the other end of the phone?" They use clinical reasoning strategies and interpret paralanguage (the vocal elements of communication such as tone of voice and breathing speed) to create this mental image, which helps them in coping for the lack of visual information. They compared their own urgency considerations with the automatically generated urgency of the NTS. Using the grounded theory analysis we found that 'congruence' is key for triage nurses while working with the NTS, which is defined as whether the NTS supports their urgency decision making. If 'congruence' was absent, triage nurses applied four working strategies; i) tinkering, ii) overruling, iii) complying with the NTS urgency recommendation, or iv) transferring the responsibility 
of the urgency allocation to the consulted supervising general practitioner (GP). It became evident that triage nurses have to deal with interactional dilemmas while working with the NTS. Understanding triage nurses' working strategies and what affects their choices may help to improve education material, and NTS developers may benefit by involving the triage nurses' input for adjustment in the triage system in such a way that it improves interactional workability.

\section{Leads for improvement of telephone triage of patients with chest discomfort}

In Chapter 5, we analyzed whether considering the time of calling could be helpful for improving telephone triage of patients with chest discomfort. Previous studies in the emergency department showed circadian variability in the occurrence of ACS, with an early morning peak incidence. ${ }^{11-13}$ We found that the risk of ACS among 1,655 patients with chest discomfort is almost twice as high for patients calling at night (between 0.00-9.00am) compared to those who called outside those hours. This was clearly shown in men (risk ratio 2.33 ( $95 \% \mathrm{Cl}$ 1.68-3.22)), but not in women (risk ratio 1.29 ( $95 \% \mathrm{Cl} 0.83-1.99)$ ). The age and gender adjusted risk ratio for ACS of all patients contacting the OHS-PC at night was 1.82 (95\% Cl 1.07-3.10). Therefore, at night, dispatching ambulances more 'straightaway' could be considered for patients with chest discomfort, notably in men.

\section{Should triage be different in men and women who present with chest discomfort?}

In Chapter 6, we compared patient and call characteristics of triage call recordings of women with ACS $(n=85,8.6 \%)$ versus 908 women without ACS. We did similarly in men; with ACS ( $n=120,15.0 \%)$ versus 682 men without ACS. Symptoms predictive of ACS were more similar than different among women and men with chest discomfort who called the OHS-PC. In both sexes, retrosternal chest pain was discriminative for ACS (women with ACS vs. without $62.3 \%$ vs. $40.3 \%, p=0.002$, men with ACS vs. without $52.5 \%$ vs. $39.7 \%, p=0.032$ ), as was pressing/tightening pain (women $78.6 \%$ vs. $61.5 \%, p=0.011$, men $82.1 \%$ vs. $57.4 \%, p=<0.001$ ) and radiation to arm (women $75.6 \%$ vs. $45.9 \%$, $p<0.001$, men $56.0 \%$ vs. $34.8 \%$, p<0.001). In women, severe pain $(65.4 \%$ vs. $38.1 \%, p=0.006)$, a pale face (50.0\% vs. $22.9 \%, p=0.007)$ and radiation to jaw (50.0\% vs. $29.8 \%, p=0.017$ ) were also discriminative for $A C S$, while in men this was sweating ( $52.4 \%$ vs. $38.1 \%, p=0.015)$, and against ACS stabbing pain ( $8.4 \%$ vs. $26.5 \%, p<0.001)$. Ambulances were dispatched equally in women (72.9\%) and men with ACS (70.0\%). 
In Chapter 7, we developed the first sex-specific prediction models for diagnosing ACS. Our prediction rule for women included seven predictors (age, sweating, radiation, pressing heavy chest pain, severe pain, chest pain duration $<12$ hours, and a history of diabetes mellitus) and had an internally validated c-statistic of 0.76 ( $95 \% \mathrm{Cl} 0.71$ o.80). Our prediction rule for men included eight predictors (age, sweating, radiation, pressing heavy chest pain, history of diabetes mellitus, calling at night, recognizing symptoms from previous cardiac event, and shortness of breath) and had an internally validated c-statistic of $0.72(95 \% \mathrm{Cl} 0.68-0.76)$. After external validation these models are applicable for telephone triage of patients with chest discomfort calling OHS-PC.

\section{Recommendations for future research and clinical practice}

In Chapter 8, we summarize the main finding of this thesis and discuss the relevance of considering the patient's eventual diagnosis in triage system research and telephone triage in clinical practice. Finally, we reflect on the clinical case presented in the introduction of the thesis.

We recommend that triage decision support systems should always be validated against clinical diagnoses in the setting for which they are intended, and this should be done before implementation of a decision support tool. Furthermore, involvement of the users (triage nurses) in the development and implementation of such a tool is important to improve congruence, and decrease the risk of interactional workability problems. Triage nurses' input can also help to improve education, and we recommend to include feedback on the patient's eventual clinical diagnosis when auditing triage calls. Furthermore, we recommend to include age in the hierarchically ordered questions behind the NTS main complaint 'chest discomfort', and when patients call at night an immediate dispatch of an ambulance should be considered, notably in men. In addition, we expect that our sex-specific prediction models can also be used in emergency medical service setting (EMS, ambulance dispatch center, ' 112 ') because the prevalence of ACS among those with chest discomfort is similar to the OHS-PC setting. ${ }^{14}$

We clearly showed that the overlap in symptom presentation between women and men with chest discomfort is greater than the difference. This is in contrast with international guidelines and public awareness campaigns which focus on the differences, and therefore risking unbalanced attention. This may lead to the unintentional believe that women think that they need to have atypical symptoms for an ACS, neglecting typical symptoms. It is time for a change. 


\section{References}

1. Ibanez B, James S, Agewall S, et al. 2017 ESC Guidelines for the management of acute myocardial infarction in patients presenting with ST-segment elevation. Revista Espanola Cardiologia 2017;70(12):1082. doi: 10.1016/j.rec.2017.11.010

2. Jansen T, Ramerman L, Verheij R. Cijfers huisartsenposten - aanmelding - urgentie. Nivel zorgregistraties eerste lijn 2020

3. Mol KA, Smoczynska A, Rahel BM, et al. Non-cardiac chest pain: prognosis and secondary healthcare utilisation. Open Heart 2018;5(2):eooo859. doi: 10.1136/ openhrt-2018-000859

4. Hoorweg BB, Willemsen RT, Cleef LE, et al. Frequency of chest pain in primary care, diagnostic tests performed and final diagnoses. Heart 2017;103(21):1727-32. doi: 10.1136/heartjnl-2016-310905

5. Plat FM, Peters YAS, Loots FJ, et al. Ambulance dispatch versus general practitioner home visit for highly urgent out-of-hours primary care. Family Practice 2017(Dec 20) doi: 10.1093/fampra/cm×121

6. Bruyninckx R, Aertgeerts $B$, Bruyninckx $P$, et al. Signs and symptoms in diagnosing acute myocardial infarction and acute coronary syndrome: a diagnostic meta-analysis. The British Journal of General Practice 2008;58(547):105-11. doi: 10.3399/bjgpo8X277014

7. van lerland $Y$, van Veen $M$, Huibers $L$, et al. Validity of telephone and physical triage in emergency care: the Netherlands Triage System. Family Practice 2011;28(3):334-41. doi: 10.1093/fampra/cmqo97

8. Keizer E, Maassen I, Smits M, et al. Reducing the use of out-of-hours primary care services: A survey among Dutch general practitioners. The European Journal of General Practice 2016;22(3):189-95. doi: 10.1080/13814788.2016.1178718

9. Rutten $\mathrm{MH}$, Kant J, Giesen P. What can we learn from calamities at out-of-hours services in primary care? [Wat kunnen we leren van calamiteiten op de huisartsenpost?]. Huisarts \& Wetenschap 2018;6(61) doi: 10.1007/s12445-018-0155-7

10. van Oosterhout REM, de Boer AR, Maas A, et al. Sex Differences in Symptom Presentation in Acute Coronary Syndromes: A Systematic Review and Meta-analysis. Journal of American Medical Association 2020;9(9):e014733. doi: 10.1161/JAHA.119.014733

11. Ekelund $U$, Akbarzadeh $M$, Khoshnood $A$, et al. Likelihood of acute coronary syndrome in emergency department chest pain patients varies with time of presentation. BMC Research Notes 2012;5:420. doi: 10.1186/1756-0500-5-420

12. Bhalla A, Sachdev A, Lehl SS, et al. Ageing and circadian variation in cardiovascular events. Singapore Medical Journal 2006;47(4):305-8.

13. Leiza JR, de Llano JM, Messa JB, et al. New insights into the circadian rhythm of acute myocardial infarction in subgroups. Chronobiology International 2007;24(1):129-41. doi: 10.1080/07420520601140027

14. Rawshani A, Larsson A, Gelang C, et al. Characteristics and outcome among patients who dial for the EMS due to chest pain. International Journal of Cardiology 2014;176(3):85965. doi: 10.1016/j.ijcard.2014.08.004 


\section{SAMENVATTING}

\section{Introductie}

Met telefonische triage op de huisartsenpost maken triagisten een inschatting van de ernst van de klachten van de patiënt, met als doel te bepalen wie het snelst medische hulp nodig heeft. Voor patiënten met acute borstkasklachten is deze inschatting voornamelijk gebaseerd op hoe groot de kans is dat zij een acuut coronair syndroom (ACS) hebben. ACS, ook wel hartinfarct genoemd, is een acute levensbedreigende aandoening van het hart waarbij zuurstoftekort van de hartspier optreedt door een afsluiting of vernauwing in de kransslagaderen. Snelle behandeling door een cardioloog om de bloeddoorstroming te herstellen verbetert de overlevingskansen van de patiënt en beperkt eventuele restschade. ${ }^{1}$ In Nederland belt $80 \%$ van de patiënten met acute borstkasklachten als eerste de eigen huisarts of huisartsenpost, en staat borstkasklachten in de top vijf van redenen voor telefonisch contact met de huisartsenpost. ${ }^{23}$ Ongeveer $10 \%$ van deze patiënten heeft een ACS en de meerderheid van patiënten heeft een niet-levensbedreigende aandoening, zoals spierklachten, maagklachten of psychische klachten. ${ }^{45}$ Telefonische triage van deze patiënten is een enorme vitdaging omdat het erg moeilijk is op basis van symptomen onderscheid te maken heeft wie een ACS heeft en wie niet. ${ }^{6}$

In 2011 werd de 'Nederlandse Triage Standaard' (NTS), een door experts ontwikkelde digitale beslisondersteuning, geïntroduceerd op huisartsenposten met als doel de veiligheid en efficiëntie van triage te bevorderen. ${ }^{7}$ De NTS is opgebouwd uit 56 'ingangsklachten' met gekoppelde lijstjes van hiërarchisch geordende vragen (triagecriteria), waarbij de antwoorden automatisch leiden tot een urgentiebepaling. Er bestaan zes verschillende urgentie levels die een tijdsindicatie aangeven hoe snel de patiënt gezien moet worden door een huisarts of ambulance, van Uo (reanimatie setting, directe ambulance sturen) tot $\mathrm{U}_{5}$ (telefonisch advies door de triagist). ${ }^{7} \mathrm{De}$ triagist kan de NTS urgentie op- of afschalen ('overrulen') en dat gaat meestal in samenspraak met een superviserende huisarts, die de eindverantwoordelijkheid draagt voor de urgentiebepaling. ${ }^{8}$

Er zijn aanwijzingen dat de huidige efficiëntie en veiligheid van telefonische triage van patiënten met acute borstkasklachten verbetering nodig heeft. Efficiëntie, omdat $68.7 \%$ van alle patiënten met borstkasklachten een hoge urgentie krijgt toegewezen (ambulance of spoed huisartsenbezoek), en zoals eerder genoemd slechts 10\% een ACS heeft. ${ }^{5}$ Veiligheid, omdat aan de andere kant een gemist ACS de meest voorkomende redenen is van een calamiteit op de huisartsenpost. ${ }^{9}$ Opmerkelijk 
is dat de NTS nooit is gevalideerd op klinische vitkomsten en dat daardoor de diagnostische betrouwbaarheid onbekend is. Verder is ook niet bekend hoe triagisten klinisch redeneren tijdens telefonische triage en hoe ze de NTS gebruiken voor de urgentiebepaling. Daarom zijn inzichten nodig over hoe de triage momenteel verloopt om daarmee aanknopingspunten te ontdekken voor verbetering.

Er bestaan geen gevalideerde klinische beslisregels om de diagnose ACS te stellen onder patiënten die de huisartsenpost bellen met acute borstkasklachten en deze zijn hard nodig. Opvallend daarbij is dat meerdere studies verschillen in klachten beschrijven bij mannen en vrouwen met een ACS, maar dat nooit geslachtsspecifieke beslisregels zijn ontwikkeld. Een belangrijke beperking van veel van deze studies is echter dat ze verschillen hebben onderzocht tussen mannen en vrouwen met een bevestigde diagnose ACS en dat patiënten die wel borstkasklachten hadden maar geen ACS niet zijn meegenomen in de analyses. ${ }^{10}$ De vergelijking is nodig waarbij symptomen van patiënten met ACS worden vergeleken met symptomen van patiënten zonder ACS, voor mannen en vrouwen apart. Dergelijke studies zijn nodig om huisartsen en triagisten te informeren over de vraag of en hoe vrouwen met ACS verschillen van vrouwen zonder ACS, en idem voor mannen.

De doelstellingen van dit proefschrift waren:

(i) Inzicht krijgen in hoe de telefonische triage van patiënten met acute borstkasklachten die de huisartsenpost bellen momenteel verloopt.

(ii) Aanknopingspunten ontdekken voor verbetering, zowel in patiëntveiligheid als efficiëntie van triage.

(iii) Onderzoeken of telefonische triage van patiënten met borstkasklachten anders zou moeten zijn voor mannen en vrouwen.

\section{Inzichten in hoe de telefonische triage van patiënten met borstkasklachten die de huisartsenpost bellen momenteel verloopt.}

In Hoofdstuk 2, beschrijven we de doelstellingen en studie opzet van het Safety First onderzoeksproject. We richten ons op de telefonische triage van patiënten met verdenking op acute cardiovasculaire ziektes, namelijk (i) patiënten die verdacht worden van een ACS en (ii) patiënten die verdacht worden van een 'transient ischemic attack' (TIA) of beroerte. De reden deze groep patiënten te onderzoeken is omdat snelle adequate triage hier van levensbelang is. We hebben een 'mixed-method' studie opzet ontworpen, bestaande uit kwantitatieve en kwalitatieve studies, met als doel de telefonische triage te beschrijven, begrijpen en te verbeteren voor patiënten met klachten verdacht voor acute cardiovasculaire ziektes die de huisartsenpost bellen. 
Voor de kwantitatieve studies hebben we een cross-sectionele studie uitgevoerd met gegevens van meer dan 5000 opgenomen telefoongesprekken uit de periode 20142017 van negen huisartsenposten in de regio Utrecht. We hebben deze gesprekken teruggeluisterd voor informatie over (i) gesprekskenmerken, (ii) patiëntkenmerken en (iii) symptomen. De onderzoekers luisterden de gesprekken terug zonder op dat moment de diagnose van de patiënt te weten. De diagnoses van de patiënten werden opgevraagd bij de eigen huisartsenpost van de patiënt, gebaseerd op ontslagbrieven van de cardioloog, neuroloog of huisartsenpost. Met deze gegevens konden we de diagnostische accuratesse van de triage beoordelen (hoofdstuk 3), 'audio gestimuleerde recall' interviews houden onder triagisten (hoofdstuk 4), onderzoeken of het tijdstip van bellen kan helpen voor de urgentiebepaling (hoofdstuk 5), evalueren of er verschillen zijn in klachtenpresentatie tussen mannen en vrouwen (hoofdstuk 6) en, als laatste, klinische beslisregels ontwikkelen voor de diagnose ACS, voor mannen en vrouwen apart (hoofdstuk 7).

In Hoofdstuk 3, hebben we de diagnostische accuratesse van de urgentiebepaling onderzocht bij 2023 patiënten die de huisartsenpost belden met acute borstkasklachten. Voor de analyses hebben we de urgentie gecategoriseerd in hoog ( $U_{1}$ en $U_{2}$ ) en laag urgent $\left(U_{3}, U_{4}\right.$ en $\left.U_{5}\right)$ en beoordeeld ten opzichte van de diagnose ACS en andere levensbedreigende aandoeningen (LBA), apart voor de NTS urgentiebepaling en de definitieve urgentiebepaling (inclusief aanpassingen van de triagist). De veiligheid van de NTS urgentie bleek slecht; in $27 \%$ van de patiënten die een ACS of andere LBA bleken te hebben werd een te lage urgentie toegekend (sensitiviteit van $0.73,95 \% \mathrm{BI}$ 0.68-0.78). In 13.2\% van de gesprekken heeft de triagist de NTS urgentie aangepast en dit betrof meestal op een opschaling (11.0\%). De definitieve urgentie was veiliger dan de NTS urgentie, maar nog steeds kreeg dan $14 \%$ van de patiënten met een ACS of een andere LBA een te lage urgentie (sensitiviteit 0.86, 95\% BI 0.81-0.90). Ook de efficiëntie van de NTS en definitieve urgentie was laag; de NTS urgentiebepaling was te hoog in $57 \%$ van de patiënten (specificiteit van $0.43,95 \% \mathrm{BI} 0.40-0.45$ ) en definitief in $67 \%$ (specificiteit van $0.34,95 \% \mathrm{BI} 0.32-0.37$ ) van de patiënten. Deze patiënten bleken niet-urgente aandoeningen te hebben, zoals reflux of spierklachten.

In Hoofdstuk 4, beschrijven we de resultaten van een 'audio gestimuleerde recall' interviewstudie onder 24 triagisten, die werden gevraagd hoe ze klinisch redeneren tijdens het gebruik van de NTS voor de triage van patiënten die verdacht worden van een ACS. Recente audio-opnames (<14 dagen oud) van telefoongesprekken van de triagisten werden gebruikt om hun reflectie te stimuleren. Het werd duidelijk dat triagisten een 'mentaal plaatje' van de patiënt creëren; "Hoe ziet de patiënt 
er aan de andere kant van de telefoon uit?" Ze gebruikten bekende klinische redeneerstrategieën zoals kennis over ziektes gebruiken, hypotheses testen en patroonherkenning. Specifiek voor telefonische triage bleken de triagisten de paralinguïstische communicatie (non-verbale communicatie zoals de toon van de stem en ademhalingssnelheid) te interpreteren om dit mentale plaatje te creëren, om te compenseren voor het gebrek aan visuele informatie. Vervolgens vergeleken de triagisten hun eigen afwegingen over de meest passende urgentie met de NTS urgentie. Op basis van de 'grounded theory benadering' vonden we dat 'congruentie' essentieel is voor triagisten in het gebruik van de NTS, wat betekent dat de NTS hun beslissingsproces ondersteunt. Wanneer congruentie afwezig was pasten triagisten vier strategieën toe: (i) ze sleutelden aan de NTS-invoer zodat hun gewenste urgentie eruit kwam, (ii) ze pasten de NTS urgentie aan ('overrulen'), (iii) ze schikten zich naar de NTS urgentie, of (iv) ze droegen de verantwoordelijkheid van de urgentiebepaling over aan de superviserende huisarts. Het werd duidelijk dat triagisten in hun werk met de NTS tegen diverse interactionele dilemma's aanliepen. Begrijpen welke strategieën triagisten toepassen en welke factoren hierbij van de invloed zijn kan helpen om onderwijs te verbeteren. NTS ontwikkelaars kunnen er baat bij hebben triagisten te betrekken om de NTS zo aan te passen dat congruentie beter wordt.

\section{Aanknopingspunten ontdekken voor verbetering}

In Hoofdstuk 5, hebben we geanalyseerd of het tijdstip van bellen kan helpen om de urgentiebepaling van patiënten met acute borstkasklachten te verbeteren. Uit eerdere ziekenhuisstudies bleek namelijk dat een ACS vaker optreedt in de vroege ochtend, wat waarschijnlijk te relateren is aan het biologisch ritme waarbij 's ochtends vroeg de bloeddruk en de hartfrequentie stijgen. ${ }^{11-13}$ We ontdekten dat het risico op een ACS onder 1655 patiënten met borstkasklachten bijna twee keer zo hoog was wanneer ze 's nachts belden (tussen 0.00 en 9.00) dan wanneer ze op andere tijden belden. Dit verhoogde risico was evident aanwezig bij mannen met een risico ratio van 2.33 ( $95 \%$ $\mathrm{BI}$ 1.68-3.22), maar minder vitgesproken bij vrouwen met een risico ratio van 1.29 (95\% BI 0.83-1.99). De voor leeftijd- en geslacht gecorrigeerde risico ratio was 1.82 (95\% BI 1.07-3.10). Op basis hiervan adviseren we bij patiënten die 's nachts bellen met borstkasklachten laagdrempelig een ambulance te sturen, met name bij mannen.

\section{Zou triage voor mannen en vrouwen anders gedaan moeten worden?}

In Hoofdstuk 6, hebben we patiënt- en gesprekskenmerken vergeleken van 85 vrouwen met ACS (8.6\%) versus 908 vrouwen zonder ACS, alsmede voor 120 mannen met ACS (15.0\%) versus 682 mannen zonder ACS. We ontdekten dat symptomen die een ACS voorspellen meer overeenkomstig dan verschillend waren voor mannen en vrouwen. 
In beide geslachten was retrosternale pijn voorspellend voor ACS (vrouwen met ACS vs. zonder $62.3 \%$ vs. $40.3 \%, p=0.002$, mannen met ACS vs. zonder $52.5 \%$ vs. $39.7 \%$, $\mathrm{p}=0.032$ ), net als drukkende zware pijn (vrouwen $78.6 \%$ vs. $61.5 \%, p=0.011$, mannen $82.1 \%$ vs. $57.4 \%, p=<0.001$ ) en uitstraling naar de arm (vrouwen $75.6 \%$ vs. $45.9 \%$, $\mathrm{p}<0.001$, mannen $56.0 \%$ vs. 34.8\%, $\mathrm{p}<0.001)$. Bij vrouwen waren daarnaast hevige pijn (65.4\% vs. $38.1 \%, p=0.006)$, bleekheid (50.0\% vs. $22.9 \%, p=0.007$ ) en uitstraling naar de arm (50.0\% vs. 29.8\%, $p=0.017$ ) ook voorspellend voor $A C S$, en in mannen bleek zweten voorspellend voor ACS (52.4\% vs. 38.1\%, p=0.015), en stekende pijn juist te pleiten tegen ACS ( $8.4 \%$ vs. $26.5 \%$, p<0.001). Naar vrouwen en mannen met een ACS werd even vaak een ambulance gestuurd (72.9\% en 70.0\%, respectievelijk).

In Hoofdstuk 7, hebben we de eerste geslachtsspecifieke klinische beslisregels ontwikkeld om de diagnose ACS te stellen op basis van symptomen. Onze beslisregel voor vrouwen bevat zeven klinische voorspellers (leeftijd, zweten, uitstraling, drukkende zware pijn, hevige pijn, tijdsduur van de pijn korter dan 12 uur en diabetes mellitus) met een intern gevalideerd discriminerend vermogen (c-statistiek) van 0.76 (95\% Bl 0.71-0.80). Onze predictieregel voor mannen bevat acht klinische voorspellers (leeftijd, zweten, uitstraling, drukkende zware pijn, diabetes mellitus, tijdstip van bellen in de nacht, herkennen van hartklachten en kortademigheid) met een intern gevalideerd discriminerend vermogen (c-statistiek) van 0.72 (95\% BI 0.68-0.76). Na externe validatie kunnen deze beslisregels toegepast worden voor de telefonische triage van patiënten met borstkasklachten die de huisartsenpost bellen.

\section{Aanbevelingen voor toekomstig onderzoek en de klinische praktijk}

In Hoofdstuk 8, vatten we de onderzoeksresultaten van dit proefschrift samen en discussiëren over het belang de diagnose te betrekken in triage-onderzoek en triage in de praktijk. Tot slot reflecteren we op de klinische casus van de introductie van dit proefschrift.

Voor onderzoek naar triagesystemen raden we aan de urgentiebepaling altijd te valideren op de diagnoses van de patiënt, om zo te kunnen beoordelen hoe accuraat het systeem is, en dat de validatie gedaan moet worden in de setting (telefonische of fysieke triage, huisartsenpost of ziekenhuis) waar het systeem gebruikt gaat worden. Bij voorkeur vindt validatie daarbij plaats voordat een triagesysteem breed in gebruik wordt genomen. Verder kan het nuttig zijn de gebruikers (de triagisten) van een triagesysteem te betrekken in de ontwikkeling en implementatie, met als doel de congruentie te verbeteren en het risico op interactionele problemen te verkleinen. De input van triagisten kan ook waardevol zijn om onderwijs te verbeteren, o.a. 
voor interpretatie van paralinguïstische communicatie. Verder benadrukken we de noodzaak dat managers van triagisten bij de kwaliteitsevaluatie van triagegesprekken ook de viteindelijke diagnose van de patiënt betrekken.

Voor verbetering van de NTS raden we aan om leeftijd te includeren als triagecriterium bij de ingangsklacht 'pijn thorax' omdat het een sterke voorspeller is voor de diagnose ACS. Ook is het te overwegen wanneer patiënten 's nachts bellen laagdrempelig een ambulance te sturen, met name bij mannen.

Verder verwachten we dat onze geslachtsspecifieke klinische beslisregels ook toepasbaar kunnen zijn voor triage van patiënten met borstkasklachten die de ambulancemeldkamer ('112') bellen, omdat de voorafkans op ACS bij deze patiënten vergelijkbaar is met die van patiënten die de huisartsenpost bellen. ${ }^{14}$

Onze studies laten duidelijk zien dat er een grote overlap is in symptomen die een ACS voorspellen bij mannen en vrouwen. Deze bevinding staat in contrast met internationale richtlijnen en publieke campagnes, die daardoor een ongebalanceerde boodschap vitzenden. Dit kan onbewust ertoe leiden dat vrouwen gaan denken dat ze alleen bij 'atypische' klachten een risico hebben op een ACS en daardoor misschien typische klachten negeren. Het is tijd voor verandering. 


\section{References}

1. Ibanez B, James S, Agewall S, et al. 2017 ESC Guidelines for the management of acute myocardial infarction in patients presenting with ST-segment elevation. Revista Espanola Cardiologia2017;70(12):1082. doi: 10.1016/j.rec.2017.11.010

2. Jansen T, Ramerman L, Verheij R. Cijfers huisartsenposten - aanmelding - urgentie. Nivel zorgregistraties eerste lijn 2020

3. Mol KA, Smoczynska A, Rahel BM, et al. Non-cardiac chest pain: prognosis and secondary healthcare utilisation. Open Heart 2018;5(2):e000859. doi: 10.1136/ openhrt-2018-000859

4. Hoorweg BB, Willemsen RT, Cleef LE, et al. Frequency of chest pain in primary care, diagnostic tests performed and final diagnoses. Heart 2017;103(21):1727-32. doi: 10.1136/heartjnl-2016-310905

5. Plat FM, Peters YAS, Loots FJ, et al. Ambulance dispatch versus general practitioner home visit for highly urgent out-of-hours primary care. Family Practice 2017(Dec 20) doi: 10.1093/fampra/cm×121

6. Bruyninckx R, Aertgeerts $B$, Bruyninckx $P$, et al. Signs and symptoms in diagnosing acute myocardial infarction and acute coronary syndrome: a diagnostic meta-analysis. The British Journal of General Practice 2008;58(547):105-11. doi: 10.3399/bjgpo8X277014

7. van lerland $Y$, van Veen $M$, Huibers $L$, et al. Validity of telephone and physical triage in emergency care: the Netherlands Triage System. Family Practice 2011;28(3):334-41. doi: 10.1093/fampra/cmq097

8. Keizer E, Maassen I, Smits M, et al. Reducing the use of out-of-hours primary care services: A survey among Dutch general practitioners. The European Journal of General Practice 2016;22(3):189-95. doi: 10.1080/13814788.2016.1178718

9. Rutten $\mathrm{MH}$, Kant J, Giesen P. What can we learn from calamities at out-of-hours services in primary care? [Wat kunnen we leren van calamiteiten op de huisartsenpost?]. Huisarts \& Wetenschap 2018;6(61) doi: 10.1007/s12445-018-0155-7

10. van Oosterhout REM, de Boer AR, Maas A, et al. Sex Differences in Symptom Presentation in Acute Coronary Syndromes: A Systematic Review and Meta-analysis. Journal of American Medical Association 2020;9(9):e014733. doi: 10.1161/JAHA.119.014733

11. Ekelund U, Akbarzadeh M, Khoshnood A, et al. Likelihood of acute coronary syndrome in emergency department chest pain patients varies with time of presentation. $B M C$ Research Notes 2012;5:420. doi: 10.1186/1756-0500-5-420

12. Bhalla A, Sachdev A, Lehl SS, et al. Ageing and circadian variation in cardiovascular events. Singapore Medical Journal 2006;47(4):305-8.

13. Leiza JR, de Llano JM, Messa JB, et al. New insights into the circadian rhythm of acute myocardial infarction in subgroups. Chronobiology International 2007;24(1):129-41. doi: 10.1080/07420520601140027

14. Rawshani A, Larsson A, Gelang C, et al. Characteristics and outcome among patients who dial for the EMS due to chest pain. International Journal of Cardiology 2014;176(3):85965. doi: 10.1016/j.ijcard.2014.08.004 


\section{LIST OF PUBLICATIONS}

\section{This thesis}

1. Erkelens DCA, Wouters LTCM, Zwart DLM, Damoiseaux RAMJ, de Groot Esther, Hoes AW, Rutten FH. Optimisation of telephone triage of callers with symptoms suggestive of acute cardiovascular disease in out-of-hours-primary care: observational design of the Safety First study. BMJ Open 2019 Jul 1;9(7):e027477.

2. Wouters LTCM, Rutten FH, Erkelens DCA, De Groot E, Damoiseaux RAMJ, Zwart DLM. Accuracy of telephone triage in primary care patients with chest discomfort: A cross-sectional study. Open Heart 2020 Sep;7:eo01376

3. Wouters LTCM, Zwart DLM, Erkelens DCA, Huijsmans MH, Hoes AW, Damoiseaux RAMJ, Rutten FH, de Groot Esther. Tinkering and overruling the computer decision support system: working strategies of telephone triagenurses who assess the urgency of callers suspected of having an acute cardiac event. J Clin Nurs 2020 Apr;29(7-8):1175-1186.

4. Wouters LTCM, Zwart DLM, Erkelens DCA, Cheung NS, de Groot Esther, Damoiseaux RAMJ, Hoes AW, Rutten FH. Chest discomfort at night and risk of acute coronary syndrome: cross-sectional study of telephone conversations. Fam Pract 2020 Sep 5;37(4):473-478.

\section{Other publications}

5. Erkelens DCA, Rutten FH, Wouters LTCM, De Groot E, Damoiseaux RAMJ, Hoes AW, Zwart DLM. Limited reliability of experts' assessment of telephone triage in primary care patients with chest discomfort. J Clin Epidemiol. 2020 July $28 ; 127: 117-124$.

6. Erkelens DCA, Van Charldorp TC, Vinck VV, Wouters LTCM, De Groot E, Damoiseaux RAMJ, Rutten FH, Zwart DLM, De Groot E. Interactional implications of either/or-questions during telephone triage of callers with chest discomfort in out-of-hours primary care: a conversation analysis. Patient Educ Couns. 2020 July 15;S0738-3991(20)30384-0. 


\section{DANKWOORD}

Wauw, mijn proefschrift is klaar! Heel graag wil ik iedereen hartelijk bedanken die direct of indirect heeft bijgedragen aan het tot stand komen van dit proefschrift.

Allereerst mijn promotieteam van de Safety First onderzoeksgroep. Bedankt dat ik met jullie deze enorm leerzame en bijzondere reis mocht maken. Van wat begon met ideeën met 'bandjes' van telefoongesprekken en acute cardiovasculaire ziektes tot het eindpunt wat dit proefschrift nu is.

Geachte prof. dr. Rutten, beste Frans. Je was altijd mijn eerste aanspreekpunt, in beginsel als co-promotor en gelukkig ook toen je mijn promotor werd vorig jaar. Bedankt voor je enorme betrokkenheid, inspirerende enthousiasme, humor en je positief kritische blik op mijn artikelen. Je enthousiasme en toewijding voor de wetenschap zijn groot, waarbij je het belang van de patiënt altijd voorop stelt; 'Hoe gaat deze kennis de patiënt helpen? Wat kunnen dokters hier mee?' Je bent scherp, soms wat eigenzinnig en stimuleert om goed tot de kern te komen. Het gemiddelde aantal revisierondes per artikel weet ik niet precies ('we zijn er bijna'), en als soms een van ons daarover begon te 'brommen', dan werd het tijd het artikel naar de anderen te sturen. $\mathrm{lk}$ vond het ook leuk om samen de vele geneeskundestudenten te begeleiden en te zien met hoeveel enthousiasme je dit deed. In de vele uurtjes die we samen doorbrachten - een afspraak van een uur werd altijd volgepraat - heb je me veel geleerd over onderzoek en de huisartsgeneeskunde, maar net zoveel over een scala aan andere onderwerpen. Vele levenswijsheden, 'politiek' in de wetenschap en bijzondere verhalen over patiënten kwamen voorbij. Je hebt wel eens gezegd dat je voor je vakantiebestemmingen je laat inspireren door jouw promovendi. Ik vond het daarom ook mooi om te zien dat mijn reiservaringen over Colombia en Japan geslaagde inspiraties bleken. Bedankt voor alles!

Geachte prof dr. Hoes, beste Arno. Ondanks je drukke agenda was je altijd goed voorbereid op ons overleg en wist je precies de knelpunten te ontdekken en op te lossen. Structuur houden in overleg met onze onderzoeksgroep was ook best een vitdaging, bedankt dat je dan ingreep om te voorkomen dat een kostbaar uurtje werd 'weggekletst'. Je uitleg over epidemiologie vond ik heel fijn; een moeilijk probleem werd ineens heel goed te begrijpen. Bedankt voor je waardevolle feedback op mijn artikelen en hoewel het soms lang wachten was, gaf je altijd net dat laatste zetje waardoor de tekst helder en scherp geformuleerd werd. 
Geachte dr. Zwart, beste Dorien. Samen met Frans de kartrekkers van Safety First, wat een ontzettend leuk onderzoek hebben jullie samen bedacht. Met jouw positieve instelling ga je geen uitdaging uit de weg, en je kan heel goed moeilijke zaken 'ontwarren' en concrete oplossingen bedenken. Of het nu ging om verschillende ideeën over de rode draad van een artikel, perikelen over de dataverzameling of een persbericht in de internationale media. Je hielp me de maatschappelijke en klinische context van ons onderzoek inzien en met een 'patiëntveiligheidsbril' onze resultaten te beschouwen. Bedankt voor je begeleiding, en ook je dochter Bo bedankt voor het oppassen op onze dochter Roos in de afrondende fase van mijn proefschrift!

Geachte dr. de Groot, beste Esther. Halverwege mijn promotie werd je van begeleider officieel mijn co-promotor, een rol die je vol toewijding hebt vervuld! Bedankt voor al je inzichten over kwalitatieve onderzoeksmethodes, tips over structuur voor artikelen en altijd snelle reacties. Ik vond het leuk samen de interviewstudie te doen en heb veel geleerd over de openvraagmethodes, die ook heel belangrijk zijn in het huisartsenvak en dagelijkse leven.

Geachte prof. dr. Damoiseaux, beste Roger. Officieel was je niet mijn promotor, maar je was net zo betrokken als de anderen van Safety First. Bedankt voor je feedback op mijn artikelen, het stimuleren van congresbezoeken en bovenal het mogelijk maken om de huisartsopleiding te combineren met promotieonderzoek in het zogenaamde AIOTHO-traject (Arts in Opleiding tot Huisarts en Onderzoeker), waarbij je waakte dat zowel de opleiding als het onderzoek goed verliep.

Geachte drs. Erkelens, lieve Carmen. Mijn Safety First onderzoeksvriendin! Wat heb ik het ontzettend getroffen dat ik met jou deze bijzondere reis mocht doorlopen. Samen de weg vinden in de onderzoekswereld, van METC protocol schrijven tot logistiek organiseren voor de studentenprojecten (wat hebben we dat mooi gestructureerd) en een paar toffe congressen afgaan. Bedankt voor het fijne samenwerken, sparren over knelpunten, helpen relativeren en je gezelligheid en humor! Vanzelfsprekend heb ik je gevraagd als paranimf, want niemand die me beter kan bijstaan tijdens de verdediging dan jij. Ik ben vereerd dat ik ook jouw paranimf mag zijn! Hoewel het oorspronkelijke plan van deze duopromotie met een symposium en een groot feest niet door kan gaan, vind ik het heel bijzonder om samen met jou op dezelfde dag onze verdedigingen te doen.

Graag wil ik ook de leden van de beoordelingscommissie bedanken: prof. dr. Y. van der Graaf, prof. dr. ir. H.M. den Ruijter, prof. dr. P.J.E. Bindels, prof. dr. A.M.W. Alings en prof. dr. A.A. de Bont. Ik wil u allen hartelijk danken voor de genomen tijd om dit proefschrift te lezen en te beoordelen. 
(Voormalig) Primair Huisartsenposten, hartelijk bedankt voor de samenwerking en het beschikbaar maken van de 'bandjes'; de data waar dit gehele proefschrift op gebaseerd is! In het bijzonder dank aan Sonja Oomkens en Dick van Brink, leuk dat jullie altijd zo geïnteresseerd waren in Safety First en geduldig ('zijn er al resultaten?'), maar nu is het echt af. Bedankt voor het warme welkom aan ons en alle geneeskundestudenten. Jan Gerritsen, Johnny Janssen en Chantal Peelen, bedankt voor het gereed maken van de 'bandjes' en voor het oplossen van allerlei technische problemen. Bedankt aan alle triagisten die bereid waren zich te laten interviewen, jullie zijn de kern van dit vak en ik hoop dat jullie dit nog met veel werkplezier blijven doen.

Hartelijk dank aan alle huisartsen, doktersassistenten en AIOS die hebben geholpen met informatie opzoeken over de diagnoses van de patiënten. De follow-up gegevens waren de kern van onze studie, veel dank voor jullie onmisbare bijdrage hierin!

Deelnemers van de Safety First klankbordgroep bijeenkomsten, Markus Kruyswijk en Tessa Postuma van Stichting de Nederlandse Triage Standaard, Ludeke van Es van Stichting Ineen, Roderick Runne van Primair Huisartsenposten, en Ellen Spierings en Konca Artan van de Inspectie Gezondheidszorg en Jeugd. Hartelijk bedankt voor jullie waardevolle inbreng tijdens de discussies over de implicaties van onze onderzoeksresultaten door het bieden van bredere context.

Stichting Stoffels-Hornstra en Stichting Nederlandse Triage Standaard, bedankt voor jullie financiële bijdrage en de vrijheid om onafhankelijk onderzoek te doen.

Van de methodologie afdeling van het Julius Centrum wil ik Sanne Peters en Maarten van Smeden bedanken. In de laatste vier maanden van mijn promotietijd mocht ik statistische analyses doen in het programma R en dit was allesbehalve gemakkelijk. Maarten, toen jij in beeld kwam en mijn R-script hebt herschreven kwam er weer licht aan het eind van de tunnel. Bedankt voor je fijne begrijpelijke uitleg en snelle reacties op mijn vragen!

Marlies Huijsmans, bedankt voor je enthousiaste bijdrage aan de interviewstudie, waar je aan meehielp voor je wetenschapsdifferentiatie in de huisartsopleiding. Voor ons beide was kwalitatief onderzoek nieuw en ik vond het heel leuk samen met jou de interviews af te nemen, en ons te verdiepen in de 'grounded theory' .

Ineke Kagenaar, tijdens je kaderopleiding spoedeisende huisartsgeneeskunde ging je mee met een paar interviews. Met je ruime ervaring als huisarts op de huisartsenpost in Amsterdam bracht je mij meer context en stelde je prikkelende vragen die verdieping 
gaven aan de interviews. Ook veel dank voor het deelnemen in het expertpanel bij de urgentiebeoordelingen.

Deze studie was niet mogelijk geweest zonder de inzet van vele hardwerkende geneeskundestudenten. Hartelijk bedankt Daan, Aryan, Amy, Cynthia, Sanne O, Nicole, Arina, Daphne, Alice, Denise, Rinske, Nikki, Yara, Marten, Jip, Sanne H, Lindsay, Marije, Karlijn, Lisa, Julia, Meggie, Ellaha en Susanne. Jullie hebben gezamenlijk ruim 5000 (!) 'bandjes' beluisterd en met de resultaten van jullie onderzoeksvragen kregen we gaandeweg steeds meer inzichten in het verloop van de telefonische triage. Bedankt voor jullie inzet en goede vragen. Ook veel dank aan de werkstudenten Gerben, Rozemarijn en Gabi die zich vol toewijding op de follow-up verzameling hebben gestort, met de vele e-mails, brieven, faxen en het bellen van huisartsen. In het bijzonder bedankt SUMMA-student Lisa voor je hulp met $\mathrm{R}$, knap hoe je je dat zo snel eigen hebt gemaakt. Faas Dolmans en Sander van Doorn, bedankt dat jullie aan het einde de studentbegeleiding overnamen.

Bedankt aan de Stichting Beroepsopleiding Huisartsen (SBOH) voor jullie ondersteuning aan AIOTHO's en de goede voorwaarden.

Tijdens mijn promotietijd heb ik verschillende kamergenoten gehad in Str. 5.122 en MvG 5.10. Ik vond het een geweldige mooie tijd met jullie! Bedankt Carmen, Eveline, Stephanie, Darren, Valentijn, Inger, Marieke, Jolien, Marjolein, Carla, Lufang, Birsen, Feike, Esther en Tim voor alle gezelligheid, borrels, etentjes, pubquizzen, Sinterklaas, de leuke Promovenski reis en 'office safari' op vrijdagmiddag. Natuurlijk werd er ook regelmatig hard gewerkt, dank dus ook voor de hulp bij lastige analyses, samen studeren voor MSc tentamens, praktische tips en tricks en de steun en het relativeren bij moeilijke momenten. Eveline en Carmen, ik vond het onwijs tof dat ik met jullie het langste kamergenoten was, en ook vond ik het heel fijn dat we de laatste loodjes konden delen. Het was een vreemde tijd toen we ineens thuis moesten werken, maar we hielden contact via virtuele kopjes koffies en later borrels om te proosten dat we onze proefschriften hadden opgestuurd! Bedankt ook aan alle 'buur' promovendi in het Stratenum, en de 'van Geunsjes'. Het lijkt me heel leuk om, zodra het weer kan, nog eens samen te proosten op alle verdedigingen van dit najaar (ik ben de tel kwijt hoeveel dat er zijn!).

Ook wil ik alle mede AIOTHO's bedanken voor jullie gezelligheid, lunchwandelingen, koffietjes, leuke congresreisjes en het delen van ervaringen. Leuk dat we nu weer samen doorgaan met de huisartsopleiding, ik zie jullie daar vast weer! 
Arno en Maarten, ik had me geen fijnere opleiders kunnen wensen in jaar 1 van de huisartsopleiding. Bedankt voor jullie blijvende interesse en ik kom graag nog eens langs voor een kopje koffie!

Lieve Ferrara-vrienden, Marijn, Fedde, Willemijn, Marloes, Myrthe en Vincent. In 2007 volgden we drie maanden onderwijs over gynaecologie in het idyllische Italiaanse stadje Ferrara met verblijf in het knusse 'Il Cenacolo'. Wat een geweldige tijd was dat en zo leuk dat we meerdere malen zijn terug geweest voor een weekendje gezelligheid en vooral om te smullen van aperitivi, pizza's, pasta's, wijn en limoncello op de beste plekjes. Marijn, Willemijn, Marloes en Myrthe, gezellig dat we nog regelmatig een meidendag houden, zoals in de jacuzzi bij Marloes. Vincent, erg leuk dat we de ervaring van een AIOTHO traject delen. Fedde, het blijft wonderlijk hoe we steeds in dezelfde groepjes terecht komen (geneeskunde, Ferrara, Pulse, huisartsopleiding jaar 1, wat volgt..?).

Lieve Marijn, in 2006 ontmoetten wij elkaar bij de Inkom in Maastricht en hebben sindsdien vele avonturen beleefd. Van samenwonen in Italië en Utrecht, meerdere vakanties samen, ontelbare etentjes en samen 'sporten', tot samen met onze kleintjes buitenspelen en pannenkoeken eten. Bedankt dat je altijd voor me klaarstaat, je gezelligheid en hulp bij de voorbereidingen voor mijn verdediging. Ik voel me enorm vereerd om jou als paranimf aan mijn zijde te hebben!

Lieve 'Zussies', Annelieke, Esther en Evelien. Wat begon als jaarclubgenootjes en geneeskundevriendinnen is uitgegroeid tot een hechte vriendschap. Met Zweden als onze favoriete vakantiebestemming voor de mooie natuur, lekkere koffie en avontuurlijke boottochtjes. Ik vind het heerlijk dat ik met jullie alles kan bespreken en geniet van onze dagjes sauna, wandelen en uit eten gaan, net als samenkomen met al onze kleintjes erbij tegenwoordig. Bedankt voor jullie betrokkenheid en alle attente lieve berichtjes!

Lieve oud-bestuursgenoten van Pulse Master, Fedde, Marleen, Sanne, Erik, Hester, Floris, Jannick en Rick. Met veel plezier kijk ik terug op alle mooie activiteiten die we hebben georganiseerd en heerlijke weekendjes, meestal om te zeilen - wat jullie gelukkig beter kunnen dan ik. Ik vind het mooi hoe we elkaar steeds weer vinden, samen mijlpalen vieren en kijk uit naar het volgende weekendje!

Lieve Kalynda en Chantal, vriendinnen van de huisartsopleiding, bedankt voor jullie gezelligheid, delen van ervaringen en leuke congresuitjes. Christianne, ook geneeskundevriendin, bedankt voor je gezelligheid, interesse en altijd goede humeur! Marein, oorspronkelijk van salsa in Maastricht en nu vooral leuke etentjes, kletsen en 
lachen over allerlei onzinnige dingen. Daniëlle, wij kennen elkaar al sinds de brugklas middelbare school en leuk dat we nog altijd afspreken!

Lieve schoonfamilie, Peter en Monique, Frank en Marjolein, Bart en Cynthia. Voordat ik Tim leerde kennen had ik nog nooit van het Westland gehoord, maar daar blijken een hoop aardige mensen vandaan te komen - en ze telen er heerlijke groentes en fruit. Bedankt voor jullie altijd warme welkom, betrokkenheid, interesse, gezelligheid en ook veelal praktische steun. Verder boft Roos met zoveel neefjes en nichtjes om mee te spelen!

Lieve papa en mama, bedankt voor jullie liefde en het vertrouwen dat jullie mij geven om mijn eigen keuzes te maken. Mama, toen jij vijf jaar geleden promoveerde stonden Bas en ik trots naast je als paranimfen. Hoewel je onderzoek van juridische aard was, zie ik veel raakvlakken met mijn promotie in je combinatie van praktijk en onderzoek. Bedankt voor je steun en inspiratie, en het kritisch lezen van mijn samenvatting. Papa, sinds kort heb je de overstap gemaakt naar de medische afdeling van Philips, en dan specifiek voor baby's. Bedankt voor je interesse in mijn onderzoek en leuk dat we nu van gedachte wisselen over de raakvlakken in ons werk. Lieve Fred en Nana, ik ben blij dat jullie erbij zijn gekomen in de familie, mijn ouders gelukkig maken en ook trotse opa en oma zijn voor Roos.

Lieve Bas, mijn grote broer, deze prachtige omslag is aan jou te danken! Onze levens zijn heel anders en ik ben benieuwd waar je je talenten straks weer voor gaat inzetten. Bedankt voor je zorgzaamheid, rust en betrokkenheid. Laura, gracias por hacer feliz a mi hermano y espero que pronto vivas un poco más cerca.

Lieve Tim, mijn grote liefde. Bijna 8 jaar geleden ontmoetten wij elkaar aan de andere kant van de wereld, maar gelukkig woonden we allebei in Nederland. In het begin met de trein van Maastricht naar Leiden, en na enige tijd samenwonen in Utrecht. Ik vind het mooi hoe onze levens nu zo verweven zijn en hoe we elkaar altijd steunen. Ik hou van je positiviteit, je humor, interesse in allerlei dingen, relativeringsvermogen, onbevangenheid en creatieve ideeën. Bedankt voor het bewerken van een eindeloos aantal figuren uit dit proefschrift, handige tips, het lezen van m'n teksten en zelfs een poging tot programmeren in R! Tijdens de lockdown waren we echt op elkaar aangewezen, met Roos thuis en allebei proberen te werken, ik ben trots op hoe we dit hebben aangepakt. Samen kunnen we alles aan.

Lieve Roos, begin vorig jaar werd jij geboren en je maakt het leven mooier. Jouw ogen zien twinkelen en je schaterlach horen, maken iedere dag weer goed. 


\section{ABOUT THE AUTHOR}

Loes Wouters was born on the $20^{\text {th }}$ of May 1988 in Eindhoven, the Netherlands. After graduation from the gymnasium at secondary school S.G. Augustinianum in 2006, she studied medicine at the University of Maastricht and graduated in 2012. She worked as a resident from 2013 to 2015 at the surgery department of the st. Laurentius Ziekenhuis in Roermond, the dermatology department of the Catharina Ziekenhuis in Eindhoven, and at the psychiatry department of

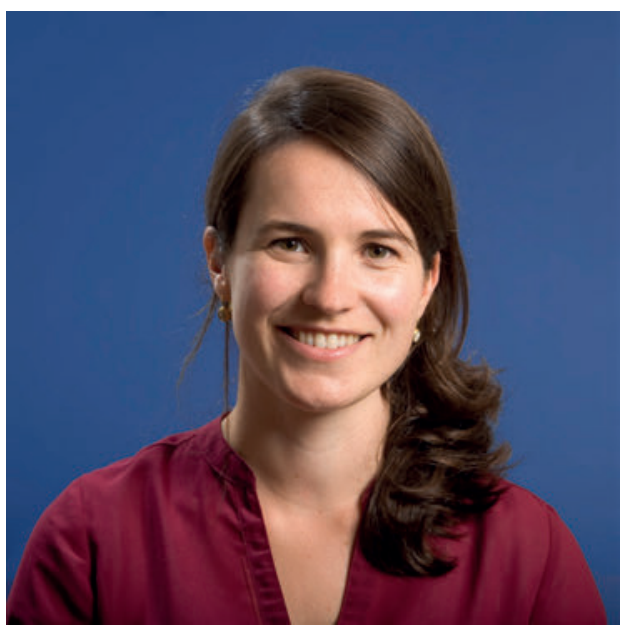
the Zaans Medisch Centrum in Zaandam. At the end of 2015, she started her PhD trajectory at the Julius center for Health Sciences and Primary Care of the University Medical Center Utrecht, under the supervision of prof. dr. F.H. Rutten, prof. dr. A.W. Hoes, dr. D.L.M. Zwart and dr. E. de Groot. In 2020 she received a master's degree in Clinical Epidemiology at Utrecht University. From 2016, she combines her PhD with the general practitioner training at Utrecht University, of which she is currently at the end of the second year. Loes lives in Utrecht with Tim and daughter Roos. 



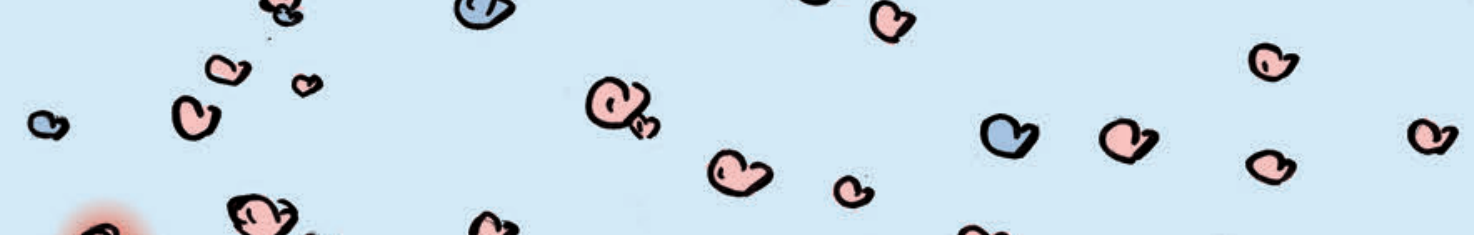

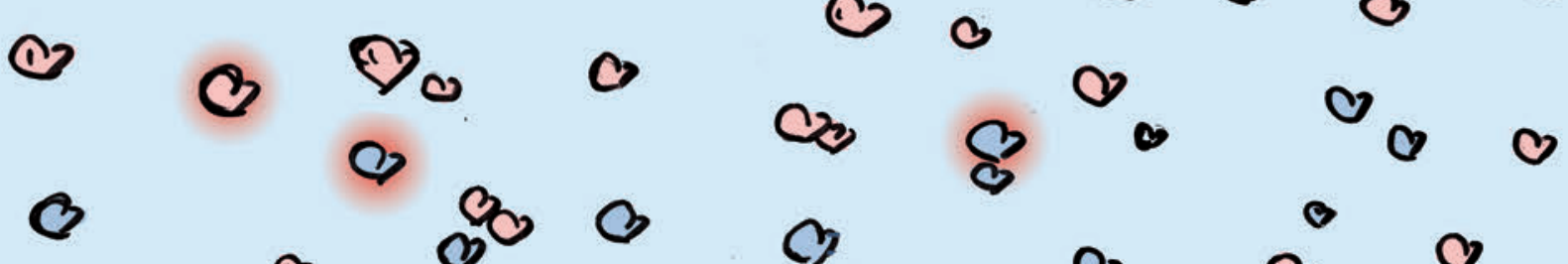

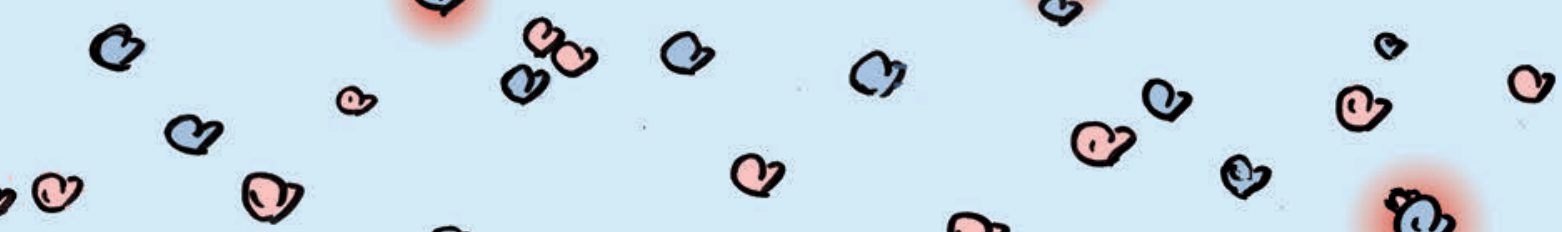

$0 \% 0$

- 8 (1) क 00

(4) $O$

C) 10

(2)

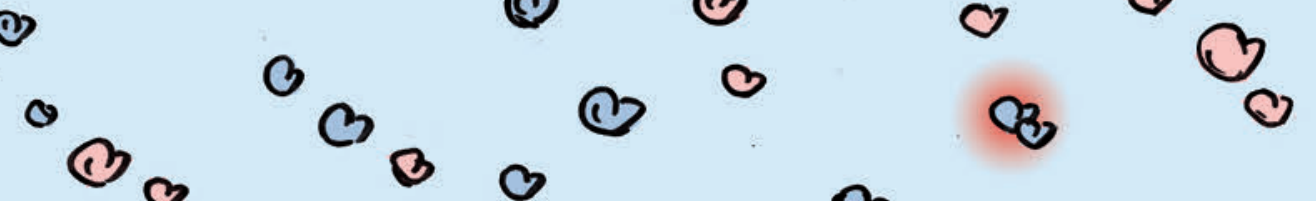

3
c 63
C $\mathrm{C}$
(1)<smiles>[CH]</smiles>

07

(3)

0

$\infty 0$

02

(1) क

00

Q

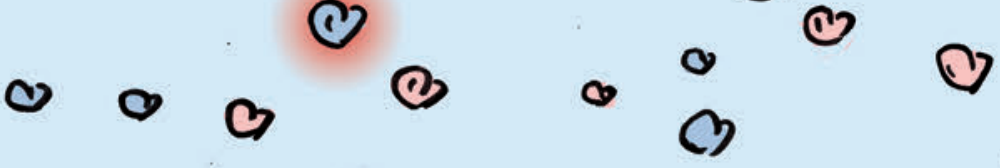

क्ण

C

(1)

⿶

(1) 00

- 00 (1)

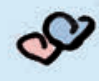

0 (a)

a)

a

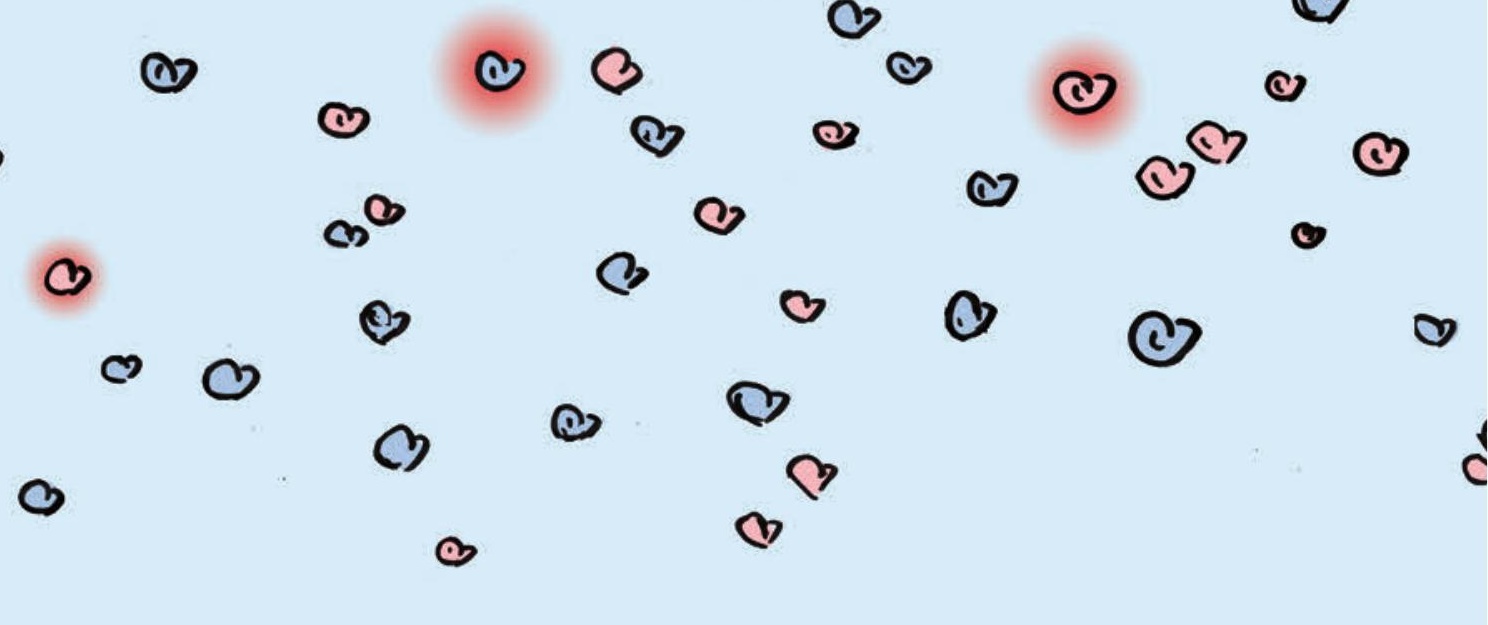

